Vinicius Mota da Cruz Gomes

APLICAÇÃO DA METODOLOGIA DA CURVA MESTRA À AVALIAÇÃO DA TEMPERATURA DE REFERÊNCIA EM UM AÇO MARTENSÍTICO 
Vinicius Mota da Cruz Gomes

\section{APLICAÇÃO DA METODOLOGIA DA CURVA MESTRA À AVALIAÇÃO DA TEMPERATURA DE REFERÊNCIA EM UM AÇO MARTENSÍTICO}

Dissertação apresentada à Escola Politécnica da Universidade de São Paulo para obtenção do título de Mestre em Ciências 
Vinicius Mota da Cruz Gomes

\section{APLICAÇÃO DA METODOLOGIA DA CURVA MESTRA À AVALIAÇÃO DA TEMPERATURA DE REFERÊNCIA EM UM AÇO MARTENSÍTICO}

\section{Versão Revisada}

Dissertação apresentada à Escola Politécnica da Universidade de São Paulo para obtenção do título de Mestre em Ciências

Área de Concentração:

Engenharia Naval e Oceânica

Orientador: Prof. Titular

Dr. Claudio Ruggieri 
Autorizo a reprodução e divulgação total ou parcial deste trabalho, por qualquer meio convencional ou eletrônico, para fins de estudo e pesquisa, desde que citada a fonte.

Este exemplar foi revisado e corrigido em relação à versão original, sob responsabilidade única do autor e com a anuência de seu orientador.

São Paulo, 07 de junho de 2021

Assinatura do autor:

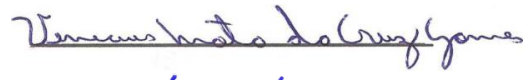

Assinatura do orientador:

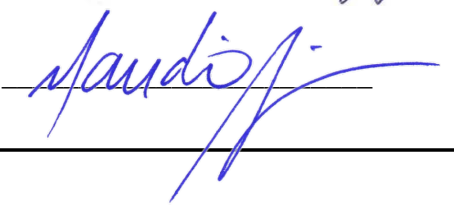

Catalogação-na-publicação

Mota da Cruz Gomes, Vinicius APLICAÇÃO DA METODOLOGIA DA CURVA MESTRA À AVALIAÇÃO DA TEMPERATURA DE REFERÊNCIA EM UM AÇO MARTENSÍTICO / V. Mota da Cruz Gomes -- versão corr. -- São Paulo, 2021.

$163 \mathrm{p}$.

Dissertação (Mestrado) - Escola Politécnica da Universidade de São Paulo. Departamento de Engenharia Naval e Oceânica.

1.Mecânica da Fratura 2.Curva Mestra 3.Transição Dúctil Frágil 4.Temperatura de Referência 5.Aço Martensítico I.Universidade de São Paulo. Escola Politécnica. Departamento de Engenharia Naval e Oceânica II.t. 


\section{AGRADECIMENTOS}

A Deus e a minha mãe, pela minha vida, instruem-me, ensinam-me e aconselham-me ao caminho que devo seguir em todos os momentos ao longo da minha simples jornada;

Ao Professor Dr. Claudio Ruggieri pelos sábios conselhos, capacitação, incentivo, exemplo de profissionalismo e por compartilhar o seu profundo e rico conhecimento acadêmico;

Ao Dr. Vitor Scarabeli Barbosa por me auxiliar e me guiar, tanto nos ensaios quanto no texto;

À Coordenação de Aperfeiçoamento de Pessoal de Nível Superior (CAPES) pela concessão do auxílio financeiro na forma de bolsa doutorado;

Aos colegas do Núcleo Avançado em Mecânica da Fratura \& Integridade Estrutural (NAMEF): Allan Stubiener, Andres Plata, Bruno Sorrija, Claudinei Ferreira, Diego Sarzosa, Lucas Carrano, Nathan Silvestre, Rafael Savioli, Vitor Scarabeli Barbosa, pela amizade, companheirismo e pelos momentos de descontração;

Aos colegas do Laboratório de Mecânica Offshore (LMO) Cristiano Emílio e Edite pela amizade, companheirismo e pelos momentos de descontração;

A todos aqueles que diretamente ou indiretamente colaboraram para o desenvolvimento deste trabalho; 


\section{RESUMO}

Este trabalho aborda uma investigação experimental em relação ao comportamento à fratura frágil de um aço martensítico usando corpos de prova SE(B) em configuração padronizada de acordo com a norma ASTM E1921. O propósito desse estudo é analisar a aplicabilidade da Metodologia da Curva Mestra (MCM) na avaliação da temperatura de referência $\left(T_{0}\right)$ a partir de dados de tenacidade à fratura medidos na região de transição dúctilfrágil (RTDF) de um aço martensítico temperado USI AR 450, o qual, de acordo com a ASTM E1921, não é aplicável a aços de microestrutura predominantemente martensítica. O trabalho também demonstra um procedimento relativamente simples para a determinação de novos coeficientes da curva mestra, a fim de obter uma melhor descrição da mediana da distribuição dos dados experimentais de tenacidade à fratura (expressos em termos do fator de intensidade de tensão elasto-plástico $K_{J_{c}}$ ) em função da temperatura na RTDF e, portanto, uma estimativa mais acurada da $T_{0}$. Os ensaios de tenacidade à fratura, realizados em diversas temperaturas da região de transição a partir de corpos de prova SE(B) extraídos na direção transversal (T-L) da chapa de aço temperado, fornecem os dados de tenacidade à fratura em termos da integral- $J$ medida no ponto de instabilidade, $J_{c}$. É importante ressaltar que os ensaios de tenacidade à fratura aqui descritos fornecem um banco de dados de tenacidade à fratura para um material pouco explorado dentro do contexto da metodologia da Curva Mestra, o que destaca a sua relevância na contribuição para a ampliação e enriquecimento do banco de dados de tenacidade à fratura de aços martensíticos de alta e ultra alta resistência. Os dados experimentais de tenacidade à fratura apresentam uma dispersão relativamente significativa e são bem descritos pela distribuição de probabilidade de Weibull na sua forma triparamétrica. Não obstante o uso da Curva Mestra na sua forma padrão fornecer uma boa descrição da dependência da tenacidade à fratura mediana com a temperatura $\left(K_{J_{c}}\right.$ vs. $\left.T\right)$, é possível obter uma correlação mais acurada a partir de novos coeficientes propostos para o aço martensítico usado neste estudo. Além disso, é proposto um novo valor para a tenacidade à fratura mediana associada à temperatura de referência.

Palavras-chave: aço martensítico, fratura frágil, temperatura de referência, curva mestra, fratura por quase-clivagem 


\begin{abstract}
This work addresses an experimental investigation concerning the brittle fracture behavior of a martensitic steel using SE(B) specimens in a standardized configuration according to the ASTM E1921 standard. The purpose of this work is to assess Master Curve Methodology (MCM) applicability on evaluation reference temperature $\left(T_{0}\right)$ derived from fracture toughness data measured in the ductile-to-brittle transition region (DBT) of a quenched martensitic steel USI AR 450 which according to ASTM E1921 is not applicable to martensitic steels only quenching. The work also presents a relatively straightforward procedure for the determination of new coefficients of the master curve for the sake of a better description of median fracture toughness change (expressed in terms of the elastic-plastic stress intensity factor $K_{J_{C}}$ ) according to the temperature in the DBT region and, hence, a more accurate $T_{0}$ estimate. Fracture toughness tests, conducted at different temperatures in the DBT region using SE(B) specimens extracted in the TL orientation of a quenched martensitic steel plate, provide the fracture toughness data in terms of the J-integral at instability point, $J_{c}$.Importantly, fracture toughness data of high strength martensitic steels tests described here provide a fracture toughness database for a material small explored in Master Curve methodology, which highlights its relevance in contributing to bank expansion and enrichment. Fracture toughness experimental data present a relatively significant dispersion and are well described by the Weibull probability distribution in its triparametric form. Notwithstanding that the Master Curve uses in its standard formulation provides a good description of fracture toughness dependence with temperature for the tested material ( $K_{J_{c}}$ vs. $T$ ), it is possible to afford a more accurate correlation from new coefficients proposed for the martensitic steel used in this study. Furthermore, a new value for the median fracture toughness closely related to the reference temperature is proposed.
\end{abstract}

Keywords: martensitic steel, brittle fracture, reference temperature, master curve, quasicleavage fracture 


\section{LISTA DE FIGURAS}

Figura 2.1 - Exemplos de superfície de fratura de uma liga de a) Fe-0,01C-0,24Mn-0,02Si

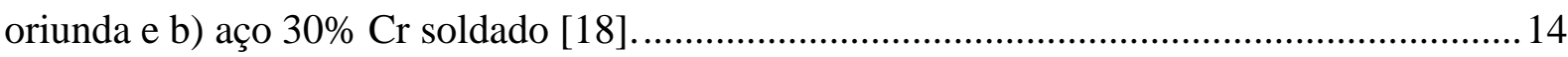

Figura 2.2 - Micromecanismo de fratura frágil-clivagem transgranular[21]...........................15 Figura 2.3 - Esquema de uma estrutura e um corpo de prova carregados e com o mesma intensidade de tensões [17]. 18

Figura 2.4 - Ilustração esquemática do mecanismo de fratura por quase clivagem em uma estrutura martensítica composto por pacotes de ripas separados por uma interface com elevado ângulo (Adaptado de [30]).

Figura 2.5 - Superfície plana com um entalhe em um campo de deformação bidimensional [32].

Figura 2.6 - Efeito de plasticidade no campo de tensão na ponta da trinca, (a) condições SSY,

(b) condições elasto-plásticas, (c) condições LSY [17].

Figura 2.7 - Divisão da curva de carga- deslocamento entre energia elástica e plástica[38]...30

Figura 2.8 - Curva de transição dúctil-frágil em aços ferríticos [17] ..................................... 32

Figura 2.9 - Iniciação de clivagem por microtrincas [17] ....................................................... 33

Figura 2.10 - Zona de processo de fratura e distribuição de valores de extremo. .....................34

Figura 2.11 - Diferença entre tenacidade a fratura entre corpos de provas $1 \mathrm{~T}$ e 4T [5]........... 35

Figura 3.1 - Curva referências de tenacidade à fratura da Seção XI do código ASME [44].... 38

Figura 3.2 - Variação da tenacidade média em função de $\left(T-T_{0}\right)$ para diversos aços estruturais ferríticos[4]

Figura 3.3 - Análise comparativa entre a Curva Mestra para aços ferríticos e modificada para aços martensíticos.

Figura 4.1 - Representação esquemática das superfícies de análise microestrutural adaptada da norma ASTM E3.

Figura 4.2 - Esquema de retirada de corpos de prova SE(B) com trinca profunda. 50

Figura 4.3 - Esquema de retirada de corpos de prova de impacto Charpy. .50

Figura 4.4 - Corpo de prova de tração padronizado segundo a ASTM E8/E8M[56] 51

Figura 4.5 - Diagrama Tensão vs. Deformação para determinação da tensão de escoamento[56].

Figura 4.6 - Ajuste da curva tensão vs. deformação na região plástica em log-log [59]..........53 


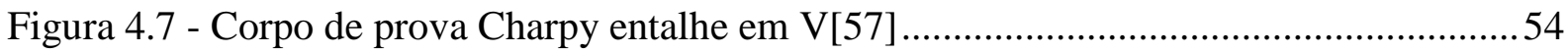

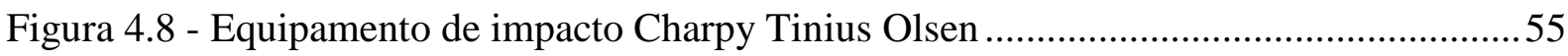

Figura 4.9 - Estufa Microprocessada para Esterilização e Secagem Sterilifer......................... 55

Figura 4.10 - Energia de Impacto por Temperatura de Ensaio................................................57

Figura 4.11 - Representação geométrica e dimensional do corpo de prova SE(B) (single edge

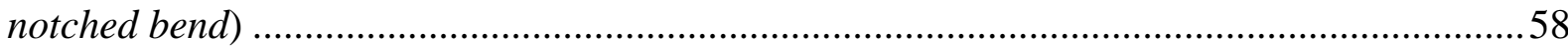

Figura 4.12 - Ensaio de tenacidade à fratura a alta temperatura............................................. 61

Figura 4.13 - Clip gage fixado no Knife-edge no corpo de prova dentro da cuba. ...................61

Figura 4.14 - Definição da área plástica usada no cálculo de Jp (adaptado) ............................64

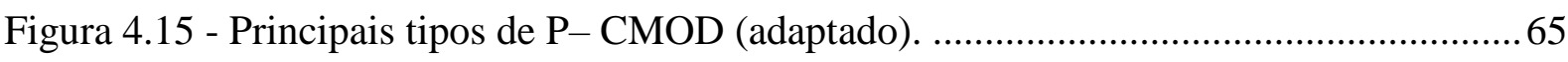

Figura 4.16 - Avaliação esquemática de pop-in (adaptado ASTM E1921[6])........................68

Figura 4.17 - Representação esquemática da medição da frente de trinca sem side grooves a

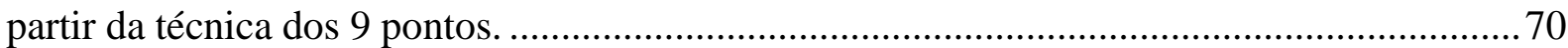

Figura 4.18 - Curva mestra e seus intervalos de tolerância associados a um nível de probabilidade acumulada de $5 \%$.

Figura 5.1 - Procedimento de preparo das amostras em baquelite com destaque para as três orientações em relação ao sentido de laminação da chapa.

Figura 5.2 - Microestruturas do aço USI AR450 no sentido longitudinal a laminação, sob ampliações de (a) 100x; (b) 200x; (c) 500x; (d) 1000x 88

Figura 5.3 - Microestrutura do aço USI AR450 no sentido transversal a laminação, sob ampliações de (a) 100x; (b) 200x; (c) 500x; (d) 1000x

Figura 5.4 - Microestrutura do aço USI AR450 no sentido normal a laminação, sob ampliações de (a) 100x; (b) 200x; (c) 500x; (d) 1000x

Figura 5.5 - Microestrutura do aço USI AR450 antes do ataque, sob ampliações de (a) 50x

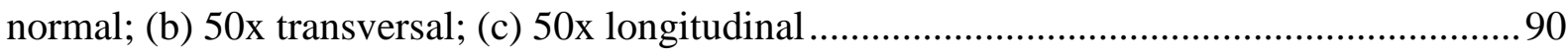

Figura 5.6 - Curva $\sigma$ vs. $\varepsilon$ obtida a temperatura ambiente.................................................... 92

Figura 5.7 - (a)-Curva $\sigma$ vs. $\varepsilon$ obtida a temperatura ambiente, método offset $0,2 \%$ para determinação da tensão de escoamento; (b) Região de mudança de regime linear elástico para o plástico.

Figura 5.8 - (a) Curva $\sigma$ vs. $\varepsilon$ acima da tensão de escoamento em log-log obtida a temperatura ambiente (offset de 0,5\% para CP3); (b) Curva Tensão vs. Deformação real acima da tensão de escoamento em log-log obtida a temperatura ambiente (offset de 0,2\% para CP3) 94 Figura 5.9 - Curvas Tensão deformação, numérica e experimental ((a), (b), (c) e (d)) e comparação da curva média numérica e experimental (e). 
Figura 5.10 - Curva de tenacidade ao impacto Charpy-V obtida a partir da função tangente hiperbólica (sugestão)

Figura 5.11 - Dados experimentais de (KJc) e os respectivos valores de K0 e KJc(med) .....102

Figura 5.12 - Curvas de carga-deslocamento (P-CMOD) a diferentes temperaturas..............105

Figura 5.13 - Curva P-CMOD a temperatura ambiente........................................................ 109

Figura 5.14 - Curva P-CMOD em condição SSY no USI AR450 ensaio a $60^{\circ} \mathrm{C}$...................109

Figura 5.15 - Curva P-CMOD em condição SSY no aço Hardox [50, 51]. ...........................110

Figura 5.16 - Distribuições triparamétrica de Weibull dos dados de Jc medidos a $-20 \leq \mathrm{T} \leq$ $25^{\circ} \mathrm{C}$

Figura 5.17 - Distribuições triparamétrica de Weibull dos dados de Jc medidos a $25<\mathrm{T} \leq 70$.

Figura 5.18 - Distribuições linearizadas de Weibull: (a) $50^{\circ} \mathrm{C}$, (b) $60^{\circ} \mathrm{C}$ e (c) $70{ }^{\circ} \mathrm{C}$ 113

Figura 5.19 - Distribuição de Weibull triparamétrica na forma linearizada referente ao valor: (a) teórico de $\alpha(\alpha K=4)$ e (b) estimado de $\alpha(\alpha K)$ Erro! Indicador não definido. Figura 5.20 - Superfície de fratura do corpo de prova CP31 ensaiado a $50{ }^{\circ} \mathrm{C}$ : (a) macrografia para medição da frente de trinca; (b) região de transição entre a pré-trinca nucleada por fadiga e início da fratura (35x); (c) microfractografia da zona de processo de fratura (200x); (d) microfractografia da zona de processo de fratura (1000x) .................................................116 Figura 5.21 - Superfície de fratura do corpo de prova CP18 ensaiado a $60{ }^{\circ} \mathrm{C}$ : (a) macrografia para medição da frente de trinca; (b) região de transição entre a pré-trinca nucleada por fadiga e início da fratura (35x); (c) microfractografia da zona de processo de fratura (200x); (d)

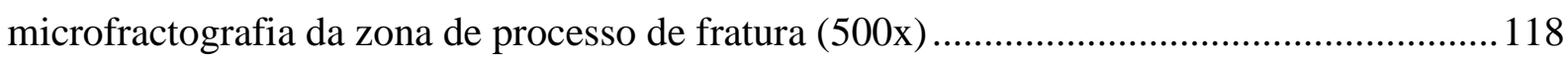
Figura 5.22 - Superfície de fratura do corpo de prova CP33 ensaiado a $70{ }^{\circ} \mathrm{C}$ : (a) macrografia para medição da frente de trinca; (b) região de transição entre a pré-trinca nucleada por fadiga e início da fratura (35x); (c) microfractografia da zona de processo de fratura (200x); (d) microfractografia da zona de processo de fratura (500x) ....................................................119 Figura 5.23 - Superfície de Fratura corpo de prova 13 e ajuste de pontos da superfície........123 Figura 5.24 - Análise da curva mestra obtida a partir da T0MT avaliada na faixa $-20 \leq \mathrm{T} \leq$ $25{ }^{\circ} \mathrm{C}$ perante (a) à janela de validade e (b) à curva mediana.................................................126 Figura 5.25 - Análise da curva mestra obtida a partir da T0MT avaliada na faixa $50 \leq \mathrm{T} \leq$ $70{ }^{\circ} \mathrm{C}$ perante (a) à janela de validade e (b) à curva mediana. 127

Figura 5.26 - Análise da curva mestra obtida a partir da T0MT avaliada na faixa $-20 \leq \mathrm{T} \leq$ $70{ }^{\circ} \mathrm{C}$ perante (a) à janela de validade e (b) à curva mediana. 
Figura 5.27 - Análise da curva mestra obtida a partir da T0MT avaliada na faixa $0 \leq \mathrm{T} \leq 70{ }^{\circ} \mathrm{C}$ perante (a) à janela de validade e (b) à curva mediana........................................................... 130 Figura 5.28 - Análise da curva mestra modificada obtida a partir da T0MT avaliada na faixa $0 \leq \mathrm{T} \leq 70^{\circ} \mathrm{C}$ perante (a) à janela de validade e (b) à curva mediana padrão. 136 Figura 5.29 - Análise da curva mestra modificada obtida a partir da T0MT avaliada na faixa $-10 \leq \mathrm{T} \leq 70^{\circ} \mathrm{C}$ perante (a) à janela de validade e (b) à curva mediana padrão 138 Figura 5.30 - Análise da curva mestra modificada obtida a partir da T0MT avaliada na faixa $-20 \leq \mathrm{T} \leq 70{ }^{\circ} \mathrm{C}$ perante (a) à janela de validade e (b) à curva mediana padrão 141 


\section{LISTA DE TABELAS}

Tabela 4.1 - Matriz experimental dos ensaios de tenacidade à fratura.

Tabela 4.2 - Constantes para a estimativa inicial da temperatura de ensaio de tenacidade à fratura. 59

Tabela 4.3 - Fator de ponderação para a estimativa da T0 via método multitemperatura 77

Tabela 4.4 - Requisitos de valores de KJc não censurados para a estimativa da T0 via método da temperatura única. 79

Tabela 5.1 - Composição química do aço USI AR450 (\% em massa). 85

Tabela 5.2 - Composição química do aço Hardox® 450 em critérios de máxima composição permitida (\% em massa) [68]. .86

Tabela 5.3 - Propriedades mecânicas do aço USI AR450. .96

Tabela 5.4 - Valores das medidas experimentais de tenacidade ao impacto Charpy-V 98

Tabela 5.5 - Coeficientes do ajuste da curva Charpy e temperaturas associadas às energias de 28 e $41 \mathrm{~J}$ incluindo os valores dos patamares inferior e superior de energia 99 Tabela 5.6 - Parâmetros de Weibull estimados pelo método dos mínimos quadrados em termos de Jc 114

Tabela 5.7 - Resumo dos dados de tenacidade à fratura e dos limites de deformação 122

Tabela 5.8 - Análise dos requisitos referentes ao tamanho mínimo do conjunto de dados usados no cálculo da temperatura de referência via método multitemperatura......

Tabela 5.9 - Análise comparativa do erro relativo percentual entre as medidas calculadas e estimadas de KJcmed nos intervalos de $-20 \leq \mathrm{T} \leq 70{ }^{\circ} \mathrm{C}$ e $0 \leq \mathrm{T} \leq 70{ }^{\circ} \mathrm{C}$ 133

Tabela 5.10 - Análise comparativa do erro relativo percentual entre as medidas calculadas e estimadas de $\mathrm{KJ} c m e d$ no intervalo de $0 \leq \mathrm{T} \leq 70{ }^{\circ} \mathrm{C}$ pelas curvas mestra padrão e modificada

Tabela 5.11 - Análise comparativa do erro relativo percentual entre as medidas calculadas e estimadas de $\mathrm{KJ} c m e d$ no intervalo de $-10 \leq \mathrm{T} \leq 70{ }^{\circ} \mathrm{C}$ pelas curvas mestra padrão e modificada

Tabela 5.12 - Análise comparativa do erro relativo percentual entre as medidas calculadas e estimadas de $\mathrm{KJ} c m e d$ no intervalo de $-20 \leq \mathrm{T} \leq 70{ }^{\circ} \mathrm{C}$ pelas curvas mestra padrão e modificada 
LISTA DE ABREVIATURAS E SIGLAS

\begin{tabular}{|c|c|c|}
\hline ASM & : & American Society for Metals \\
\hline ASME & : & The American Society of Mechanical Engineers \\
\hline ASTM & : & American Society for Testing and Materials \\
\hline ARBL & : & High Strength Low Alloy Steel \\
\hline API & : & American Petrolium Institute \\
\hline CCC & $:$ & Cúbica de Corpo de Centrado \\
\hline CMOD & $:$ & Crack Mounth Opening Displacement \\
\hline COD & : & Crack Opening Displacement \\
\hline CTOD & : & Crack Tip Opening Displacement \\
\hline $\mathrm{CP}$ & : & Corpo de prova \\
\hline DWT & : & Drop weight test \\
\hline $\mathrm{E} C V N$ & : & Energia de impacto \\
\hline EPT & : & Estado Plano de Tensão \\
\hline EPD & : & Estado Plano de Deformação \\
\hline HRR & : & Hutchinson - Rice - Rosengren \\
\hline LLD & : & Load Line Displacement \\
\hline LSY & : & Large Scale Yielding conditions \\
\hline PVRC & : & Pressure Vessel Research Committee \\
\hline PCVN's & : & Precracked Charpy V-Notch specimens \\
\hline$R T_{T 0}$ & : & Temperatura de Referência Alternativa \\
\hline NDTT & : & Nil Ductility Transition Temperature \\
\hline RTDF & : & Ductile to Brittle Transition Region \\
\hline RITDF & : & Região inferior de transição dúctil frágil \\
\hline RSTDF & : & Região superior de transição dúctil frágil \\
\hline RTNDT & : & Reference Temperature for Nil-Ductile Transition \\
\hline SE(B) & $:$ & Single-Edge Notched Bend Specimen \\
\hline SSY & $:$ & Small Scale Yielding \\
\hline TCC & $:$ & Tetragonal de Corpo Centrado \\
\hline$T_{0}$ & $:$ & Temperatura de referência \\
\hline$T_{0}^{S T}$ & : & Temperatura de referência por única temperatura \\
\hline$T_{0}^{M T}$ & : & Temperatura de referência por multi temperatura \\
\hline$T_{c v n}^{28 J}$ & $:$ & Temperatura associada à Energia de $28 \mathrm{~J}$ \\
\hline
\end{tabular}




$\begin{array}{lll}T_{c v n}^{41 J} & : & \text { Temperatura associada } \wedge \text { `a Energia de 41J } \\ \text { LIT } & : & \text { Limite Inferior de Tolerância } \\ \text { LST } & : & \text { Limite Superior de Tolerância } \\ \text { MCM } & : & \text { metodologia da Curva Mestra } \\ \text { CMM } & : & \text { Curva Mestra Modificada } \\ \text { MFEL } & : & \text { Mecânica da fratura elástica linear } \\ \text { MFEP } & : & \text { Mecânica da Fratura Elasto-Plástica } \\ \text { MMQ } & : & \text { Método dos mínimos quadrados } \\ \text { MMV } & : & \text { Método da máxima verossimilhança } \\ \text { VPR } & : & \text { Vasos de pressão } \\ \text { PIE } & : & \text { Patamar inferior de energia } \\ \text { PSE } & : & \text { Patamar superior de energia } \\ V A R & : & \text { Variância }\end{array}$




\section{SUMÁRIO}

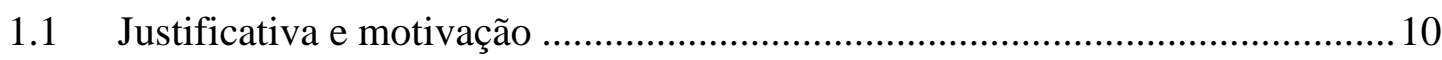

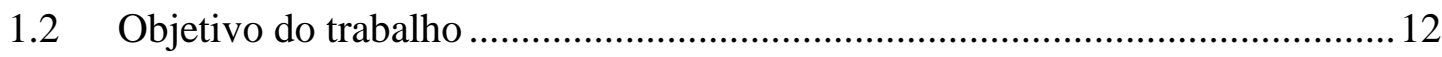

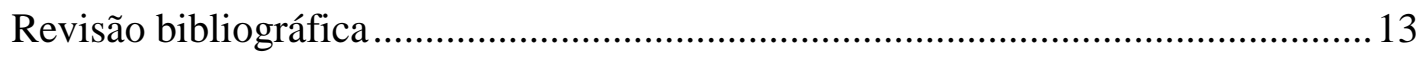

2.1 Introdução à fratura frágil - clivagem transgranular ..................................... 13

2.2 Fator Elástico-Linear de Intensidade de Tensão..............................................17

2.3 Fratura frágil em aços martensíticos.............................................................. 19

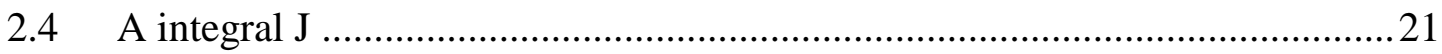

2.5 Procedimento de avaliação da Integral $\boldsymbol{J}$ utilizando medições experimentais de

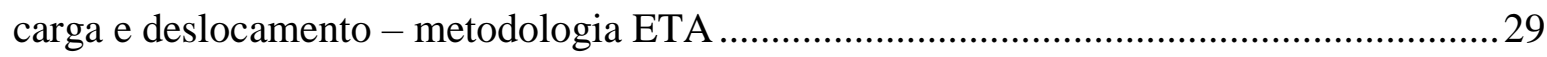

2.6 Descrição Estatística da Tenacidade à Fratura ................................................32

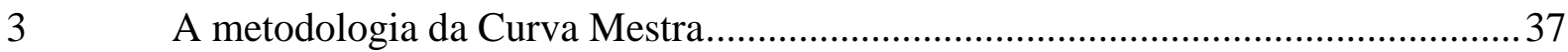

3.1 Curvas Referenciais para Avaliação da Dependência da Tenacidade com a

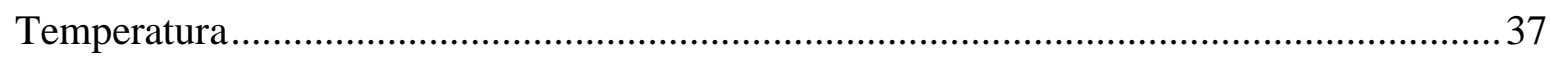

3.2 A Metodologia da Curva Mestra e o Procedimento ASTM E1921................... 39

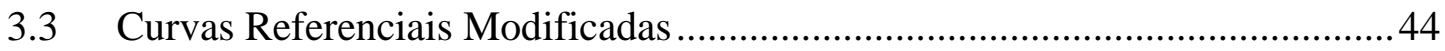

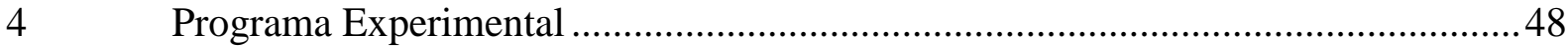

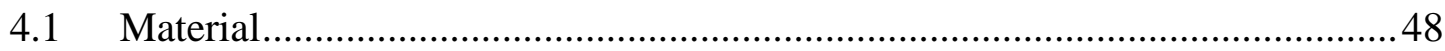

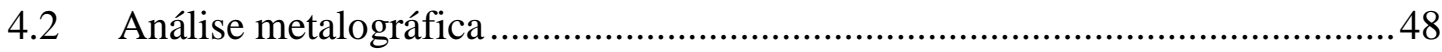

4.3 Preparação das chapas para extração dos corpos de prova................................49

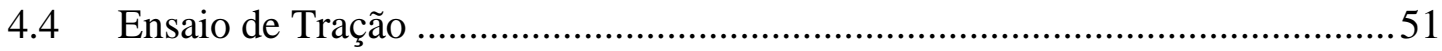

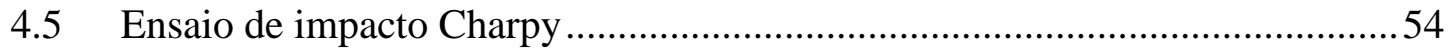

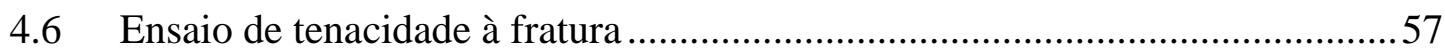

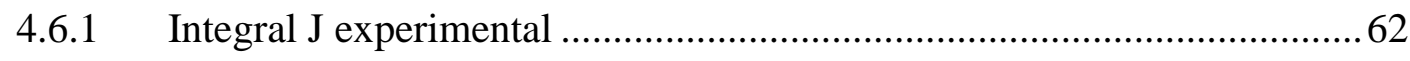

4.6.2 Avaliação da significância de pop-in’s na curva P-CMOD ...................... 64

4.6.3 Caracterização fractográfica e medição da frente de trinca...................... 68

4.6.4 Análise estatística dos dados de tenacidade à fratura ............................... 71 
4.6.5 Métodos para a determinação da temperatura de referência (T0)............ 73

4.6.6 Caracterização da tenacidade à fratura pela Curva Mestra......................... 79

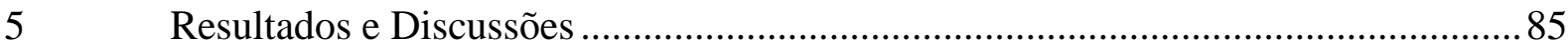

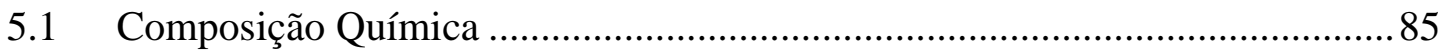

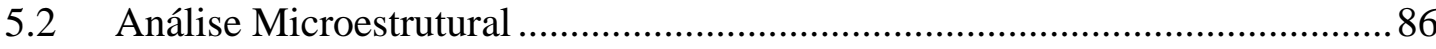

5.3 Análise das Propriedades Mecânicas de Tração................................................91

5.4 Resultados de tenacidade ao entalhe em V por impacto Charpy .......................98

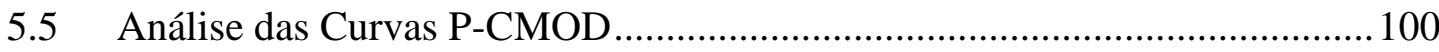

5.6 Análise da distribuição estatísticas dos dados de tenacidade à fratura............110

5.7 Análise fractográfica e medição da frente de trinca ........................................115

5.8 Análise da temperatura de referência multitemperatura a partir da curva mestra padrão 124

5.9 Análise da temperatura de referência multitemperatura a partir da curva mestra modificada 134

CONCLUSÕES E CONSIDERAÇÕES FINAIS 144

7 SUGESTÕES E RECOMENDAÇÕES PARA ESTUDOS FUTUROS.................147

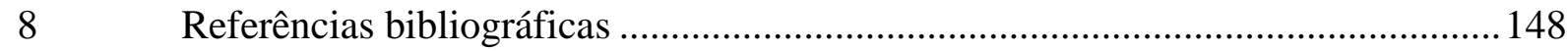

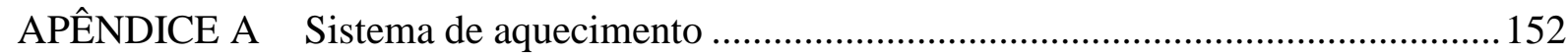

APÊNDICE B Curva mestra por única temperatura.......................................................... 155

APÊNDICE C Procedimento de otimização para a determinação de novos coeficientes ..159 


\section{Introdução}

A mecânica da fratura é uma ciência relativamente nova e, certamente, uma das responsáveis pelo efetivo avanço na compreensão do comportamento mecânico de estruturas submetidas a carregamentos complexos associados à presença de descontinuidades do tipo trinca. Os avanços da mecânica da fratura possibilitaram a introdução de ferramentas eficazes e relativamente simples para avaliar a capacidade de materiais pouco tenazes em suportar trincas estacionárias sob elevadas tensões sem a ocorrência de falhas [1]. A avaliação precisa do comportamento à fratura permanece essencial nos códigos de projeto e de fabricação, bem como nos procedimentos de avaliação de criticidade de defeitos ("fitness for service" - FFS) utilizados nas tomadas de decisões de reparos e programas de extensão da vida útil de equipamentos de grande responsabilidade estrutural. Em materiais ferríticos, tais como os aços de alta resistência e baixa liga (ARBL ou HSLA do inglês High Strength Low Alloy Steel) tipicamente utilizados em componentes estruturais que ocasionalmente podem operar na região da temperatura de transição dúctil-frágil (RTDF ou DBTR do inglês Ductile to Brittle Transition Region), fraturas instáveis por clivagem transgranular, a partir de defeitos do tipo trinca, representam um dos mais sérios modos de falha, podendo potencialmente causar falhas estruturais catastróficas sob baixas amplitudes de tensão e com pouca deformação plástica precedente à instabilidade [2].

A metodologia da Curva Mestra (MCM) foi antecedida pela chamada curva de referência ASME a qual foi desenvolvida em meados do século passado pelo ASME Boiler and Pressure Vessel Committee. Embora a curva de tenacidade referencial estabelecida pela ASME tenha representado um enorme avanço à época, a sua aplicação se limitava ao comportamento à fratura na região do patamar inferior e na região inicial da temperatura de transição devido ao fato de a mesma ter sido formulada com base nos preceitos da mecânica da fratura elástica linear (MFEL) [1], [3]. O desenvolvimento de corpos de prova miniaturizados (e.g., PCVN do inglês Precracked Charpy V-Notch) para a caracterização da tenacidade à fratura de materiais estruturais, particularmente de ligas ferrosas aplicadas na indústria nuclear, motivou novas discussões sobre a sua aplicabilidade devido ao uso de materiais mais tenazes associado aos efeitos de deformação plástica observados sobre os valores de tenacidade. Tais discussões acerca das limitações da curva de referência ASME promoveram contínuos progressos e que culminaram no desenvolvimento da metodologia da Curva Mestra [4]. 
A metodologia da CM, normatizada como ASTM E1921 [5] e intitulada "Determinação da temperatura de referência, $T_{0}$, para aços ferríticos na região de transição", teve seu desenvolvimento impulsionado pela indústria, mais especificamente pela setor de energia nuclear cujo foco era voltado para a análise de integridade estrutural de vasos de pressão aplicados em reatores de centrais nucleares (VPR's) [6] por meio dos chamados programas de monitoramento (surveillance). Tais programas visam monitorar periodicamente a integridade estrutural de VPR's, mais especificamente em regiões severamente expostas aos efeitos da fragilização por irradiação neutrônica (FIN), a partir de resultados de tenacidade à fratura obtidos de inúmeros corpos de prova em escala reduzida (subsize) os quais são encapsulados e alojados no interior do reator durante sua fase operacional. A CM mostrou-se uma ferramenta altamente robusta e eficaz em descrever a dependência das medidas de tenacidade à fratura mediana em relação à uma ampla faixa de temperatura definida na RTDF oriundas de uma extensa gama de aços ferríticos e suas juntas soldadas, tanto em condições irradiada quanto não irradiada, aplicados em vasos de pressão [2].

\subsection{Justificativa e motivação}

Historicamente, os aços utilizados na concepção e fabricação de vasos de pressão, caldeiras, tanques de armazenamento e trocadores de calor (e.g., A302 grau B, A212 grade B, SA336 grade F-1, A508 class 2, A515, A516, A533, A537, A542, A543) são em sua grande maioria compostos tipicamente por uma matriz ferrítica-perlítica. Dentro do contexto da indústria nuclear, à exceção das tubulações nas quais são utilizados aços austeníticos, na grande maioria dos componentes que compõe a barreira de pressão do circuito primário (i.e., o vaso do reator e o gerador de vapor) são empregados aços ferríticos. Embora tais aços sejam bem consolidados e profundamente estudados, a necessidade em aumentar capacidade de geração de energia e a vida útil das centrais nucleares tem impulsionado uma crescente demanda por materiais mais tenazes e resistentes. Dentro desse contexto, a indústria siderúrgica em cooperação com setor nuclear tem buscado novas soluções para o desenvolvimento de aços cada vez mais resistentes não somente em termos mecânicos, mas também aos efeitos da fragilização por irradiação neutrônica. Em sintonia com essa tendência, muitos projetos de vasos de pressão aplicados em reatores nucleares comerciais (VPR's) estão migrando para o uso de aços compostos por fases martensíticas. A título de exemplo o aço de baixa liga SA508 Gr.4N Ni-Mo-Cr, que possui um teor mais elevado de Ni e Cr em comparação à tradicional liga 
de aço SA508 Gr. $3^{1}$ (também conhecido como 20MnMoNi55 na Europa, particularmente na Alemanha), além de um maior percentual de martensita revenida, tem se mostrado um forte candidato devido ao excelente balanço entre resistência mecânica tenacidade à fratura [6]. Aliado ao fato de que grande parte das usinas nucleares já operam próximas ao término da vida útil [7], o desenvolvimento de VPR's com maior capacidade de geração de energia e operação a longo prazo torna-se não somente uma questão de economia e estratégia, mas também de segurança operacional. Além disso, os aços martensíticos com alto teor de cromo vêm sendo considerados materiais promissores na construção reatores de fusão desde o final da década de 1970 [8].

Diversos trabalhos [6], [9], [10] têm sido conduzidos em aços martensíticos, inclusive em aço duplex [11], com potencial aplicação na fabricação de VPR's. Neimitz [9], Lee et al. [6] e Mueller et al. [10] propuseram o uso da metodologia da Curva Mestra para descrever o comportamento da tenacidade à fratura na região de transição dúctil frágil dos aços S960QC, AS508 Gr.4N e Eurofer97, respectivamente, sendo todos temperados e revenidos e os dois últimos com elevado teor percentual de cromo. Conforme reportado por Yu et al. [12],o teor mais elevado de cromo e níquel no aço A508-4A em comparação com o teor do tradicional A508-3 contribui para a elevação da tensão de escoamento ( $\left.\sigma_{y s} \geq 690 \mathrm{MPa}\right)$ e da resistência à tração $\left(795 \leq \sigma_{u t s} \leq 965 \mathrm{MPa}\right)$.

O interesse por aços mais resistentes não se limita somente à indústria nuclear. Há também uma demanda crescente por aços de ultra alta resistência para a fabricação de chassis e superestruturas para veículos comerciais, além de barras para máquinas florestais, braços de guindaste e outros equipamentos de elevação. Uma outra classe de aço de ultra alta resistência e de grande interesse industrial são aços aplicados em operações que envolvem resistência ao desgaste, tais como os aços Hardox ${ }^{\circledR}$ os quais são altamente resistentes à abrasão (com uma dureza nominal de 450 HBW - Hardox 450) e possuem uma elevada resistência mecânica. Devido às suas notáveis propriedades mecânicas e de resistência ao desgaste, essa classe também tem se tornado objeto de estudo. Esses aços, assim como os aços comumente aplicados em tubulações para o transporte de óleo e gás, tais como os aços grau API [13], apresentam uma baixa capacidade de encruamento (i.e., um expoente de encruamento relativamente elevado, ou seja, da ordem de n igual a 20 para o modelo de Ramberg-Osgood [14]).

${ }^{1} \mathrm{O}$ aço A508-3 recebe diferentes designações dependendo da região, como o alemão 20MnMoNi55, o francês 16MND5, o japonês SFVV3 e o chinês A508-3 e difere frequentemente em composições químicas e processos de fabricação[6], embora todos possuam a mesma designação básica de aço A508-3. 
A avaliação quantitativa da tenacidade à fratura em função da temperatura na RTDF de aços aplicados na construção de vasos de pressão e tubulações de óleo e gás é feita utilizando a MCM [6]. Por se tratar de uma ferramenta robusta, essa metodologia é vista como uma importante ferramenta avaliativa de aços promissores a serem empregados em modernos projetos de vasos de pressão e dutos aplicados, respectivamente, nos setores nuclear e de óleo e gás. Todavia, é de suma importância ressaltar que a MCM foi desenvolvida com foco em aços ferríticos cujo processo de fratura é frequentemente governado por uma disputa entre os micromecanismos de clivagem (fratura frágil controlada por tensão) e de cisalhamento (fratura dúctil controlada por deformação) em uma determinada faixa de temperatura na RTDF. A coexistência de ambos os micromecanismos, associado ao fato de que a clivagem pode se dar em duas etapas distintas (i.e., nucleação e propagação de microtrincas), na RTDF é um dos fatores responsáveis pela elevada dispersão nas medidas de tenacidade à fratura, o que exige um tratamento estatístico adequado para o fornecimento de um valor médio representativo da distribuição de tenacidade. Neste contexto, a aplicabilidade da norma ASTM E1921 [5] é voltada especificamente para a classe de aços ferríticos, que incorporam aços bainíticos, bainíticos revenidos, martensíticos revenidos, ferríticos e perlíticos, com tensão de escoamento entre 275MPa e 825MPa [5]. Apesar destas restrições, diversos autores utilizaram a metodologia da CM para descrever o comportamento da tenacidade à fratura mediana avaliada na RTDF de diferentes tipos de aços (e.g., aços martensíticos [6], [9], [10], [12] e duplex [11]) e demonstraram relativo sucesso da MCM ao proporem alterações nos coeficientes da expressão que rege o comportamento exponencial da MCM.

\subsection{Objetivo do trabalho}

O objetivo do presente estudo é analisar a aplicabilidade da Metodologia da Curva Mestra (MCM) na avaliação da temperatura de referência $\left(T_{0}\right)$ a partir de dados de tenacidade à fratura frágil medidos na região de transição dúctil-frágil (RTDF) de um aço martensítico de alta resistência. O trabalho também visa demonstrar um procedimento relativamente simples para a determinação de novos coeficientes de ajuste da curva mestra, a fim de obter uma melhor descrição da mediana da distribuição dos dados experimentais de tenacidade à fratura (expressos em termos do fator de intensidade de tensão elasto-plástico $K_{J_{c}}$ ) em função da temperatura da RTDF e, portanto, uma estimativa mais acurada da $T_{0}$ para o aço temperado usado neste estudo. 


\section{Revisão bibliográfica}

\subsection{Introdução à fratura frágil - clivagem transgranular}

A fratura por clivagem transgranular pode ser definida como a rápida propagação de uma trinca a partir da separação de planos cristalográficos preferenciais. Os planos de clivagem preferenciais são aqueles de menor densidade de empacotamento atômico, ou seja, uma quantidade menor de ligações atômicas são rompidas e causam um espaçamento atômico maior. No caso de materiais que apresentam estrutura cristalina do tipo cúbica de corpo centrado (CCC), tais como os aços estruturais ferríticos, a clivagem ocorre nos planos \{100\} [15], [16].

Teoricamente, uma fratura por clivagem pode ter faces perfeitamente combinadas, as quais podem ser completamente planas Entretanto, ligas de engenharia são policristalinas e contêm grãos e superfícies de sub-grãos, inclusões, desorientação² (comumente denominada de misorietation angle) e outras imperfeições que afetam a propagação da fratura por clivagem, de forma que a clivagem inexpressiva é raramente observada nesses materiais [17]. Na realidade, a propagação da trinca muda de direção a cada vez que a mesma cruza um contorno de grão e tende a caminhar para o plano de clivagem com orientação mais favorável em cada grão. Além disso, a sua orientação de propagação (i.e., o plano da trinca) se dá perpendicularmente à máxima tensão principal [16].

Conforme indicado na Figura 2.1, a superfície de fratura no local da instabilidade, em escala microscópica, revela faces de clivagem cristalográficas brilhantes com faixas em padrões de rios. Já em escala macroscópica, as trincas por clivagem se apresentam na forma de pacotes em linha plana sob uma superfície de fratura global cuja aparência se dá em padrões planos e suaves com pequenas evidencias de deformação plástica [15].

${ }^{2}$ A desorientação é a diferença na orientação cristalográfica entre dois grãos adjacentes em um material policristalino. 
Figura 2.1 - Exemplos de superfície de fratura de uma liga de a) Fe-0,01C-0,24Mn-0,02Si oriunda e b) aço 30\% Cr soldado [17].

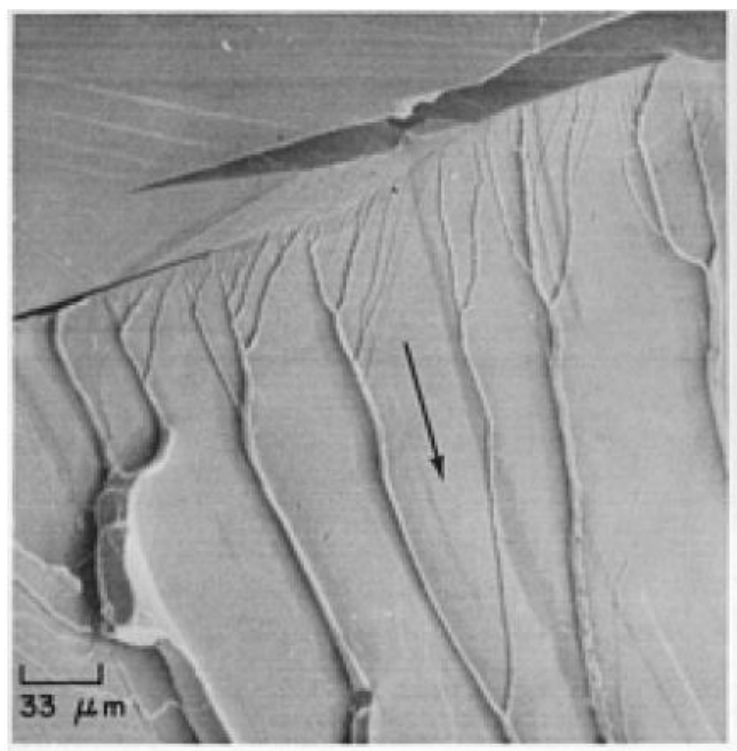

a)

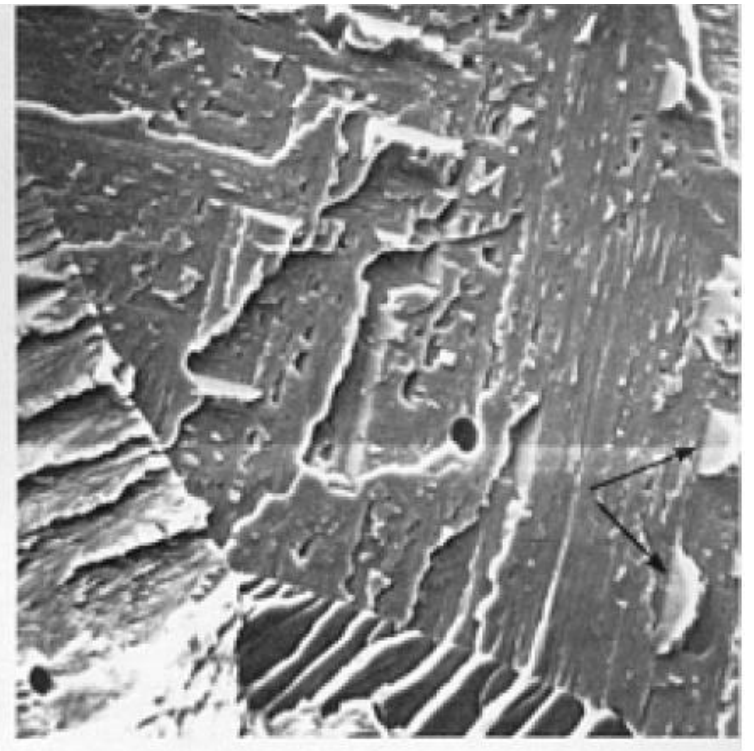

b)

$$
\longmapsto_{20 \mathrm{~mm}}
$$

A fratura por clivagem controla a tenacidade nas regiões de temperatura do patamar inferior da região frágil-dúctil. Adicionalmente, a fratura por clivagem é caracterizada pelos seguintes eventos [15]:

I. Fratura frágil sob baixas tensões. A fratura por clivagem frequentemente ocorre antes do escoamento, sob baixos carregamentos nominais remotos. Isto implica que as tensões globais de fratura são muito menores do que as tensões de escoamento generalizado. A fratura está associada a pequenas deformações e pouca energia dissipada.

II. A fratura por clivagem se desenvolve em altas velocidades (de 1000-3000 m/s), a qual pode causar acidentes catastróficos em muito pouco tempo sem que possa ser pressentida.

III. A fratura por clivagem frequentemente ocorre sob baixas temperaturas e sob altas taxas de carregamento.

O processo de fratura por clivagem demonstra claramente que o seu comportamento macroscópico pode ser relacionado com os micromecanismos de fratura, os quais são intrinsicamente dependentes da microestrutura e das propriedades mecânicas [18].É demonstrado experimentalmente que a fratura por clivagem na ponta de uma trinca não tem somente que exceder uma tensão crítica de fratura, mas tem que exceder algumas distâncias mínimas à frente da trinca as quais são características para uma determinada microestrutura. 
Em um típico aço de microestrutura ferrítica, essas distâncias características são da ordem de duas vezes o diâmetro do grão [19]. A distância característica é determinada pela competição estatística entre muitas partículas de pequenos carbonetos e poucas partículas de grandes carbonetos, ocorrendo durante a nucleação de fratura por clivagem na região da ponta da trinca em aços macios. O micromecanismo de fratura por clivagem em uma estrutura trincada é simplificado de acordo com a Figura 2.2.[20]

Figura 2.2 - Micromecanismo de fratura frágil-clivagem transgranular[20].
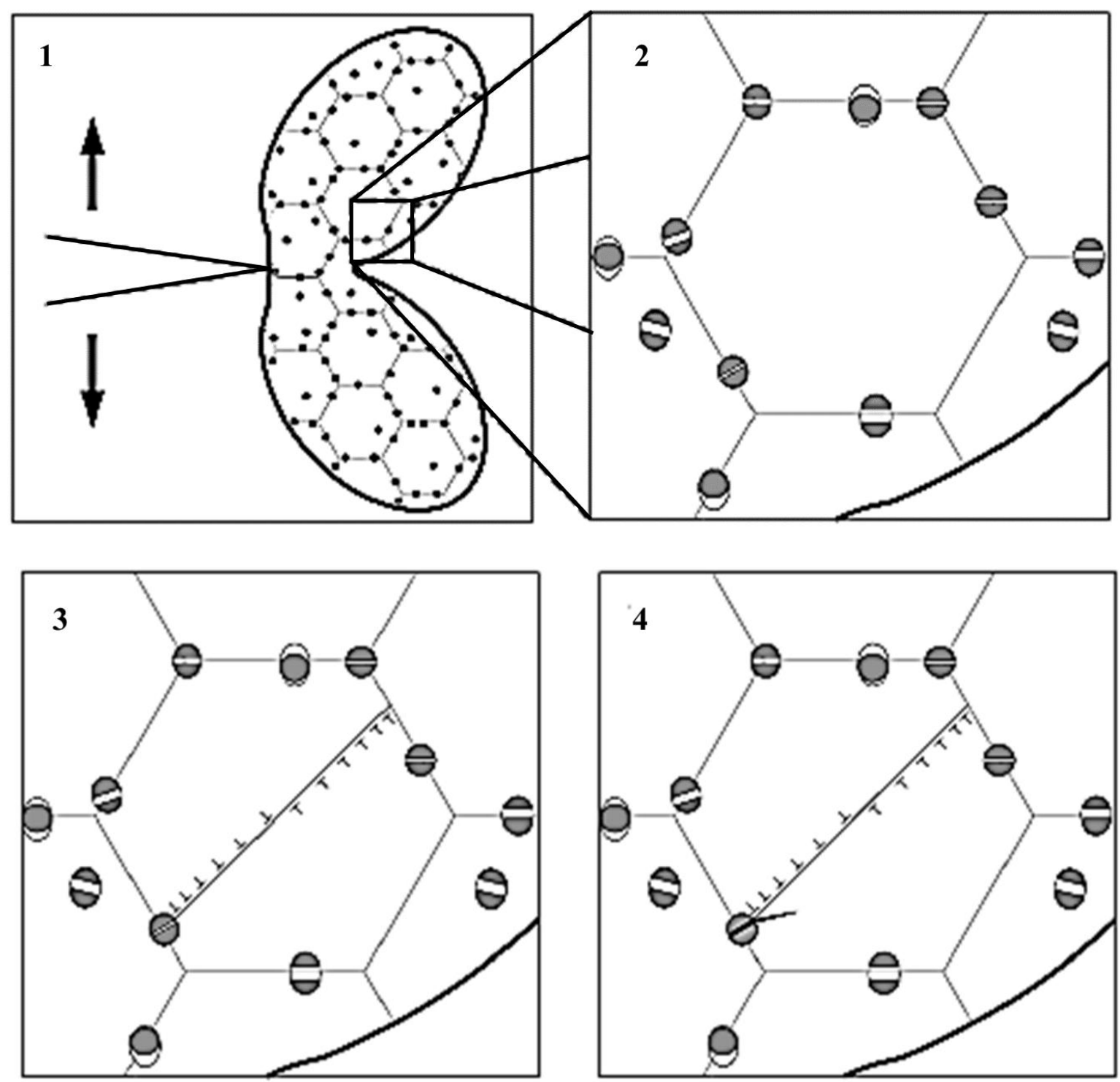

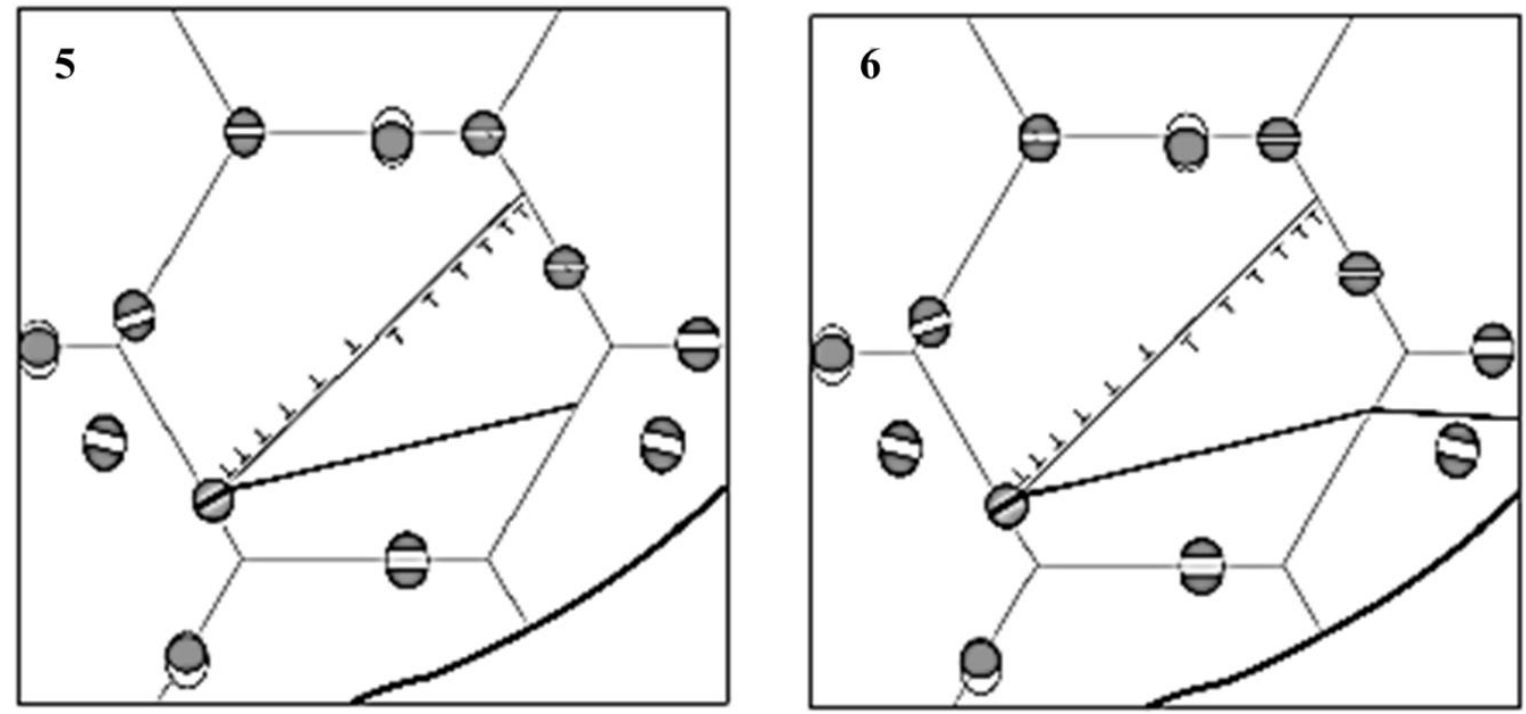

Na Figura 2.2, a etapa (1) corresponde à formação da zona plástica à frente de uma trinca macroscópica contida em um material policristalino. O desenvolvimento dessa zona ocorre devido às elevadas tensões que se desenvolvem nas regiões adjacentes à ponta da trinca de forma que as suas magnitudes atingem rapidamente o limite de escoamento do material. Devido ao campo de tensões e, principalmente, à singularidade desse campo estabelecida em virtude da presença da trinca, tensões da ordem de duas a três vezes a tensão de escoamento (i.e., $\sigma_{y y}=$ $2 \sim 3 \sigma_{y s}$, em que $\sigma_{y y}$ representa a tensão de abertura) se desenvolvem logo à frente da zona plástica promovendo a (2) fratura das partículas de segunda fase as quais são constituídas, na sua grande maioria, de pequenos carbonetos esféricos localizados nos contornos de grãos. O resultado desse processo é a formação de microtrincas (as quais são comumente designadas como microtrincas de Griffith [21] na fronteira entre dois ou mais grãos. Ademais, a fratura dessas partículas gera uma concentração local de tensão favorecendo o desenvolvimento de uma plasticidade localizada e consequente acúmulo de discordâncias (3). A interação entre as discordâncias, por sua vez, promove um aumento local das tensões as quais acabam contribuindo para a elevação das tensões de abertura $\left(\sigma_{y y}\right)$ e consequente crescimento da microtrinca (4). Caso a trinca não seja arrestada (crack arrest); isto é, caso a sua propagação não seja cessada, o seu crescimento tende a continuar para o interior do grão (5) em direção ao grão adjacente e, ao atingir esse grão, finalmente se propagar instavelmente. Esse micromecanismo de fratura era pouco conhecido na época em que as primeiras normas de tenacidade à fratura foram desenvolvidas (meados do século passado). Isso fez com que as análises de integridade estrutural na época vigentes fossem baseadas em abordagens determinísticas as quais tinham como principal parâmetro para a medição experimental de 
tenacidade à fratura o fator de intensidade de tensões $K_{I C}$ [22],o qual é descrito sucintamente na seção a seguir.

\subsection{Fator Elástico-Linear de Intensidade de Tensão}

O fator de intensidade de tensão (K) emergiu como um dos principais parâmetros da Mecânica da Fratura Elástica-Linear (MFEL), senão o principal, para descrever o comportamento à fratura de materiais resistentes, porém pouco tenazes, tais como os primeiros aços estruturais aplicados na indústria, particularmente na construção naval. Esse parâmetro elástico-linear foi proposto por Irwin [23], o qual se baseou nas soluções analíticas de Westergaard [24], para descrever o comportamento do campo de tensões atuantes em sólidos trincados de comportamento elástico-linear e estabelecer correlações com o comportamento à fratura dessa importante classe de materiais.

A grande contribuição do fator $K$ para o entendimento dos fenômenos associados à fratura frágil deu-se a partir da sua capacidade em descrever e quantificar a singularidade dos campos de tensões, deformações e deslocamentos em materiais de comportamento elástico-linear. Embora grande parte dos materiais de engenharia, tais como os aços e ligas não ferrosas, não apresente um comportamento puramente elástico, justamente devido à capacidade de se deformar quando submetido a elevadas tensões, sob determinadas condições restritivas, o fator $K$ mostra-se capaz em descrever e quantificar a singularidade desses campos. Esse foi um dos motivos pelos quais o parâmetro $K$ pôde, desde o início dos primeiros estudos experimentais acerca das medições de tenacidade à fratura [25], [26], ser utilizado nas análises dos campos de tensões em materiais estruturais tais como as ligas ferrosas e, assim, ser utilizado na previsão do comportamento à fratura de tais materiais.

A singularidade dos campos elástico-lineares em questão refere-se ao gradiente de tais campos, com particular interesse para o campo de tensões o qual apresenta uma forte variação ao longo da frente de trinca e é o responsável por promover o processo de fratura frágil por clivagem em uma extensa classe de aços estruturais. Essa singularidade faz com que as tensões na ponta da trinca variem fortemente em função da razão $(1 / \sqrt{r})$, onde r é a distância entre o ponto material e a ponta da trinca expressa em coordenadas polares.

A partir de uma melhor compreensão sobre a maneira pela qual as tensões se distribuíam ao redor de defeitos do tipo trinca em materiais elástico-lineares, foi possível prever as 
condições necessárias para desencadear um processo de fratura frágil [19], [21] . Outra característica importante desse parâmetro é a sua capacidade em correlacionar as condições de tensões locais existentes nas imediações da ponta da trinca contida em uma estrutura de engenharia (comumente representada pelo modelo da placa infinita) com as encontradas em pequenos corpos de prova laboratoriais por meio do princípio da similitude ou similaridade esquematicamente ilustrado na Figura 2.3. Esse princípio estabelece a igualdade entre os campos de tensões desenvolvidos na estrutura e no corpo de prova sob condições de escoamento em pequena escala (comumente denominada de condições SSY, do inglês Small Scale Yielding). Nesta condição, presume-se que a zona plástica formada à frente da ponta da trinca é muito pequena quando comparada com as dimensões da estrutura e do corpo de prova de forma que a plasticidade permanece confinada a uma pequena e limitada região.

Figura 2.3 - Esquema de uma estrutura e um corpo de prova carregados e com o mesma intensidade de tensões [16].

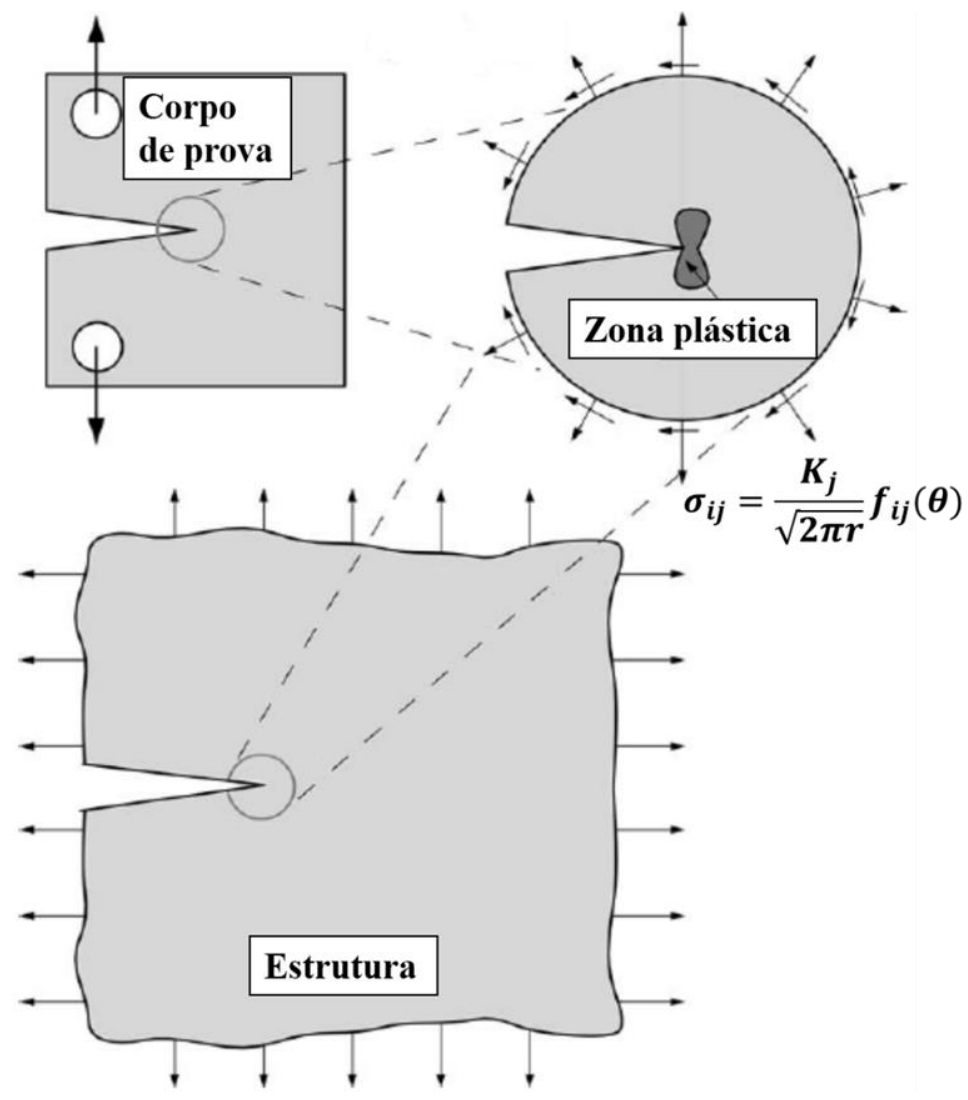

Portanto, sob tais condições, é possível correlacionar diretamente os valores experimentais de tenacidade à fratura, obtidos a partir de corpos de prova laboratoriais, com o comportamento à fratura das estruturas em escala real. Com isso, presume-se que tanto o corpo 
de prova quanto a estrutura falham a partir de um mesmo valor crítico do fator de intensidade de tensão $\left(K_{c}\right)$, o qual frequentemente é estudado sob o modo I de carregamento $\left(K_{I_{C}}\right)$; isto é, com o deslocamento da superfície da trinca em tração [16]. Os requisitos para que o domínio de $K$ seja válido são estabelecidos pela norma ASTM E399 [27], [28]. Assim, os valores de $\left(K_{I_{c}}\right)$ são validos se, e somente se, atenderem as seguintes relações:

$$
B, a,(W-a)=2,5\left(K_{I C} / \sigma_{Y S}\right)^{2}, 0,45 \leq \frac{a}{W} \leq 0,55
$$

onde $\left(\sigma_{Y S}\right)$ é a tensão de escoamento, definida em $0,2 \%$, B espessura do corpo de prova, $a$ é o comprimento de trinca, $(W-a)$ é o ligamento remanescente. Os requisitos apresentados para a validade de dominância de $K$ são rigorosos e apresentam uma estreita faixa. Tais requisitos são justamente para assegurar a condições SSY durante o processo de fratura.

A versatilidade do fator $K$ em quantificar a singularidade do campo de tensões e ser utilizado como um robusto parâmetro elástico-linear, o fez ser amplamente adotado por diversos códigos de projeto e construção como um parâmetro de tenacidade à fratura sob condições de deformação plana. Dentre esses códigos, destaca-se o código ASME que permitiu com que a indústria nuclear pudesse adotar uma curva de tenacidade à fratura referencial para estimar a tenacidade à fratura em termos de $K$ para diferentes temperaturas da região de transição dúctil-frágil dos aços ferríticos aplicados em vasos de pressão de reatores nuclear (VPR).

\subsection{Fratura frágil em aços martensíticos}

Os modos e micromecanismos de clivagem transgranular brevemente descritos anteriormente são associados fundamentalmente a materiais ferríticos, incluindo aços estruturais com baixo C utilizados em vasos de pressão. Em aços martensíticos, tal como o aço USI AR450 utilizado neste estudo, as superfícies de fratura podem exibir simultaneamente áreas com características típicas de clivagem transgranular e regiões com evidências típicas de deformação plástica por escorregamento de planos associado ao cisalhamento. Este modo de fratura frágil, no qual coexistem as morfologias de clivagem transgranular e cavidades ou rasgamento plástico é denominado fratura por "quase-clivagem”. 
Uma das principais razões pela qual a fratura de aços de microestrutura martensítica é controlada por um micromecanismo de quase clivagem reside sobre as características cristalográficas da estrutura martensítica. Especificadamente, as unidades microestruturais associadas ao grão consistem de um pacote de ripas de martensita de mesma orientação adjacente a outro pacote de ripas com outra orientação, como ilustrado na Figura 2.4. Outra característica importante evidenciada na figura é a separação dos pacotes adjacentes por uma interface com elevado ângulo (high-angle misorientations ${ }^{3}$ ). Tais fronteiras em ângulo elevado atuam efetivamente como uma barreira à propagação de uma microtrinca podendo, inclusive, causar um desvio significativo na direção de propagação, como ilustrado na Figura 2.4. Adicionalmente, esta barreira angular em conexão ao sabido desalinhamento de pacotes adjacentes de ripas possui forte efeito sobe a temperatura de transição dúctil fragil (DBT) [29].

A questão central associada aos argumentos é a aplicabilidade da metodologia da Curva Mestra (MCM) apresentada na seção 3 em descrever a dependência da tenacidade com a temperatura na região DBT de um aço martensítico. Com efeito, os procedimentos da MCM foram desenvolvidos para aços estruturais ferríticos e baseiam-se sobre os mecanismos de clivagem transgranular "pura" que tipicamente ocorrem nesta classe de materiais. Entretanto a MCM adota hipóteses mecânicas mais gerais sem incorporar explicitamente uma descrição muito detalhada das características microestruturais do material e do processo de fratura. Em particular a teoria do elo mais fraco e a descrição do campo de tensões na ponta da trinca por um parâmetro elasto-plástico (tal como a integral $J$ a qual é abordada na próxima seção) podem ser plausivelmente assumidos, em uma primeira aproximação, válidos tanto para materiais ferríticos como para aços martensíticos. Portanto, dentro do presente contexto, o comportamento de aços martensíticos pode ser comparado ao de aços ferríticos.

\footnotetext{
${ }^{3}$ Contornos de alto ângulo são definidos como aqueles contornos cujo ângulo de desalinhamento $(\varphi)$ entre grãos é maior ou igual a 15 graus; i.e., $\varphi \geq 15^{\circ}$ [77].
} 
Figura 2.4 - Ilustração esquemática do mecanismo de fratura por quase clivagem em uma estrutura martensítica composto por pacotes de ripas separados por uma interface com elevado ângulo (Adaptado de [30]).

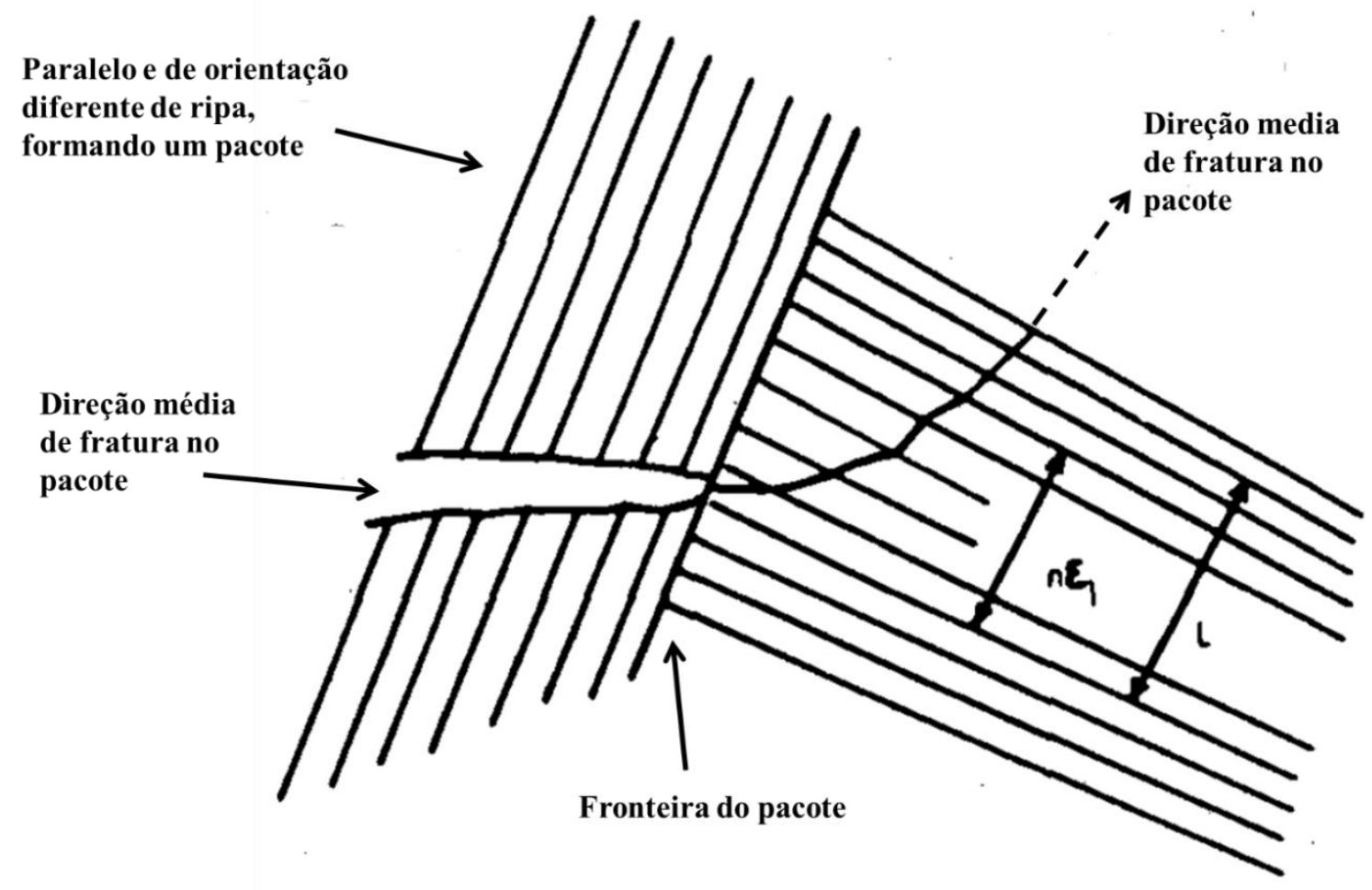

\subsection{A integral $\mathrm{J}$}

Embora o fator de intensidade de tensões $(K)$ tenha se configurado como um importante parâmetro de tenacidade à fratura, permitindo que a indústria o adotasse amplamente nas análises de integridade estrutural em diversos códigos de projeto e fabricação, a sua limitação em descrever e prever o comportamento à fratura de materiais mais tenazes ou sob condições de menores níveis de triaxialidade de tensão (e.g., uso de corpos de prova de pequenas espessuras, ensaios em temperaturas elevadas, etc.) fez com que novos parâmetros (e.g., integral J e o parâmetro CTOD) fossem propostos a fim de suprir tais limitações. Dentre esses parâmetros, destaca-se a integral $J$, a qual é definida analiticamente como uma integral de linha independente do caminho de integração e que pode ser utilizada para medir o trabalho das forças externas dissipado na forma de energia de deformação interna nas imediações de uma trinca macroscópica, conforme abordagem em detalhes mais adiante. 
Apesar do conceito matemático da integral $J$ ter sido originalmente abordado em trabalhos anteriores [31], Rice [32] foi quem introduziu a definição da integral $J$ como um parâmetro elasto-plástico de tenacidade à fratura, bem como a sua base metodológica e os seus limites de validação, consolidando a chamada Mecânica da Fratura Elasto-Plástica (MFEP) [32].

Enquanto o fator $K$ e, portanto a MFEL, é válido somente enquanto as deformações não lineares permanecem confinadas em uma pequena região ao redor da ponta da trinca [16], a integral $J$ ainda é capaz de descrever e quantificar a singularidade dos campos de tensões e deformações para regimes de carregamento que envolvem maiores níveis de deformação. Sob tais condições, comumente denominada de zona de dominância $J$, o fator $K$ perde a sua validade e, portanto, sua capacidade em quantificar a intensidade desses campos.

Uma das polivalências da integral $J$ refere-se justamente a sua capacidade em fornecer medidas da amplitude desses campos independentes do seu caminho de integração. Em outras palavras, é possível medi-la em diferentes regiões de interesse sem, no entanto, alterar as suas propriedades e, portanto, o seu valor. Essa característica é fundamental, pois a região próxima à ponta da trinca é intensamente deformada (região de grandes deformações), o que também violaria as condições da sua validade dentro de um regime elasto-plástico (i.e., zona de dominância $J$ ). Desse modo, a integral $J$ pode ser medida em regiões suficientemente distantes da ponta da trinca, porém, ainda assim, dentro de uma região deformada sem, no entanto, perder a sua capacidade de quantificar a singularidade desses campos. Essa característica contribui para as análises numéricas no que tange à convergência das soluções de $J$ visto que nas regiões intensamente deformadas as soluções tornam-se imprecisas devido aos efeitos das grandes deformações [33].

Em muitos materiais e em algumas condições de ensaios, como altas temperaturas e baixos níveis de triaxialidade de tensões, é impossível caracterizar o comportamento à fratura por meio da MFEL. Dentro desse contexto, a integral $J$ [32] emerge como um parâmetro chave na avalição de tenacidade à fratura e, portanto, de integridade estrutural. A sua base metodológica bem como os seus limites de validação foram introduzidas por James Rice [32] um pouco antes da publicação da primeira norma de tenacidade pela ASTM (sob a denominação de ASTM E399-70T e que na sua versão mais atual é designada por ASTM E399-20[28], a qual estabeleceu os procedimentos de ensaio e validação de medidas experimentais da tenacidade à fratura expressas em termos do fator crítico de intensidade de tensões em condições de deformação plana e modo I de carregamento $\left(K_{I_{c}}\right)$. 
A formulação da integral $J$ proposta por Rice[32] é baseada na teoria de deformação plástica (deformation theory) associada à condição de carregamentos proporcionais. A sua definição é dada a partir da representação de um corpo homogêneo de comportamento linear ou não-linear elástico, isento de forças de campo e submetido a um campo de deformação bidimensional (seja nas condições de deformação plana, tensão plana ou deformação antiplana (modo 3)) - de forma que todas as tensões dependam somente de duas coordenadas cartesianas, conforme representação esquemática da Figura 2.5. Para um corpo contendo uma trinca (vide Figura 2.5) com superfícies planas paralelas ao eixo $x$ (i.e., superfície superior e inferior) e uma ponta arredondada indicada pelo arco $\Gamma_{i}$, e definindo $W$ como densidade de energia de deformação, dada pela Equação 2.1 [32]

$$
W=W(x, y)=W(\varepsilon)=\int_{0}^{\varepsilon} \sigma_{i j} d \epsilon_{i j}
$$

em que $\left(\varepsilon=\left\{\epsilon_{i j}\right\}\right)$ é o tensor de deformação infinitesimal, a integral $J$ é definida pela Equação 2.2

$$
J=\int_{\Gamma}\left(W d y-T \frac{\partial u}{\partial x} d s\right)
$$

onde a $\Gamma$ delimita um contorno arbitrário ao redor da ponta da trinca. Na Eq. 2.2, a integral é avaliada em sentido anti-horário, iniciando o seu contorno pela parte inferior da superfície e continuando ao longo do caminho de $\Gamma$ até a superfície superior, e $T$ é o vetor de tração definido como normal saindo de $\Gamma$, $\left(T_{i}=\sigma_{i j} n_{j}\right)$, $u$ é o vetor de deslocamento e $d s$ é o comprimento infinitesimal de arco ao longo de $\Gamma$ [32]. 
Figura 2.5 - Superfície plana com um entalhe em um campo de deformação bidimensional [32].

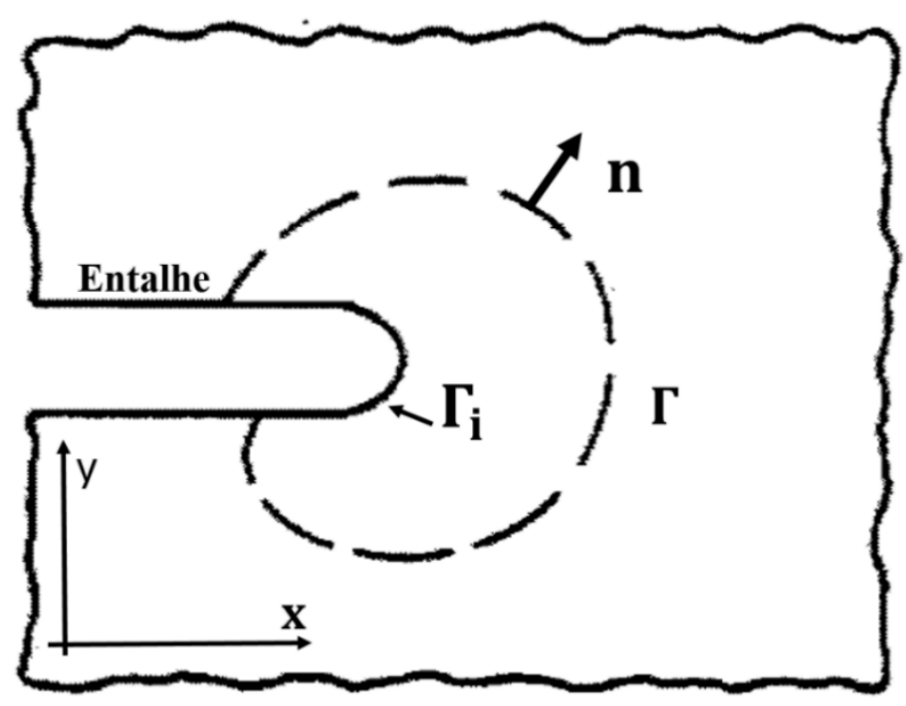

Fonte: [32]

Baseando-se na definição de taxa de dissipação de energia $(\mathcal{G})$, Rice [32] demonstra que a integral $J$ pode ser interpretada como a taxa de dissipação de energia liberada durante o avanço da trinca em corpos elásticos não-lineares. Nesta abordagem, a definição é similar à adotada para materiais elástico lineares, contanto que não haja o desenvolvimento de plasticidade na ponta da trinca. Desse modo, pode-se admitir a validade da seguinte relação de igualdade $J=\mathcal{G}$ de forma que, sob condições SSY, a integral $J$ pode ser associada ao fator de intensidade de tensões por meio da seguinte expressão

$$
J=\frac{\left(1-v^{2}\right)}{E} K_{I}^{2}
$$

em que $E$ é o módulo de Young e $v$ é o coeficiente de Poisson.

Conforme abordagem da próxima seção, é importante salientar que a relação expressa pela Eq. 2.3 representou um enorme avanço para os experimentalistas da época, pois a partir da relação entre $J$ e $K_{I}$ foi possível obter valores de tenacidade à fratura expressos em termos de $J$ para materiais cujos limites para a validade de $K$ exigiam o uso de corpos de prova superdimensionados o que, em muitas vezes, tornava a sua medição praticamente impossível.

Além de ser interpretada à partir dos preceitos da taxa de dissipação de energia, a integral $J$ também admite uma interpretação mecânica em termos do conceito do fator de intensidade de tensão. Uma característica muito importante é a sua capacidade em descrever a singularidade dos campos de tensões e deformações em materiais cujo comportamento mecânico, em termos 
da sua capacidade de encruamento sob um carregamento monotônico crescente, é mais bem descrita por uma relação constitutiva elasto-plástica do tipo Ramberg e Osgood (R\&O)[14] .

Estudos conduzidos, de forma independente, por Hutchinson [34] e Rice e Rosengren [35] demonstraram a caracterização do campo de tensões à frente da ponta de uma trinca por meio de $J$ para um material elástico não-linear. Eles assumiram uma lei de potência para descrever o comportamento da relação entre a tensão verdadeira $(\sigma)$ e a deformação (logarítmica) verdadeira $(\epsilon)$. Se a deformação elástica é incluída, essa relação de potência para uma deformação uniaxial pode ser expressa da seguinte maneira

$$
\frac{\epsilon}{\epsilon_{0}}=\frac{\sigma}{\sigma_{0}}+\alpha\left(\frac{\sigma}{\sigma_{0}}\right)^{n}
$$

em que $\sigma_{0}$ e $\epsilon_{0}$ representam a tensão e a deformação de referência, frequentemente definidas no ponto de escoamento onde $\epsilon_{0}=\sigma_{0} / E, \alpha$ uma constante adimensional e $n$ o expoente de encruamento, esse último responsável pela singularidade dos campos de tensões e deformações conforme abordagem mais adiante. A expressão acima é conhecida como modelo de RambergOsgood e é amplamente utilizada para ajustes de curvas de tensão-deformação [16] das mais variadas classes de aços estruturais e, portanto, de grande parte dos materiais de engenharia de caráter estrutural.

Baseando-se na relação constitutiva de R\&O[14], Hutchinson [34] e Rice e Rosengren [35] demonstram que para a integral $J$ ser válida e independente do caminho, o produto da tensão-deformação deve variar na razão $1 / r$ nas regiões próximas à ponta da trinca, ou seja, por meio da singularidade expressa:

$$
\sigma_{i j} \epsilon_{i j} \rightarrow \frac{u m a \text { função de } \theta}{r} \operatorname{com} r \rightarrow 0
$$

Para distâncias suficientemente próximas à ponta da trinca; isto é, próximas à região de grandes deformações, as deformações elásticas são pequenas se comparadas com a deformação total, e o comportamento da tensão-deformação se reduz a uma simples lei de potência. Essas duas condições implicam na variação de tensão e deformação à frente da ponta da trinca, como demonstrado pelas Equações 2.6 e 2.7 [19, 20] 


$$
\begin{gathered}
\sigma_{i j}=\sigma_{0}\left(\frac{E J}{\alpha \sigma_{0}^{2} I_{n} r}\right)^{\frac{1}{n+1}} \tilde{\sigma}_{i j}(n, \theta) \\
\varepsilon_{i j}=\frac{\alpha \sigma_{0}}{E}\left(\frac{E J}{\alpha \sigma_{0}{ }^{2} I_{n} r}\right)^{\frac{n}{n+1}} \tilde{\epsilon}_{i j}(n, \theta)
\end{gathered}
$$

em que $\left(I_{n}\right)$ é uma constante resultante do processo de integração e dependente de $n$ e do estado de tensões (i.e., EPT - Estado Plano de Tensão ou EPD - Estado Plano de Deformação), $\tilde{\sigma}_{i j}$ e $\tilde{\epsilon}_{i j}$ funções adimensionais dependentes de $n$ e $\theta$. A rigor, todos esses termos também dependem do modo de carregamento da trinca, ou seja, seja ele isolado (i.e., modo I, II ou III), seja combinado (i.e., modos I-II, I-III ou II-III). O conjunto de Eqs. 2.6 e 2.7 constitui a chamada solução HRR [19, 20] a qual é capaz de caracterizar os campos de tensões e deformações na ponta da trinca em materiais elasto-plásticos.

A Integral $J$ define a amplitude/intensidade do campo elasto-plástico de tensões de forma análoga ao fator elástico de intensidade de tensões $(K)$ em relação à amplitude do campo linearelástico de tensões. A validade dos parâmetros $J$ e $K$ como descritores das singularidades elastoplástica e linear elástica, respectivamente, é condicionada a um dado limite de plasticidade. Quando em condições SSY, condições essas associadas a baixos níveis de carregamento, a região que circunda a trinca encontra-se essencialmente sob dois regimes: elástico-linear e elasto-plástico, sendo esse mais próximo da região de grandes deformações e aquele mais distante, conforme representação da Figura 2.6. Na Figura 2.6 está ilustrada esquematicamente as condições de validade da dominância de $J$ e de $K$ e no texto adiante o comportamento de cada item (a, b e c) da Figura 2.6. 
Figura 2.6 - Efeito de plasticidade no campo de tensão na ponta da trinca, (a) condições SSY, (b) condições elasto-plásticas, (c) condições LSY [16].
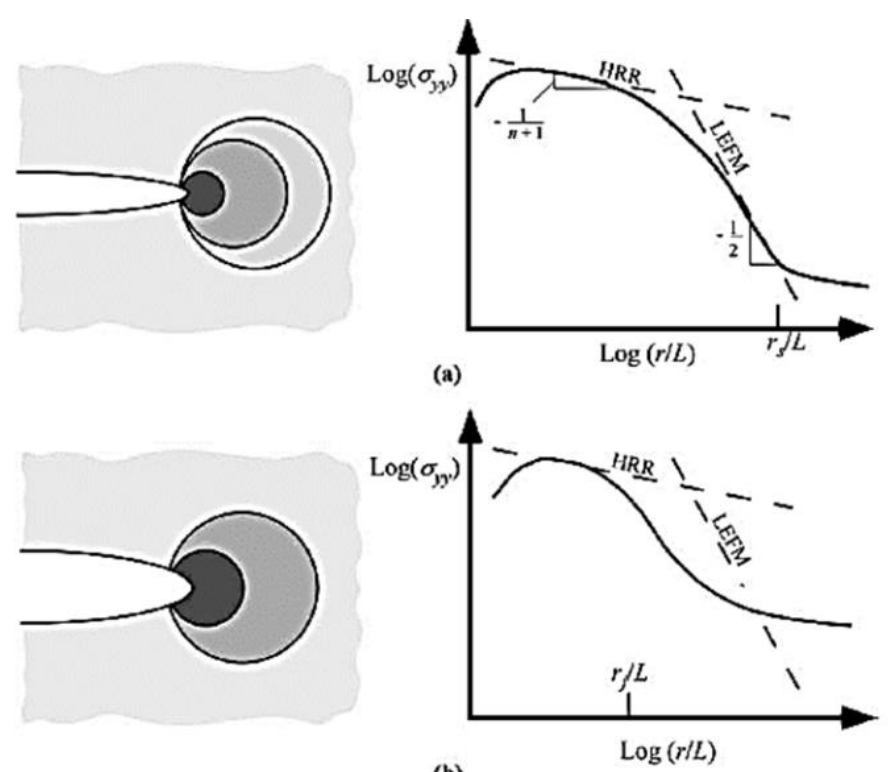

(b)

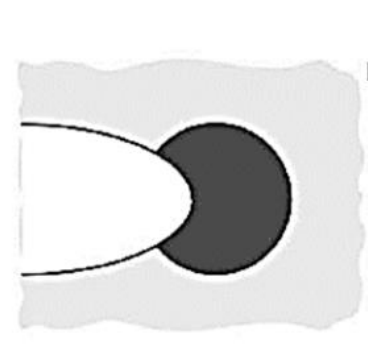

Legenda

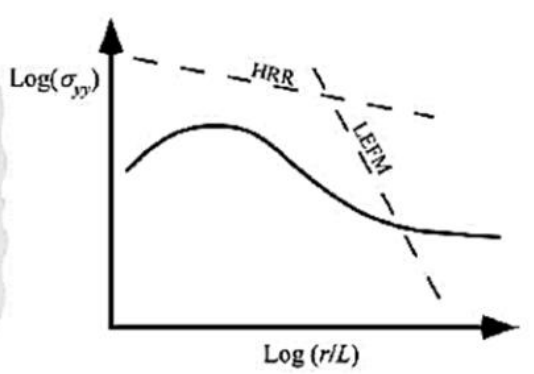

(c)

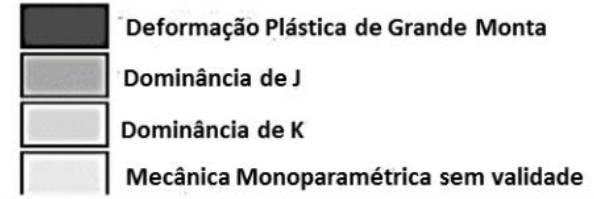

Fonte: Anderson [16]

Sob condições SSY, a variação das tensões normais ao plano da trinca $\left(\sigma_{y y}\right.$ para $\left.\theta=0^{\circ}\right)$ em função da distância normalizada à frente da trinca é dada por $1 / \sqrt{r}$ (ou $-1 / 2$ na escala logarítmica) de forma que a singularidade elástica pode ser convenientemente descrita tanto por $K$ quanto por $J$, conforme indicado na Figura 2.6(a), uma vez que $J$ está diretamente relacionada ao fator $K$ sob condições SSY. Já para maiores níveis de deformação, ou seja, para condições predominantemente elasto-plásticas, Fig. 2.6(b), as tensões variam de acordo com $r^{-1 /(n+1)}$ [ou $-1 /(n+1)$ na escala logarítmica]. Neste último caso, o fator $K$ perde sua validade, porém J ainda continua válido como um parâmetro descritor da singularidade dos campos de tensões. A integral $J$, quando dentro de sua dominância, é calculada em medições experimentais a partir 
da metodologia-eta (assim denominada em decorrência do uso de um fator adimensional $\eta$ ), a qual é abordada na próxima seção.

Todavia, quando ocorrem excessivas deformações plásticas nas proximidades da ponta da trinca (LSY - Large Scale Yielding conditions), Fig. 2.6(c), a zona de singularidade elastoplástica tende a desaparecer, ou seja, $J$ deixa de descrever univocamente essa singularidade [16], [32], [34], [35]. Esse comportamento invalida o conceito de Mecânica da Fratura Monoparamétrica (MFM) onde apenas um parâmetro é suficiente para correlacionar univocamente a singularidade dos campos de tensões e deformações. Nessas condições, o valor da integral $J$ deixa de ser uma propriedade inerente do material, o que a torna fortemente dependente do tipo de geometria e das dimensões dos corpos de prova sobre os quais são feitas as medições de tenacidade à fratura em escala laboratorial. Tal comportamento pode ocorrer em corpos de prova miniaturizados, tais como os PCVN's (Precracked Charpy V-Notch specimens) comumente utilizados nos programas de monitoramento (surveillance programs) da indústria nuclear, os quais tendem a sofrer severas perdas de restrição plástica na ponta da trinca.

Visando garantir o conceito de similitude e, portanto, a validade da MFM, o dimensionamento dos corpos de prova deve obedecer a rigorosos requisitos dimensionais. Esses requisitos são baseados em um limite de deformação $(M)$ a fim de minimizar o desvio do campo de tensões em relação à solução HRR dentro de uma região microestruturalmente significativa no que tange as condições fenomenológicas do processo de fratura à frente da ponta da trinca. Assim, o limite de deformação é comumente expresso por

$$
M=\frac{b_{0} \sigma_{0}}{J}
$$

em que $M$ representa o limite de deformação adimensional, $b_{0}$ o comprimento original do ligamento remanescente da trinca $\left(b_{0}=W-a_{0}\right)$ e $\sigma_{0}$ a tensão de referência, a qual pode ser expressa pela tensão de escoamento ou tensão de fluxo $\left(\sigma_{\text {fluxo }}=\sigma_{y s}+\sigma_{u t s} / 2\right)$ onde $\sigma_{u t s}$ representa a tensão última em tração.

Dentro de um contexto de fratura frágil, onde os requisitos dimensionais são mais restritivos, normas como a ASTM E1921[5], estabelecem um limite de deformação igual a 30 $(M=30)$ independentemente da geometria de corpo de prova [e.g., C(T), SE(B) ou PCVN] a ser utilizado nas medidas experimentais da integral $J$ no ponto de instabilidade por clivagem $\left(J_{c}\right)$. Embora tal valor não seja tão restritivo, uma vez que valores maiores tendem a penalizar 
severamente os corpos de prova de dimensões reduzidas (tal como o PCVN), ainda assim garante a validade do campo HRR sobre as condições fenomenológicas do processo de fratura por clivagem e, portanto, a condição de similitude.

A consolidação da integral $J$, assim como do parâmetro CTOD proposto anteriormente por Wells em 1963 [36], promoveu o surgimento de uma nova frente da mecânica da fratura, a qual passou a ser denominada de Mecânica da Fratura Elasto-Plástica (MFEP). Desde então, diversos procedimentos de ensaio, códigos de projeto e fabricação, bem como procedimentos de avaliação de criticidade de defeitos, tem se utilizado desses importantes parâmetros nos mais variados setores industriais. A seção a seguir faz uma breve abordagem da metodologia eta a qual é amplamente utilizada para o cálculo experimental da integral $J$.

\subsection{Procedimento de avaliação da Integral $J$ utilizando medições experimentais de carga e deslocamento - metodologia ETA}

A metodologia ETA $(\eta)$, foi proposta Sumper e Turner [37], como um método para avaliar $J$ para um corpo de prova do tipo SE(B) e os efeitos do crescimento lento de trincas, limite de carregamento experimental. Assim sendo um procedimento compatível com mecânica da fratura linear-elástica e com o procedimento de deslocamento de abertura da trinca (crack opening displacement (COD)) para medir experimentalmente o valor de $J$. Essa metodologia correlaciona um parâmetro adimensional $\eta$ com a energia de deformação, dada pela Integral $J$, com o valor da área sob a curva de carga vs. deslocamento, o qual é obtida em laboratório, mostrada na Figura 2.7. Essa metodologia aborda a taxa de energia liberada que é dividida em duas componentes de $J$, uma corresponde à componente elástica $\left(J_{e}\right)$ e outra à componente plástica $\left(U_{p}\right)$, conforme Equação 2.10. A norma ASTM E1921 [5] utiliza tal metodologia para o cálculo do parâmetro $J$. 
Figura 2.7 - Divisão da curva de carga- deslocamento entre energia elástica e plástica[37].

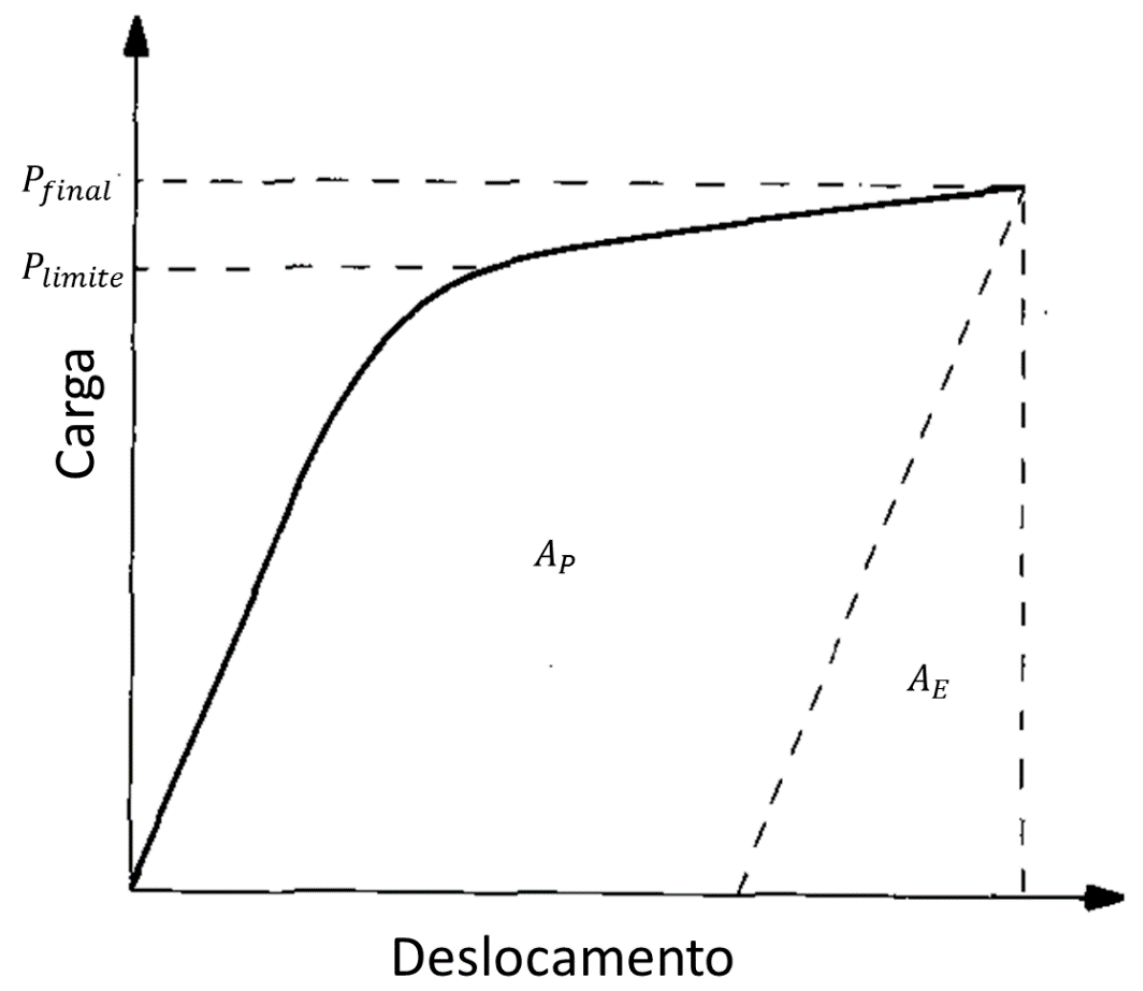

$$
J_{\text {total }}=J_{E}+J_{p}
$$

A componente de J elástico é dado pela Equação 2.11 .

$$
J_{E}=\frac{\left(1-v^{2}\right) K_{I}^{2}}{E}
$$

O fator de intensidade de tensões $\left(K_{I}\right)$ é definido analiticamente para o corpo de prova SE(B) pela Equação 2.12 .

$$
K_{e}=\left\{\frac{P S}{\left[\left(B B_{N}\right)^{1 / 2} W^{3 / 2}\right]}\right\} f\left(a_{0} / W\right)
$$

O fator de intensidade de tensões adimensional $\left(f\left(a_{0} / W\right)\right)$ para a geometria $\mathrm{SE}(\mathrm{B})$ é dado pela Equação 2.13 .

$$
f\left(a_{0} / W\right)=g\left(a_{0} / W\right) * h\left(a_{0} / W\right)
$$


onde

$$
\begin{gathered}
g\left(a_{0} / W\right)=\frac{3\left(a_{0} / W\right)^{1 / 2}}{2\left[1+2\left(a_{0} / W\right)\right]} \\
h\left(a_{0} / W\right)=\left(\frac{1,99-\left(a_{0} / W\right)\left(1-a_{0} / W\right)\left[2,15-3,93\left(a_{0} / W\right)+2,7\left(a_{0} / W\right)^{2}\right]}{\left(1-a_{0} / W\right)^{3 / 2}}\right)
\end{gathered}
$$

Na Equação 2.12, $P$ é o carregamento aplicado ao corpo de prova, $B$ é a espessura, $W$ é a largura do corpo de prova, $a$ é o comprimento da trinca e $S$ é a distância entre os roletes de apoio, no ensaio de flexão 3 pontos.

A componente plástica $J_{P}$ é avaliada a partir do cálculo da área plástica sob a curva de carga-deslocamento, pela Equação 2.15 [5]:

$$
J_{P}=\frac{-1}{B} \int_{0}^{\Delta p}\left(\frac{\partial P}{\partial a}\right) d \Delta_{p}=\frac{\eta_{J}}{B b} A_{p}
$$

em que $A_{p}$ é a área plástica da curva de carga-deslocamento, $P$ é o carregamento, $\Delta_{p}$ componente plástica do deslocamento, $b$ é o ligamento remanescente do corpo de prova antes do ensaio, $B$ é a espessura do corpo de prova e $\eta_{J}$ é o fator adimensional que relaciona a contribuição plástica da curva com a energia de deformação plástica.

As equações acima são baseadas pela medição da abertura da boca da trinca, CMOD (V) ou deslocamento da linha de carga (LLD). No trabalho atual foi medido a partir da abertura da trinca, que define $\eta_{J}$ pela Equação 2.16 [5].

$$
\eta_{C M O D}=3,667-2,199\left(\frac{a}{W}\right)+0,4376\left(\frac{a}{W}\right)^{2}
$$

A Equação 2.16 é derivada de modelos computacionais que utilizam modelamento por elementos finitos que consideram um comportamento sob estado plano de deformações. 


\subsection{Descrição Estatística da Tenacidade à Fratura}

O comportamento à fratura e o micromecanismo associado possuem grande sensibilidade à temperatura, similarmente ao comportamento à fratura em ensaios de impacto Charpy. Como ilustrado tipicamente em modo transgranular pela Figura 2.8 [16]. Para baixas temperaturas, o aço é frágil e falha por clivagem, para altas temperaturas, o material é dúctil e falha por coalescência de microcavidades (microvoid). Mas logo acima da Temperatura de Transição os mecanismos de falha são concorrentes, ou seja, no início ainda predomina a falha frágil (com um pouco da fratura dúctil) e a medida que a temperatura aumenta progressivamente também aumenta a "parcela" da falha dúctil (enquanto diminui até desaparecer a fratura frágil) Figura 2.8 .

Na região de transição dúctil frágil esses dois micromecanismos de fratura competem entre si. Assim, os valores de tenacidade apresentam grande dispersão de modo que, quando combinados aos efeitos geométricos dos corpos de prova [16], tornam as análises determinísticas muito conservadoras para se determinar o comportamento da tenacidade à fratura em função da temperatura.

Figura 2.8 - Curva de transição dúctil-frágil em aços ferríticos [16].

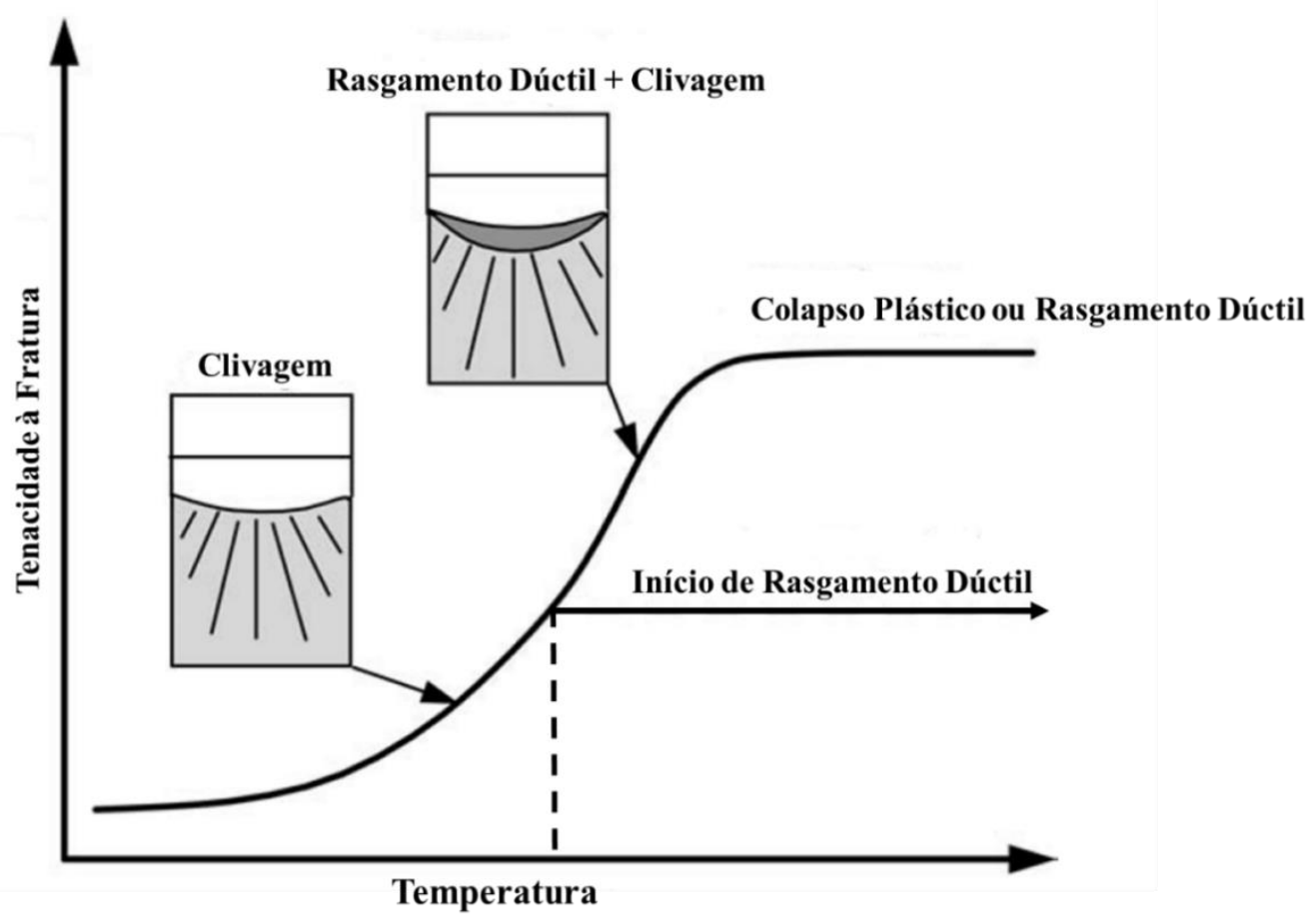

O micromecanismo de clivagem na RTDF é governado pelas etapas de nucleação e propagação de microtrincas, provenientes de partículas de segunda fase e inclusões presentes 
nos contornos de grão de aços ferríticos. O mecanismo de nucleação de trincas em aços ferríticos é ilustrado na Figura 2.9, onde a trinca macroscópica fornece concentração de tensões e deformações locais. Devido a isso, partículas de segunda fase, tal como carbonetos ou inclusões que estão dispersos na matriz, são elegíveis (carbonetos maiores e que sofram altas tensões como também empilhamento de discordâncias) a nuclear microtrincas por deformação plástica. Nesse ponto, as microtrincas podem ser tratadas como trincas de Griffith, que, de acordo com o modelo de Griffith, essas microtrincas geram altos níveis de tensões locais, disparando processos de propagação dentro da matriz ferrítica [21, 29].

Figura 2.9 - Iniciação de clivagem por microtrincas [16].

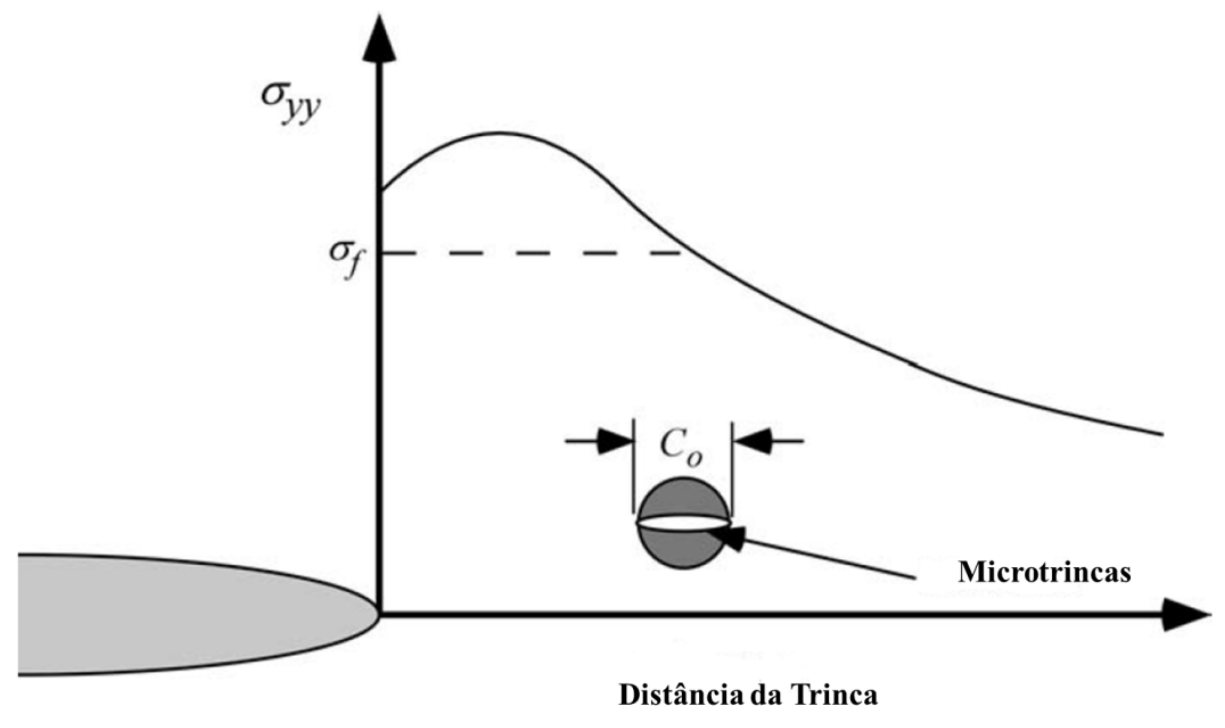

Essas microtrincas ou microdefeitos estão uniformemente distribuídos em um pequeno volume de dimensões de 5 a 10X CTOD à frente de trinca[21], como ilustrado na Figura 2.10. O modelo estatístico micromecânico determina um tamanho critico dessas microtrincas para que ocorra clivagem $a \geq a_{c}$, que é exemplificado como um modelo de distribuição de valores de extremos. 
Figura 2.10 - Zona de processo de fratura e distribuição de valores de extremo.
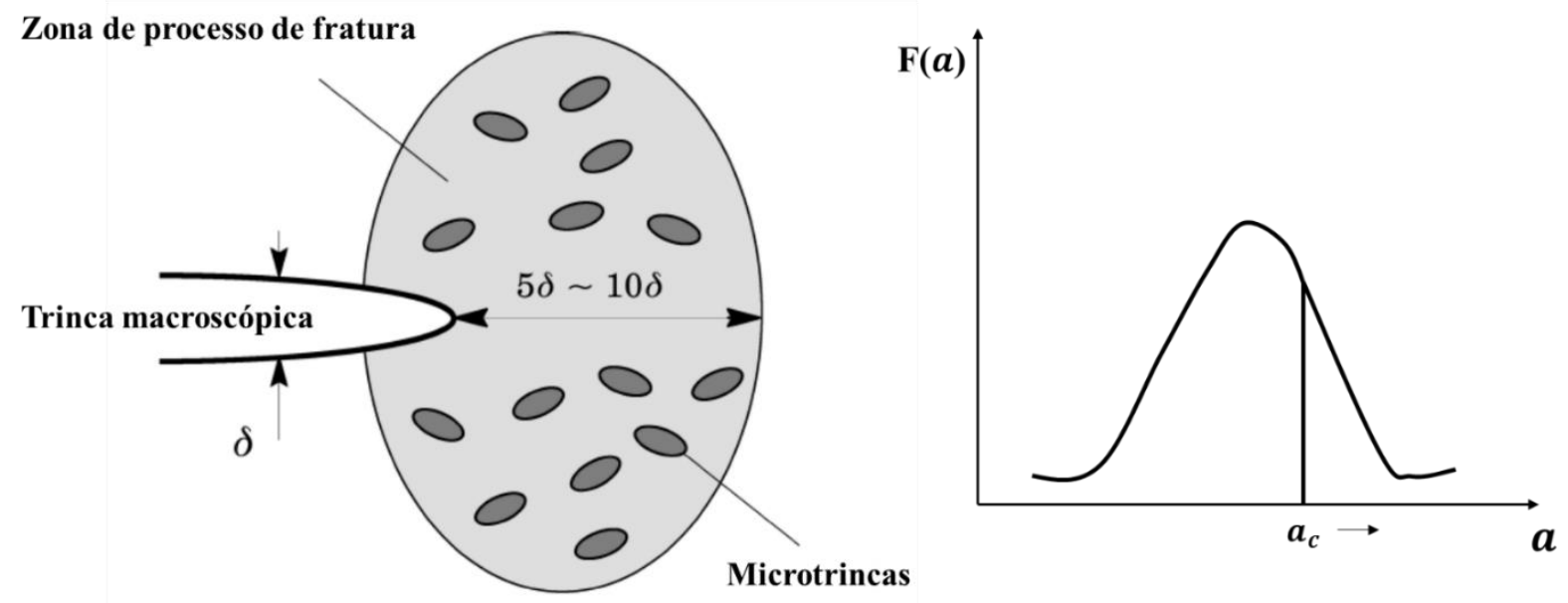

Existem três tipos de distribuição de valores de extremos, os quais tiveram seu desenvolvimento baseado na descrição de eventos que dependem da ocorrência de valores de máximos e mínimos [38]. Em mecânica da fratura, a principal distribuição utilizada para descrever a distribuição de tenacidade à fratura na região de transição dúctil frágil é a distribuição de Weibull. A distribuição de Weibull é uma distribuição de extremos associada a valores mínimos.

Landes e Shaffer[4] utilizaram a distribuição de Weibull para estudar o comportamento de corpos de prova de diferentes espessuras e concluíram que a distribuição de Weibull explicava corretamente a diferença de tenacidade na região de transição. Devido a isso, foi proposta a distribuição estatística de Weibull em sua forma bi paramétrica para descrever o comportamento de corpos de prova na região de transição. Dessa forma a probabilidade de fratura em função da força motriz foi proposta de acordo com a Equação 2.17 [4].

$$
F_{1}(x)=1-e^{\left[-\left(\frac{x}{b}\right)\right]^{c}} \quad x>0
$$

em que a função $F_{1}(x)$ é a probabilidade acumulada de falha para $x, c$ representa o modulo de Weibull, sendo que a variável aleatória é igual a zero e $b$ é a tenacidade característica. A determinação do modulo de Weibull dava-se a partir do estimador de Rank médio para amostras completas de acordo com a Equação 2.18[4].

$$
P_{f, i}=\frac{i}{N+1}
$$


onde $P_{f, i}$ representa a probabilidade acumulada de falhas referente a i ésima posição média da amostra de $\mathrm{N}$ dados de tenacidade em ordem crescente.

Landes e Shaffer [4] utilizaram a Equação 2.19 e propuseram prever os efeitos de espessura sobre os valores de tenacidade medidos em corpos de prova de diferentes espessuras. Assim adotaram por meio de uma simples analogia, como se as distribuição dos defeitos a frente de trinca representassem os elos de uma corrente, sendo uma corrente com n elos, se o mais fraco falhar toda a estrutura falhará, ou seja, uma estrutura com defeitos, irá falhar por meio da instabilidade da primeira trinca que atingir o tamanho crítico, como demonstrado na Figura 2.11 .

$$
K_{C(n T)}=K_{C(1 T)}\left(\frac{B_{1 T}}{B_{n T}}\right)^{\frac{1}{\alpha}}
$$

em que $B_{1 T}$ é a espessura do corpo de prova de referência $1 \mathrm{~T}$ e $B_{n T}$ espessura do corpo de prova ensaiado e $K_{C(1 T)}$ tenacidade de referência a 1T e $K_{C(n T)}$ tenacidade do corpo de prova ensaiado. Figura 2.11 - Diferença entre tenacidade a fratura entre corpos de provas 1T e 4T [4].
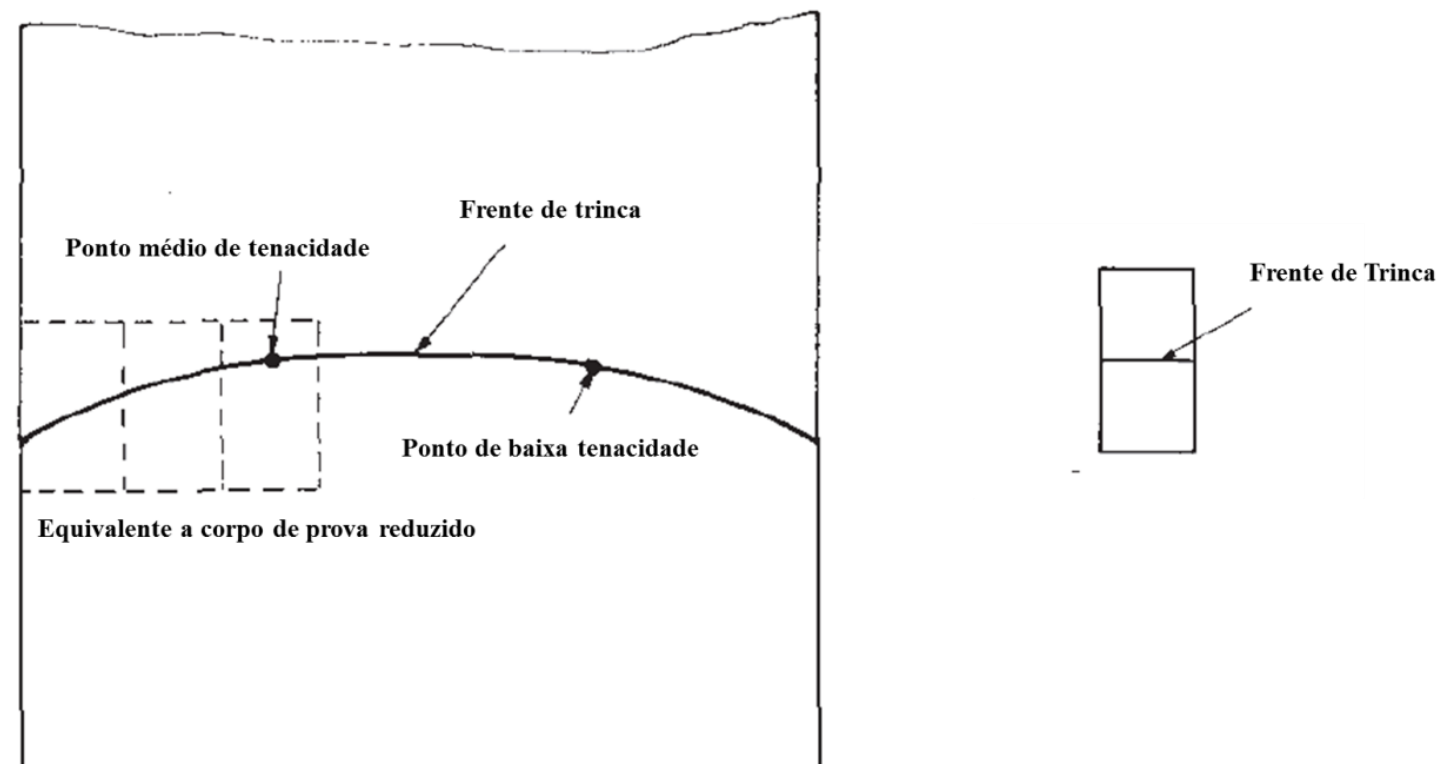

Landes e McCabe[39] analisando a expressão matemática bi paramétrica de Weibull sugerida por Landes e Shaffer [4], observaram que conforme as dimensões dos corpos de prova tendessem ao infinito, a tenacidade à fratura tenderia ir a zero, isso demonstrando uma inconsistência no modelo matemático proposto. Assim Landes e McCabe [39] propuseram um 
valor mínimo de tenacidade à fratura porém foi proposto a partir de valores de $J$ e não por $K$ ( $J_{\min }=13,73 \mathrm{~kJ} / \mathrm{m}^{2}$ ), que abaixo do qual não poderia ocorrer fratura. Sendo assim proposto o modelo matemático da triparamétrica de Weibull, mostrado na Equação 2.20. Wallin [40] seguindo os conceitos apresentados por Landes e McCabe [39] demonstrou que o valor de $\alpha$ era igual 4, assim também propôs valores de tenacidade mínima entre 10 e $20 \mathrm{MPa} \sqrt{\mathrm{m}}$

$$
P_{f}\left(J_{C}\right)=1-e^{\left[-\left(\frac{J_{C}-J_{\min }}{J_{0}-J_{\min }}\right)\right]^{\alpha}}
$$

em que o valor de $\alpha$ representa (i.e subst. $\alpha=2$ ) a magnitude de dispersão baseada na solução HRR. Esse modelamento matemático é até hoje utilizado na norma ASTM E1921[4] para avaliar a temperatura de referência na região de transição dúctil frágil de aços ferríticos. 


\section{A metodologia da Curva Mestra}

\subsection{Curvas Referenciais para Avaliação da Dependência da Tenacidade com a Temperatura}

As medidas de tenacidade à fratura utilizadas nas avaliações de integridade estrutural e determinação da dimensão crítica de defeitos em equipamentos e componentes de responsabilidade estrutural (e.g., vasos de pressão de reatores nucleares - VPR's) são frequentemente estimadas por meio de curvas de tenacidade à fratura referenciais [22]. Tais curvas descrevem os limites inferiores (lower bonds) dos valores de tenacidade à fratura, os quais são obtidos sob condições predominantemente elásticas (e.g., $K_{I_{a}}$ e $K_{I_{c}}$ ), em função da temperatura na região de transição dúctil-frágil. Tais curvas são obtidas a partir de uma extensa base de dados cujas medidas são provenientes majoritariamente de aços ferríticos característicos de vasos de pressão (e.g., aços ASTM A515, A516, A508, A533, etc.). Dentro deste conceito, a relação de dependência entre $K_{I c}$ e temperatura apresenta a forma geral

$$
K_{I_{C}}=A+B e^{\left(C T_{R}\right)}
$$

onde $A, B$ e $C$ são constantes do material e $T_{R}=\left(T-T_{D B T}\right)$ representa uma temperatura normalizada em relação a uma temperatura característica e representativa da região de transição frágil-dúctil (DBT do inglês Ductile-To-Brittle Transition).

As curvas de tenacidade referenciais incorporadas no Apêndice G da Seção III do código ASME [41] representam as primeiras curvas desenvolvidas. Essas curvas são resultantes de diversos esforços do Pressure Vessel Research Commitee (PVRC) conduzidos em 1971 para a formulação de uma metodologia de avaliação de integridade estrutural de VPRs baseada em conceitos da mecânica da fratura. Inicialmente, foi proposta uma curva referencial cujo valor de tenacidade era associado ao menor valor dentre os valores apresentados pelos parâmetros $K I c, K I d$ e $K I a$, conforme a seguinte expressão:

$$
K_{I_{R}}=29,4+1,334 e^{\left[0,026\left(T-T_{N D T}+89\right)\right]} \quad\left(\mathrm{MPa} \sqrt{\mathrm{m}},{ }^{\circ} \mathrm{C}\right)
$$


onde $K_{I R}$ é definido como o valor crítico de referência do fator de intensidade de tensões e descreve o envelope inferior de uma grande base de valores de tenacidade em função da temperatura de teste, como ilustrado na Figura 3.1.

Figura 3.1 - Curva referências de tenacidade à fratura da Seção XI do código ASME [42]

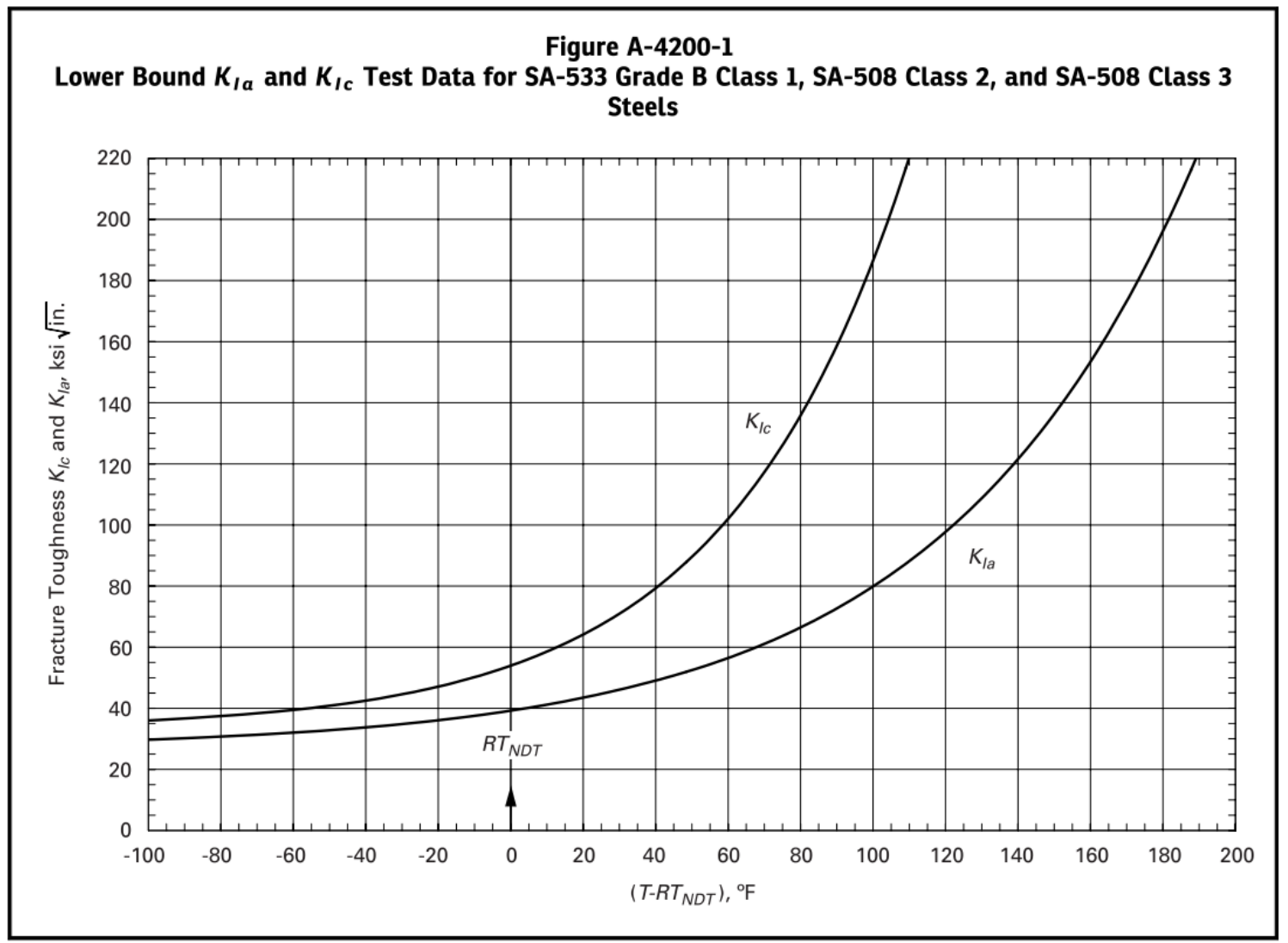

Com o intuito de diminuir o excesso de conservadorismo, o código ASME passou a permitir o uso de uma curva de referência baseada no parâmetro $K_{I C}$ após a aprovação do ASME Code Case N-640 [43] em 1998, conforme expressão a seguir

$$
K_{I_{C}}=36,5+3,084 e^{\left[0,036\left(T-T_{N D T}+56\right)\right]} \quad\left(\mathrm{MPa} \sqrt{\mathrm{m}},{ }^{\circ} \mathrm{C}\right)
$$

a redução no excesso de conservadorismo pode ser mais bem visualizada na Figura 3.1, onde para uma mesma temperatura, a curva de tenacidade em termos de $K_{I_{C}}$ fornece uma estimativa maior de tenacidade. Neste gráfico, os resultados de tenacidade incluem valores de $K_{I c}$ (tenacidade à fratura sob condições quase- estáticas), $K_{I a}$ (tenacidade à fratura correspondente à condições de arresto ou aprisionamento da trinca). Ainda nas expressões anteriores, a temperatura de teste ou de operação é normalizada em termos de temperatura de ductilidade 
nula NDT (nil-ductility temperature) como valor de $T_{N D T}$, comumente obtida experimentalmente por intermédio de ensaios drop weight test (DWT) [16].

Diversas limitações relacionadas ao desenvolvimento das curvas de referência apresentadas anteriormente questionam sua efetiva aplicabilidade como procedimento de avaliação da integridade estrutural de vasos de pressão nucleares, incluindo a correta definição e significância da temperatura de normalização, $T_{N D T}$ [44]. Talvez mais importante, entretanto, houve o reconhecimento nas últimas duas décadas da enorme importância de considerar os efeitos de plasticidade sobre a tenacidade à fratura em conexão com a grande dispersão de valores de tenacidade dentro da região de transição DBT de aços ferríticos. Estes aspectos tornam-se particularmente importantes em programas de monitoramento de degradação em operação de vasos de pressão nucleares, nos quais corpos de prova de dimensões reduzidas tipo PCVN (precracked Charpy V-notch) são frequentemente utilizados na avaliação de tenacidade do material. Neste caso, as curvas de referência apresentadas acima não são mais aplicáveis, o que motivou a introdução da metodologia da Curva Mestra descrita a seguir.

Desde então, diversas modificações e desenvolvimentos adicionais foram conduzidos visando o estabelecimento de curvas de referência menos conservadoras e aplicáveis a um espectro relativamente amplo de aços estruturais ferríticos utilizados nos mais variados equipamentos componentes estruturais. Em paralelo aos avanços da metodologia da Curva Mestra (abordada na próxima seção), a partir das aprovações dos Code Cases N-631 [45] e N629 [45], as Seções III e XI do código ASME passaram a permitir o uso da temperatura de referência determinada via Curva Mestra, $T 0$, para indexar a tenacidade à fratura (KIc vs. RTT0).

\subsection{A Metodologia da Curva Mestra e o Procedimento ASTM E1921}

Os estudos conduzidos por Wallin [44], [46]-[48] avançaram com o conceito da curva de referência ASME e introduziram uma metodologia relativamente simples, mas eficaz, comumente denominada Metodologia da Curva Mestra (MCM). Tal metodologia descreve a tenacidade à fratura em função da temperatura dentro da região de transição dúctil-frágil (RTDF) e é experimentalmente assegurada para uma ampla variedade de aços ferríticos de vasos de pressão e aços estruturais. Tais medidas são oriundas de corpos de prova padronizados contendo espessura equivalente a 25,4 mm (comumente designados por 1T).

Embora a espessura equivalente a 1T garanta condições de elevada triaxialidade na ponta da trinca, pequenos indícios de plasticidade precedentes à instabilidade por clivagem são 
frequentes nas medidas de tenacidade, particularmente quando se trata de aços ferríticos na RTDF. Desse modo, os valores de tenacidade são expressos preferencialmente em termos da integral $J\left(J_{c}\right)$ a qual permite determinar a tenacidade à fratura em condições elasto-plásticos sem, no entanto, violar as condições de fratura governada por tensão, isto é, em condições SSY.

Portanto, embora a formulação da curva mestra seja oriunda de curvas referenciais baseadas no fator elástico-linear de intensidade de tensão, $K_{I_{C}}{ }^{4}$, os valores de tenacidade usados pela curva mestra são expressos em termos do fator elasto-plástico de intensidade de tensão, $K_{J_{c}}$, a partir da seguinte relação,

$$
K_{J_{c}}=\sqrt{E^{\prime} J_{c}}
$$

cuja validade está condicionada a condições de escoamento em pequena escala, onde $E^{\prime}$ é o módulo de elasticidade longitudinal em que $E^{\prime}=E$ para o Estado Plano de Tensões (EPT) e $E^{\prime}=E /\left(1-v^{2}\right)$ para o Estado Plano de Deformações (EPD) onde $v$ representa o coeficiente de Poisson.

A base do procedimento da MCM é a interpretação da fratura frágil na RTDF como um mecanismo (microestrutural) de clivagem transgranular acoplado a uma descrição probabilística da fratura associada ao conceito estatístico do elo mais fraco (weakest link model). Dentro deste contexto, a distribuição estatística dos valores de tenacidade, $K_{J c}$, é mais bem representada por uma distribuição de Weibull na sua forma triparamétrica [49] conforme expressão a seguir

$$
P\left[K_{J_{c}}\right]=1-e^{\left(-\frac{B_{n T}}{B_{1 T}}\left[\frac{K_{J c}-K_{\min }}{K_{0}-K_{\min }}\right]^{\alpha}\right)}
$$

onde $\alpha, K_{0}$ e $K_{\min }$ são parâmetros da distribuição e $K_{J_{c}}$ medidas de tenacidade obtidas a partir da relação $K_{J c}=\sqrt{E^{\prime} J_{C}}$ conforme já mencionada. O parâmetro $\alpha$, estatisticamente denominado de parâmetro de forma por quantificar o grau da dispersão dos dados, corresponde ao módulo de Weibull e de acordo com o campo HRR, tal valor é definido igual a 4 [50]. Já o parâmetro $K_{0}$ representa o parâmetro de escala e é comumente definido como a tenacidade característica do material e está associado a uma probabilidade acumulada de falha de 63,2\%. Por fim, $K_{\min }$

\footnotetext{
${ }^{4} K_{J_{C}}$ é um fator elasto-plástico equivalente a um fator de intensidade de tensões proveniente da Integral $J[6]$
} 
representa o parâmetro de localização e é definido como o patamar inferior (lower bound) de tenacidade à fratura (valor frequentemente utilizado é de $20 \mathrm{MPa} \sqrt{\mathrm{m}}$ ) abaixo do qual não ocorre a fratura (i.e., $P\left[K_{J c}<K_{\min }\right]=0$ ).

A abordagem da MCM começa adotando a distribuição de Weibull triparamétrica, a qual se baseia no modelo estatístico da fratura frágil por clivagem transgranular, e descreve a dispersão dos valores de tenacidade à fratura de acordo com a Equação 3.5 [44]. Além de descrever a dispersão da tenacidade na RTDF, a Eq. 3.5 também é capaz de capturar efeitos estatísticos associados ao volume de material da zona de processo de fratura (ZPF). Esse efeito é simplificadamente expresso em termos da espessura (i.e., dimensão da frente de trinca) por meio da relação $B_{n T} / B_{1 T}$, onde $B_{n T}$ corresponde a uma espessura diferente da espessura de referência $B_{1 T}=25,4 \mathrm{~mm}$. Desse modo, o modelo prevê com razoável acurácia os efeitos estatísticos associados à geometria dos corpos de prova (ou componentes) onde pode-se calcular a tenacidade conforme a espessura ou volume de material da zona de processo fratura, conforme a seguinte expressão [44]

$$
K_{B(n T)}=K_{\min }+\left(\frac{B_{1 T}}{B_{n T}}\right)^{\frac{1}{4}}\left[K_{B(1 T)}-K_{\min }\right]
$$

No patamar inferior (lower shelf) de tenacidade à fratura $\left(K_{I C} \ll 50 M P a \sqrt{m}\right)$, a equação 3.5 começa a perder sua precisão, pois tais valores são mais representativos do patamar inferior de energia (PIE) onde a tenacidade é pouco sensível às variações de temperatura. Nesse patamar, a clivagem é apenas governada pela etapa de propagação. Nesse caso, os efeitos geométricos associados ao conceito do elo mais fraco passam a ser desprezíveis (Equação 3.6) e a tenacidade deixa de ser sensível às variações de temperatura de modo que a distribuição dada pela Equação 3.5 perde a sua validade.

Já para medidas de tenacidade provenientes de regiões próximas ao patamar superior de energia (PSE) onde a clivagem pode coexistir com crescimento dúctil de trinca (vide Figura 2.8), a fratura deixa de ser governada exclusivamente por tensão. Desse modo, níveis elevados de plasticidade (fratura governada por deformação) passam a afetar as medidas de tenacidade e, portanto, a acurácia da curva mestra em prever a tenacidade na RTDF. Visando mitigar a influência de tais dados na estimativa da temperatura de referência do material, Moskovic [51] apresentou um método de análise para dados de tenacidade à fratura censurados obtidos em diversas temperaturas. Este método é baseado no processo de inferência estatística por máxima 
verossimilhança de modo que, quando combinado com as Equações 3.5 e 3.10, se torna mais simplificado [51].

A estimativa por verossimilhança para dados aleatoriamente censurados é utilizada para calcular a $T_{0}$ a partir da seguinte equação [51]

$$
\sum_{i=1}^{n} \delta_{i} \frac{e^{\left[0,019\left(T_{i}-T_{0}\right)\right]}}{11+77 e^{\left[0,019\left(T_{i}-T_{0}\right)\right]}}-\sum_{i=1}^{n} \frac{\delta\left(K_{I C(i)}-20\right)^{4} e^{\left[0,019\left(T_{i}-T_{0}\right)\right]}}{\left\{11+77 e^{\left[0,019\left(T_{i}-T_{0}\right)\right]}\right\}^{5}}=0
$$

em que $\delta_{i}$ é operador Delta de Kronecker sendo igual a 1 quando $\left(K_{J c(i)}\right)$ corresponde a uma falha por fratura frágil e zero quando censurado por apresentar efeitos excessivos de plasticidade a partir de evidências de crescimento estável de trinca [51]. O valor da $T_{0}$, nesse caso obtido a partir de dados de $K_{J c(i)}$ oriundos de inúmeras temperaturas (multitemperatura), é calculado por meio de um processo iterativo.

Se todos os dados corresponderem a uma única temperatura de ensaio, a Equação 3.7 pode ser simplificada para produzir uma estimativa pelo método da máxima verossimilhança para a tenacidade característica $\mathrm{K}_{0}$, assim se reduzindo a seguinte expressão [51]

$$
\mathrm{K}_{0}=\left\{\frac{\sum_{\mathrm{i}=1}^{\mathrm{n}}\left(\mathrm{K}_{\mathrm{Jc}(\mathrm{i})}-20\right)^{4}}{\mathrm{r}}\right\}^{1 / 4}+20 \mathrm{MPa} \sqrt{\mathrm{m}}
$$

onde $n$ é o número total de valores de tenacidade à fratura e $r$ é o número de valores de tenacidade válidos ( $r=\mathrm{n}-\mathrm{c}$, em que c representa o número de dados censurados).

A Eq. (3.8) fornece a tenacidade característica a qual é utilizada no cálculo da tenacidade à fratura mediana, $K_{J c(\text { med })}$, a partir da Eq. (3.5) para uma $P\left[K_{J_{c}}\right]=50 \%=0,5$, fornecendo a seguinte relação

$$
K_{J c(m e d)}=20+0,91\left(K_{0}-20\right)
$$

A análise estatística dos valores experimentais de tenacidade por intermédio da Equação 3.5 permite determinar o valor mediano ( médio) de tenacidade, $K_{J C-1 T}^{m e d}$, correspondente a $50 \%$ de probabilidade de falha e ajustado para uma espessura de referência de 25,4mm (configuração denominada 1-T equivalente a um corpo-de-prova de 1 polegada de espessura conforme já 
mencionado) conforme evidenciado pela Eq. (3.6). A partir de uma extensiva base de dados experimentais para a verificação e validação da Equação 3.5, Wallin [47] propôs uma forma similar à Equação 3.1 para descrever a relação de dependência da tenacidade com a temperatura, representado pela seguinte forma exponencial

$$
K_{J c-1 T}^{m e d}=30+70 e^{\left(0,019\left[T-T_{0}\right]\right)}
$$

onde $T$ é a temperatura de teste $\left({ }^{\circ} \mathrm{C}\right)$ e $T_{0}$ representa uma temperatura de referência $\left({ }^{\circ} \mathrm{C}\right)$ correspondente a um valor $K_{J c-1 T}^{\text {med }}=100 \mathrm{MPa} \sqrt{\mathrm{m}}$.

Alternativamente, a curva mestra pode ser expressa em termos da tenacidade característica, vide Figura 3.2, cuja relação probabilística estabelecida com $K_{J_{c}(\text { med })}$ fornece a seguinte relação exponencial [44]

$$
K_{0}=31+77 e^{\left(0,019\left[T-T_{0}\right]\right)}
$$

de modo que na temperatura de referência do material $K_{0}=108 \mathrm{MPa} \sqrt{\mathrm{m}}$. Diante dessas considerações, caso os valores de $K_{J_{c}(\text { med })}$ e $K_{0}$ obtidos a partir de um conjunto de dados de $K_{J_{c}}$ oriundo de uma única temperatura sejam próximos dos valores de $100 \mathrm{MPa} \sqrt{\mathrm{m}}$ e $108 \mathrm{MPa} \sqrt{\mathrm{m}}$, respectivamente, há fortes indícios de que a temperatura na qual tais dados são obtidos seja a própria $T_{0}$.

A metodologia da Curva Mestra definida pela Equação 3.10 emergiu como um dos procedimentos mais amplamente utilizados para avaliação da fragilização de materiais irradiados e, ao mesmo tempo, descrever efeitos de temperatura sobre a tenacidade de aços ferríticos. Extensivos esforços de verificação da aplicabilidade geral da Equação 3.10 resultaram na geração e publicação da norma ASTM E1921 em 1998 pelo Comitê de Mecânica da Fratura E08 e recentemente revisada em sua edição de 2018 [5]. A sua utilização é, inclusive, recomendada em procedimentos correntes para avaliação de integridade e defeitos tais como API 579 [52] e BS7910 [53]. 
Figura 3.2 - Variação da tenacidade média em função de ( $\left.\mathrm{T}-\mathrm{T}_{0}\right)$ para diversos aços estruturais ferríticos[1]

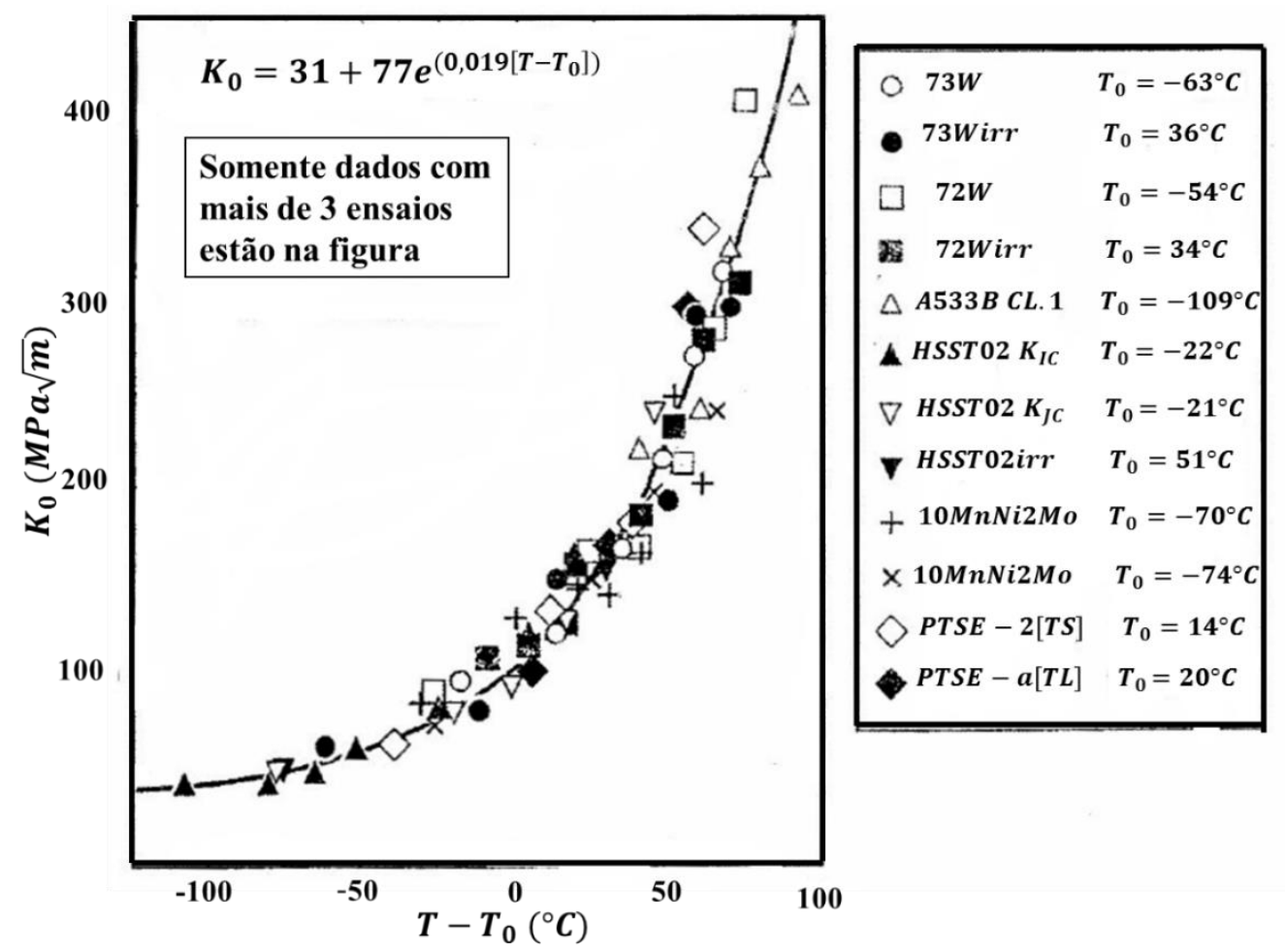

\subsection{Curvas Referenciais Modificadas}

Embora a temperatura de referência possa ser estimada experimentalmente a partir de pequenos espaços amostrais (i.e., conjuntos contendo da ordem de $6 \sim 8$ dados experimentais válidos de tenacidade), nem sempre a sua estimativa é factível, principalmente quando há limitações severas na disponibilidade do material de interesse. É neste cenário e dentre outros que entra a importância da curva mestra, onde, a partir do conhecimento da $T_{0}$, é possível estimar o valor mediano da tenacidade em qualquer temperatura contida na RTDF e, portanto, diferente daquela usada para estimar a própria $T_{0}$. Além disso, é possível estimar a tenacidade em estruturas de espessuras diferentes daquelas utilizadas nos corpos de prova devido à estatística do elo mais fraco associada à formulação da curva mestra, particularmente quando o principal interesse envolve seções muito espessas onde o ensaio de corpos de prova com espessura na escala real é praticamente inviável.

Diante da grande versatilidade da curva mestra, inúmeros autores [6], [9], [10] propuseram curvas referenciais modificadas visando descrições mais realistas e confiáveis da correlação entre a tenacidade à fratura e a temperatura na RTDF para aços diferentes daqueles 
comumente utilizados na MCM. Dentre esses aços, os aços de microestrutura martensítica têm ganhado cada vez mais importância devido, principalmente, a sua elevada resistência mecânica combinada, em casos como o aço A508 [6] aplicado em VPRs, a uma alta tenacidade. Ao estudar os efeitos da mudança de composição química no aço SA508 martensítico temperado, Lee et al [6] constatam mudanças significativas no tamanho e fração das ripas de martensita influenciando a tenacidade à fratura de tal modo que novos coeficientes para a descrição da correlação entre a tenacidade e a temperatura na RTDF são propostos(o que evidencia que a microestrutura e tamanho de grãos afeta a tenacidade à fratura), conforme a seguinte relação:

$$
K_{\text {mat }}=30+70 * e^{\left[0,031\left(T-T_{\text {trans }}\right)\right]}
$$

Visando ampliar o uso da MCM a aços martensíticos de ultra alta resistência, Neimitz [9] propõe modificações na curva mestra a qual é voltada para aços ferríticos cujo limite de escoamento é limitado pela faixa 275 a $825 \mathrm{MPa}$. A partir de um procedimento de ajuste para a determinação de novos coeficientes, Neimitz apresenta a relação de tenacidade à fratura em função da temperatura de trabalho a partir da seguinte relação geral:

$$
K_{\text {mat }}=A+\left\{B+C e^{\left[D\left(T-T_{r e f}\right)\right]}\right\}
$$

onde $\mathrm{A}+\mathrm{B}$ representa a assíntota do patamar inferior de tenacidade, $\mathrm{C}$ e $\mathrm{D}$ as constantes dependentes do material, $\mathrm{T}$ a temperatura na ponta da trinca ou de operação, $T_{r e f}$ representa a temperatura de referência na região de transição dúctil frágil e $K_{m a t}$ tenacidade à fratura. Observe que a relação entre os coeficientes de ajuste dada pela Eq. (3.13) difere da forma apresentada anteriormente pela Eq. (3.1). Assim, os coeficientes associados à curva mestra são dados respectivamente por: $\mathrm{A}=20, \mathrm{~B}=10, \mathrm{C}=70$ e $\mathrm{D}=0,019$ de modo que, quando associado à diferentes níveis de probabilidade acumulada de falha, a Equação 3.13 assume a seguinte forma

$$
K_{m a t}=A+\left\{B^{*}+C^{*} e^{\left[D\left(T-T_{r e f}\right)\right]}\right\}\left[\ln \frac{1}{1-P_{f}}\right]^{1 / 4}
$$

em que $P_{f}$ é a probabilidade de fratura (geralmente a probabilidade é em torno de 0,95 e 0,05), $B^{*}=11$ ou seja aproximadamente $10 /[\ln (2)]^{1 / 4}, C^{*}=77$ ou seja $70 /[\ln (2)]^{1 / 4}$, demonstrando que $K_{0}[\ln 2]^{1 / 4}$ é igual a $K_{\text {mat }}$ ou $K_{j m e d}$. Baseando-se nesse procedimento e 
levando-se em consideração diferentes aspectos microestruturais dessa classe de aços martensíticos, Neimitz propõe a seguinte curva mestra:

$$
K_{\text {mat }}=35+132 * e^{\left[0,016\left(T-T_{\text {trans }}\right)\right]}
$$

Mueller et al [10] também demonstra que o comportamento da tenacidade à fratura do aço EUROFER97 temperado e revenido na região média e inferior da transição dúctil-frágil é mais bem descrita peça seguinte curva referencial:

$$
K_{\text {mat }}=12+88 * e^{\left[0,019\left(T-T_{\text {trans }}\right)\right]}
$$

Utilizando os ajustes mencionados anteriormente e comparando a Curva Mestra padronizada com uma temperatura de referência comum, pode-se observar que a curva ajustada por Neimitz et al, se diferencia muito das demais, Figura 3.3. Isso pode estar relacionado ao fato de que as dimensões dos corpos de prova utilizados em seus ajustes, tem baixa restrição e assim desenvolvendo maior plasticidade e, portanto, maior tenacidade à fratura.

Figura 3.3 - Análise comparativa entre a Curva Mestra Padrão e Modificada para aços martensíticos [6], [9], [10] e dados experimentais apresentados na Seção 5.

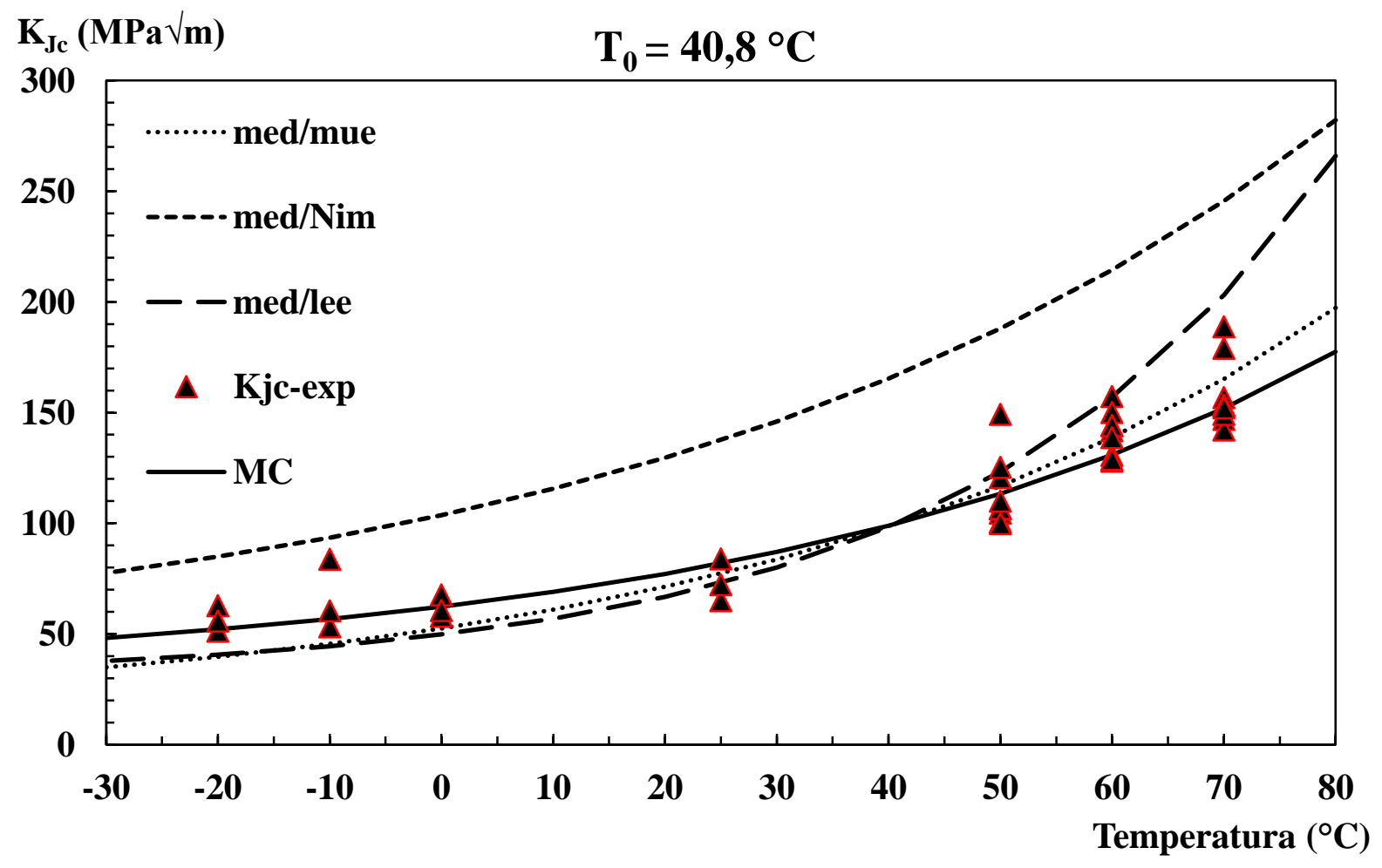


Na Figura 3.3 é demonstrada uma análise comparativa dos comportamentos da curva mestra em sua forma padrão, comumente usada para aços ferríticos, e suas formas derivadas propostas para aços martensíticos. Nesta mesma figura, dados experimentais de tenacidade à fratura obtidos neste trabalho e detalhadamente discutidos na Seção 5 estão dispostos para uma melhor visualização. Observa-se que dentre as curvas modificadas, a curva proposta por Muller et al. [10] é que, aparentemente, melhor descreve a variação da mediana em função da temperatura na RTDF do aço martensítico usado neste estudo.

O estudo da tenacidade à fratura de aços martensíticos tem demonstrado que o seu comportamento na região de transição dúctil frágil se diferencia do comportamento previsto pelos aços ferríticos devido, principalmente, à questão da microestrutura, ou seja, mudanças na curva mestra devem ser pautadas perante as mudanças microestruturais. Diante disso, inúmeras modificações a partir de novos coeficientes têm sido propostas a fim de obter uma melhor descrição dos dados obtidos em ensaios experimentais e, portanto, uma $T_{0}$ mais acurada e confiável.

Diante das considerações mencionadas anteriormente, o programa experimental a seguir aborda a aplicabilidade da metodologia da curva mestra em um aço martensítico de alta resistência mecânica e discute a proposta de novos coeficientes a partir de um procedimento de otimização relativamente simples e direto. 


\section{Programa Experimental}

Esta seção descreve o planejamento experimental com ênfase no dimensionamento e orientação de extração dos corpos de prova empregados nos ensaios para a determinação das propriedades mecânicas. Os ensaios de tração visam fornecer propriedades de resistência mecânica as quais são implementadas nos procedimentos de avaliação de tenacidade à fratura frágil por clivagem a partir da abordagem da Curva Mestra. Em complementação aos ensaios de tração, ensaios de tenacidade ao impacto fornecem estimativas do comportamento à fratura e auxiliam na tomada de decisão em relação às temperaturas dos ensaios de tenacidade à fratura. Todos os ensaios realizados neste estudo seguem as diretrizes das normas da ASTM ( E8/E8M[54], E23[55] e E1921[5]).

É importante ressaltar que os ensaios de tenacidade à fratura aqui descritos fornecem um banco de dados de tenacidade à fratura para um material pouco explorado dentro do contexto da metodologia da Curva Mestra, o que destaca a sua relevância na contribuição para a ampliação e enriquecimento do banco de dados de tenacidade à fratura de aços martensíticos de alta e ultra alta resistência.

\subsection{Material}

O Material utilizado na avaliação exploratória da metodologia da Curva Mestra consiste em uma chapa de aço martensítico USI AR450, termicamente tratada pela empresa Usiminas, com dimensões de 31,5 mm de espessura, 2440,0 mm de largura e $12000 \mathrm{~mm}$ de comprimento.

\subsection{Análise metalográfica}

A análise metalográfica do aço USI AR 450 é preparada de acordo com as diretrizes da norma ASTM E3-11[56]. O procedimento inicial envolve a retirada de pequenas amostras a partir de uma das metades de um corpo de prova de impacto Charpy devido à facilidade atribuída à geometria do corpo de prova em questão conforme indicado na Figura 4.1. Deve-se ressaltar que tais segmentos são extraídos em regiões distantes da superfície de fratura a fim de evitar possíveis indícios de deformação e, portanto, interferências na morfologia microestrutural do material. Nesse processo são extraídos 3 pequenos segmentos cúbicos de 
10x10x10mm utilizando um disco de corte abrasivo de corte fino. Cada segmento representa uma orientação específica da superfície onde D indica a seção superior ou seção normal mais à frente nomeada de $\mathrm{N}, \mathrm{F}$ a seção transversal que mais à frente nomeada de $\mathrm{T}$ e $\mathrm{E}$ a seção longitudinal, sendo essa paralela à direção de laminação e mais adiante nomeada de L. Na sequência, tais segmentos são embutidos com resina (baquelite) a quente para posterior desbaste abrasivo e polimento final, sendo ambos realizados por um processo automatizado em uma politriz Struers Tegramin-25. A revelação da microestrutura é dada a partir de um ataque químico seletivo com Nital 2\%. As micrografias são obtidas por um microscópio ótico convencional com ampliações que variam de 100x até 1000x.

Figura 4.1 - Representação esquemática das superfícies de análise microestrutural adaptada da norma ASTM E3.

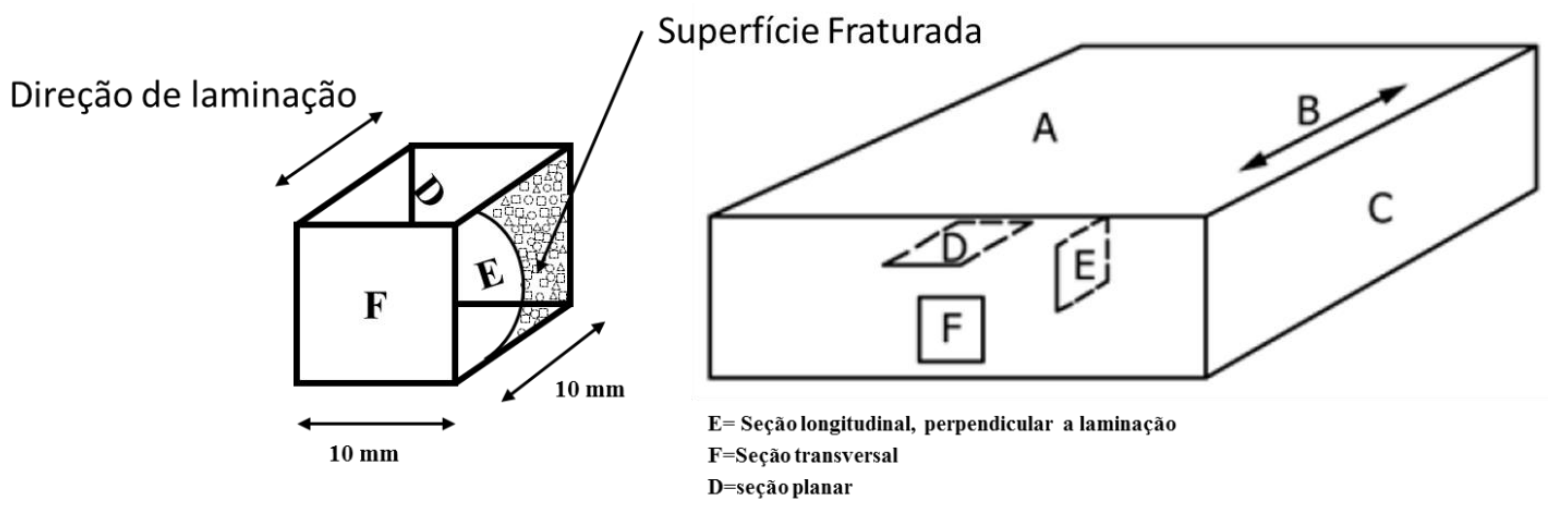

Fonte: Adaptado de ASTM E3[56]

\subsection{Preparação das chapas para extração dos corpos de prova}

O preparado da chapa envolve a extração de três tipos de corpos de prova para a realização dos ensaios de caracterização mecânica e do comportamento à fratura do material, a saber:

- Ensaio de tração;

- Ensaio de tenacidade ao impacto Charpy;

- Ensaio de tenacidade à fratura.

A extração e usinagem dos corpos de prova de tenacidade à fratura (tipo SE(B) com $\mathrm{a} / \mathrm{W}=0,5$ e $\mathrm{S}=4 \mathrm{~W}$ ) e de tenacidade ao impacto Charpy (com entalhe tipo $\mathrm{V}$ ) seguem os layouts apresentados nas Figuras 4.2 e 4.3, respectivamente. Observa-se que ambos os tipos de corpos de prova são extraídos na orientação T-L (do inglês, transverse-longitudinal em que o plano do 
entalhe e, portanto, a propagação da trinca se dá na direção paralela à direção de laminação da chapa e o carregamento na direção transversal) ao longo do centro da chapa. Os corpos de prova de tração também obedecem a tal orientação visto que os mesmos são provenientes das metades dos corpos de prova SE(B) ensaiados a baixa temperatura.

Figura 4.2 - Esquema de retirada em mm de corpos de prova SE(B) com trinca profunda.

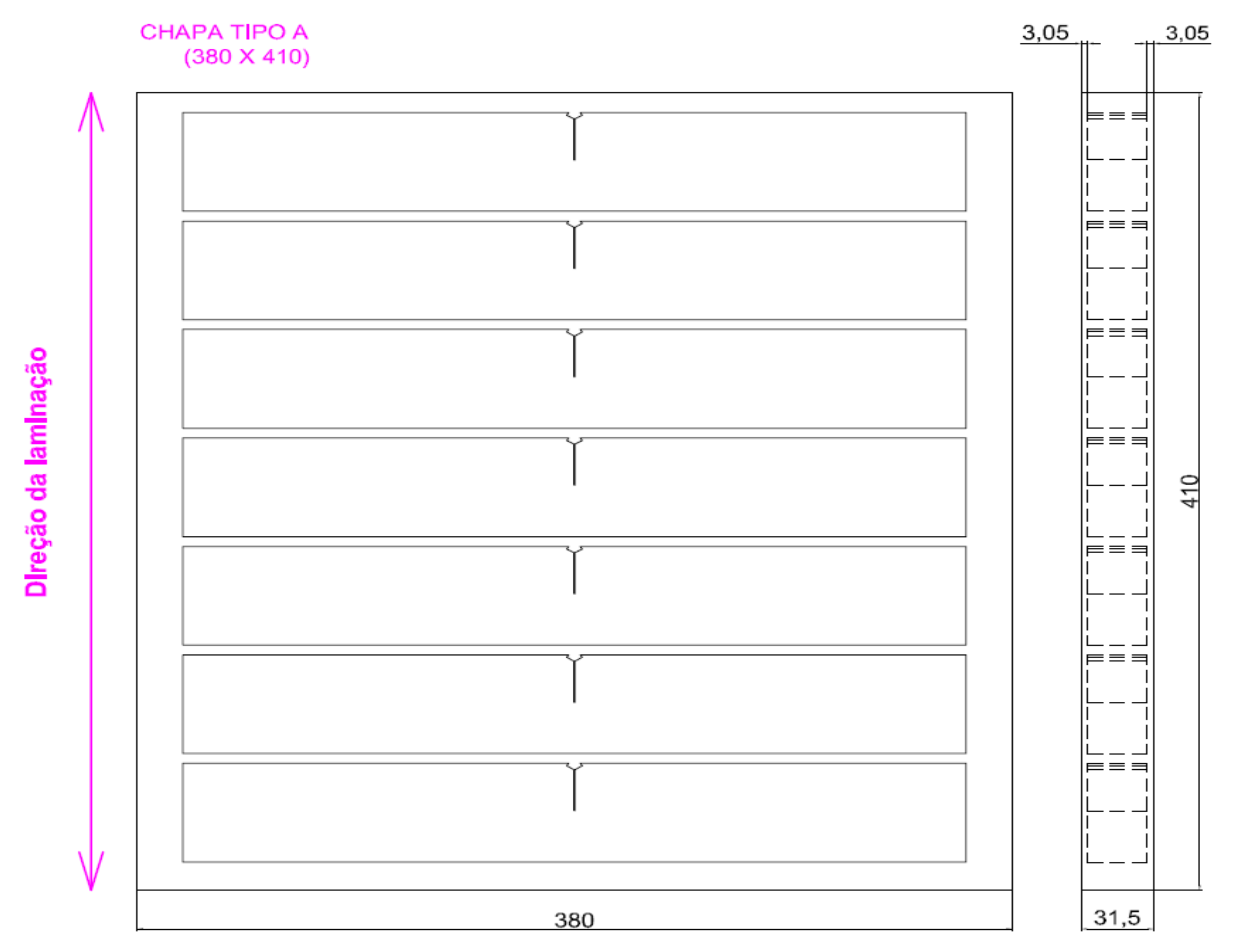

Figura 4.3 - Esquema de retirada em mm de corpos de prova de impacto Charpy.

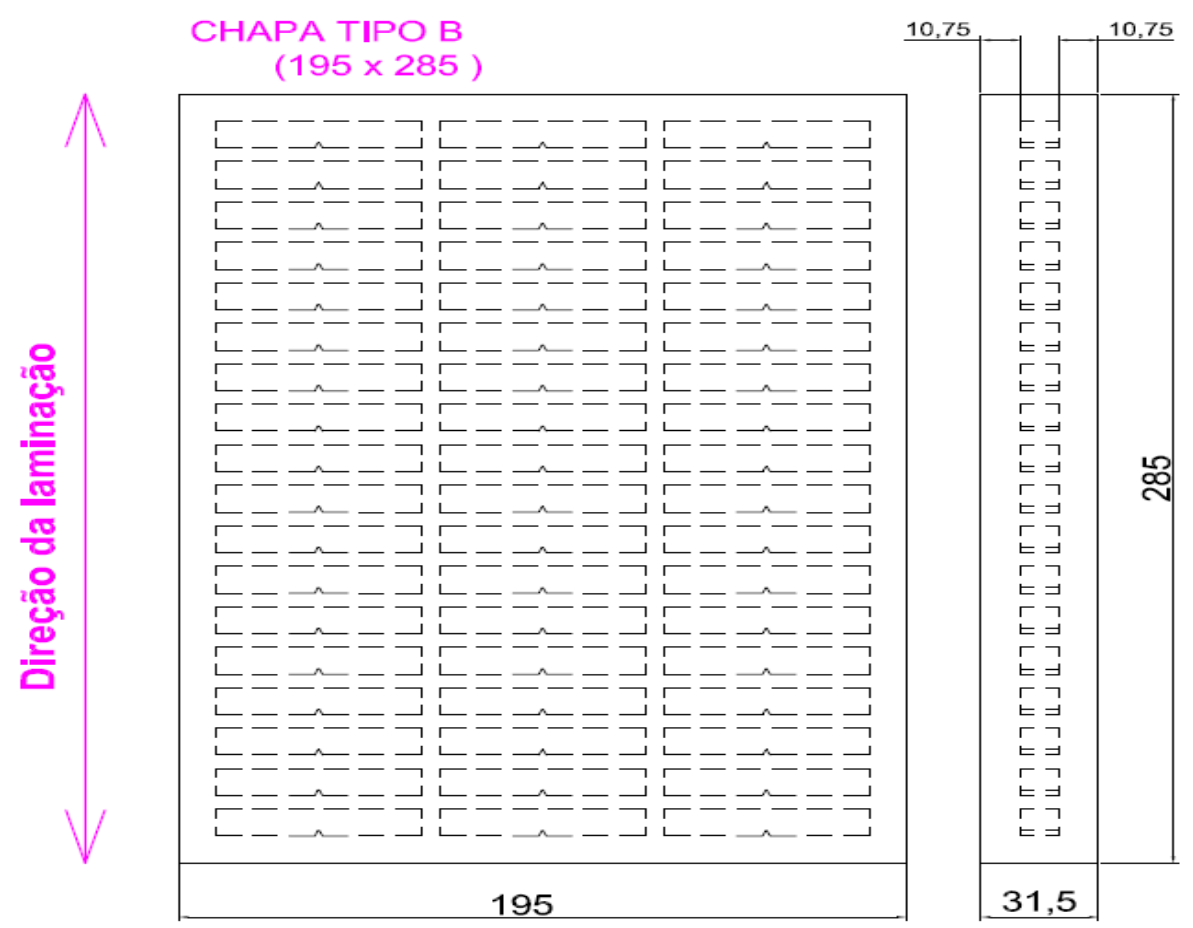


Os ensaios de tenacidade ao impacto Charpy e de tenacidade à fratura frágil por clivagem são conduzidos seguindo as diretrizes das normas ASTM E23[55] e ASTM E1921[5].

\subsection{Ensaio de Tração}

Os ensaios de tração são realizados conforme as recomendações da norma ASTM E8/E8M [54] No total são realizados 3 ensaios de tração a temperatura ambiente $\left(\mathrm{T} \sim 2{ }^{\circ} \mathrm{C}\right)$, conforme já mencionado na seção anterior. Os corpos de prova de aço USI AR 450 seguem uma configuração cilíndrica de dimensões padrão conforme ilustração da Figura 4.4 [54].

Figura 4.4 - Corpo de prova de tração de dimensões em mm padronizado segundo a ASTM E8/E8M[54]
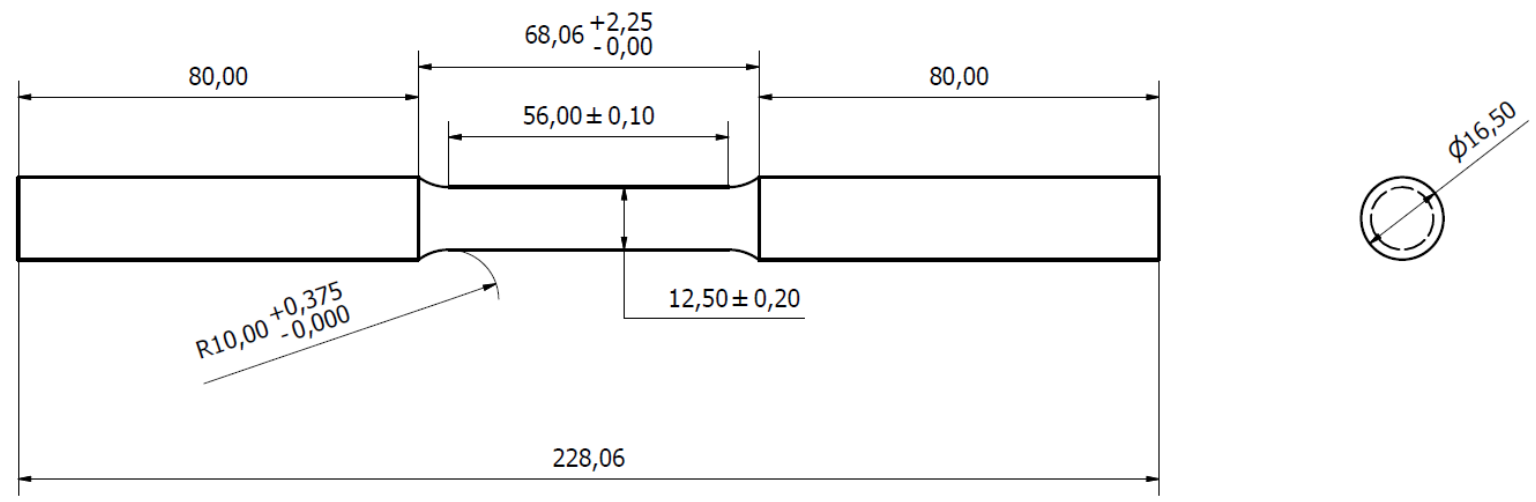

Os ensaios de tração são realizados em uma máquina servo hidráulica MTS com célula de carga de $250 \mathrm{kN}$. O registro do alongamento da região útil indicada pela norma ASTM E8/E8M[54] é feito a partir de um extensômetro axial com gage length de $25 \mathrm{~mm}$. O objetivo do ensaio de tração é fornecer as propriedades mecânicas necessárias para o cálculo ajustado das medições experimentais de tenacidade à fratura. Embora os ensaios de tenacidade à fratura sejam conduzidos em baixas temperaturas $\left(\mathrm{T}<20^{\circ} \mathrm{C}\right)$ e elevadas temperaturas $\left(\mathrm{T}>20^{\circ} \mathrm{C}\right)$, é importante salientar que a norma E1921[5] fornece expressões matemáticas (vide seção 4.6 mais adiante) para o ajuste da tensão de escoamento e do módulo de elasticidade para que tais propriedades sejam devidamente ajustadas na temperatura dos ensaios de tenacidade à fratura. O módulo de elasticidade é calculado com maior precisão quando se utiliza um ensaio por ultrassom (pulso eco), porém, devido a questões técnicas que inviabilizam a execução do ensaio, como a disponibilidade do equipamento, o ajuste do módulo é feito seguindo as recomendações da norma ASTM E1921[5]. 
Outra propriedade relevante é o coeficiente de encruamento do material que é obtido utilizando dados do ensaio de tração, ou seja, a curva Tensão vs. Deformação. Caso não seja possível obter uma curva de Tensão vs. Deformação do material, a literatura fornece relações analíticas alternativas para o seu cálculo que estão disponíveis na API 579[52]. A Equação 4.1 pode ser empregada para o cálculo do coeficiente de encruamento (Dowling [57]) a partir da curva tensão vs. deformação.

$$
\varepsilon=\frac{\sigma}{E}+\left(\frac{\sigma}{H}\right)^{1 / n}
$$

A Equação 4.1 é similar à proposta por Ramberg e Osgood em 1943[14]. Nessa expressão é proposto um termo responsável pelo comportamento elástico e outro pelo comportamento plástico, onde o segundo termo elevado a 1/n é o responsável por representar o comportamento plástico, sendo n o coeficiente de encruamento do material. A proposta feita por Ramberg e Osgood [14] é aplicada à curva tensão-deformação verdadeira, $\sigma_{t}=\left(1+\varepsilon_{e}\right) \sigma_{e}$ e $\varepsilon_{t}=$ $\ln \left(1+\varepsilon_{e}\right)$. Assim, a curva tensão vs. deformação verdadeira é traçada de forma que a tensão de escoamento pode ser facilmente obtida conforme esquema exemplificado na Figura 4.5 [3941].

Figura 4.5 - Diagrama Tensão vs. Deformação para determinação da tensão de escoamento[54].

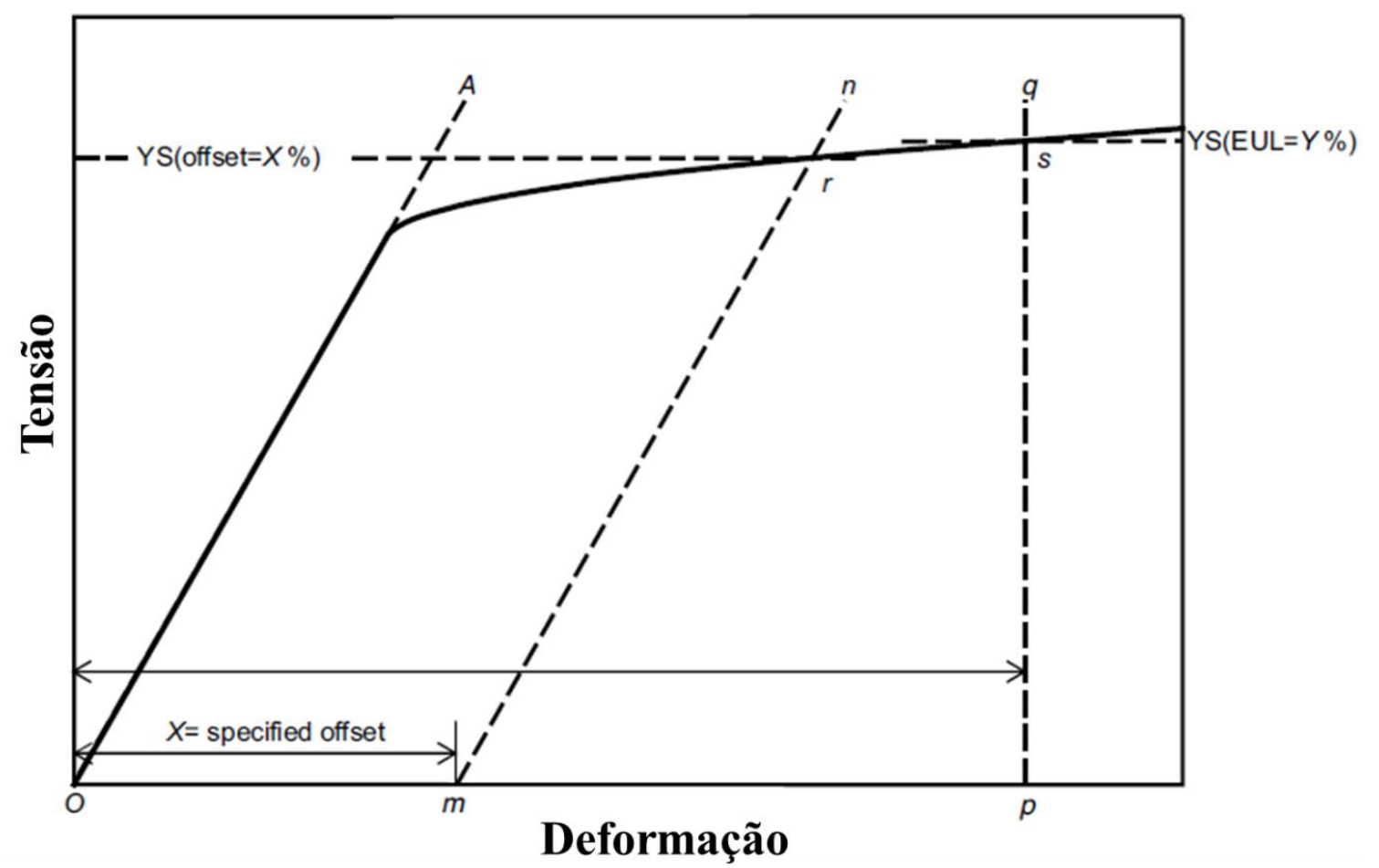


Na representação esquemática da Fig. 4.5, o segmento AO tem o mesmo ângulo (i.e., inclinação) que mn e o deslocamento Om é igual a 0,2\% da deformação, sendo $\mathbf{r}$ a intersecção de mn com a curva de tensão vs. deformação indicando o valor da tensão de escoamento. Após determinar a tensão de escoamento, pode-se prosseguir para o cálculo dos termos plásticos da equação proposta por Ramberg e Osgood. Para isso, utiliza-se um método gráfico log-log de acordo com a representação esquemática ilustrada na Figura 4.6. O esquema apresentado na Figura 4.6 é aplicado à curva tensão vs. deformação verdadeira onde os termos da curva são ajustados para uma formulação em formato de potência. No entanto, os dados ajustados são somente dados acima da tensão de escoamento definida na etapa anterior. Uma vez obtidos todos os dados, pode-se completar a Equação 4.1 que descreve com precisão o comportamento do material sob carregamento uniaxial utilizando o corpo de prova padrão mostrado da Figura 4.4. O coeficiente de encruamento e a tensão de escoamento são propriedades fundamentais para a descrição do comportamento da tenacidade à fratura [57]

Figura 4.6 - Ajuste da curva tensão vs. deformação na região plástica em log-log [57].

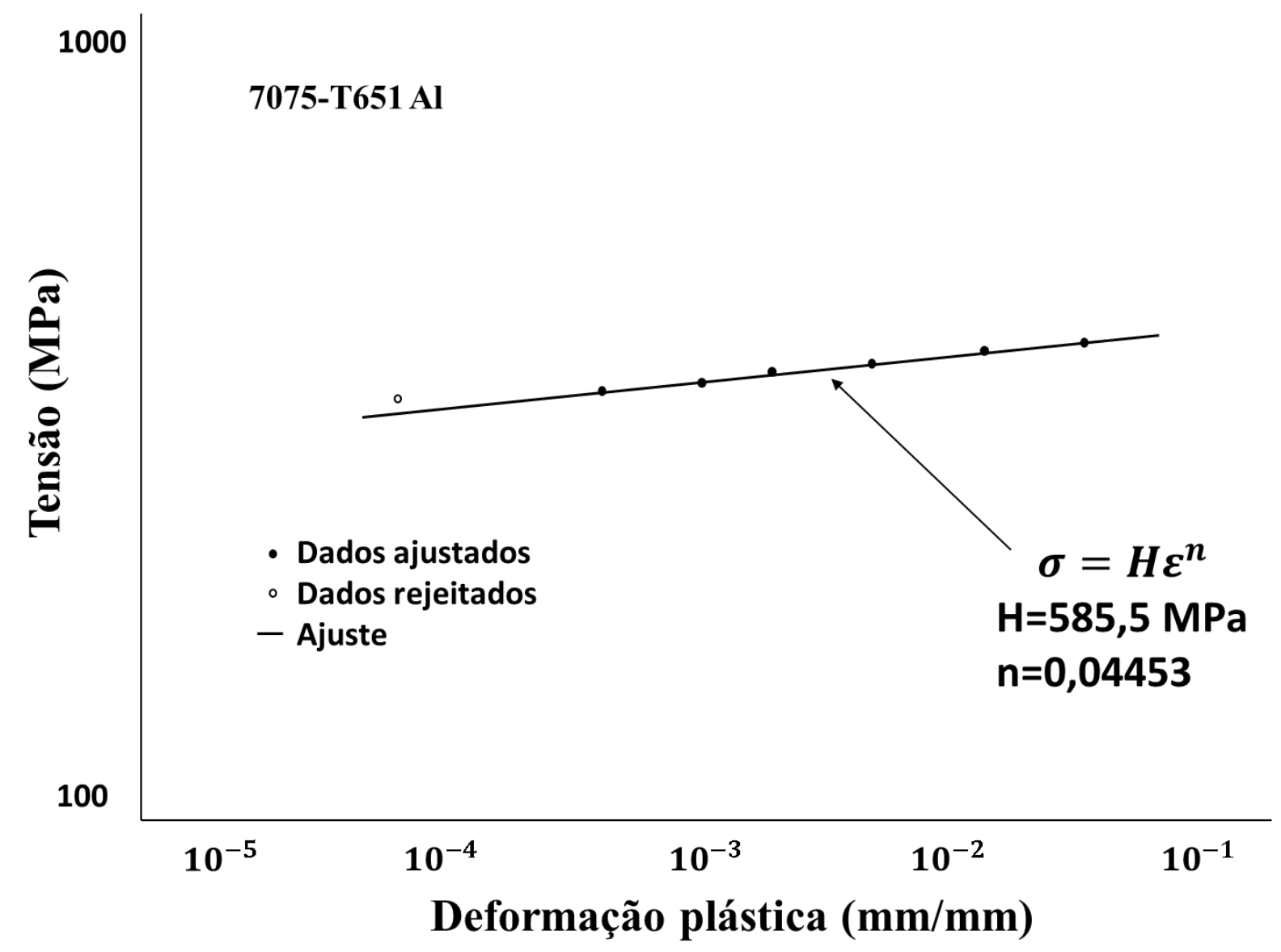




\subsection{Ensaio de impacto Charpy}

Os ensaios de tenacidade ao impacto Charpy-V são conduzidos de acordo com as diretrizes da ASTM E23 [55] com o intuito de avaliar o comportamento da região de transição dúctil-frágil e fornecer estimativas para as temperaturas de ensaio de tenacidade à fratura posteriormente realizadas, conforme recomendação da E1921 [5].

Os corpos de prova são usinados com entalhe em V, conforme Fig. 4.7, e extraídos a partir do centro da espessura da chapa de acordo com a especificação da norma ASTM E23 [55].

Figura 4.7 - Corpo de prova Charpy entalhe em V com dimensões e mm[55]

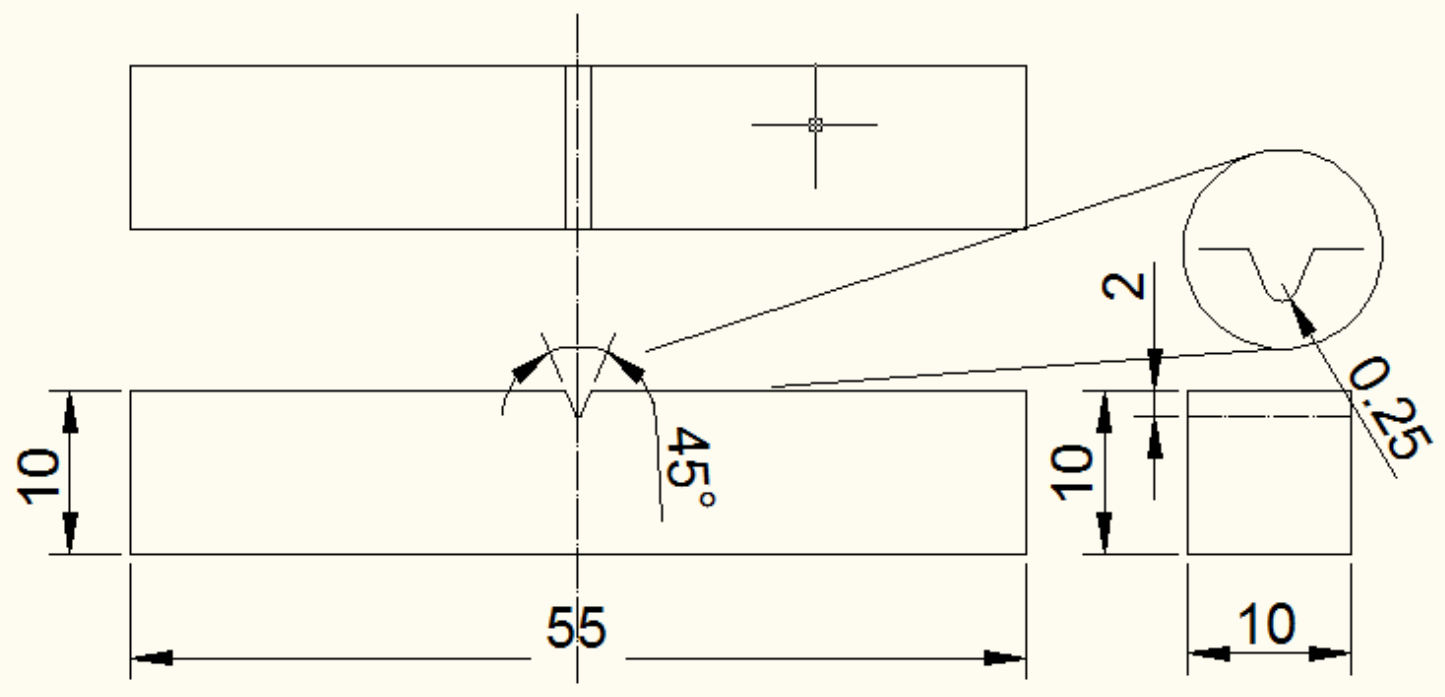

O levantamento da curva completa de tenacidade ao impacto envolve a realização de um total de 44 ensaios em um equipamento Tinius Olsen ${ }^{\circledR}$ IT 406 digital com capacidade de 406 Joules, conforme demonstrado na Figura 4.8. Para os ensaios conduzidos em baixas temperaturas é utilizada uma mistura de álcool etílico e nitrogênio líquido em diferentes proporções para refrigeração dos corpos de prova em diferentes temperaturas, os quais devem ser mantidos imersos em um recipiente com isolamento térmico a fim de garantir uma completa estabilização térmica. O monitoramento da temperatura é feito a partir de um termopar do tipo K. Para os ensaios conduzidos em elevadas temperaturas, é utilizada uma estufa com ajuste controlado de temperatura, esterilização e secagem de marca Sterilifer, conforme mostrada na Figura 4.9. 
Na Figura 4.10 é feita uma representação esquemática da curva de tenacidade ao impacto Charpy a qual correlaciona os dados de energia absorvida em função da temperatura, onde os pontos representam os dados experimentais e a linha o ajuste por meio de uma tangente hiperbólica [1, 3] .

Figura 4.8 - Equipamento de impacto Charpy Tinius Olsen

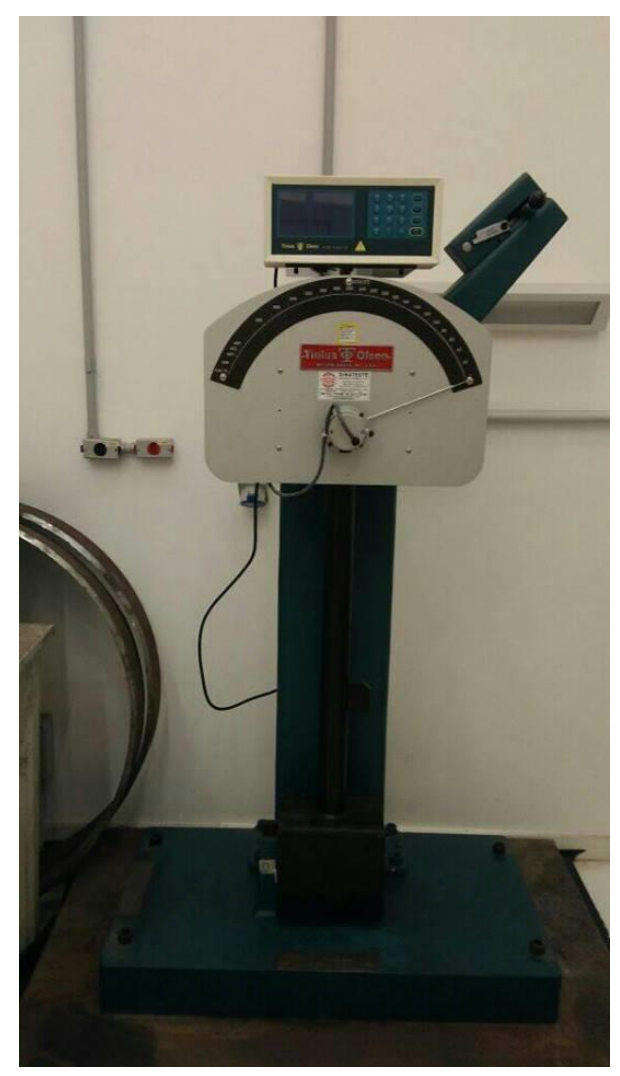

Figura 4.9 - Estufa Microprocessada para Esterilização e Secagem Sterilifer

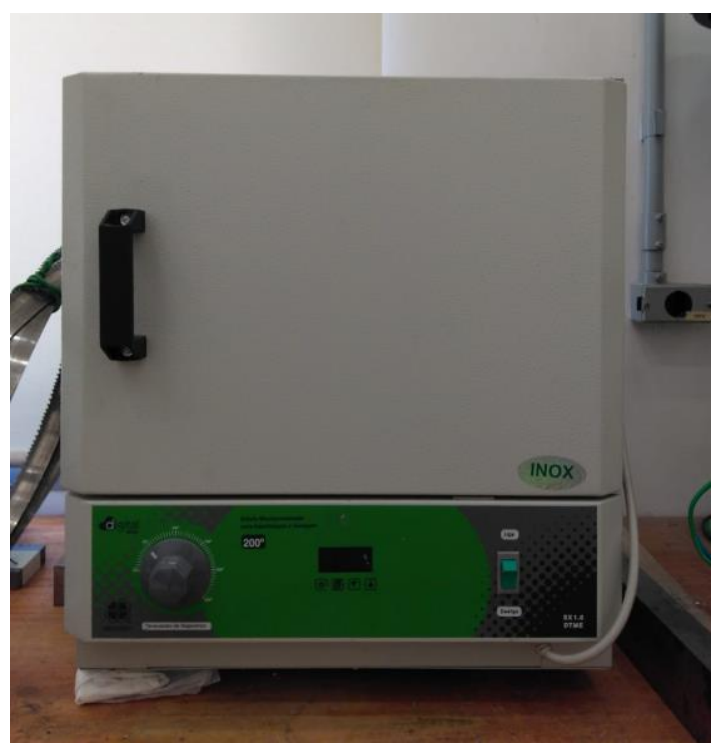


O ajuste dos dados experimentais é feito de acordo com o procedimento originalmente estabelecido por Oldfield [3], [59] que permite estabelecer uma acurada correlação entre a energia absorvida e a temperatura por meio de uma função tangente hiperbólica conforme indicada pela Eq. 4.2:

$$
Y=A+B \cdot \tanh \left(\frac{T-D}{C}\right)
$$

onde as variáveis têm significados físicos como:

$$
\begin{array}{lll}
\text { Lower Shelf } & = & (A-B) ; \\
\text { Upper Shelf } & = & (A+B) ; \\
\text { Temperatura de transição } & = & T_{0} \text { (ponto médio da temperatura de transição); } \\
\text { Inclinação da } T_{0} & = & B / C ;
\end{array}
$$

Os coeficientes obtidos são calculados da seguinte maneira:

$$
\begin{array}{lll}
\text { A } & = & \left(Y_{L S}+Y_{U S}\right) / 2 \\
B & = & Y_{U S}-A \\
Y_{L S} & = & \text { valores de energia no patamar mais baixo (foi utilizado } \\
& & \text { uma média de } 9 \text { valores mais baixos) } \\
Y_{U S} & = & \text { valores de energia no patamar mais alto (foi utilizado uma } \\
& & \text { média de } 9 \text { valores mais altos) }
\end{array}
$$

onde C e D são coeficientes calculados utilizando o solver do software Excel a partir de um procedimento iterativo não linear cuja finalidade é minimizar a soma dos quadrados das diferenças entre as medidas experimentais e as estimativas teóricas da tangente hiperbólica. $\mathrm{Na}$ Figura 4.10 está ilustrado um exemplo de ajuste para aços martensiticos. 
Figura 4.10 - Energia de Impacto por Temperatura de Ensaio

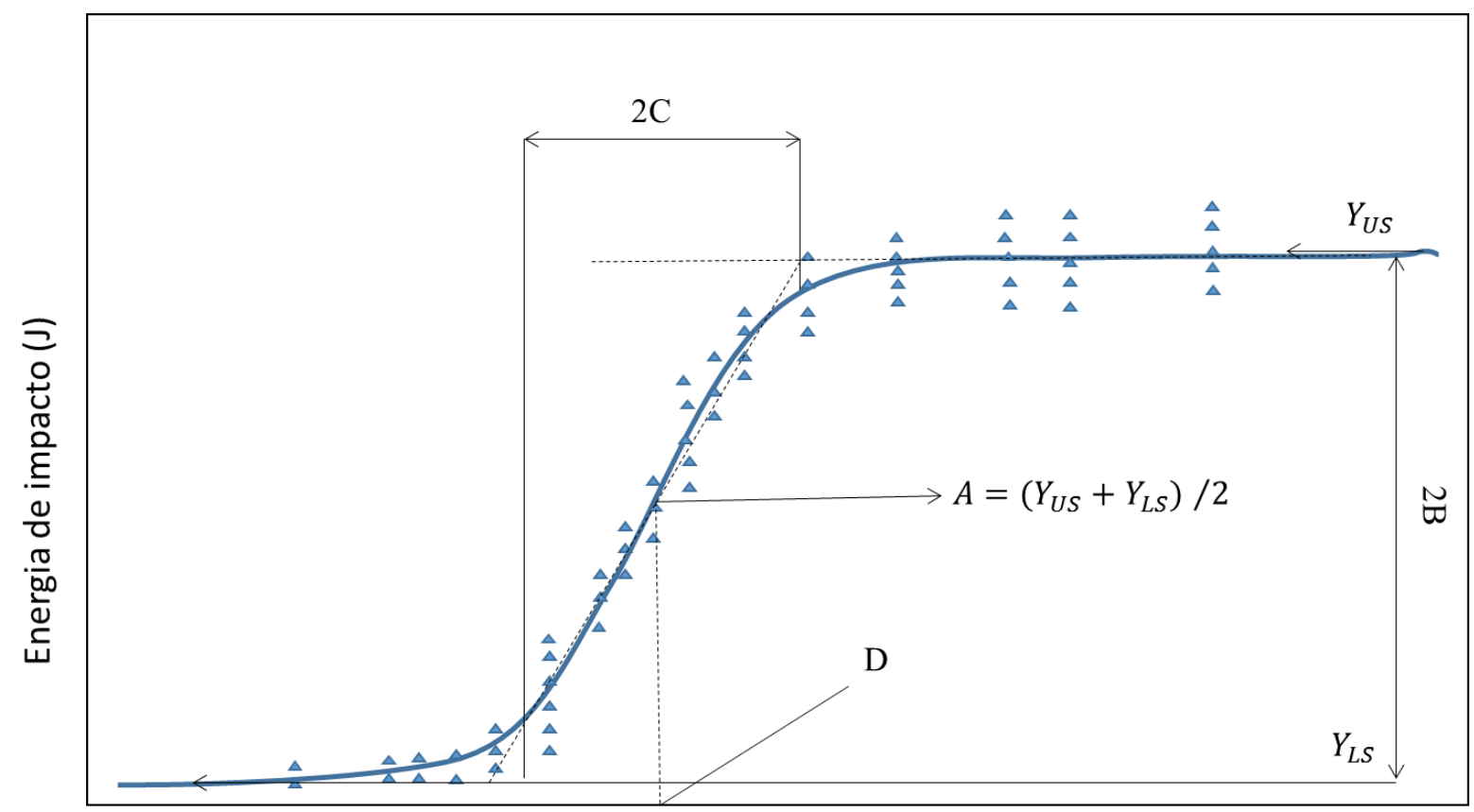

Temperatura $\left({ }^{\circ} \mathrm{C}\right)$

\subsection{Ensaio de tenacidade à fratura}

Os ensaios de tenacidade à fratura são conduzidos em uma ampla faixa da região de transição dúctil-frágil (RTDF) com o intuito de determinar a temperatura de referência $\left(T_{0}\right)$ do aço USI AR450 e, portanto, avaliar a aplicabilidade da metodologia da Curva Mestra sobre a classe dos aços martensíticos. Visando avaliar o comportamento à fratura frágil por clivagem na RTDF, são utilizados 39 corpos de prova do tipo SE(B) (single-edge notched bend) todos com dimensões 1T (i.e., com 1 polegada de espessura) padrão de seção transversal retangular $\mathrm{W} / \mathrm{B}=2$ e $\mathrm{S} / \mathrm{W}=4$, sendo $\mathrm{B}$ a espessura, $\mathrm{W}$ a largura e $\mathrm{S}$ a distância entre os apoios no carregamento por flexão em 3 pontos, conforme normatizado pela ASTM E1921[5] e ilustrado na Figura 4.11.

Todos os corpos de prova apresentam trinca profunda com razão nominal a/W = 0,5 e são usinados em condições plane-sided, ou seja, com as superfícies dos bordos livres isenta de entalhes laterais (side-grooves). Desse modo, o entalhe é subdimensionado de tal forma que haja ligamento remanescente suficiente para a nucleação de uma pré-trinca na raiz do entalhe do corpo de prova, por carregamento cíclico em flexão 3 pontos a temperatura ambiente, e que seja respeitada a razão a/W = 0,5. A dimensão nominal adotada para o comprimento do entalhe, 
o qual é usinado em eletroerosão a fio de 0,20 mm de diâmetro, é de 24,4 mm, o que permite introduzir uma pré-trinca da ordem de 1,0 mm de comprimento, de acordo com os requisitos em norma.

Conforme recomendações da E1921, a pré-trinca é nucleada sob controle de forças de baixas magnitudes (valor máximo permitido $\mathrm{K} \sim 25 \mathrm{MPa} \sqrt{\mathrm{m}}$ ) para minimizar os efeitos de warm prestressing (i.e., deformações plásticas na raiz da trinca ocasionadas por regiões de tensões compressivas e, portanto, aumento aparente da tenacidade) e, ao mesmo tempo, obter uma frente de trinca mais uniforme [5]. Além disso, o processo de nucleação da pré-trinca se dá a partir da diminuição gradual do fator de intensidade de tensão à medida que a pré-trinca cresce. Portanto, tal processo ocorre a partir da diminuição contínua dos níveis de carregamento de tal forma que os possíveis aumentos no fator $\mathrm{K}$ em decorrência do crescimento incremental da trinca sejam compensados e, ao mesmo tempo, promova uma diminuição das forças motrizes responsáveis pela abertura e crescimento da trinca.

Já controle do comprimento da pré-trinca por fadiga é realizado pelo método da flexibilidade elástica, o qual permite um controle preciso do comprimento da trinca (i.e., comprimento do entalhe somado ao comprimento da pré-trinca por fadiga) com base na perda de rigidez do componente (neste caso, o próprio corpo de prova) inerente ao processo de crescimento da trinca.

Os ensaios estão especificados na Tabela 4.1, onde demonstra como é feita a distribuição de ensaios dentro das temperaturas.

Figura 4.11 - Representação geométrica e dimensional do corpo de prova (dimensões em mm) $\mathrm{SE}(\mathrm{B})$ (single edge notched bend)
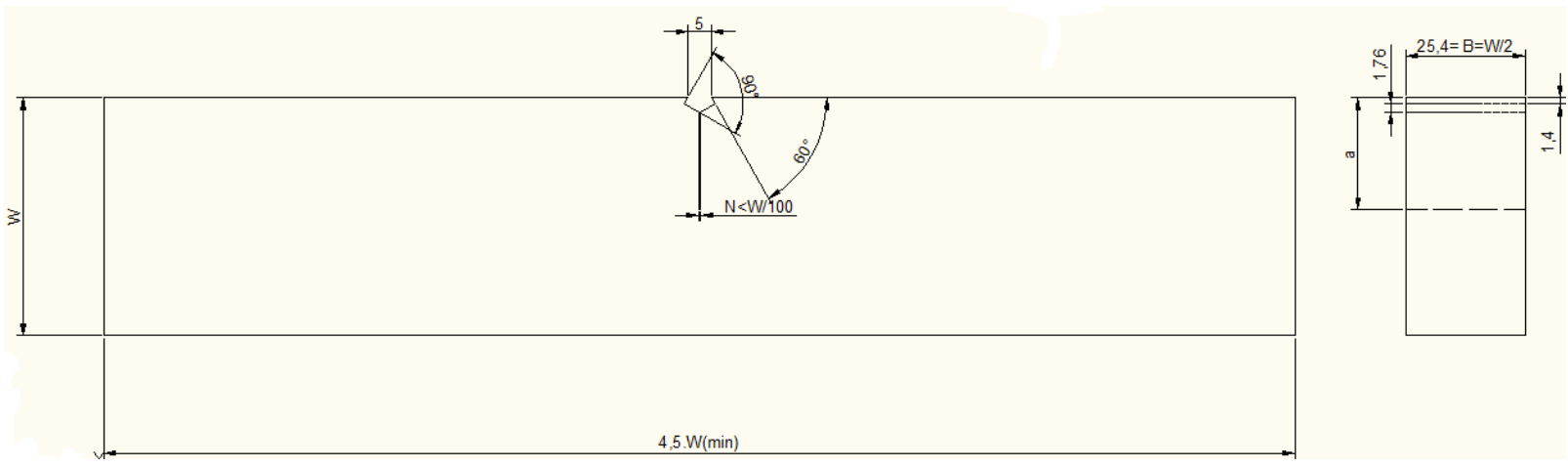

Fonte: Adaptado de ASTM E1921 [5] 
Tabela 4.1 - Matriz experimental dos ensaios de tenacidade à fratura

\begin{tabular}{c|c}
\hline Temperatura de ensaio $\left({ }^{\circ} \mathrm{C}\right)$ & Quantidade de corpos de prova \\
\hline-20 & 3 \\
-10 & 3 \\
0 & 3 \\
25 & 3 \\
50 & 9 \\
60 & 9 \\
70 & 9 \\
\hline
\end{tabular}

Em uma etapa que antecede os ensaios de tenacidade, os corpos de prova são devidamente identificados com caneta de gravação em metais para garantir a rastreabilidade dos ensaios e, portanto, das superfícies de fratura utilizadas nas medições de frente de trinca e eventuais análises fractográficas. O intuito é assegurar a correlação entre os valores de tenacidade à fratura e as características macro e microfractográficas dos corpos de prova.

Para o início dos ensaios de tenacidade à fratura, é preciso estimar uma temperatura que seja a mais próxima possível da temperatura de referência a priori desconhecida. Essa estimativa $\left(T_{0}^{C V N}\right.$ ) é baseada em uma correlação estabelecida entre os valores de tenacidade ao impacto Charpy, $T^{C V N}$ [1], [3], e uma constante $C$ dependente das dimensões dos corpos de prova de tenacidade à fratura. Assim, a partir de uma curva Charpy bem ajustada pelo método da tangente hiperbólica, a primeira estimativa de temperatura recomendada pela E1921 é dada pela Equação 4.3

$$
T_{0(\text { estimativa })}^{C V N}=T^{C V N}+C
$$

onde a temperatura ( $T^{C V N}$ ) é associada a uma energia de 28J $\left(T^{28 J}\right)$ ou $41 \mathrm{~J}\left(T^{41 J}\right)$ e C a constante fornecida em função da energia utilizada (28J ou 41J) e da espessura do corpo de prova B, conforme indicada na Tabela 4.2 [1], [5].

Tabela 4.2 - Constantes para a estimativa inicial da temperatura de ensaio de tenacidade à fratura

Tabela de constantes para equação curva Charpy V estimativa de temperatura 


\begin{tabular}{c|cc}
$\begin{array}{c}\text { Tamanho do corpo de } \\
\text { prova (nT) }\end{array}$ & $28 \mathrm{~J}$ & $41 \mathrm{~J}$ \\
\hline 0.4 & -32 & -38 \\
0.5 & -28 & -34 \\
1 & -18 & -24 \\
2 & -8 & -14 \\
3 & -1 & -7 \\
4 & 2 & -4 \\
\hline
\end{tabular}

Para corpo de provas Charpy pré trincado use $\mathrm{C}=-50$ ou $-56^{\circ} \mathrm{C}$

Uma vez estabelecida a temperatura de ensaio, os corpos de prova são imersos em uma cuba térmica cuja temperatura é monitorada a partir de dois termopares do tipo $\mathrm{K}$, sendo um deles disposto nas proximidades da ponta da trinca e o outro no fundo da cuba com o intuito de monitorar a estabilidade térmica do sistema e reduzir o gradiente térmico. As baixas temperaturas de ensaio são asseguradas por uma mistura de álcool etílico e nitrogênio líquido, enquanto as elevadas são estabelecidas a partir de uma solução aquosa de óleo solúvel semissintético biodegradável (para evitar a corrosão). Particularmente nos ensaios em elevadas temperaturas, é utilizado uma bomba recirculante para homogeneização e estabilização da temperatura do fluído térmico. Além disso, o controle da temperatura é garantido a partir de um circuito integrado por um ebulidor elétrico, termostato e um dispositivo eletromecânico (contator AC) que permite, a partir de um circuito de comando, efetuar o controle de cargas no circuito de potência, conforme Figura 4.12. Detalhes do sistema de aquecimento podem ser encontrados no Apêndice A ao final do trabalho. Logo após a imersão na cuba a qual é acoplada na garra inferior do atuador servo-hidráulico da máquina universal de ensaios, os corpos de prova permanecem por aproximadamente $30 \mathrm{~min}$ na temperatura de ensaio ( 1 min por mm de espessura) para garantir uma completa estabilização térmica. Em seguida é dado início ao ensaio a partir do encaixe do clip gage no knife edge usinado no entalhe do corpo de prova para obtenção dos dados de carga e deslocamento da abertura da boca da trinca.

A curva P-CMOD é obtida experimentalmente por uma máquina servo-hidráulica que aplica um carregamento por controle de deslocamento sobre o corpo de prova submetido à flexão por 3 pontos. O deslocamento é expresso em termos do deslocamento de abertura da boca da trinca, comumente designado de V ou CMOD (do inglês, Crack Mouth Opening Displacement). O CMOD é registrado pelo clip gage fixado no knife-edge conforme indicado nas Figura 4.13. Os ensaios são conduzidos sob carregamento quase estático, monotônico e 
crescente, com taxas de carregamento da ordem de $0,1<d K / d t<2 \mathrm{MPa} \sqrt{\mathrm{m}} / \mathrm{s}$ até a instabilidade do corpo de prova a fim de não introduzir efeitos dinâmicos sobre os valores de tenacidade à fratura.

Figura 4.12 - Ensaio de tenacidade à fratura a alta temperatura.

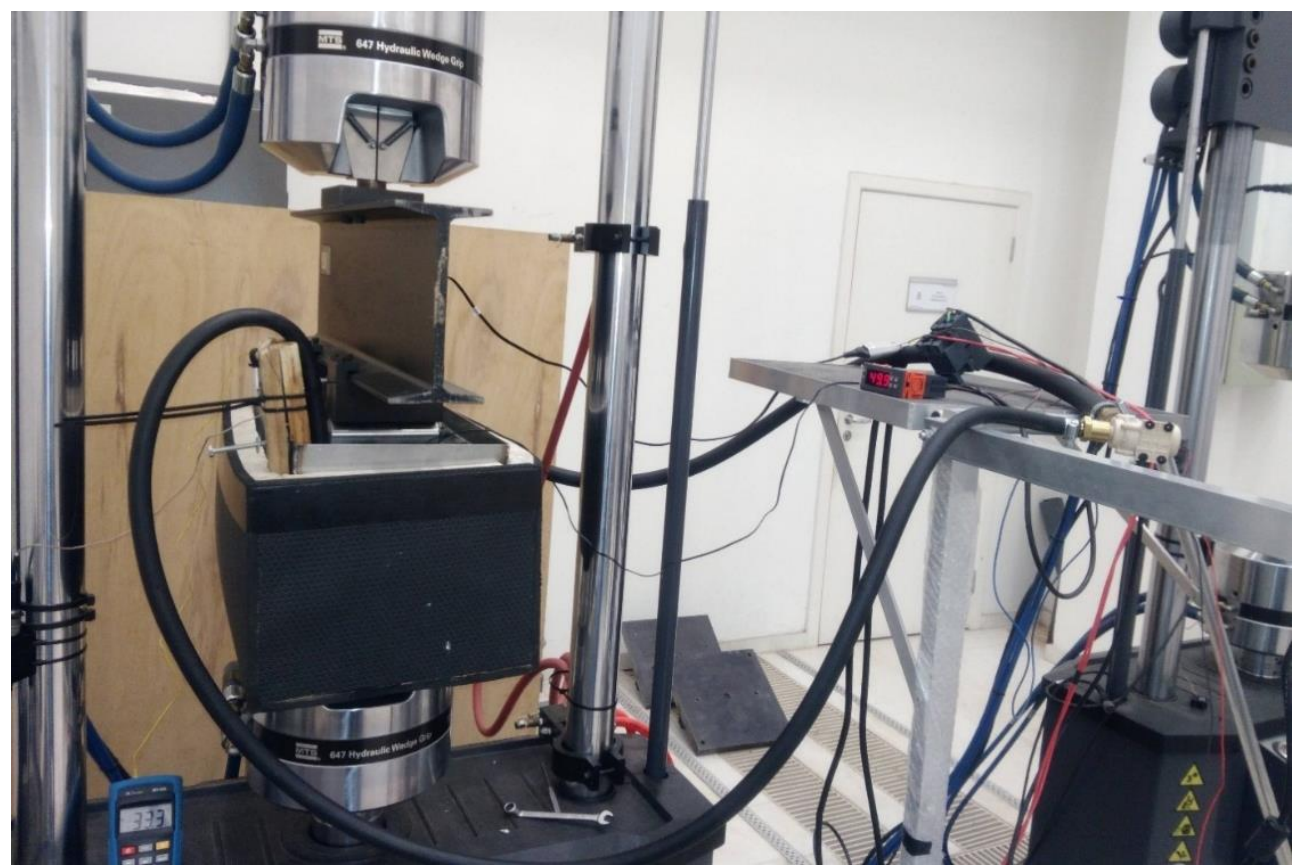

Figura 4.13 - Clip gage fixado no Knife-edge no corpo de prova dentro da cuba.

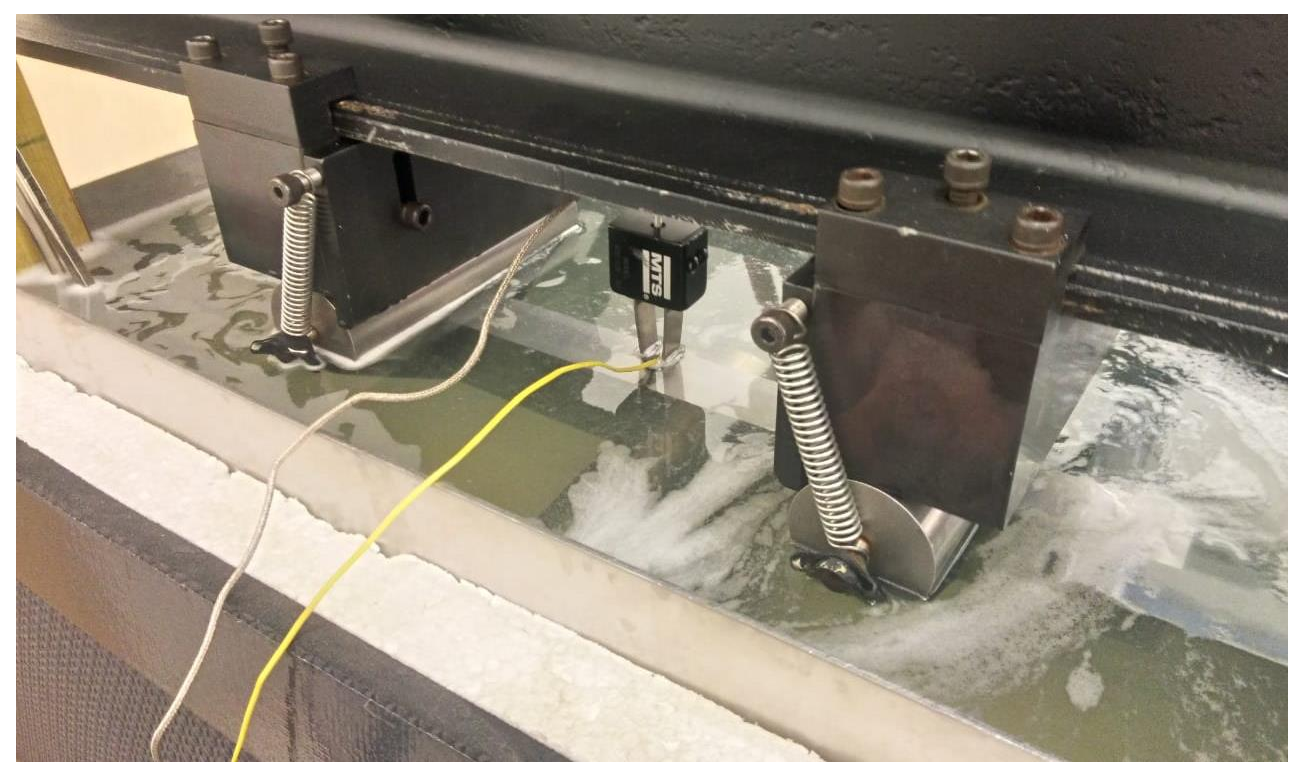




\subsubsection{Integral $J$ experimental}

O cálculo da integral J experimental é baseado metodologia $\eta$ a qual é normatizada pela ASTM E1820-18[60]. Esse procedimento também encontra-se descrito na ASTM E1921-18[5]. A determinação da integral $J$ no ponto da instabilidade por clivagem é dada pela soma dos componentes elástica e plástica conforme a seguinte expressão [5]:

$$
J_{c}=J_{e}+J_{p}
$$

Conforme já mencionado nas seções anteriores, os ensaios de tenacidade à fratura frágil por clivagem são conduzidos em corpos de prova de geometria SE(B) padrão. Dessa forma, a expressão para o cálculo da componente elástica, tanto para geometrias de seção quadrada (i.e., W/B = 1) quanto para seções retangulares (i.e., W/B >1), é dada por:

$$
J_{e}=\frac{\left(1-v^{2}\right) K_{I}^{2}}{E}
$$

onde $K_{I}$ representa o fator elástico de intensidade de tensão, $E$ e $v$ representam o módulo de elasticidade longitudinal obtido no ensaio de tração uniaxial e o coeficiente de Poisson. O fator $K_{I}$ referente à geometria $\mathrm{SE}(\mathrm{B})$ submetida à flexão por 3 pontos é dado por:

$$
\begin{gathered}
K_{I}=\left\{\frac{P S}{\left[\left(B B_{N}\right)^{1 / 2} W^{3 / 2}\right]}\right\} f\left(a_{0} / W\right) \\
f\left(a_{0} / W\right)=g\left(a_{0} / W\right) * h\left(a_{0} / W\right) \\
g\left(a_{0} / W\right)=\frac{3\left(a_{0} / W\right)^{1 / 2}}{2\left[1+2\left(a_{0} / W\right)\right]} \\
h\left(a_{0} / W\right)=\left(\frac{1,99-\left(a_{0} / W\right)\left(1-a_{0} / W\right)\left[2,15-3,93\left(a_{0} / W\right)+2,7\left(a_{0} / W\right)^{2}\right]}{\left(1-a_{0} / W\right)^{3 / 2}}\right)
\end{gathered}
$$


em que $P$ representa a carga no ponto de instabilidade da curva P-CMOD, $S$ a distância entre os apoios (neste caso dada por $S=4 W=4 * 50,8=203,2 \mathrm{~mm}$ ), $B_{N}$ a espessura líquida (i.e., $B_{N}=B$ caso não haja side-grooves), $a_{0}$ o comprimento original da trinca medido a partir da técnica dos 9 pontos e $f\left(a_{0} / W\right)$ o fator de intensidade de tensão adimensional.

Já a componente plástica de $J$ é calculada a partir do fator $\eta$ e cuja expressão é dada por

$$
J_{P}=\frac{\eta A_{p}}{B_{N} b_{0}}
$$

em que $\eta$ representa o fator plástico adimensional responsável por relacionar a contribuição do trabalho plástico realizado sobre o componente e a componente plástica da força motriz, $A_{p}$ a área plástica sob a curva P-CMOD, ligamento remanescente original da trinca $\left(b_{0}=W-a_{0}\right)$. O cálculo da área plástica é dado pela flexibilidade inicial $\left(C_{0}\right)$ conforme expressão a seguir

$$
\begin{aligned}
& A_{p}=A-1 / 2 C_{0} P^{2} \\
& A=A_{e}+A_{p}
\end{aligned}
$$

em que $A$ é a área total sob a curva P-CMOD conforme demonstrada na Figura 4.14.

É importante ressaltar que a área plástica $\left(A_{p}\right)$ pode ser baseada no deslocamento da linha de carga (LLD - load line displacement) ou no deslocamento de abertura da boca da trinca (CMOD - crack mouth displacement). Desse modo, a escolha do fator $\eta$ deve ser condizente com o tipo de deslocamento registrado, de forma que para LLD tem-se que $\eta=1,9$ e para o CMOD tal fator é dado pela seguinte polinômio: $\eta=3,667-2,199\left(a_{0} / W\right)+$ $0,4376\left(a_{0} / W\right)^{2}[5]$. No presente trabalho, conforme já mencionado em seções anteriores, o monitoramento do deslocamento é dado em termos do CMOD a partir de um clip-gage acoplado ao knife-edge usinado no próprio corpo de prova.

Uma vez calculados os valores de tenacidade à fratura em termos de $J_{c}$, tais valores são devidamente convertidos em unidades de $\mathrm{MPa} \sqrt{ } \mathrm{m}$ a partir da seguinte correlação

$$
K_{J_{c}}=\sqrt{J_{c} \frac{E}{1-v^{2}}}
$$


em que os valores do módulo de elasticidade $(E)$ são ajustados para cada temperatura de ensaio de forma que os valores de $J_{C}$ são convertidos para $K_{J c}$ em suas respectivas temperaturas de ensaio. A norma da ASTM E1921[5] fornece uma expressão que permite estimar o valor de $E$ de forma rápida e direta para uma ampla faixa de temperatura, conforme Eq. (4.11):

$$
E^{T-t e s t}=204-T / 16 G P a
$$

onde (T) é a temperatura de ensaio expressa em graus Celsius. A Equação 4.11 é proveniente de um ajuste de inúmeros valores de módulo de Young dispostos em uma tabela para aços ferríticos contida na parte D da Seção II do código ASME. Esse ajuste garante valores de E válidos na faixa de temperatura entre $-200^{\circ} \mathrm{C}$ e $300^{\circ} \mathrm{C}$, o que permite uma ampla aplicabilidade.

Figura 4.14 - Definição da área plástica usada no cálculo de $J_{p}$ (adaptado)

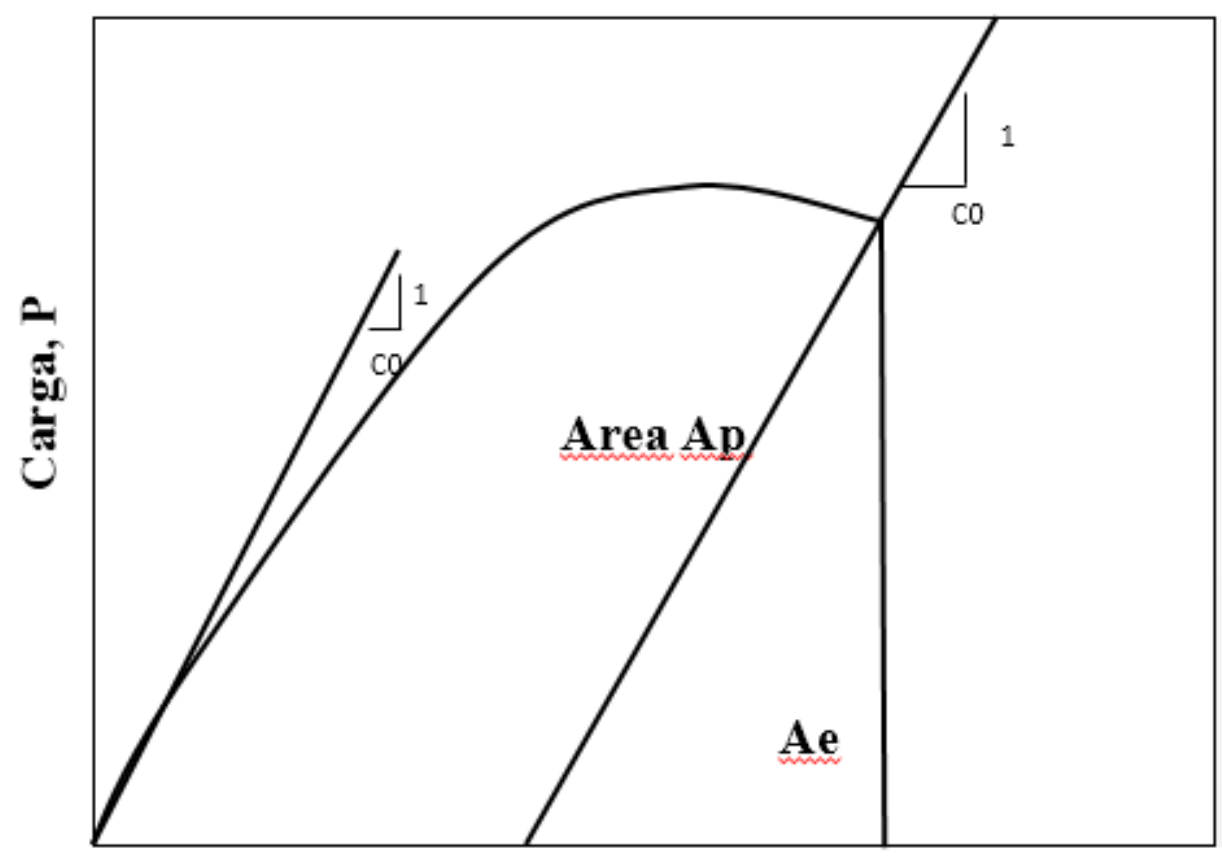

Linha de deslocamento, $\mathrm{V}$

\subsubsection{Avaliação da significância de pop-in's na curva P-CMOD}

O cálculo dos valores de tenacidade à fratura exige uma leitura adequada da curva PCMOD, pois em certos casos pode haver a ocorrência de pontos de instabilidade ou 
descontinuidade no registro da força versus deslocamento antes de se atingir a força máxima (curva P-CMOD), os quais são comumente denominados de pop-in, conforme evidenciado pela Figura 4.15 Esses pontos são caracterizados por um súbito aumento no deslocamento acompanhado, geralmente, de uma diminuição na força. Posteriormente a essa ocorrência, o deslocamento e a força aumentam acima de seus respectivos valores no momento do pop-in podendo ainda, em certos casos, haver outras ocorrências de instabilidades. Já para os casos em que a presença de descontinuidades no registro da curva P-CMOD ocorre somente após atingir a força máxima, considera-se que tais pontos de instabilidade não são considerados eventos de pop-in e, portanto, não devem ser tratados segundo o procedimento aqui descrito. Dessa forma, o registro da curva P-CMOD a partir de um ensaio de tenacidade à fratura deve ser categorizado em uma das três curvas apresentadas na Figura 4.15.

Figura 4.15 - Principais tipos de P- CMOD (adaptado).

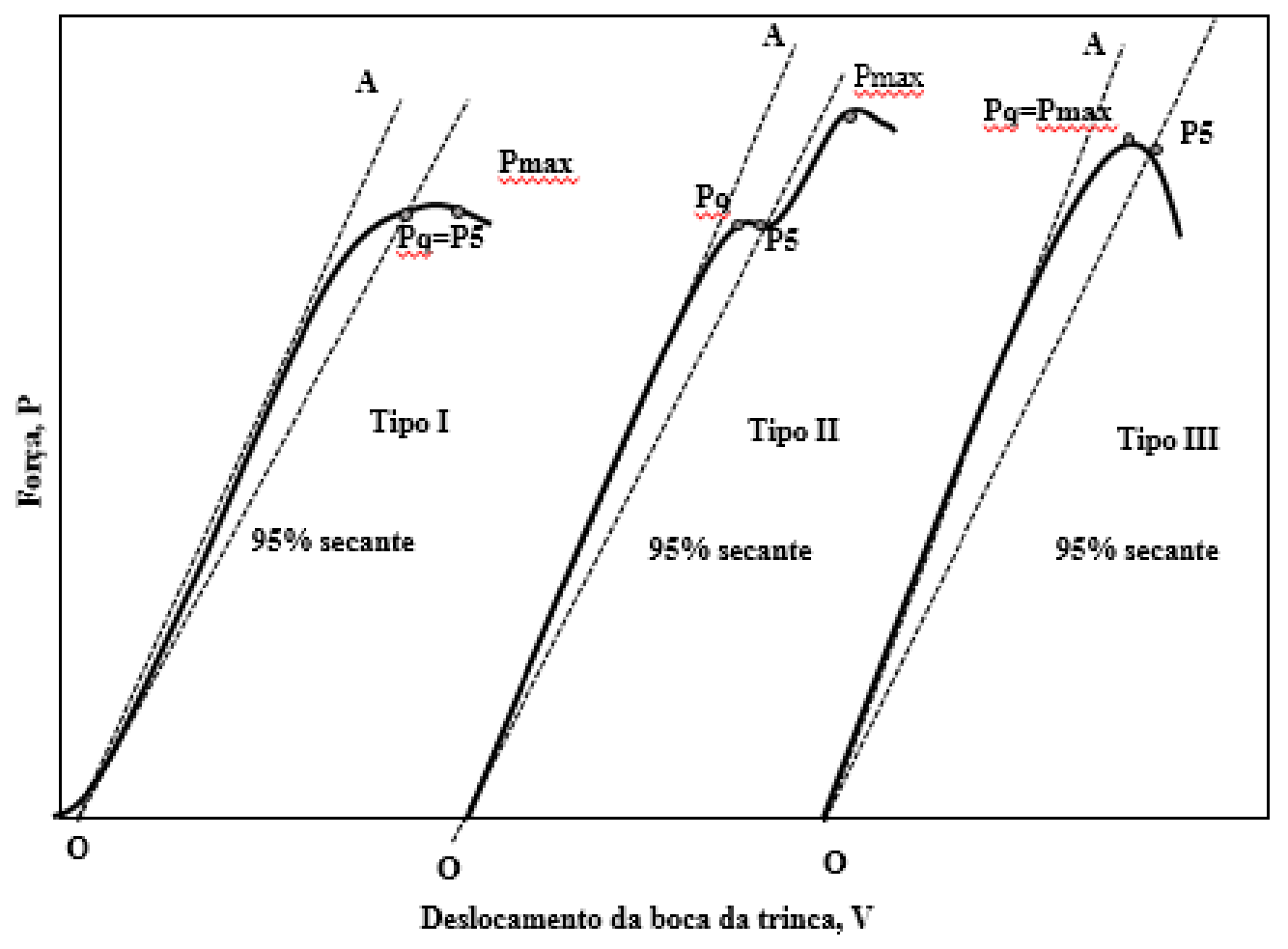

O pop-in pode ser atribuído a uma extensão instável da trinca (e.g., formação de trincas secundárias, delaminações ou fraturas de inclusões) ou a alguma interferência no monitoramento da carga e do deslocamento, por exemplo, a partir de algum ruído de sinal do clip-gage. Caso o pop-in seja atribuído à extensão instável da trinca aprisionada (arrested) no plano da pré-trinca de fadiga, o resultado deve ser considerado uma característica do material testado. Com o intuito de auxiliar na significância de tais pontos, ou seja, se os mesmos devem 
ser levados ou não em consideração no cálculo dos valores de tenacidade à fratura, a norma E399 [27] estabelece um procedimento de avaliação para um regime linear elástico, do qual é caracterizado por 3 comportamentos, conforme apresentado na figura 4.15.

A norma E399 [27] apresenta um procedimento de avaliação de pop-in’s em matérias com comportamento linear elástico da curva P-CMOD. A avaliação de validade do pop-in é a partir da determinação do ponto de carga $P_{Q}$, o qual é determinado pelo desenho da linha secante traçada de acordo com a Figura 4.15, tal secante é definida utilizando a inclinação apresentada pela curva P-CMOD até o limite linear utilizando 95\% de sua inclinação, assim avaliando se o pop-in tem relevância e se o ensaio é válido para cálculo de K [27](apresentando plasticidade relevante deve se prosseguir a Norma E1921). Assim para se definir os pontos de análise da curva P-CMOD utiliza-se as seguintes avaliações dos pontos de inflexão da curva:

Se a força máxima a qual antecede $\left(P_{5}\right)$ é menor que $P_{5}$ (curva tipo I), então $\left(P_{5}\right)$ é $\left(P_{Q}\right)$.

Se a força máxima antecedente a força $\left(P_{5}\right)$, excede a força $\left(P_{5}\right)$, então a máxima força é $P_{Q}$ (curvas tipo II e III) [27].

Após localização dos pontos principais de avaliação da curva P-CMOD. Avalia-se a relevância do pop-in e até mesmo a validade do ensaio (com base em comportamento elástico linear) utilizando os seguintes critérios [27]:

Se a razão $\left(P_{\max } / P_{Q}\right)$ não exceder 1,10 , proceder para o cálculo do $\left(K_{Q}\right)$ de acordo com a configuração do corpo de prova apresentado anteriormente.

Se $\left(P_{\max } / P_{Q}\right)$ excede 1,10 então o teste não valida $\left(K_{Q}\right)$ como $\left(K_{I c}\right)$, deve se usar a ASTM E1820 para tenacidade à fratura elasto-plástica[60].

Para que o $\left(K_{Q}\right)$ seja igual $\left(K_{I c}\right)$, o valor de $\left(2,5\left(K_{Q} / \sigma_{Y S}\right)^{2}\right)$ terá que ser menor do que o ligamento remanescente do corpo de prova $(W-a)$, sendo que $\left(\sigma_{Y S}\right)$ é a tensão de escoamento com 0,2\% de deformação elástica. Caso contrário o $\left(K_{Q}\right)$ não fornece um $\left(K_{I c}\right)$ valido [27].

Em caso de comportamento elasto-plástico a norma E1921 estabelece um procedimento de avaliação baseado na mudança da flexibilidade, conforme sucintamente descrito a seguir.

Para as situações nas quais são observadas a presença de um único ou múltiplos pop-in’s durante o ensaio, deve ser feita uma avaliação da flexibilidade $\left(C_{o}\right)$ registrada pela abertura da boca da trinca para averiguar se há ou não uma variação significativa em sua magnitude em decorrência do surgimento dos pontos de instabilidade. A norma E1921 estabelece uma variação máxima de 2\%, acima da qual deve-se levar em consideração os efeitos dos pop-in's no cálculo da tenacidade à fratura, ou seja, o pop-in deve ser tratado como um evento relevante e, portanto, o valor de tenacidade à fratura associado a tal evento deve ser usado como resultado 
do ensaio. É importante enfatizar que, dependendo da geometria e dimensão do corpo de prova ensaiado, a variação na flexibilidade de $2 \%$ prevê um aumento no comprimento da trinca não superior a $1 \%$, o que preserva a acurácia e confiabilidade do cálculo da tenacidade. Conforme ilustrado na Figura 4.15, a variação acumulada na flexibilidade, registrada pela abertura da boca trinca, antes e depois da ocorrência de um ou mais pop-in's é estimada por

$$
1-C_{0} \cdot\left(\frac{P_{n}-y_{n}}{v_{n}+x_{n}}\right)
$$

onde:

n : número sequencial do último de uma série particular de pop-in's avaliada. Para o caso particular onde só ocorre um pop-in, tem-se que $n=1$;

$v_{1} \quad: \quad$ componente elástica do deslocamento correspondente ao primeiro popin (vide Fig.4.16);

$\begin{array}{lll}P_{n} & : & \text { força do n-ésimo pop-in; } \\ v_{n} & : \quad \text { componente elástica do deslocamento correspondente ao n-ésimo pop in }\end{array}$ cuja magnitude pode ser determinada graficamente ou analiticamente, conforme indicado na Fig. 4.16;
$y_{n} \quad:$
magnitude da diminuição da força no n-ésimo pop-in;
$x_{n} \quad:$
magnitude do aumento do deslocamento no n-ésimo pop-in.

Para a situação na qual há somente a ocorrência de um único pop-in, caso a variação acumulada seja igual ou superior a $2 \%$; isto é, $1-C_{o} \cdot\left(\frac{P_{1}-y_{1}}{v_{1}+x_{1}}\right) \geq 0,02$, o pop-in deve ser considerado um evento significante. Quando múltiplos eventos de pop-in ocorrem, a variação acumulada, $1-C_{o} \cdot\left(\frac{P_{i}-y_{i}}{v_{i}+x_{i}}\right)$, deve ser analisada caso a caso na sequência de ocorrência (i.e., para $\mathrm{i}=1,2, \ldots, \mathrm{n}$-ésimo pop-in). Portanto, o valor de tenacidade à fratura que deve ser usado como resultado do ensaio deve ser o valor calculado no ponto de instabilidade cujo pop-in promove uma variação $1-C_{0} \cdot\left(\frac{P_{i}-y_{i}}{v_{i}+x_{i}}\right)$ superior a 0,02 , caso contrário, $1-C_{0} \cdot\left(\frac{P_{n}-y_{n}}{v_{n}+x_{n}}\right)<0,02$, o valor de tenacidade à fratura deve ser calculado no ponto final de instabilidade. Em suma, a seleção da carga de instabilidade, $P_{c}$, vai depender da magnitude da variação da flexibilidade ocasionada pelo pop-in. Caso tais eventos não promovam variações significativas, o cálculo é feito simplesmente como base no último registro da carga de instabilidade. 
Figura 4.16 - Avaliação esquemática de pop-in (adaptado ASTM E1921[5]).

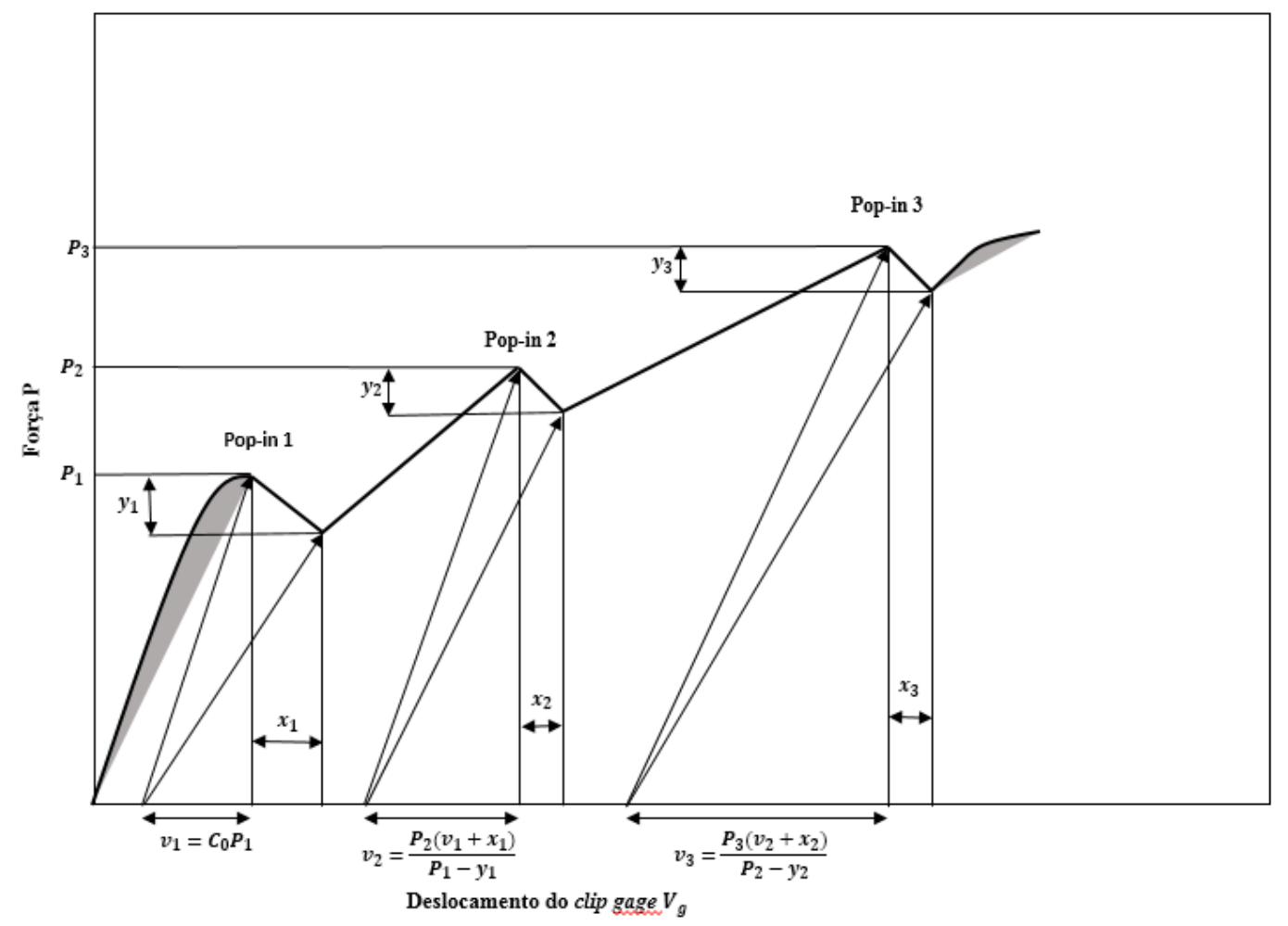

\subsubsection{Caracterização fractográfica e medição da frente de trinca.}

A análise fractográfica a níveis microestruturais visa identificar as características morfológicas da superfície de fratura (e.g., facetas de clivagem, marcas de rio, microcavidades, etc.) para correlacionar os micromecanismos de fratura operantes com a resposta macroscópica da fratura [17]. Já a análise a níveis macroestruturais visa averiguar a possível ocorrência de crescimentos subcríticos de trinca; isto é, crescimento estável precedente à instabilidade por clivagem. No que diz respeito à metodologia da curva mestra (MCM), essas análises são importantes para certificar se o processo de fratura na RTDF é realmente governado por tensões, o que valida as medidas de tenacidade à fratura frágil por clivagem (i.e., medidas que podem ser expressas em termos de $J, J_{c}$, ou em termos de $K, K_{J_{c}}$ ) utilizadas no cálculo da temperatura de referência do material

Embora a norma ASTM E1921[5] recomenda somente uma análise visual simples da superfície de fratura para fins de validação e mensuração do comprimento real de trinca, $a_{0}$ (i.e., comprimento do entalhe somado ao comprimento da pré-trinca por fadiga) a ser utilizado no cálculo da tenacidade à fratura, análises complementares utilizando microscópio eletrônico de varredura (MEV) são conduzidas neste trabalho. O intuito é investigar as características 
morfológicas dos micromecanismos de fratura atuantes visto que os ensaios conduzidos neste estudo envolvem aços martensíticos e, portanto, microestruturas que de certa forma diferem das microestruturas dos aços ferríticos tipicamente analisados pela MCM.

Visto que esse tipo de análise é considerado extremamente custoso, o seu uso deve ser utilizado com critério para fins de otimização sem, no entanto, prejudicar as conclusões das análises. Assim, os corpos de prova selecionados para a análise fractográfica via MEV devem ser escolhidos de acordo com o comportamento da curva P vs. CMOD (e.g., presença excessiva de pop-in's) e/ou dos aspectos macrofractográficos (e.g., indícios de rasgamento dúctil de trinca) provenientes dos exames em lupa estereoscópica. Tal seleção se faz necessária devido ao elevado número de corpos de prova da matriz de análise experimental

Os exames das frentes de trinca em lupa estereoscópica têm uma função essencial, tanto para determinar a necessidade de uma possível análise microfractográfica em MEV, conforme já mencionado, como para determinar os comprimentos da frente de trinca a serem utilizados nos cálculos de tenacidade à fratura. As medições de frente de trinca são feitas utilizando uma régua de calibração. Essas medidas têm por objetivo determinar o comprimento real da trinca $a_{0}$ e, quando presente, a quantidade de crescimento estável de trinca a qual é definida por $\Delta a_{p}=$ $a_{f}-a_{0}$, onde $a_{f}$ é o comprimento final da trinca. As medições de $a_{0}$ e de $\Delta a_{p}$ são feitas com base nas normas E1921, E1820, as quais preconizam o uso da técnica dos 9 pontos igualmente espaçados por 0,01B, sendo B espessura do corpo de prova como demonstrado na Figura 4.17[5], [60]. 
Figura 4.17 - Representação esquemática da medição da frente de trinca sem side grooves a partir da técnica dos 9 pontos.

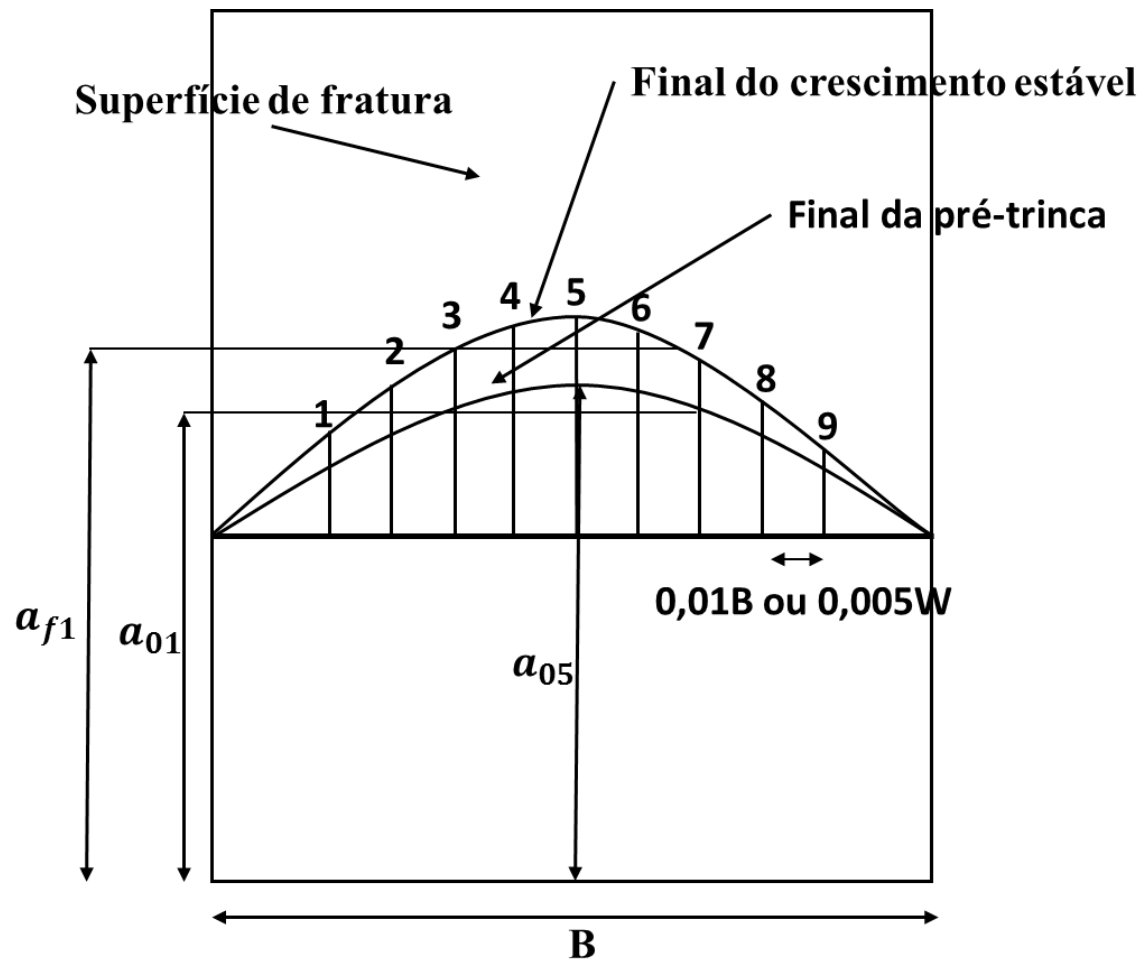

O método de 9 pontos ilustrado na Figura 4.17 baseia-se em medidas equidistantes a partir da linha de simetria em relação à espessura, ou seja, exatamente em B/2. Assim, o cálculo do valor médio de $a_{0}$ e $a_{f}$ é feito por meio das seguintes expressões.

$$
\begin{gathered}
a_{0}=\frac{\frac{\left(a_{01}+a_{09}\right)}{2} \sum_{i=2}^{8} a_{0 i}}{8} \\
a_{f}=\frac{\frac{\left(a_{f 1}+a_{f 9}\right)}{2} \sum_{i=2}^{8} a_{f i}}{8}
\end{gathered}
$$

Para as situações nas quais ocorre crescimento estável de trinca, a validade dos valores de tenacidade à fratura fica condicionada a um valor crítico $\left(\Delta a_{c}\right)$ para o crescimento estável de trinca $\left(\Delta a_{p}\right)$. O valor de $\Delta a_{c}$ não pode exceder o menor valor estabelecido entre $1 \mathrm{~mm}$ e $0,05\left(W-a_{0}\right)$. Já em relação à pré-trinca por fadiga é importante ressaltar que nenhuma das nove medições do comprimento físico original e final da trinca pode diferir em mais de $0,1\left(b_{o} B_{N}\right)^{1 / 2}, 5 \%$ ou $0,5 \mathrm{~mm}$ do comprimento médio da trinca definido pela Eq. (4.15). O 
atendimento a esse último requisito garante uma frente de trinca uniforme, o que dá a entender a predominância de um campo de tensões mais uniforme ao longo da espessura[5], [60], [61].

\subsubsection{Análise estatística dos dados de tenacidade à fratura}

Conforme os fundamentos teóricos já abordados na Seção 2.6, sabe-se que os dados de tenacidade à fratura medidos na RTDF de aços ferríticos apresentam uma elevada dispersão e podem ser facilmente ajustados para diferentes espessuras simplesmente pelo uso do conceito estatístico do elo mais fraco. Em vista disso, a distribuição de probabilidade que melhor modela o comportamento desses dados é a distribuição de Weibull triparamétrica.

Embora o material utilizado no presente estudo seja um aço martensítico, as suas características microestruturais, no que diz respeito à forma pela qual se distribuem as partículas de segunda fase, possuem uma certa correlação com as apresentadas pelos aços ferríticos. Além disso, apresentam um regime de transição dúctil-frágil similar ao demonstrado pelos aços ferríticos. Dessa forma, espera-se que o processo de fratura por frágil e, portanto, o comportamento dos dados de tenacidade à fratura medidos na RTDF seja muito próximo daquilo que é observado para os aços ferríticos-perlíticos tipicamente utilizados em componentes estruturais e equipamentos mecânicos.

Portanto, a fim de demonstrar se, de fato, os dados de tenacidade à fratura frágil (expressos em unidades de $\mathrm{kJ} / \mathrm{m}^{2}$ para $J_{c}$ e MPa $\sqrt{\mathrm{m}}$ para $K_{J_{c}}$ ) do aço USI AR450 medidos na RTDF são bem descritos pela distribuição de Weibull triparamétrica, antes de realizar a avaliação da temperatura de referência, torna-se necessário fazer o tratamento estatístico dos dados de $K_{J_{c}}$ por meio de distribuições acumulada de falha. Esse tratamento preliminar dos dados de tenacidade envolve análises de aderência da distribuição experimental dos dados de tenacidade (por meio do estimador de rank mediano) em relação à distribuição teóricaexperimental de Weibull (i.e., uma distribuição cuja tenacidade característica provém de um valor fixo de $\alpha_{J}=2$ para $J_{c}$ e $\alpha_{k}=4$ para $K_{J_{c}}$ ).

A análise estatística envolve basicamente dispor os dados de tenacidade por meio de um estimador de probabilidade não-paramétrico proposto por Benard e Bosi-Levenbach [62], o qual é baseado no rank mediano e demonstrado pela seguinte Equação

$$
\widehat{F}\left(K_{J_{c}}\right)=\frac{i-0,3}{N+0,4}
$$


onde $i$ representa a posição ordenada do valor de $\left(K_{J_{c}}\right.$ ou $\left.J_{c}\right)$ presente em uma amostra aleatória de tamanho $N$, o qual os dados são organizados em ordem crescente. Já os ajustes para verificar a aderência da distribuição experimental em relação à distribuição teórica-experimental de Weibull são baseados na seguinte expressão

$$
p_{f}=1-e^{\left\{-\frac{B_{(n T)}}{B_{(1 T)}}\left[\frac{K_{J_{C}}-K_{\min }}{K_{0}-K_{\min }}\right]^{\alpha}\right\}}
$$

onde a tenacidade característica, $K_{0}$, é estimada a partir do método da máxima verossimilhança (MMV) [49] baseando-se em no valor teórico $\alpha=4$.

Com o intuito de avaliar o valor experimental de $\alpha$ da distribuição dos valores de $K_{J_{c}} \mathrm{e}$ seu impacto sobre as estimativas de $K_{0}$ e $K_{\text {min }}$, é feita uma análise estatística por meio da linearização da função de distribuição acumulada (f.d.a.) de Weibull, vide Eq. (4.17). Nessa análise, os dados experimentais são ajustados utilizando o método dos mínimos quadrados (MMQ), conforme as seguintes expressões:

$$
\begin{gathered}
y=a x+b \\
y=\ln \left\{\ln \left[\frac{1}{1-P_{f}}\right]\right\} \\
x=\ln \left(K_{j c}-K_{\min }\right) \\
a=\alpha \\
b=-\alpha \ln \left(K_{0}-K_{\min }\right)
\end{gathered}
$$

A partir das equações geradas por cada conjunto de dados (conjuntos separados por temperatura de ensaio), estima-se os valores de $\hat{\alpha}$ e $\widehat{K}_{0}$ experimental, de cada conjunto de dados. 


\subsubsection{Métodos para a determinação da temperatura de referência $\left(T_{0}\right)$}

O procedimento para estimativa da temperatura de referência $\left(T_{0}\right)$ a partir de dados de $K_{J_{c}}$ provenientes de corpos de prova $1 \mathrm{~T}$ requer uma quantidade mínima de resultados válidos, ou seja, de medidas de $K_{J_{c}}$ que sejam provenientes de processos de fratura governados pelo campo HRR. Conforme abordagem mais adiante, essa quantidade depende do método utilizado para o cálculo da $T_{0}$ e do número de resultados censurados, ou seja, medidas inválidas segundo os critérios de aceitação a E1921[5] como medidas de tenacidade representativas de processos de fratura controlados essencialmente por tensão. Antes de abordar os métodos para a estimativa da $T_{0}$, é necessário descrever o procedimento de análise das medidas experimentais de tenacidade à fratura expressas em termos do fator de intensidade de tensão elasto-plástico (i.e., em unidades de $\mathrm{MPa} \sqrt{\mathrm{m}}$ ) a partir da conversão das medidas inicialmente expressas em temos da integral $J$ no ponto de instabilidade por clivagem $\left(\mathrm{kJ} / \mathrm{m}^{2}\right)$, conforme descrição a seguir.

A análise dos dados de tenacidade à fratura (i.e., das medidas de $J_{c}$ ou $K_{J_{c}}$ ) medidos na RTDF é baseada na distribuição triparamétrica de Weibull cuja expressão é dada pela Eq. (4.19). A formulação da Eq. (4.19) é capaz de descrever a elevada dispersão dos dados ao mesmo tempo em que engloba o modelo do elo mais fraco (weakest link model). Detalhes da fundamentação teórica dessa distribuição podem ser encontrados na Seção 2.6. A Eq. (4.19) representa mais precisamente a distribuição de probabilidade acumulada de falha $\left(p_{f}\right)$ expressa em termos de $K_{J_{c}}$ a qual é estabelecida por uma relação triparamétrica dada por

$$
p_{f}=1-e^{\left\{-\frac{B_{(n T)}}{B_{(1 T)}}\left[\frac{K_{J_{c}}-K_{\min }}{K_{0}-K_{\min }}\right]^{\alpha}\right\}}
$$

em que $K_{\text {min }}, K_{0}$ e $\alpha$ representam, nessa ordem, o fator de intensidade de tensão mínimo abaixo do qual pressupõe-se que a fratura não ocorre (definido como o parâmetro de localização da distribuição), a tenacidade à fratura característica (parâmetro de escala associado a uma $p_{f}=$ $63,2 \%$ ) e o módulo de Weibull que mede o grau da dispersão dos dados de $K_{J_{c}}$ (parâmetro de forma). Ainda em relação à Eq. (4.19), os termos $B_{(1 T)}$ e $B_{(n T)}$ representam a espessura dos corpos de prova em que $1 T$ equivale a uma espessura de 25,4 $\mathrm{mm}$ e $n T$ a qualquer valor que seja diferente de 25,4 mm. Dentro os parâmetros de Weibull, somente o $K_{0}$ necessita ser estimado, pois tanto o valor de $\alpha$ quanto de $K_{\min }$ já são fornecidos pela E1921[5]. A estimativa de $K_{0}$ é baseada no método paramétrico da Máxima Verossimilhança (MMV) cujo valor visa 
maximizar a probabilidade dos dados amostrados de $K_{J_{c}}$. O cálculo da estimativa de $K_{0}$ é dado pela seguinte expressão, o qual já está com os valores de $K_{\text {min }}=20 M P a \sqrt{m}$ e $\alpha=4$ ambos fornecidos pela E1921

$$
K_{0}=\left[\sum_{i=1}^{N} \frac{\left(K_{J_{c(i)}}-20\right)^{4}}{r}\right]^{1 / 4}+20 \mathrm{MPa} \sqrt{\mathrm{m}}
$$

em que $K_{J_{c(i)}}$ representa as medidas de tenacidade à fratura da amostra $(i=1,2, \ldots, N)$ e $r$ o número de ensaios válidos segundo os critérios da E1921[5], o qual é dado por $r=N-c$ onde $N$ é o número total de ensaios (i.e., no caso o tamanho da amostra) e $c$ o número de ensaios com resultados censurados. É importante ressaltar que todas as medidas de tenacidade à fratura devem ser ajustadas para os seus correspondentes valores referentes à espessura padrão de 1 polegada. Caso o valor de $K_{0}$ seja estimado a partir de medidas $K_{J c(i)}$ não ajustadas para o seu equivalente $1 \mathrm{~T}, K_{0(n T)}$, deve-se usar a seguinte expressão para tal ajuste

$$
K_{0}=K_{\min }+\left[K_{0(n T)}-K_{\min }\right]\left[\frac{B_{(n T)}}{B_{(1 T)}}\right]^{1 / 4}
$$

a qual nada mais é do que aplicação indireta do conceito do elo mais fraco sobre os valores de $K_{J c(i)}$. Em relação aos dados censurados de $K_{J c(i)}$, os quais são assim classificados por violarem o valor limite de $K_{J c}\left(K_{J_{c}(l i m i t e)}\right)$ ou por apresentarem crescimento subcrítico de trinca superior ao valor limite $\left(\Delta a_{c}\right)$, os mesmos devem ser substituídos de acordo com o tipo de violação. Caso os dados sejam censurados apenas por apresentarem valores superiores a $K_{J_{c}(\text { limite) }}$, os mesmos devem ser substituídos pelo $K_{J_{c} \text { (limite) }}$ condizente com a dimensão planar $b_{o}$ dos corpos de prova usados nos ensaios; isto é, pela seguinte expressão

$$
K_{J_{c}(\text { limite })}=\sqrt{\frac{E b_{o} \sigma_{y s}}{M\left(1-v^{2}\right)}}
$$

em que $b_{o}=W-a_{o}$ é o ligamento remanescente da trinca e $M$ o limite de deformação, o qual é dado por $M=30$ pela E1921[5]. Esse limite visa assegurar a validade do campo HRR durante 
o processo de fratura; isto é, de que o processo é realmente governado por tensões. Além do mais, é importante ressaltar que o valor de $K_{J_{c}(\text { limite })}$ também deve ser condizente com a temperatura de ensaio, de forma que os valores do módulo de elasticidade longitudinal e da tensão de escoamento devem ser ajustados para as temperaturas de interesse por meio das seguintes expressões

$$
\begin{gathered}
\sigma_{y s}=\sigma_{y s}^{R T}+\frac{10^{5}}{491+1,8 T}-189 \quad(\mathrm{MPa}) \\
E=204-T / 16 \quad(\mathrm{GPa})
\end{gathered}
$$

onde $T$ é a temperatura de ensaio expressa em ${ }^{\circ} \mathrm{C}$.

Para os casos em que os dados de $K_{J_{c(i)}}$ são censurados por apresentarem um crescimento subcrítico de trinca superior ao valor limite estabelecido pela E1921[5] (i.e., $\Delta a_{p}>0,05(W-$ $a_{o}$ ) ou $1 \mathrm{~mm}$, o que for menor), o valor de $K_{J_{c(i)}}$ censurado $\left(K_{J_{c} \Delta a}\right)$ deve ser substituído pelo maior valor não censurado $\left(K_{J_{c(i)}}^{\text {maior }}\right)$ contido nas diversas amostras ensaiadas. Em outras palavras, a substituição deve ser feita independentemente se a amostra na qual o maior valor está presente é obtida ou não na mesma temperatura e nas mesmas dimensões dos corpos de prova do ensaio censurado, pois o valor de $K_{J_{c} \Delta a}$ deve ser independente do tamanho e também insensível à temperatura de ensaio. Alternativamente, o valor de $K_{J c \Delta a}$ pode ser substituído pelo valor de $J$ no início do crescimento estável de trinca $\left(U_{I_{c}}\right)$ medido a partir de ensaios de curva de resistência $J-\Delta a$, caso esse valor seja conhecido para o material em estudo. Em uma última situação, onde o valor de $K_{J_{c(i)}}$ é censurado por ambos os mecanismos (i.e., limite de deformação e crescimento subcrítico de trinca), o valor de $K_{J_{c(i)}}$ deve ser substituído pelo menor valor apresentado entre os dois valores limites (i.e., entre $K_{J_{c(i)}}^{\text {maior }}$ e $K_{J_{c}(\text { limite) }}$ ).

Após o cálculo dos valores de tenacidade à fratura e devida atribuição do mecanismo de censurado aos dados inválidos, pode-se determinar a temperatura de referência $\left(T_{0}\right)$ do material a partir de dois métodos cuja escolha depende da quantidade de ensaios e do número de temperaturas associadas a tais ensaios.

Para as situações nas quais os dados de $K_{J_{c(i)}}$ são obtidos a partir diversas temperaturas que supostamente representam a RTDF, a $T_{0}$ pode ser estimada pelo método multitemperatura 
(multi-temperatura analysis) o qual envolve um processo iterativo [1], [44], [51] conforme a seguinte expressão

$$
\sum_{i=1}^{N} \delta_{i} \frac{e^{\left[0,019\left(T_{i}-T_{0 Q}\right)\right]}}{11,0+76,7 e^{\left[0,019\left(T_{i}-T_{0 Q}\right)\right]}}-\sum_{i=1}^{N} \frac{\left(K_{J_{c(i)}}-20\right)^{4} e^{\left[0,019\left(T_{i}-T_{0 Q}\right)\right]}}{\left\{11,0+76,7 e^{\left[0,019\left(T_{i}-T_{0 Q}\right)\right]}\right\}^{5}}=0
$$

onde:

$N \quad$ : $\quad$ número de corpos de prova testados,

$T_{i} \quad: \quad$ temperatura de ensaio correspondente ao $K_{J_{c(i)}}$,

$K_{J_{c(i)}} \quad: \quad$ medida $K_{J_{c}}$ não censurada ou medida substituída por algum valor de censura,

$\delta_{i} \quad: \quad 1$ se o dado é um valor não censurado ou zero se o dado é um valor censurado,

11,0 : aproximadamente $10 /(\ln 2)^{1 / 4} \mathrm{MPa} \sqrt{\mathrm{m}}$ com 3 dígitos significativos,

76,7 : $\quad$ aproximadamente $70 /(\ln 2)^{1 / 4} \mathrm{MPa} \sqrt{\mathrm{m}}$ com 3 dígitos significativos.

O valor da $T_{0}$ estimado a partir do procedimento multitemperatura é designado provisoriamente por $T_{0 Q}$, visto que a sua legitimidade como uma temperatura realmente representativa da RTDF fica condicionada ao cumprimento de certas exigências as quais visam conferir acurácia a tal valor. Em vista disso, a norma E1921 estabelece alguns critérios relacionados ao tamanho do conjunto de dados amostrais de $K_{J_{c(i)}}$ em função das temperaturas de ensaio que compõem a estimativa provisória da $T_{0}$. Para valores de $K_{J_{c(i)}}$ calculados nas temperaturas de ensaio compreendidas na faixa $T_{0}-50 \leq T \leq T_{0}-14$, pressupõe-se haver uma redução na acurácia da estimativa $T_{0}$ em decorrência das possíveis violações do micromecanismo de clivagem governado pelas subsequentes etapas de nucleação e propagação das microtrincas de Griffith. Uma vez que as temperaturas associadas a essa faixa são muito próximas do patamar inferior de tenacidade à fratura, há uma forte tendência do processo de fratura ocorrer sem o intermédio da clivagem de sítios preferenciais, o que de certa forma mitiga os efeitos estatísticos associados ao conceito do elo mais fraco e, portanto, à dispersão dos dados de $K_{J_{c(i)}}$. Como consequência, é exigido um maior número de dados de $K_{J_{c(i)}}$ oriundos dessa faixa de temperatura. Para tal, atribui-se um sistema de ponderação o qual especifica a número de dados requeridos para preservar a acurácia da $T_{0}$ estimada via método iterativo, conforme a seguinte regra: 


$$
\sum_{i=1}^{3} r_{i} n_{i} \geq 1
$$

onde $r_{i}$ é o número de dados de $K_{J_{c(i)}}$ não censurados calculados dentro da amplitude de temperatura ( $T-T_{0}$ ) e $n_{i}$ é o fator de ponderação atribuído aos ensaios conduzidos na mesma amplitude de temperatura, conforme mostrado na Tabela 4.3 [6].

Tabela 4.3 - Fator de ponderação para a estimativa da $T_{0}$ via método multitemperatura

\begin{tabular}{ccc}
\hline $\begin{array}{c}\text { Faixa }\left(T-T_{0}\right) \\
\left({ }^{\circ} \mathrm{C}\right)\end{array}$ & $\begin{array}{c}\text { Faixa } 1 \mathrm{~T} \\
K_{J_{c}(\text { med })}(\mathrm{MPa} \sqrt{\mathrm{m}})\end{array}$ & $\begin{array}{c}\text { Fator de ponderação } \\
\left(n_{i}\right)\end{array}$ \\
\hline 50 até -14 & 212 até 84 & $1 / 6$ \\
-15 até -35 & 83 até 66 & $1 / 7$ \\
-36 até -50 & 65 até 58 & $1 / 8$ \\
\hline
\end{tabular}

Caso a relação expressa pela Eq. (4.24) não seja satisfeita, o número de ensaios deve ser aumentado até que a relação seja plenamente satisfeita. A título de exemplo, caso sejam obtidos somente dados compreendidos na faixa $T_{0}-36 \leq T \leq T_{0}-50$ e cujo valor mediano $\left(K_{J_{c}(\text { med })}\right)$ da distribuição triparamétrica de Weibull dos dados de $K_{J_{c(i)}}$ esteja definido entre 58 e $65 \mathrm{MPa} \sqrt{\mathrm{m}}$, tem-se que o número mínimo de valores não censurados de $K_{J_{c(i)}}$ e, portanto, de ensaios válidos deva ser igual 8, ou seja, 2 ensaios a mais em comparação aos resultados obtidos unicamente na faixa de temperatura mais distante do patamar inferior de tenacidade (i.e., $T_{0}$ $36 \leq T \leq T_{0}-50$ ).

Dado que a faixa de temperatura de ensaio válida é conhecida apenas após a determinação da $T_{0 Q}$, recomenda-se realizar uma quantidade mínima de ensaios que seja suficiente para gerar ao menos de 3 a 4 resultados não censurados na temperatura de ensaio inicialmente estimada $\left(T_{0}^{C V N}\right.$ ) via correlação com os dados de tenacidade ao entalhe em V por impacto Charpy (vide Tabela 4.2 da Seção 4.6). A partir de então é que se estima o valor de $T_{0 Q}$ (o qual é inicialmente designado de $\left.T_{0 Q(e s t)}\right)$ a partir da Eq. (4.23) e, portanto, a faixa de temperatura representativa dos ensaios conduzidos na $T_{0}^{C V N}$. Uma vez determinada a $T_{0 Q(e s t)}$, deve-se realizar os demais ensaios nessa temperatura e, desse modo, verificar se os resultados obtidos atendem as condições impostas pela Eq. 4.24 e Tabela 4.3. Uma vez atendida a exigência, espera-se que a nova temperatura de referência $\left(T_{0 Q}\right)$, estimada a partir da inclusão dos resultados desses novos 
ensaios, não difira de forma significativa da $T_{0 Q(e s t)}$. No entanto, certos conjuntos de dados podem resultar em uma iteração oscilante entre dois (ou mais) valores $T_{0 Q}$ distintos, ainda que tais dados satisfaçam a condição limite da janela de validade definida por $T_{0 Q} \pm 50^{\circ} \mathrm{C}$. Nesses casos, o valor da $T_{0 Q}$ a ser adotada definitivamente como a temperatura em que $K_{J_{c}(\text { med })}=$ $100 \mathrm{MPa} \sqrt{\mathrm{m}}$ (i.e., como a $T_{0}$ do material de interesse) deve ser a média dos valores calculados de $T_{0 Q}$.

Para os casos em que as medidas de tenacidade à fratura são medidas unicamente em uma única temperatura, a norma E1921[5] disponibiliza um método alternativo ao procedimento iterativo, o qual é mais direto e relativamente mais simples para se determinar a $T_{0}$ do material de interesse. A partir do valor mediano da distribuição acumulada de falha (i.e., valor associado a uma $p_{f}=50 \%$ ) dos valores de $K_{J_{c}}$ fornecida pela Eq. (4.20), é possível calcular a $T_{0}$ a partir da seguinte expressão

$$
T_{0 Q}=T-\left(\frac{1}{0,019}\right) \ln \left[\frac{\left(K_{J c(m e d)}-30\right)}{70}\right]
$$

em que $K_{J c(m e d)}$ é calculado para uma $p_{f}=50 \%$, ou seja,

$$
\begin{gathered}
p_{f}=1-e^{\left\{-\frac{B_{(n T)}}{B_{(1 T)}}\left[\frac{K_{J_{c}}-K_{\min }}{K_{0}-K_{\min }}\right]^{\alpha}\right\}} \Rightarrow 0,5=1-e^{\left\{-\left[\frac{K_{J_{c}(m e d)}-K_{\min }}{K_{0}-K_{\min }}\right]^{4}\right\}} \\
e^{\left\{-\frac{B_{(n T)}}{B_{(1 T)}}\left[\frac{K_{J_{c}(\text { med })}-K_{\min }}{K_{0}-K_{\min }}\right]^{4}\right\}}=0,5 \Rightarrow-\frac{B_{(n T)}}{B_{(1 T)}}\left[\frac{K_{J_{c}(\text { med })}-K_{\min }}{K_{0}-K_{\min }}\right]^{4}=\ln (1 / 2) \\
-\frac{B_{(n T)}}{B_{(1 T)}}\left[\frac{K_{J_{c}(\text { med })}-K_{\text {min }}}{K_{0}-K_{\min }}\right]^{4}=-\ln (2) \Longrightarrow\left[\frac{K_{J_{c}(\text { med })}-K_{\min }}{K_{0}-K_{\min }}\right]=\left\{\left[\frac{B_{(1 T)}}{B_{(n T)}}\right][\ln (2)]\right\}^{1 / 4} \\
K_{J_{c}(\text { med })}=20+\left(K_{0}-20\right)\left\{\left[\frac{B_{(1 T)}}{B_{(n T)}}\right][\ln (2)]\right\}^{1 / 4} \operatorname{MPa} \sqrt{\mathrm{m}}
\end{gathered}
$$

ou,

$$
K_{J_{c}(\text { med })}=20+\left(K_{0}-20\right)[\ln (2)]^{1 / 4} \mathrm{MPa} \sqrt{\mathrm{m}}
$$


para o caso particular em que $B_{(n T)}=B_{(1 T)}$, conforme recomendação da norma.

De forma similar aos requisitos relacionados à quantidade mínima de resultados válidos exigidos pelo método multitemperatura, a estimativa pelo método da temperatura única (single temperatura analysis) também requer uma quantidade mínima de dados $K_{J_{c}}$ que seja suficiente para fornecer uma estimativa acurada da $T_{0}$, conforme a Tabela 4.4.

Tabela 4.4 - Requisitos de valores de $K_{J_{c}}$ não censurados para a estimativa da $T_{0}$ via método da temperatura única

\begin{tabular}{|c|c|c|c|}
\hline $\begin{array}{r}\text { Faixa } \\
\left(T-T_{0}\right)\left({ }^{\circ} \mathrm{C}\right)\end{array}$ & $\begin{array}{l}\text { Faixa } 1 \mathrm{~T} \\
K_{J c(\text { med })} \\
(\mathrm{MPa} \sqrt{\mathrm{m}})\end{array}$ & $\begin{array}{l}\text { Número de } \\
\text { dados } K_{J_{c}} \text { não } \\
\text { censurados }\end{array}$ & $\begin{array}{r}\text { Possível número } \\
\text { de dados } K_{J_{c}} \text { censurados }\end{array}$ \\
\hline 50 até -14 & 212 até 84 & 6 & 3 \\
\hline -15 até -35 & 83 até 66 & 7 & 1 \\
\hline-36 até -50 & 65 até 58 & 8 & 0 \\
\hline
\end{tabular}

Conforme se observa nas Tabelas 4.3 e 4.4, o menor valor admissível para $K_{J_{c}(m e d)}$ é de $58 \mathrm{MPa} \sqrt{\mathrm{m}}$. Isso significa dizer que conjuntos de $K_{J_{c(i)}}$ cuja mediana seja inferior a $58 \mathrm{MPa} \sqrt{\mathrm{m}}$ muito provavelmente são compostos por medidas de tenacidade representativas do patamar inferior de energia, o que viola os fundamentos estatísticos associados ao processo de fratura frágil por clivagem na RTDF de aços ferríticos. Portanto, não se deve estimar a $T_{0 Q}$ a partir desses conjuntos de dados experimentais. Uma vez atendido os requisitos e critérios de validade dos valores de $K_{J_{c(i)}}$, a $T_{0}$ provisoriamente designada por $T_{0 Q}$ pode ser caracterizada como a temperatura na qual a tenacidade à fratura mediana equivale a $100 \mathrm{MPa} \sqrt{\mathrm{m}}$; isto é, definitivamente como a $T_{0}$ do material. Assim como no método multitemperatura, a janela de validade da curva mestra baseada em uma $T_{0}$ obtida via temperatura única é dada por $T_{0} \pm$ $50{ }^{\circ} \mathrm{C}$, conforme abordagem da próxima seção.

\subsubsection{Caracterização da tenacidade à fratura pela Curva Mestra}

Uma vez estabelecida a $T_{0}$ do material, é possível definir uma curva de tenacidade à fratura referencial, cuja região de validade é capaz de fornecer estimativas acuradas de $K_{J_{c}}($ med $)$ 
ao longo de uma ampla faixa de temperatura característica da RTDF, de forma muito similar às curvas de tenacidade do código ASME (i.e., curvas $K_{I_{C}}$ e $K_{I R}$ ) ([45], [63], [64],[42]). Portanto, a curva de tenacidade à fratura associada à temperatura $T_{0}$, designada como curva mestra, segue o comportamento de uma exponencial cuja expressa é dada por

$$
K_{J_{C}(m e d)}=30+70 e^{\left[0,019\left(T-T_{0}\right)\right]} \quad \mathrm{MPa} \sqrt{\mathrm{m}}
$$

em que $K_{J_{c}(\text { med })}$ está relacionada à uma probabilidade acumulada de falha $\left(p_{f}\right)$ de $50 \% \mathrm{e}$ $T$ é a temperatura de ensaio. Na Figura 4.18 está representada o formato da curva mestra bem como os limites inferior e superior de tolerância associados a um nível $(0, \mathrm{xx})$ de probabilidade acumulada de falha expresso em percentual. Na Figura 4.18, os intervalos de tolerância estão associados a um percentual de $5 \%$, ou seja, $0, \mathrm{xx}=0,05$. Esse intervalo define a probabilidade de um valor individual de $K_{J_{c}}$ (i.e., $K_{J_{c}(i)}$ ) estar dentro do intervalo especificado, ou seja, uma vez determinada a curva mestra e seus intervalos de tolerância, a probabilidade de um dado amostral de tenacidade ficar acima do limite superior ou abaixo do limite inferior é de apenas 5\% e, quanto maior o nível de probabilidade acumulada, mais estreito fica o intervalo e, portanto, maior é a probabilidade do dado amostral ficar fora do intervalo definido pelo nível de probabilidade. 
Figura 4.18 - Curva mestra e seus intervalos de tolerância associados a um nível de probabilidade acumulada de 5\%

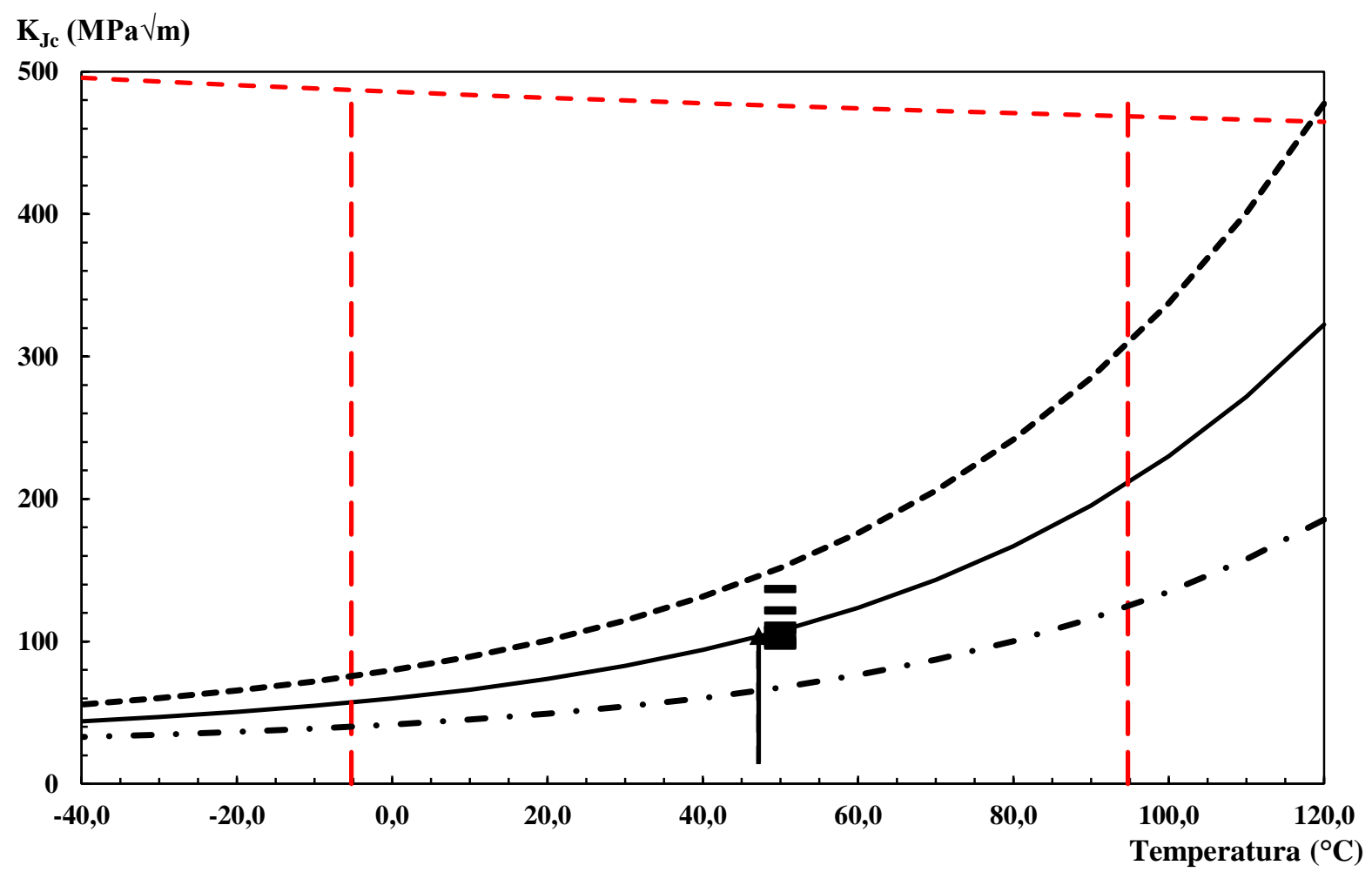

A expressão utilizada para calcular os intervalos inferior e superior de tolerância, é dada pela seguinte Equação [6]

$$
K_{J_{c}(0, x x)}=20+\left[\ln \left(\frac{1}{1-0, x x}\right)\right]^{\frac{1}{4}}\left\{11+77 e^{\left[0,019\left(T-T_{0}\right)\right]}\right\}
$$

em que $(0, \mathrm{xx})$ representa o nível de probabilidade acumulada de falha expresso em percentual.

A determinação da $T_{0}$ e da sua respectiva curva mestra associada aos intervalos de tolerância permite estimar valores medianos de tenacidade à fratura em toda a faixa de temperatura da RTDF, o que a torna uma ferramenta de engenharia muito versátil no contexto industrial. É importante ressaltar que a quantificação da tenacidade à fratura mediana bem como a descrição estatística associada à dispersão dos dados de $K_{J_{c}}$ fica condicionada à uma janela de validade (conforme destacada na Figura 4.18), a qual é limitada pelo limite de deformação (i.e., pela curva $K_{J_{c}(\text { limite })}$ ) e pela faixa de temperatura (i.e., pela variação $T_{0} \pm 50^{\circ} \mathrm{C}$ ) onde a $T_{0}$ ainda mantém uma boa acurácia nas previsões das estimativas medianas da tenacidade à fratura frágil por clivagem. 
Em decorrência de possíveis incertezas associadas ao uso de poucos corpos de prova e de fatores experimentais (e.g., variações de temperatura ao longo do ensaio acima de $\pm 2{ }^{\circ} \mathrm{C}$ ) e variações metalúrgicas (e.g., linhas de segregação, vide estudo conduzido por Viehrig et al.[22]), a norma E1921[5] estabelece um procedimento de ajuste sobre a $T_{0}$. Esse procedimento consiste em adicionar uma variação ascendente sobre a $T_{0}$ a fim de assegurar uma estimativa menos conservadora. Para tal, a norma estabelece uma expressão para o desvio padrão associado à estimativa da $T_{0}$ que leva em consideração o tamanho da amostra e as incertezas experimentais, conforme a seguinte expressão

$$
\sigma\left(T_{0}\right)=\sqrt{\frac{\beta}{r}+\sigma_{e x p}^{2}}
$$

onde $\beta$ é o fator de incerteza associado ao tamanho da amostra, $\mathrm{r}$ o número total de dados não censurados usados para estimar a $T_{0}$ e $\sigma_{\text {exp }}$ o fator de contribuição das incertezas experimentais. Caso as práticas padronizadas de calibração sejam seguidas rigorosamente, pode-se adotar $\sigma_{\text {exp }}=4^{\circ} \mathrm{C}$. Já o valor do fator $\beta$ é dado em função da tenacidade à fratura mediana equivalente, cujo valor contabiliza as contribuições das diversas temperaturas usadas na estimativa da $T_{0}$, conforme a seguinte expressão

$$
K_{J_{c}(\text { med })}^{e q}=\left\{\frac{1}{\mathrm{r}} \sum_{i=1}^{\mathrm{r}} 30+70 e^{\left[0,019\left(T_{i}-T_{0}\right)\right]}\right\} \quad \mathrm{MPa} \sqrt{\mathrm{m}}
$$

Para valores de $K_{J_{c} \text { (med) }}^{e q}$ iguais ou superiores a $83 \mathrm{MPa} \sqrt{\mathrm{m}}$, adota-se $\beta=18^{\circ} \mathrm{C}$. Já para valores de $K_{J_{c}(\text { med })}^{e q}$ inferiores a $83 \mathrm{MPa} \sqrt{\mathrm{m}}$, adota-se o seguinte critério de seleção apresentado na Tabela 4.5 a seguir.

Tabela 4.5 - Critério para escolha do fator de incerteza

\begin{tabular}{cc}
\hline $\begin{array}{c}K_{J_{c}(\text { med })}^{\text {eq }} \text { referente a } 1 \mathrm{~T} \\
(\mathrm{MPa} \sqrt{\mathrm{m}})\end{array}$ & $\beta\left({ }^{\circ} \mathrm{C}\right)$ \\
\hline 83 a 66 & 18,8 \\
66 a 58 & 20,1 \\
\hline
\end{tabular}


Ainda em relação à distribuição triparamétrica de Weibull, é importante salientar que a mediana se relaciona com o parâmetro de escala por meio da seguinte expressão

$$
K_{0}=\frac{\left[K_{J_{c}(m e d)}-20\right]}{[\ln (2)]^{\frac{1}{4}}}+20 \quad \mathrm{MPa} \sqrt{\mathrm{m}}
$$

A Eq. (4.31) é facilmente obtida a partir do simples isolamento do termo $K_{0}$ contido na Eq. (4.26b). Sabe-se também que a mediana da distribuição triparamétrica de Weibull $(\alpha, \beta, \gamma)$ relaciona-se com o parâmetro de escala $(\beta)$ por meio da seguinte Equação

$$
\text { mediana }=\beta\left\{[\ln (2)]^{\frac{1}{\alpha}}\right\}
$$

onde $\alpha, \beta, \gamma$ representam, nessa ordem, os parâmetros de forma, escala e posição [65], enquanto a correlação entre a média e $\beta$ é dada por

$$
\text { média }=\beta \Gamma\left(1+\frac{1}{\alpha}\right)
$$

onde $\Gamma$ representa a função gama [65]. Para o caso particular em que $\alpha=4$, tem-se que $K_{J_{c} \text { (médio) }}=K_{0} \Gamma(1,25)=0,9064 K_{0}$. Relacionando as Eqs. (4.32a) e (4.32b), é possível estabelecer a seguinte relação entre a média e a mediana,

$$
\text { mediana }=\text { média } \frac{[\ln (2)]^{\frac{1}{4}}}{\Gamma(1,25)}=1,0067 \text { média }
$$

o que demonstra que a média é muito próxima à mediana na distribuição triparamétrica de Weibull. Já a variância $\operatorname{VAR}\left(K_{J c}\right)$ dada pela Eq. (4.33a) e, consequentemente, o desvio padrão $\sigma\left(K_{J c}\right)$, é uma função matemática da média cuja relação é expressa por

$$
\operatorname{VAR}\left(K_{J c}\right)=K_{0}{ }^{2}\left\{\Gamma\left(1+\frac{2}{\alpha}\right)-\left[\Gamma\left(1+\frac{1}{\alpha}\right)\right]^{2}\right\}
$$


de forma que, a partir da manipulação da Eq. (4.32a), tal correlação com a média fica demonstrada por

$$
\begin{gathered}
\operatorname{VAR}\left(K_{J C}\right)=K_{0}{ }^{2}\left\{\Gamma\left(1+\frac{2}{\alpha}\right)-\left[\Gamma\left(1+\frac{1}{\alpha}\right)\right]^{2}\right\}=\left\{K_{0}{ }^{2} \Gamma\left(1+\frac{2}{\alpha}\right)-K_{0}{ }^{2}\left[\Gamma\left(1+\frac{1}{\alpha}\right)\right]^{2}\right\} \\
\operatorname{VAR}\left(K_{J C}\right)=\left\{K_{0}{ }^{2} \Gamma\left(1+\frac{2}{\alpha}\right)-\left[K_{0} \Gamma\left(1+\frac{1}{\alpha}\right)\right]^{2}\right\}=\left\{K_{0}{ }^{2} \Gamma\left(1+\frac{2}{\alpha}\right)-\left[\text { média }\left(K_{J c}\right)\right]^{2}\right\} \\
\sigma\left(K_{J C}\right)^{2}=\left\{K_{0}{ }^{2} \Gamma\left(1+\frac{2}{\alpha}\right)-\left[\text { média }\left(K_{J C}\right)\right]^{2}\right\}
\end{gathered}
$$

Fazendo a substituição de $\alpha=4$ na Eq. (4.33a) e a devida manipulação, o desvio padrão associado aos dados de tenacidade, $\sigma\left(K_{J_{c}}\right)$, é dado por

$$
\begin{gathered}
\operatorname{VAR}\left(K_{J_{c}}\right)=K_{0}^{2}\left\{\Gamma\left(1+\frac{2}{4}\right)-\left[\Gamma\left(1+\frac{1}{4}\right)\right]^{2}\right\}= \\
\sigma\left(K_{J_{c}}\right)=\left\{\frac{\left[K_{J c(\text { med })}-20\right]}{[\ln (2)]^{\frac{1}{4}}}+20\right\}\left\{\Gamma(1,5)-[\Gamma(1,25)]^{2}\right\}^{1 / 2}= \\
\sigma\left(K_{J_{c}}\right)=\left\{\frac{\left[K_{J c(\text { med })}-20\right]}{\left.[\ln (2)]^{\frac{1}{4}}+20\right\} 0,2543=\left\{\frac{\left[K_{J c(\text { med })}-20\right]+20[\ln (2)]^{\frac{1}{4}}}{[\ln (2)]^{\frac{1}{4}}}\right\} 0,2543=}\right. \\
\sigma\left(K_{J_{c}}\right)=0,2787\left\{K_{J c(\text { med })}-20+20[\ln (2)]^{\frac{1}{4}}\right\}
\end{gathered}
$$

Observa-se que o desvio padrão dos dados de $K_{J_{c}}$ tende a apresentar uma magnitude relativamente alta em virtude da elevada dispersão tipicamente encontrada nos dados de tenacidade à fratura frágil por clivagem medidos na RTDF de aços estruturais ferríticos.

No capítulo a seguir são apresentados e discutidos todos os resultados referentes à caracterização mecânica e das propriedades de tenacidade à fratura avaliadas na RTDF do material utilizado neste estudo 


\section{$5 \quad$ Resultados e Discussões}

Neste capítulo são abordados os resultados obtidos a partir dos ensaios de tenacidade ao entalhe $\mathrm{V}$ por impacto Charpy $\left(E_{C V N}\right)$ e de tenacidade à fratura no ponto de instabilidade, expressa em termos da integral $J\left(J_{c}\right)$, do aço martensítico USI AR450 de alta resistência mecânica. Ênfase especial é dada à discussão dos resultados de $J_{C}$ e dos seus correspondentes valores expressos em termos do fator elasto-plástico de intensidade de tensão $K_{J_{c}}$ (i.e., medidas de tenacidade em unidades de $\mathrm{MPa} \sqrt{ } \mathrm{m}$ ), os quais são analisados à luz da abordagem da Curva Mestra (CM) com o intuito de se avaliar a aplicabilidade dessa metodologia em um aço de microestrutura essencialmente martensítica. Como avaliação complementar, é feita uma breve discussão das análises metalográficas e das propriedades de resistência mecânica.

\subsection{Composição Química}

O material utilizado neste estudo consiste em um aço martensítico USI AR450 de elevada resistência à abrasão e alta resistência mecânica. Esse aço é termicamente tratado pela empresa Usiminas e cuja composição química, obtida por espectrometria de emissão óptica conforme norma ASTM E415-17[66], é apresentada na Tabela 5.1. Observa-se que a composição química do aço USI AR 450 é semelhante à composição nominal do Hardox® 450 apresentada na Tabela 5.2, sendo esse aço também caracterizado por apresentar uma alta resistência à abrasão e uma dureza nominal de $450 \mathrm{HBW}^{5}$ (tal comparação é feita pois em tese o USI AR450 teria as mesmas aplicações que o Hardox $\left.{ }^{\circledR} 450\right)$. É importante salientar que, embora os teores percentuais apresentados pelo USI AR450 respeitem os teores máximos permitidos para cada elemento de liga no Hardox ${ }^{\circledR}$ 450, há algumas diferenças de composição química, o que confere ao aço USI AR450 sua composição particular conforme análise das Tabelas 5.1 e 5.2.

Tabela 5.1 - Composição química do aço USI AR450 (\% em massa).

\begin{tabular}{ccccccccccc}
\hline USI AR450 & C & Mn & P & S & Cr & Mo & V & Ni & Si & Cu \\
\hline Medido & 0,22 & 1,38 & 0,016 & 0,003 & 0,24 & 0,00 & 0,003 & 0,02 & 0,34 & 0,01 \\
\hline
\end{tabular}

${ }^{5} \mathrm{HBW}$ sigla que representa a dureza $(\mathrm{H})$ medida na escala Brinell (B) por meio de um penetrador fabricado com carboneto tungstênio (W) 
Além dos elementos de liga apresentados na Tabela 5.1, o aço USI AR450 apresenta os seguintes elementos químicos: Al (0,029-0,037), Nb (0,029-0,028), Ti (0,035-0,031), Sn (0,001), N (0,0041-0,0040), B (0,0010), Ca (0,0008-0,0004), Pb (0,001-0,004), todos estimados em termos percentuais em massa e estão apresentados em faixa, pois foram utilizadas duas corridas, o qual apresentam composições minimamente distintas.

Tabela 5.2 - Composição química do aço Hardox® 450 em critérios de máxima composição permitida (\% em massa) [67].

\begin{tabular}{cccccccccc}
\hline Hardox®450 & C & Mn & Si & P & S & Cr & Ni & Mo & B \\
\hline Nominal & 0,23 & 1,60 & 0,5 & 0,025 & 0,010 & 1,20 & 0,25 & 0,25 & 0,005
\end{tabular}

\subsection{Análise Microestrutural}

A microestrutura do aço AR450 é representada em ampliações distintas e subdivididas em faces de acordo com a norma ASTM E3[56]. As amostras são embutidas em resina a quente de acordo com o procedimento apresentado na Figura 5.1, onde as orientações L (longitudinal), T (transversal), N (normal) são dadas em relação ao sentido de laminação como representado na Figura5.1. 
Figura 5.1 - Procedimento de preparo das amostras em baquelite com destaque para as três orientações em relação ao sentido de laminação da chapa.

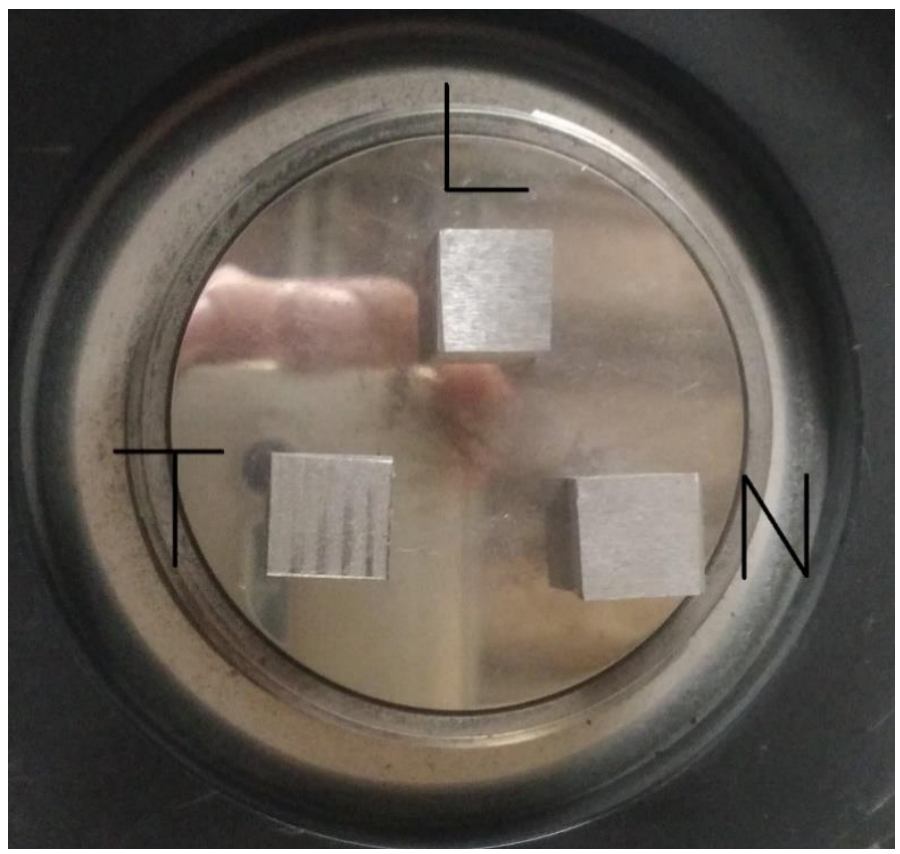

As micrografias revelam uma microestrutura constituída essencialmente de ripas de martensita (conforme morfologia em placas longas e finas). A formação dos grãos de martensita em ripas deve-se ao baixo teor de carbono (0,22\% conforme Tabela 5.1), pois tal morfologia se dá preferencialmente em ligas que contêm teores de C inferiores a 0,6\% [68]. A microestrutura apresentada pacotes de ripas e não se pode identificar os contornos de grãos, de acordo com o sentido de laminação. A microestrutura avaliada na direção longitudinal de laminação (i.e., na superfície paralela à direção de laminação) é demonstrada pela Figura 5.2, onde todas as fotomicrografias são obtidas na parte central da superfície identificada como L, conforme demonstrado na Seção 4.2. As micrografias apresentadas na Figura 5.3 são retiradas da seção transversal ao sentido de laminação, identificado como T na Seção 4.2. Já a Figura 5.4 apresenta as micrografias no sentido normal ao sentido de laminação, identificado como $\mathrm{N}$ na Seção 4.2.

Embora pouco evidenciada , a microestrutura pode ou não ser constituída de bainita e conter austenita não transformada (austenita retida), porém a austenita retida é mais frequente em aços de alto carbono [68], assim não se pode afirmar que o aço em estudo apresente tais microestruturas, devido a seu baixo teor de carbono. Em virtude dos detalhes/aspectos microestruturais serem relativamente muito finos, para uma melhor distinção e identificação das fases, morfologias e microconstituintes presentes em uma microestruturas martensítica, fazse necessário o uso de microscópio eletrônico de varredura (MEV) para uma melhor caracterização microestrutural [30]. Todavia, é importante ressaltar que uma caracterização 
microestrutural mais refinada não constitui o cerne do trabalho, pois o intuito é apenas demonstrar as características essenciais da microestrutura martensítica para evidenciar a sua distinção da microestrutura ferrítica-perlítica que compõe as bases fenomenológicas da metodologia da Curva Mestra.

Figura 5.2 - Microestruturas do aço USI AR450 no sentido longitudinal a laminação, sob ampliações de (a) 100x; (b) 200x; (c) 500x; (d) 1000x

(a)

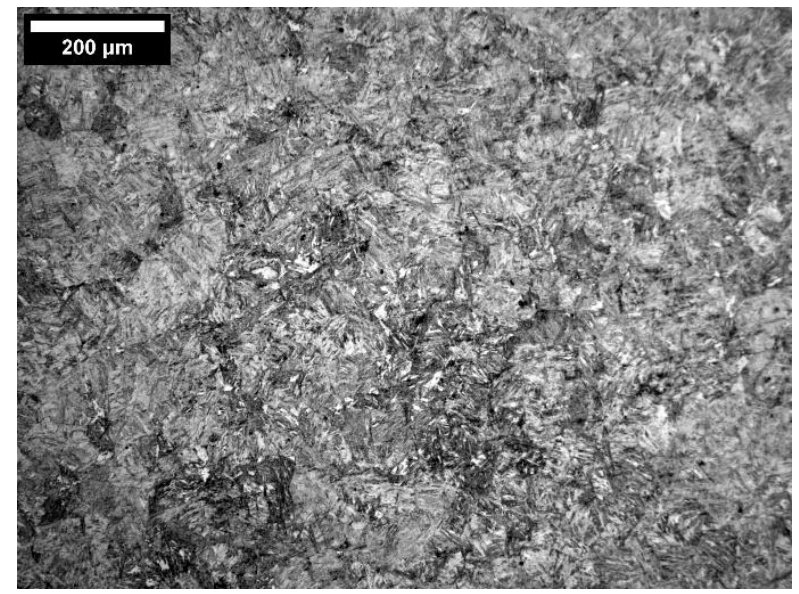

(c)

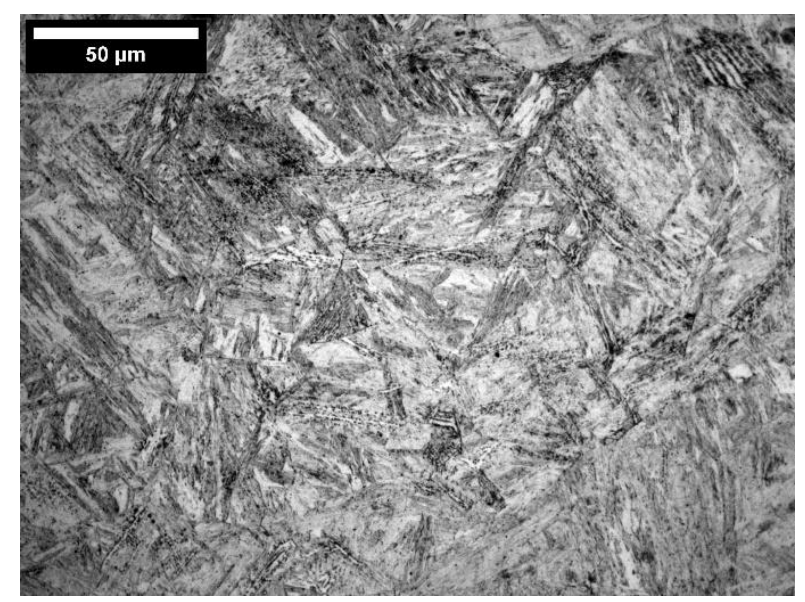

(b)

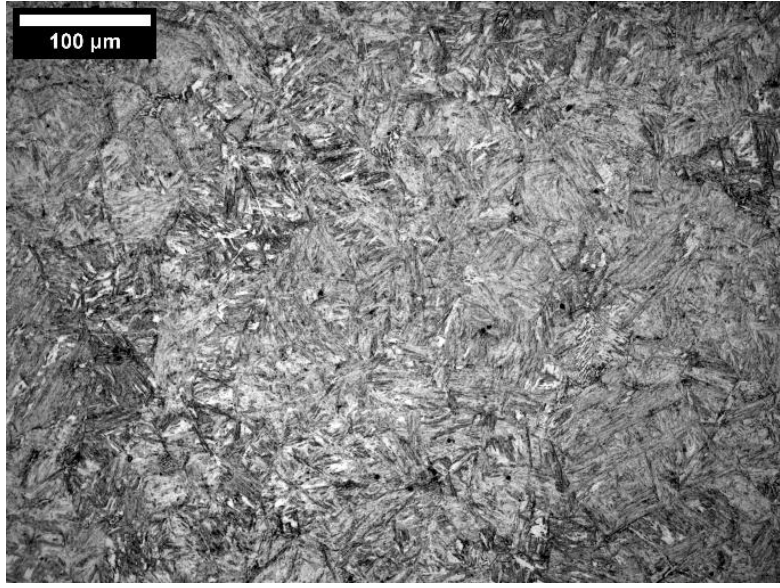

(d)

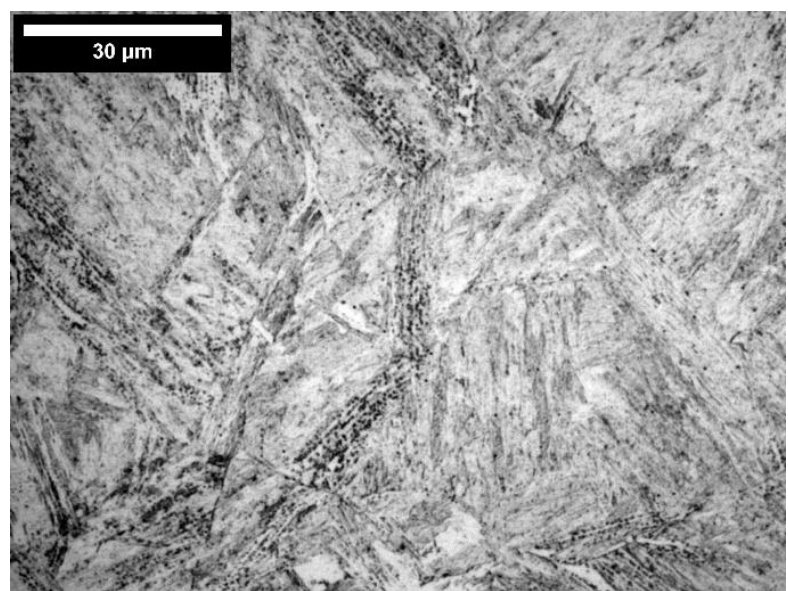


Figura 5.3 - Microestrutura do aço USI AR450 no sentido transversal a laminação, sob ampliações de (a) 100x; (b) 200x; (c) 500x; (d) 1000x

(a)

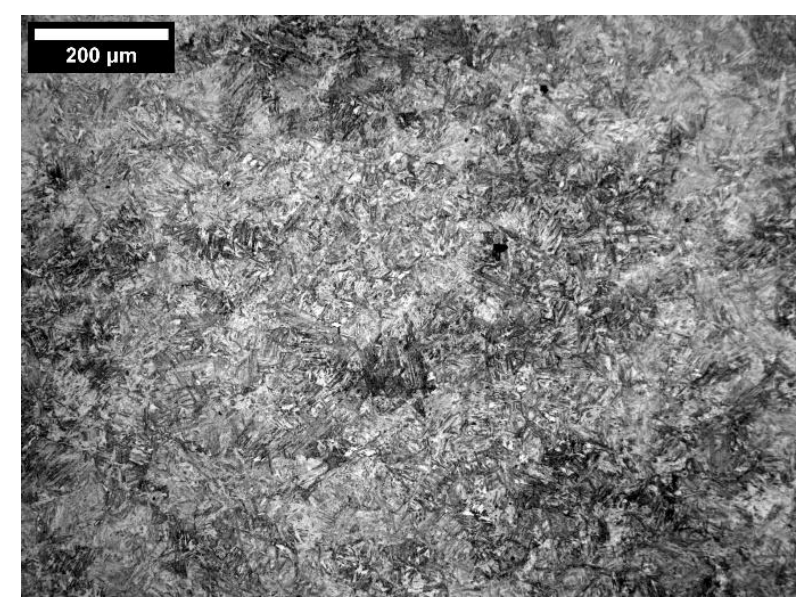

(c)

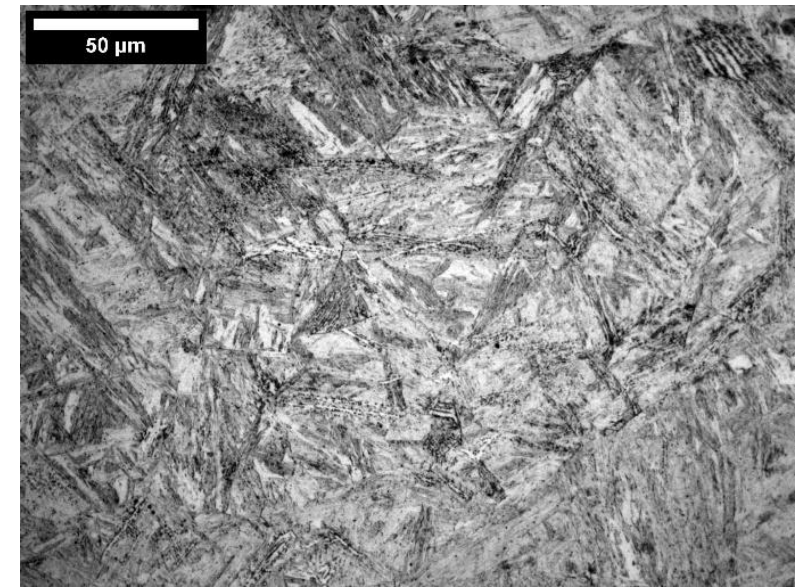

(b)

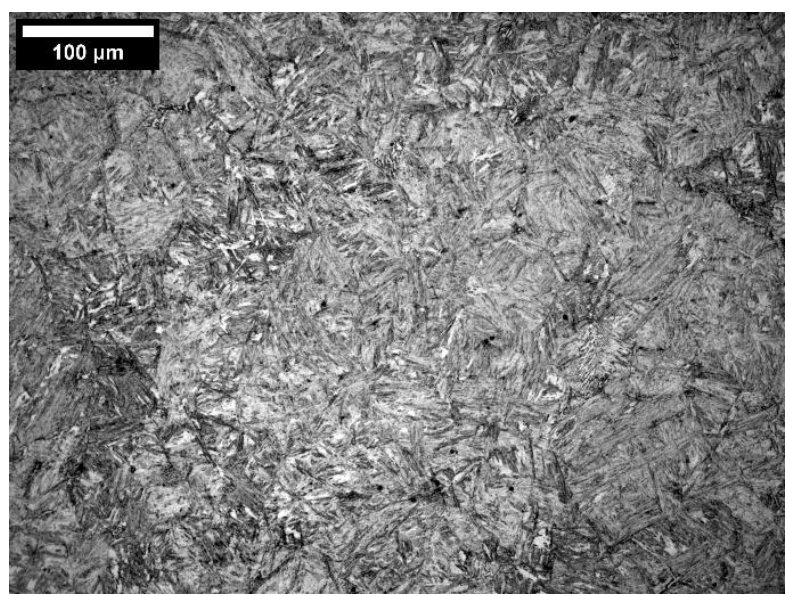

(d)

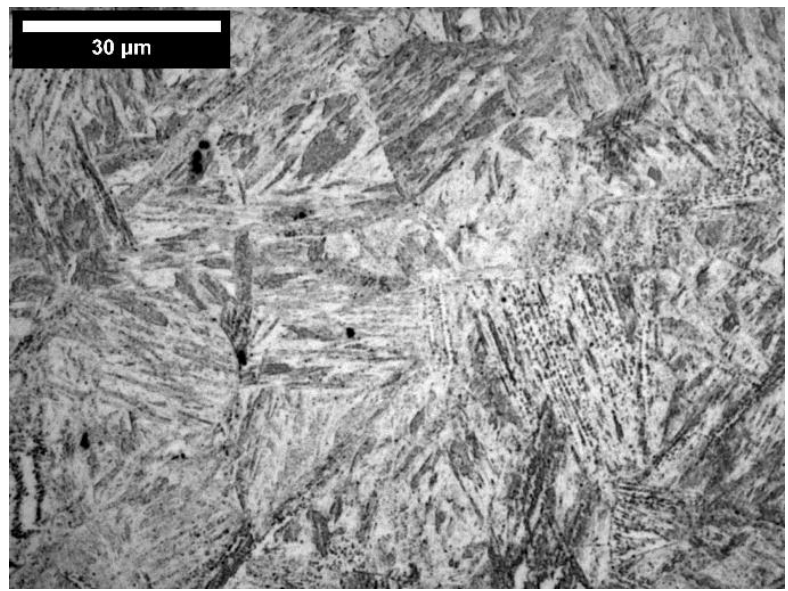

Figura 5.4 - Microestrutura do aço USI AR450 no sentido normal a laminação, sob ampliações de (a) 100x; (b) 200x; (c) 500x; (d) 1000x

(a)

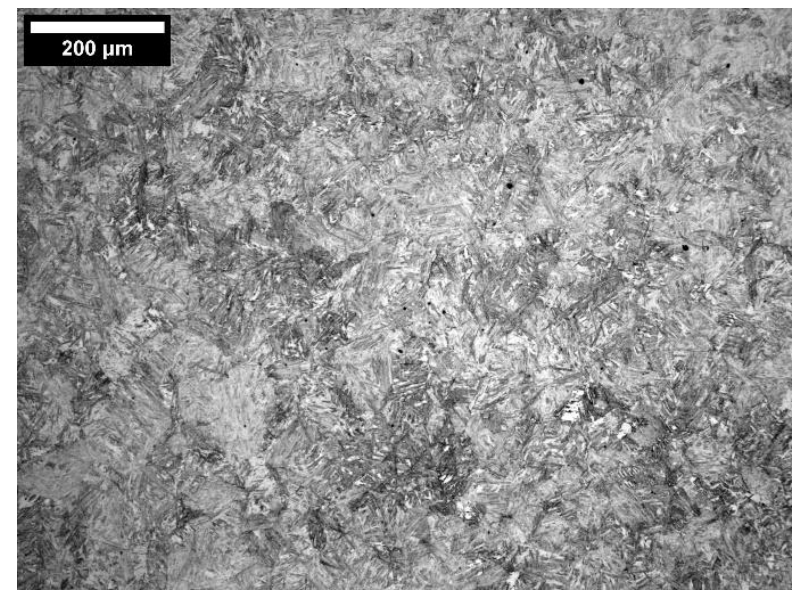

(b)

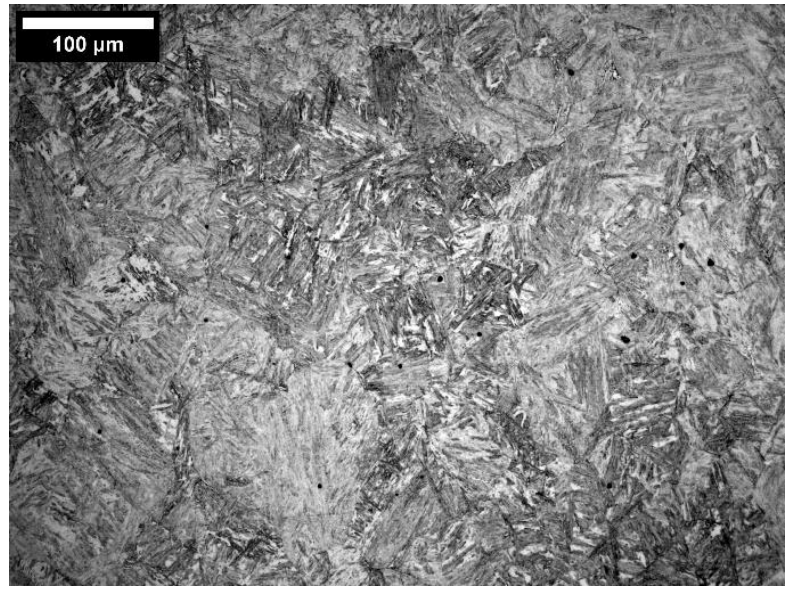


(c)

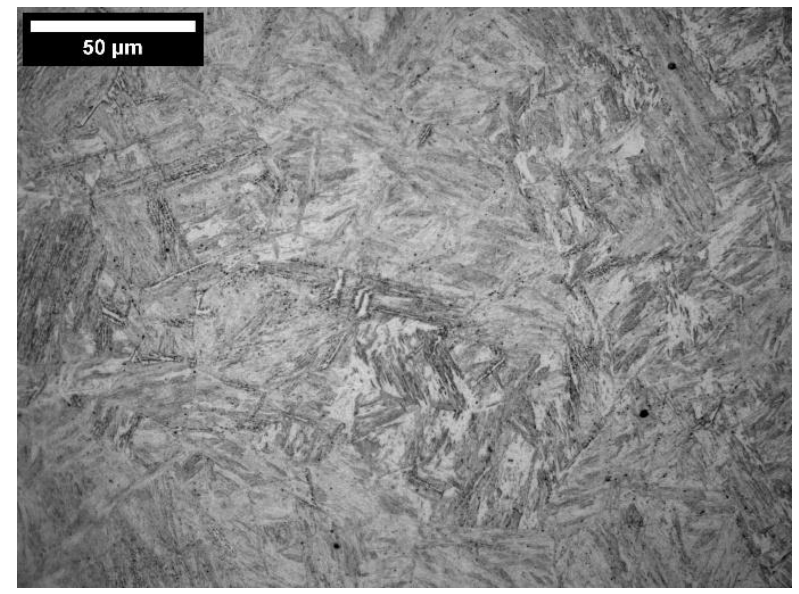

(d)

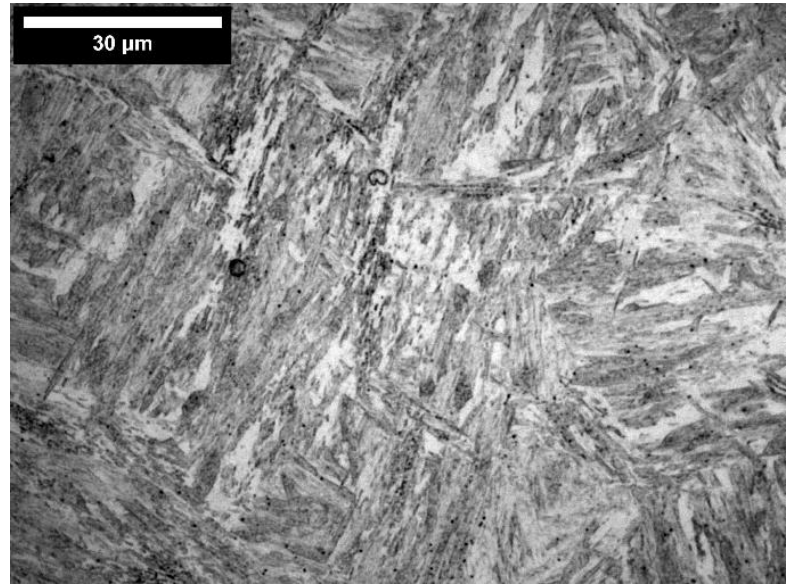

Além das considerações supracitadas, a importância das micrografias é demonstrar uma possível anisotropia presente no material em virtude do processo de laminação. No entanto, a visualização do sentido dos grãos em tais micrografias não é muito perceptível por justamente se tratar de um aço temperado. Quando se trata de um material de microestrutura martensítica/bainítica, a diversidade de sentido das agulhas apresentadas pelos pacotes de ripa demonstra a severidade da formação da microestrutura, que também apresenta muitas inclusões (indicadas pelos pontos mais escuros e circulares nas micrografias) as quais ficam mais evidentes antes do ataque, conforme demonstrados na Figura 5.5.

Figura 5.5 - Microestrutura do aço USI AR450 antes do ataque, sob ampliações de (a) 50x normal; (b) 50x transversal; (c) 50x longitudinal

(a)

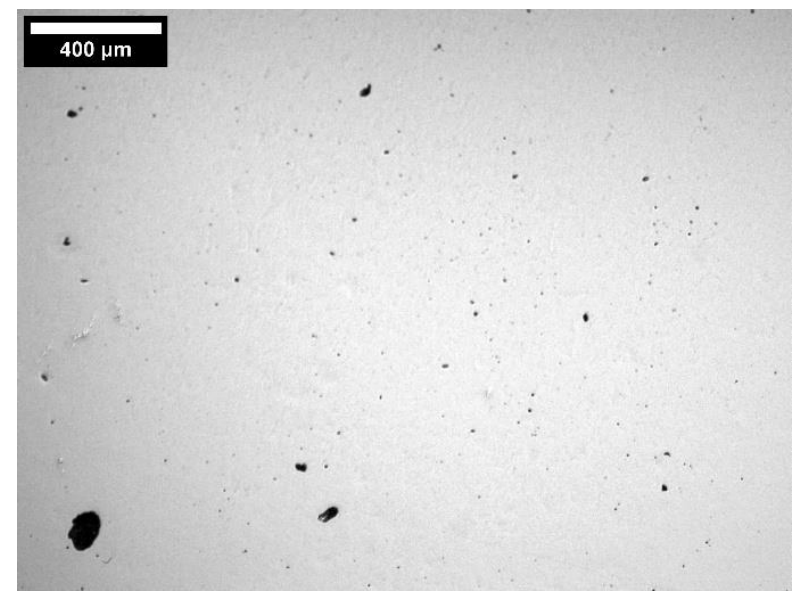

(b)

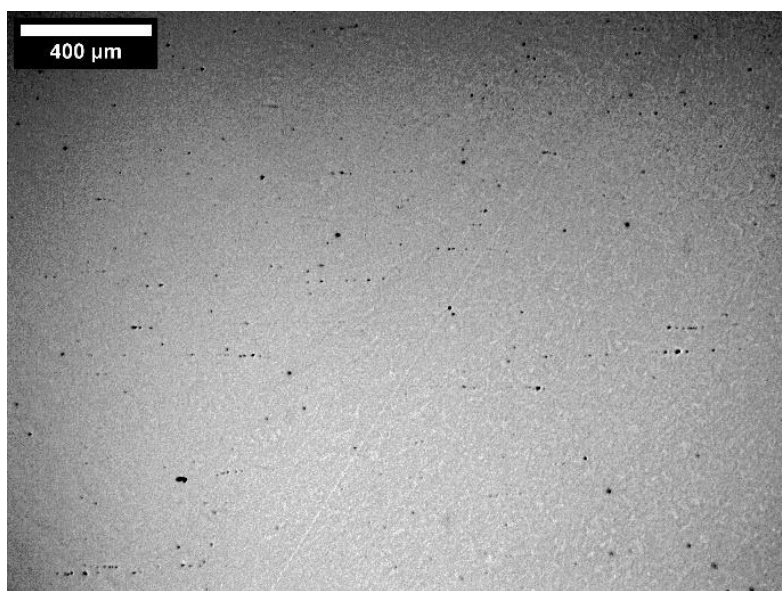




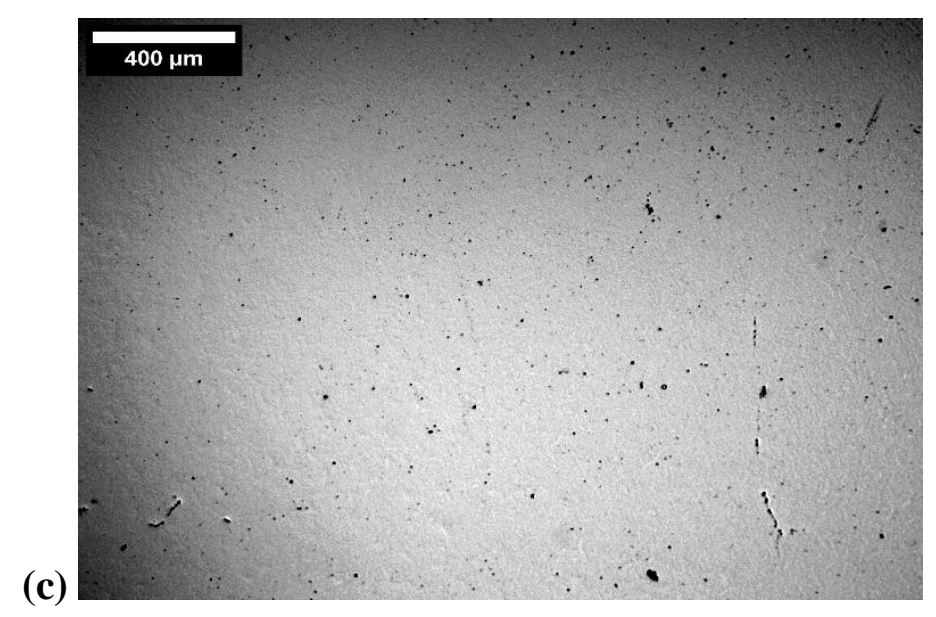

\subsection{Análise das Propriedades Mecânicas de Tração}

Esta seção apresenta os resultados e procedimentos abordados para avaliar as principais propriedades mecânicas obtidas nos ensaios de tração em temperatura ambiente $\left(\sim 25^{\circ} \mathrm{C}\right)$. Conforme procedimento descrito na Seção 4.4, são conduzidos 3 ensaios de tração para avaliar as propriedades mecânicas do aço USI AR450. As normas e procedimentos utilizados para analisar os resultados experimentais estão detalhados na Seção 4.4. As curvas tensão vs. deformação de engenharia ( $\sigma$ vs. $\varepsilon$ ) são obtidas a temperatura ambiente ( $\mathrm{T}=25{ }^{\circ} \mathrm{C}$ ) e estão representadas na Figura 5.6. 
Figura 5.6 - Curva $\sigma$ vs. $\varepsilon$ obtida a temperatura ambiente.

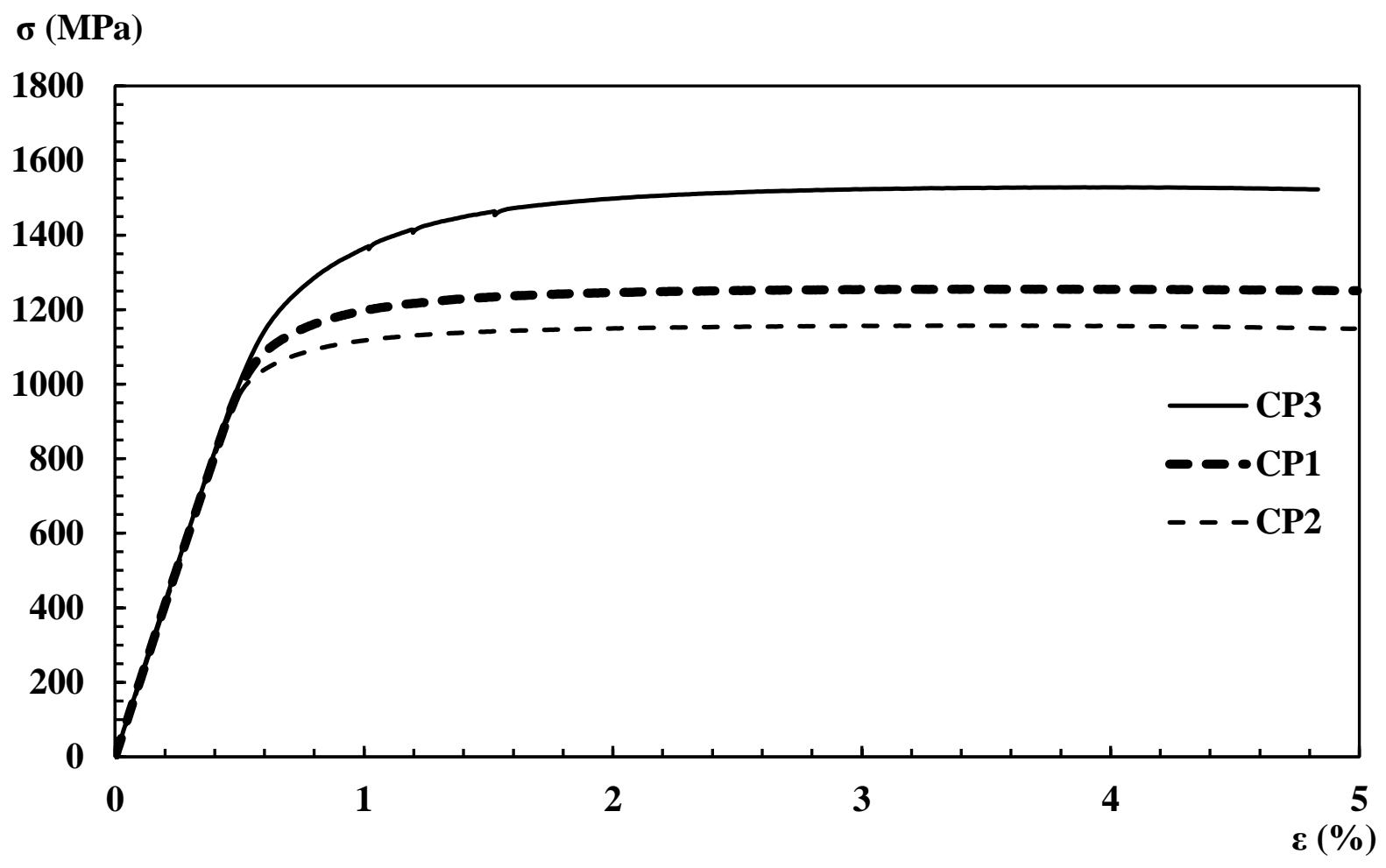

Pela análise da Figura 5.6, observa-se que, apesar de as curvas apresentarem uma dispersão relativamente grande em virtude do corpo de prova 3 (сp3), o comportamento da curva $\sigma$ vs. $\varepsilon$ é preservado, o que evidencia a baixa capacidade de encruamento do material. Observa-se também que os níveis de resistência à tração medidos a temperatura ambiente são superiores a $1100 \mathrm{MPa},\left(\sigma_{u t s}^{R T}>1100 \mathrm{MPa}\right)$, o que demonstra sua ultra-alta resistência mecânica. De modo geral, as curvas $\sigma$ vs. $\varepsilon$ não apresentam um patamar de escoamento bem definido, pois a transição entre o regime elástico e plástico se dá praticamente com a ausência das bandas de Lüders. Neste caso, o limite de escoamento $\sigma_{y s}^{R T}$ é definido por meio de uma reta tangente que intercepta a curva $\sigma$ vs. $\varepsilon$ a partir de um deslocamento (também denominado de offset) de $0,2 \%$ para os corpos de prova cp01 e cp02, enquanto para o cp03 é adotado um offset de $0,5 \%$.

Já na Figura 5.7 (a) estão representadas as curvas tensão vs. deformação verdadeira ( $\tilde{\sigma}$ vs. $\tilde{\varepsilon}$ ) obtidas a partir daquelas demonstradas anteriormente na Figura 5.6. Observa-se que as curvas $\tilde{\sigma}$ vs. $\tilde{\varepsilon}$ são definidas até o máximo valor de $\varepsilon$ com alongamento uniforme (i.e., na deformação onde $\sigma=\sigma_{u t s}^{R T}$, a qual é comumente designada por $\varepsilon_{u}$ ou $\varepsilon_{t}$ ). Assim, a partir da análise das curvas da Figura 5.7 (a) é observado que o corpo de prova 3 tem uma ligeira diferença entre o 
comportamento apresentado pelos outros corpos de prova, isso pode ser evidenciado na Figura 5.7 (b) que apresenta pequenas descontinuidades em sua curva.

A partir do trecho definido entre o ponto de escoamento e o limite de resistência à tração das curvas $\tilde{\sigma}$ vs. $\tilde{\varepsilon}$, é possível estimar os coeficientes de encruamento a partir de uma simples regressão linear na escala logarítmica dos valores de $\tilde{\sigma}$ vs. $\tilde{\varepsilon}$ compreendidos nesse trecho, conforme regressões apresentadas na Figura 5.8.

Figura 5.7 - (a)-Curva $\tilde{\sigma}$ vs. $\tilde{\varepsilon}$ obtida a temperatura ambiente, método offset $0,2 \%$ para determinação da tensão de escoamento; (b) Região de mudança de regime linear elástico para o plástico.

$$
\tilde{\sigma}(\mathbf{M P a})
$$

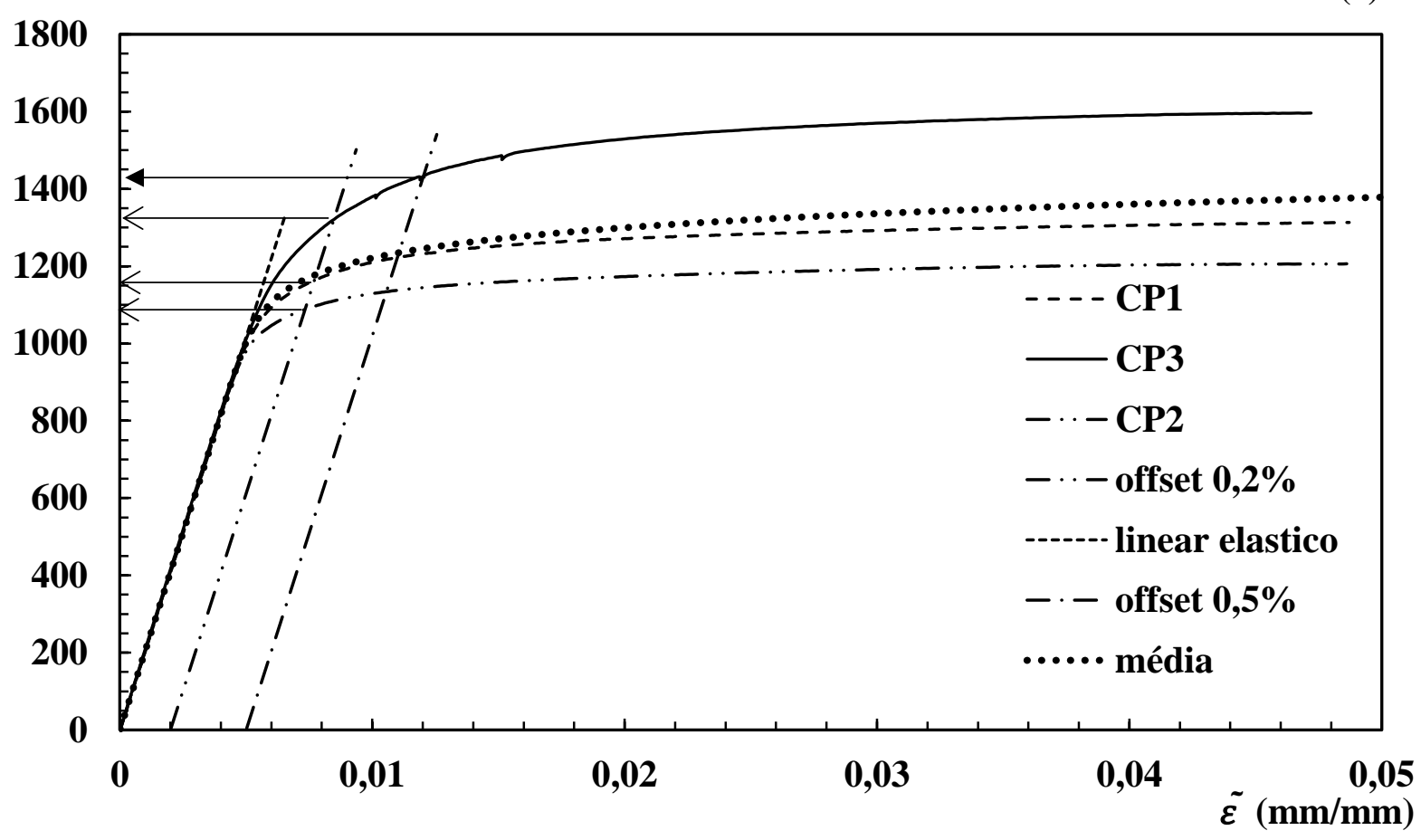




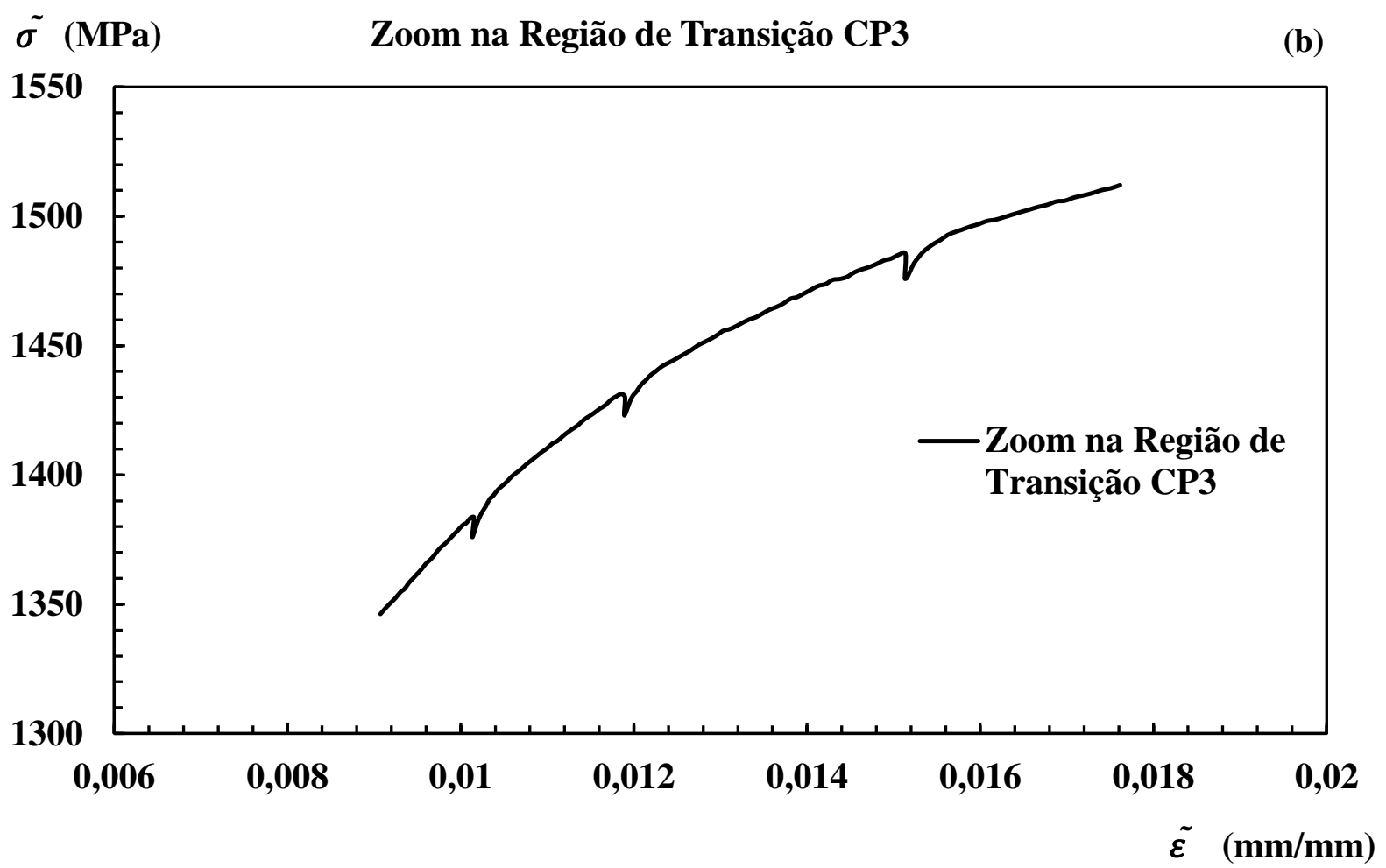

Figura 5.8 - (a) Curva $\tilde{\sigma}$ vs. $\tilde{\varepsilon}$ acima da tensão de escoamento em log-log obtida a temperatura ambiente (offset de 0,5\% para CP3); (b) Curva Tensão vs. Deformação real acima da tensão de escoamento em log-log obtida a temperatura ambiente (offset de 0,2\% para CP3)

(a)

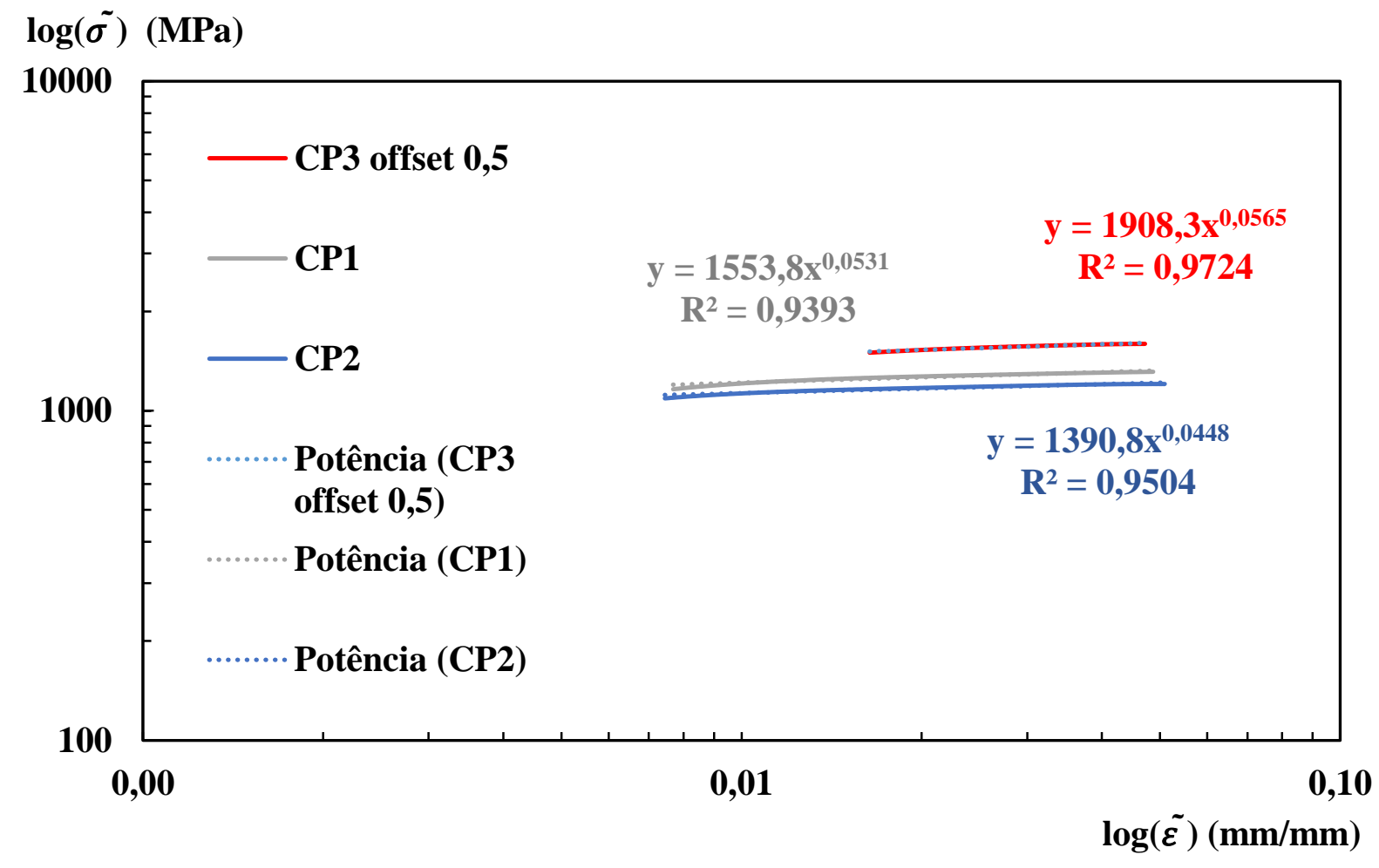


(b)

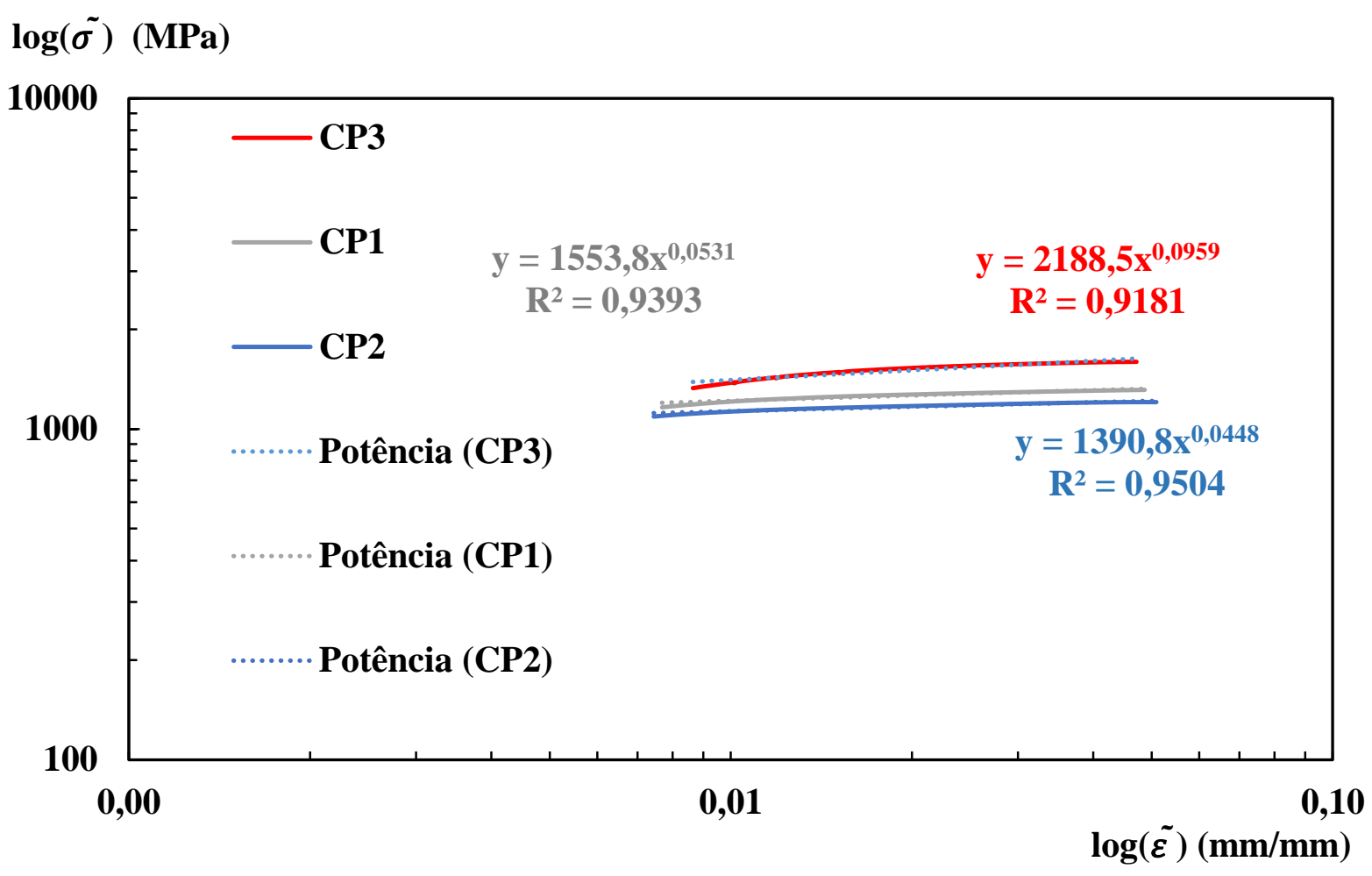

Com base na análise da Figura 5.8 (b), nota-se que, à exceção do corpo de prova CP03, o comportamento do $\log (\tilde{\sigma})$ vs $\log (\tilde{\varepsilon})$ segue uma relação linear em toda o regime elasto-plástico, o que evidencia um bom ajuste da relação $\tilde{\sigma}$ vs. $\tilde{\varepsilon}$ por uma lei de potência dada a ausência das bandas de Lüders (i.e., ausência de um patamar de escoamento bem definido). Devido ao comportamento do corpo de prova CP3 não ter uma boa aderência utilizando offset igual a $0,2 \%$, é utilizado offset igual a $0,5 \%$, proporcionando uma melhor aderência conforme demonstrado pelos valores de $R^{2}$ iguais a 0,97 (para 0,5\%) e 0,91 (para 0,2\%) indicados, respectivamente, nas Figuras 5.8 (a) e Figura 5.8 (b). O uso de um offset de 0,5\% também melhora a aderência da curva numérica (curva gerada pelo modelo de Ramberg-Osgood) à curva experimental $\tilde{\sigma}$ vs. $\tilde{\varepsilon}$, conforme evidenciados pelas Figuras 5.9 (c) e Figura 5.9 (d). O coeficiente de resistência $H$ e o expoente de encruamento $n$ determinados tanto pela regressão linear da relação $\log (\tilde{\sigma})$ vs $\log (\tilde{\varepsilon})$ são apresentados na Tabela 5.3. 
Tabela 5.3 - Propriedades mecânicas do aço USI AR450

\begin{tabular}{|c|c|c|c|c|c|c|c|c|c|}
\hline $\begin{array}{c}\text { cdp }^{*} \text { offse } \\
t\end{array}$ & $\sigma_{y s}$ & $\sigma_{u t s}$ & $\frac{\sigma_{y s}}{\sigma_{u t s}}$ & $\begin{array}{c}n \\
\text { regressão }\end{array}$ & $\begin{array}{c}n \\
\text { API579 }\end{array}$ & $\begin{array}{c}H \\
\text { regressão }\end{array}$ & $\begin{array}{c}H \\
\text { API579 }\end{array}$ & $\begin{array}{c}1 / n \\
\text { regressão }\end{array}$ & $\begin{array}{c}\text { API579 } \\
1 / n\end{array}$ \\
\hline- & (MP) & (MPa) & - & - & & - & & - & \\
\hline $1^{* 0,2}$ & 1162 & 1313 & 0,88 & 0,053 & 0,053 & 1553,8 & 1619,1 & 18,8 & 18,7 \\
\hline $2^{* 0,2}$ & 1090 & 1206 & 0,90 & 0,044 & 0,046 & 1390,8 & 1459,0 & 22,3 & 21,3 \\
\hline $3^{* 0,5}$ & 1435 & 1596 & 0,83 & 0,056 & 0,048 & 1908,3 & 1940,2 & 17,6 & 20,6 \\
\hline $\begin{array}{c}\text { Média } \\
\text { (cdp 1, } \\
2,3 \text { ) }\end{array}$ & 1229 & 1371 & 0,89 & 0,051 & 0,049 & 1617,6 & 1672,9 & 19,6 & 20,1 \\
\hline
\end{tabular}

Para uma análise comparativa com o expoente de encruamento determinado via regressão linear do regime elasto-plastico (vide Dowling [57]), na Tabela 5.3 também é apresentado o valor do expoente de encruamento obtido segundo o procedimento da API 579 [52], o qual é recomendado para aços ferríticos, porém é possível notar que ambos os termos estão muito próximos entre si, demonstrando que pode ser sim aplicado a aços martensíticos. Deve-se ressaltar que o valor de $n$ obtido via regressão linear corresponde ao inverso do valor dado pelo expoente do modelo de Ramberg e Osgood [14]. Dessa forma os valores de $n$ referentes ao método da regressão linear (vide Tabela 5.3) nada mais são do que os valores inversos dos coeficientes reportados pelas equações de potência apresentadas nos gráficos da Figura 5.8. Com base nos valores reportados de $n$, observa-se o aço USI AR 450 apresenta uma baixa capacidade de encruamento, o que também pode ser evidenciado pela relação $\sigma_{y s} / \sigma_{u t s} \sim 0,9$. A partir dos valores de $n$ é possível demonstrar que o modelo de $\mathrm{R} \& \mathrm{O}$ descreve com boa acurácia o comportamento da curva $\tilde{\sigma}$ vs. $\tilde{\varepsilon}$, dado que o modelo de $\mathrm{R} \& \mathrm{O}$ é mais preciso para curvas $\sigma$ vs. $\varepsilon$ isentas de bandas de Lüders, conforme curvas numéricas apresentadas na Figura 5.9. Uma curva média obtida a partir do valor médio de $n$ é demonstrada na Figura 5.9(e). 
Figura 5.9 - Curvas Tensão deformação, numérica e experimental ((a), (b), (c) e (d)) e comparação da curva média numérica e experimental (e).

(a)

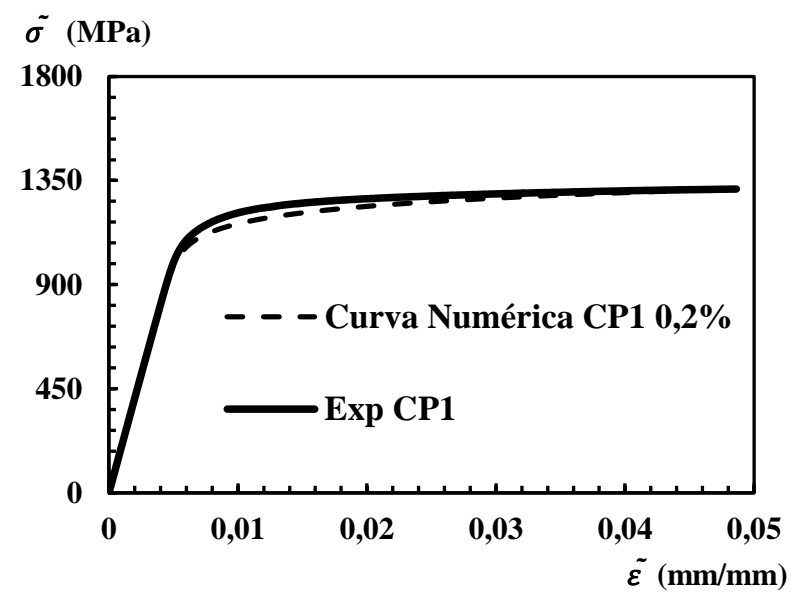

(c)

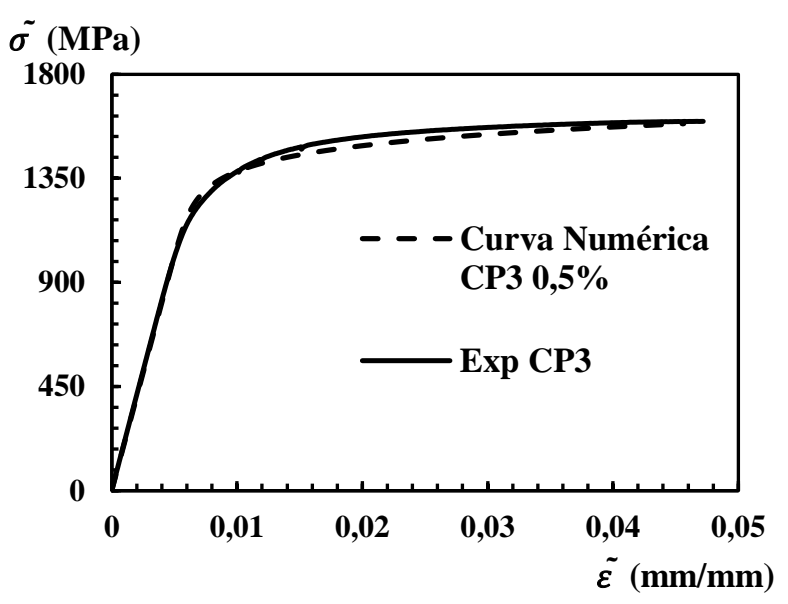

(b)

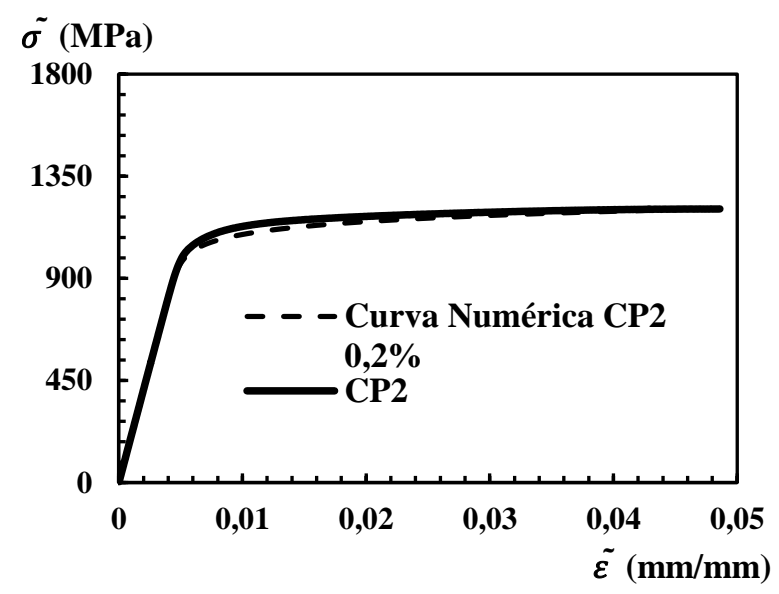

(d)

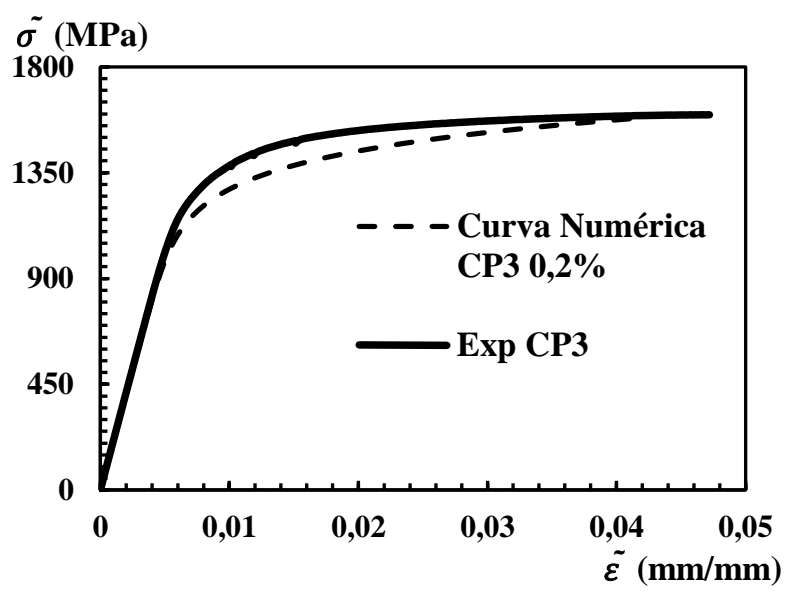

(e)

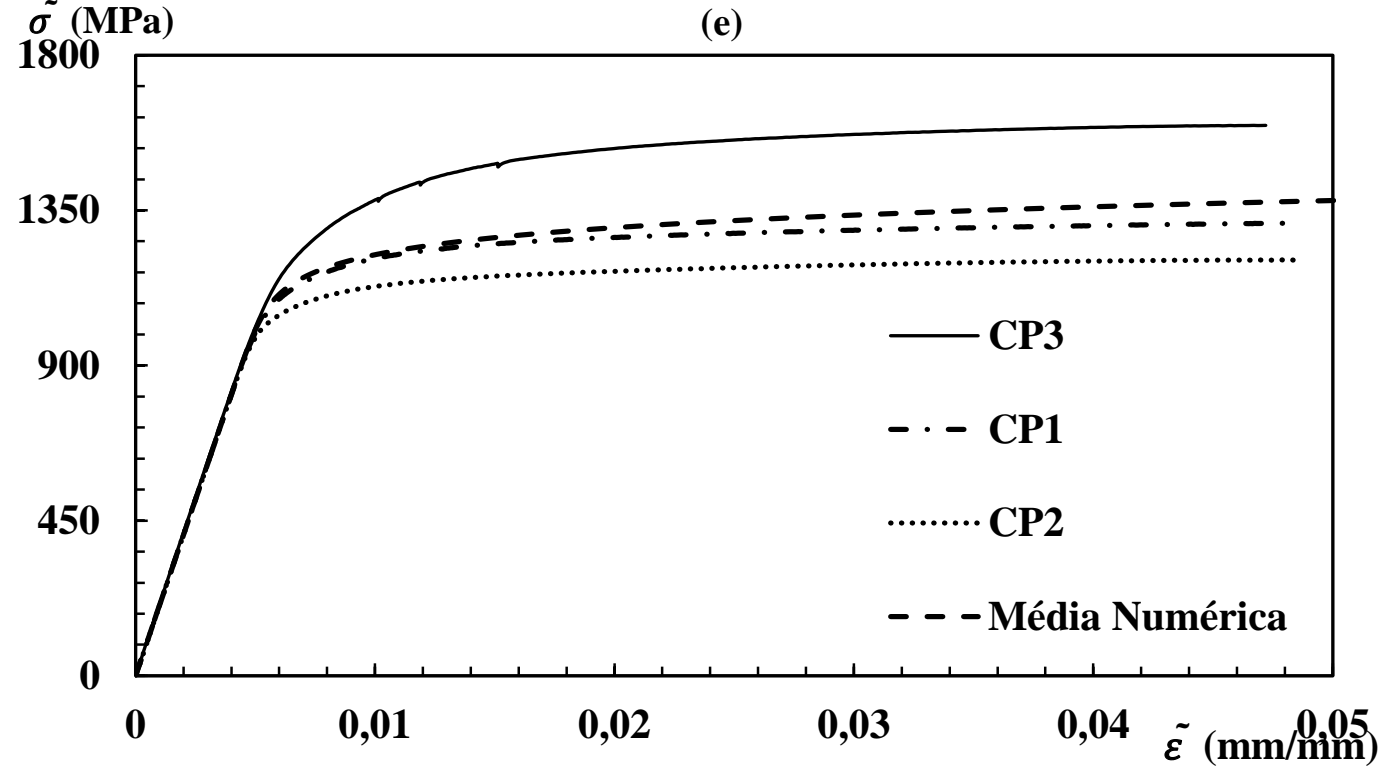


Conforme se observa nos gráficos das Figuras 5.9, os modelos numéricos aderem muito bem às curvas experimentas (CP3 com offset de 0,5\%). Na Figura 5.9(e) é feita uma análise comparativa entre a curva numérica média e as curvas verdadeiras oriundas dos dados experimentais. Observa-se que a curva numérica média representa relativamente bem o comportamento médio das curvas experimentais, o que demonstra ser uma estimativa confiável da resposta tensão vs. deformação verdadeira quando não se tem dados suficientes para gerar uma curva verdadeira (no caso apenas os dados de limite de escoamento e resistência à tração).

\subsection{Resultados de tenacidade ao entalhe em V por impacto Charpy}

Os resultados de tenacidade ao entalhe em V por impacto Charpy $\left(E_{C V N}\right)$ são obtidos a partir de uma ampla faixa de temperatura, a qual compreende toda a região de transição dúctilfrágil (RTDF) e os patamares inferior (PIE) e superior de energia (PSE), conforme dados apresentados na Tabela 5.4 e ajustados por uma função tangente hiperbólica na Figura 5.10.

Tabela 5.4 - Valores das medidas experimentais de tenacidade ao impacto Charpy-V

\begin{tabular}{|c|c|c|c|c|c|c|c|c|c|}
\hline $\begin{array}{c}\mathrm{T} \\
\left({ }^{\circ} \mathrm{C}\right)\end{array}$ & $\begin{array}{c}\text { Medida } \\
1 \\
(\mathrm{~J})\end{array}$ & $\begin{array}{c}\text { Medida } \\
2 \\
\text { (J) }\end{array}$ & $\begin{array}{c}\text { Medida } \\
3 \\
(\mathrm{~J})\end{array}$ & $\begin{array}{c}\text { Medida } \\
4 \\
\text { (J) }\end{array}$ & $\begin{array}{c}\text { Medida } \\
5 \\
\text { (J) }\end{array}$ & $\begin{array}{c}E_{C V N} \\
(\mathrm{~J}) \\
\text { Média }\end{array}$ & $\begin{array}{c}\sigma\left(E_{C V N}\right) \\
\text { Desvio } \\
\text { Padrão }\end{array}$ & $\begin{array}{c}E_{C V N}^{\tanh } \\
(\mathrm{J})\end{array}$ & $\begin{array}{l}\text { Erro } \\
\text { (\%) } \\
\text { Rela- } \\
\text { tivo }\end{array}$ \\
\hline-196 & 3,2 & 4,5 & 2,8 & & & 3,5 & 0,71 & 3,5 & 0,0 \\
\hline-125 & 11,2 & 7,7 & 8,9 & 9,7 & & 9,4 & 1,26 & 8,3 & 11,5 \\
\hline-100 & 12,0 & 11,7 & 10,2 & & & 11,3 & 0,76 & 10,8 & 4,6 \\
\hline-50 & 15,3 & 18,8 & 16,1 & & & 16,7 & 1,47 & 18,2 & 8,6 \\
\hline-25 & 24,0 & 24,5 & 26,3 & & & 25,0 & 0,96 & 22,9 & 8,2 \\
\hline-10 & 26,5 & 24,8 & 24,7 & & & 25,4 & 0,82 & 25,8 & 1,8 \\
\hline 0 & 29,5 & 25,4 & 23,6 & 27,3 & 25,7 & 26,3 & 1,98 & 27,8 & 5,6 \\
\hline 25 & 32,0 & 34,6 & 30,9 & & & 32,5 & 1,55 & 32,3 & 0,4 \\
\hline 50 & 35,1 & 36,4 & 39,0 & & & 36,8 & 1,62 & 36,2 & 1,6 \\
\hline 75 & 39,9 & 39,9 & 39,1 & & & 39,6 & 0,34 & 39,3 & 0,8 \\
\hline 110 & 38,2 & 44,5 & 48,7 & 42,0 & & 43,3 & 3,82 & 42,2 & 2,4 \\
\hline 150 & 40,0 & 43,7 & 44,6 & & & 42,7 & 1,97 & 44,2 & 3,3 \\
\hline 200 & 44,1 & 47,0 & 44,8 & & & 45,3 & 1,25 & 45,4 & 0,1 \\
\hline
\end{tabular}


Figura 5.10 - Curva de tenacidade ao impacto Charpy-V obtida a partir da função tangente hiperbólica

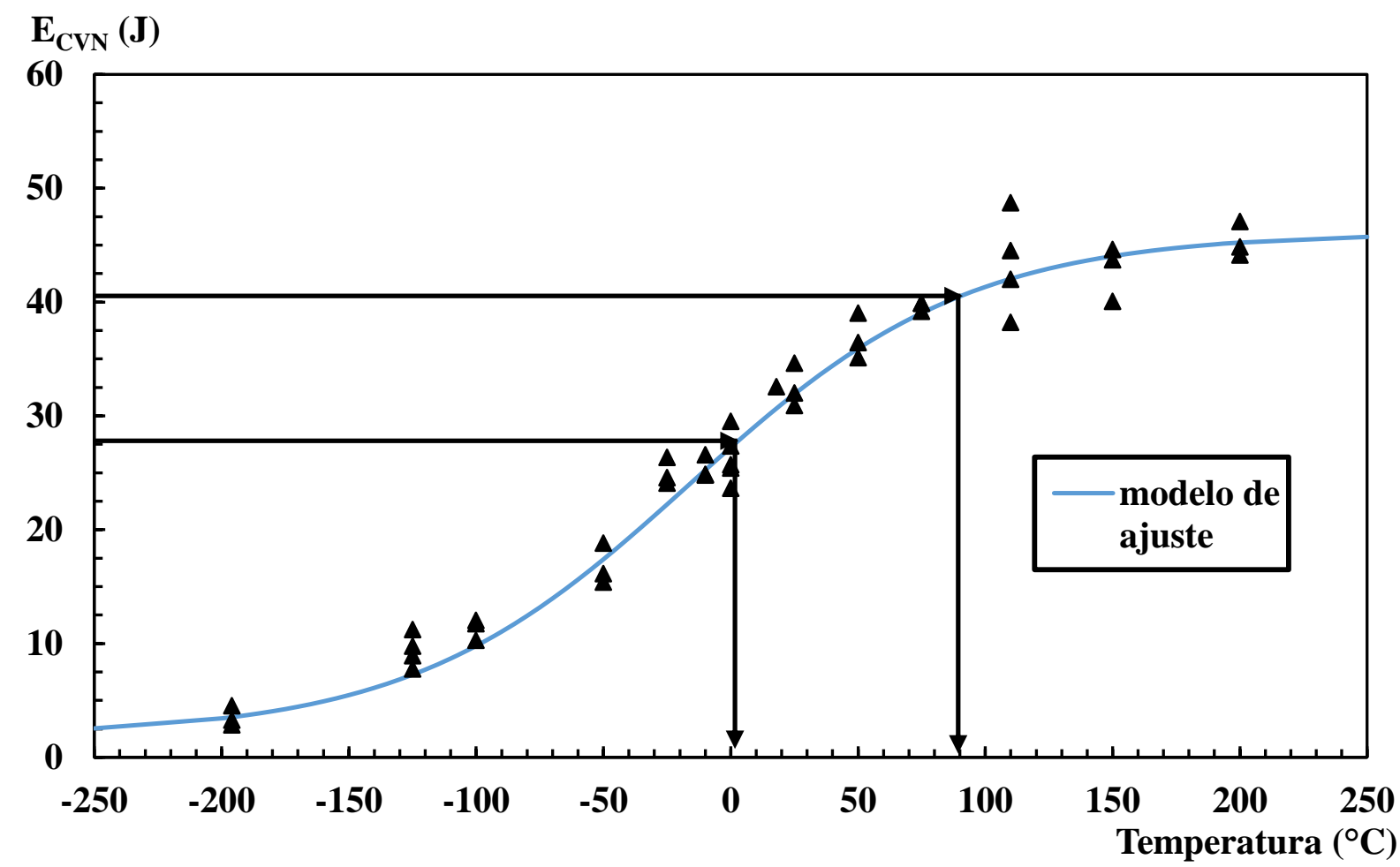

O ajuste dos dados é feito a partir da função tangente hiperbólica (vide Eq. 5.1) cujos coeficientes, determinados a partir do método dos mínimos quadrados, são apresentados na Tabela 5.5. Os coeficientes são ajustados utilizando um método numérico iterativo disponível como solver no software Excel ${ }^{\circledR}$. Após os coeficientes serem ajustados conforme procedimento ilustrado na Figura 4.10, são definidas as temperaturas associadas às energias de 28 e $41 \mathrm{~J}\left(T_{C V N}^{28 \mathrm{~J}}\right.$ e $T_{C V N}^{41 \mathrm{~J}}$ ) utilizando a Tabela 4.3 (vide Seção 4.3) e a Figura 5.10.

$$
E_{C V N}^{\tanh }=23,9+22,0 \cdot \tanh \left[\frac{T-(-16,2)}{109,6}\right]
$$

Tabela 5.5 - Coeficientes do ajuste da curva Charpy e temperaturas associadas às energias de 28 e $41 \mathrm{~J}$ incluindo os valores dos patamares inferior e superior de energia

\begin{tabular}{cccccccc}
\hline $\mathrm{A}$ & $\mathrm{B}$ & $\mathrm{C}$ & $\mathrm{D}$ & $T_{C V N}^{28 \mathrm{~J}}$ & $T_{C V N}^{41 \mathrm{~J}}$ & $E_{C V N}^{L S}$ & $E_{C V N}^{U S}$ \\
$\mathrm{~J}$ & $\mathrm{~J}$ & ${ }^{\circ} \mathrm{C}$ & ${ }^{\circ} \mathrm{C}$ & ${ }^{\circ} \mathrm{C}$ & ${ }^{\circ} \mathrm{C}$ & $\mathrm{J}$ & $\mathrm{J}$ \\
23,9 & 22,0 & 109,6 & $-16,2$ & 0 & 85 & 2,0 & 45,3 \\
\hline
\end{tabular}


Conforme se observa na Figura 5.10, a curva EcvN para o aço martensítico apresenta um comportamento muito similar ao apresentado pelos aços ferríticos, onde é possível notar uma transição abrupta entre o regime dúctil e o regime frágil conforme a temperatura diminui a partir do PSE cuja energia é da ordem de $45 \mathrm{~J}$. Esse comportamento fornece indícios que na RTDF os micromecanismos de fratura frágil e dúctil competem simultaneamente, assim como nos aços ferríticos.

Embora a dispersão dos dados de ECvN não ocorra em toda a faixa de transição (i.e., $50 \leq T \leq 50^{\circ} \mathrm{C}$ ), ainda assim é possível notar que somente na temperatura de $110^{\circ} \mathrm{C}$ demonstrou um alto grau de dispersão associada às medidas $E_{C V N}$, já nas demais temperatura a dispersão foi relativamente baixa. Uma justificativa plausível para esse comportamento pode estar diretamente associada à microestrutura do material, porém tal discussão não é o foco do trabalho, pois necessitária de maiores evidencias sobre sua influência no comportamento à tenacidade ao impacto. Mas deve se ressaltar que a investigação de tal influência é deverás importante para se elucidar o comportamento na região de transição desse material.

Baseando-se nas considerações anteriores, o comportamento observado pelos dados de tenacidade ao impacto Charpy-V na Figura 5.10 fornece fortes indícios que o processo de fratura governado na RTDF do aço martensítico em estudo apresenta caráter estocástico, o que leva a inferir uma possível dispersão associada às medidas de tenacidade à fratura. Essa constatação fornece argumentos convincentes do uso da metodologia da curva mestra para se avaliar o comportamento da tenacidade à fratura mediana em toda a faixa de transição dúctilfrágil para essa classe de liga ferrosa, conforme resultados apresentados mais adiante.

\subsection{Análise das Curvas P-CMOD}

Esta seção faz uma análise do comportamento das curvas carga-deslocamento obtidas em uma ampla faixa de temperatura na realização dos ensaios de tenacidade à fratura no ponto de instabilidade. Deve-se ressaltar que, para os ensaios de tenacidade conduzidos nesta pesquisa, o deslocamento é registrado em termos do CMOD a partir de um extensômetro do tipo clipgage acoplado ao knife-edge diretamente usinado no corpo de prova.

Em vista da quantidade relativamente alta de ensaios em determinadas temperaturas, são apresentadas apenas as curvas P-CMOD cuja medida de tenacidade à fratura (expressa em unidades de $\mathrm{MPa} \sqrt{\mathrm{m}}$ ) resultante seja mais próxima do parâmetro de escala da distribuição de Weibull (i.e., do valor de $K_{0}$ e que, no presente contexto, também é denominado de tenacidade 
característica conforme abordagem da seção seguinte), o qual está associado a uma probabilidade acumulada de falha de 63,2\%. Tal escolha está associada às distribuições dos dados de tenacidade à fratura demonstradas na Figura 5.11 e mais detalhadamente discutidas na Seção 5.6. A partir dessas distribuições, é possível observar nitidamente que os valores de $K_{0}$ estão geometricamente centralizados (exatamente no centro da distribuição) entre as magnitudes extremas dos dados de $K_{J_{c}}$, enquanto os valores medianos, $K_{J_{c}(m e d)}$, se localizam preferencialmente na parte inferior devido à grande parte dos dados se concentrarem nesse patamar conforme demonstrado na Figura 5.11. Para uma distribuição cuja maioria dos dados apresente valor de tenacidade relativamente baixo, a tendência é que a mediana também seja baixa, pois a sua definição estatística consiste em separar a distribuição a partir dos dados individuais em metade superior e metade inferior. O fato das medianas nas distribuições apresentadas na Figura 5.11 se localizarem na parte inferior da amplitude dos valores de $K_{J_{c}}$ mostra o forte efeito do tamanho do espaço amostral sobre tal estatística. Uma vez que o tamanho do espaço amostral afeta a proporção populacional, é plausível pressupor que ao aumentar a quantidade de dados em cada distribuição (i.e., aumentar o número de ensaios em cada temperatura - $T_{i}$ ), a magnitude da mediana tende a se posicionar mais ao centro da distribuição. Nesse caso, uma quantidade relativamente maior de dados contendo maiores níveis de tenacidade tende a contrabalancear a outra metade contendo os menores valores de tenacidade à fratura. Desse modo, o valor de tenacidade mais centralizado nas distribuições apresentadas na Figura 5.11 tende a ser mais representativo do real valor médio da população. Essa consideração é retomada mais adiante nas Seções 5.8 e 5.9 ao abordar a determinação dos novos coeficientes de ajuste da curva mestra para o material em estudo. 
Figura 5.11 - Dados experimentais de $\left(K_{J_{c}}\right)$ e os respectivos valores de $K_{0}$ e $\left.K_{J_{c}(\text { med }}\right)$

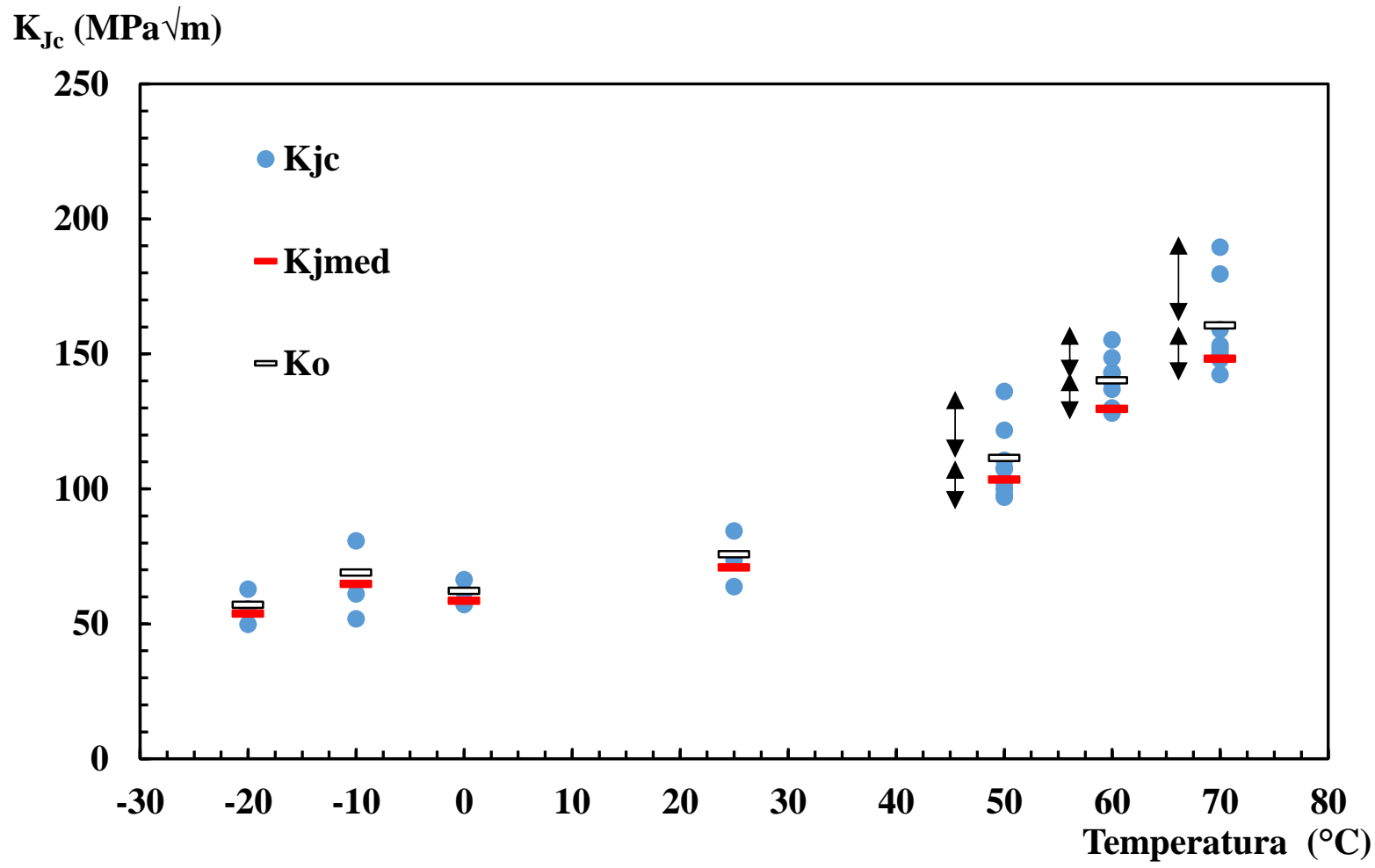

O comportamento das curvas P-CMOD apresentadas na Figura 5.12 deixa evidente a forte influência da temperatura no ponto de instabilidade da fratura frágil do aço USI AR 450. Na Figura 5.12(a) são apresentadas as curvas obtidas na faixa de $-20 \leq T \leq 25^{\circ} \mathrm{C}$. Antes de abordar o comportamento das curvas P-CMOD obtidas nessa faixa de temperatura, é importante mencionar o critério adotado para a estimativa inicial da temperatura de ensaio de tenacidade à fratura conforme recomendação da ASTM E1921 [5].

De acordo com a E1921[5], a temperatura de ensaio de tenacidade à fratura frágil por clivagem na RTDF de aços ferríticos, recomendada inicialmente quando não se sabe ao certo a temperatura de referência do material $\left(T_{0}\right)$, deve ser baseada na temperatura de energia Charpy$\mathrm{V}$ equivalente a $28 \mathrm{~J}\left(T_{C V N}^{28 \mathrm{~J}}\right)$ associada, por sua vez, a uma constante dada em função da espessura do corpo de prova (vide Tabela 4.2). Logo, conforme procedimento descrito na Seção 4.6 e resultado de $T_{C V N}^{28 \mathrm{~J}}$ apresentado na Tabela 5.5 (vide Seção 5.4), a temperatura de ensaio inicialmente recomendada é dada em ordem de $-20^{\circ} \mathrm{C}$. Baseando-se nessa recomendação, fica estabelecida que a temperatura de referência do material, a priori, é de aproximadamente -20 ${ }^{\circ} \mathrm{C}$. No entanto, deve-se enfatizar que tal recomendação é baseada em um procedimento voltado 
exclusivamente para aços ferríticos, o que não permite afirmar que essa mesma recomendação sirva igualmente bem para o material em estudo.

Diante do procedimento explicado no parágrafo anterior, inicialmente são conduzidos apenas 3 ensaios a $-20{ }^{\circ} \mathrm{C}$ para se avaliar preliminarmente o comportamento à fratura do material. Conforme observado na Figura 5.12(a), a curva P-CMOD $\left(\mathrm{T}=-20^{\circ} \mathrm{C}\right)$ apresenta um comportamento essencialmente elástico-linear, o que caracteriza um comportamento à fratura típico do patamar inferior de energia (i.e., de caráter muito conservador - lower bound). As demais curvas obtidas nessa temperatura apresentam comportamento similar, as quais são omitidas para preservar a qualidade da análise gráfica (i.e., para não sobrecarregar com gráficos sobrepostos). Nesse patamar, presume-se que o micromecanismo de fratura associado à fratura frágil é essencialmente governado apenas pela etapa de propagação, o que mitiga o efeito estatístico associado à etapa de nucleação a partir de sítios preferenciais (e.g., partículas de segunda fase precipitadas preferencialmente em contornos de grão e inclusões dispersas na matriz), dado que a matriz passa também a atuar como sítio preferencial. Esse comportamento fenomenológico compromete a aplicabilidade do conceito estatístico do elo mais fraco e, portanto, nos ajustes dos valores de tenacidade para contabilizar os efeitos de espessura quando necessários.

Uma vez que a aplicabilidade da metodologia da Curva Mestra é avaliar justamente o comportamento da tenacidade à fratura mediana em vista da elevada dispersão associada às medidas de tenacidade na RTDF, além de incorporar efeitos dimensionais associados ao conceito do elo mais fraco, o uso de dados característicos do PIE compromete a precisão da temperatura de referência $\left(T_{0}\right)$ e, portanto, as estimativas dos valores medianos de tenacidade.

Com o intuito de obter valores de tenacidade à fratura frágil mais representativos da RTDF, particularmente na sua região inferior (RITDF), novos ensaios são conduzidos em uma temperatura relativamente mais elevada $\left(\mathrm{T}=-10^{\circ} \mathrm{C}\right)$. $\mathrm{O}$ aumento de apenas $10^{\circ} \mathrm{C}$ se justifica pela alta sensibilidade do aço USI AR450 a pequenas variações de temperatura, conforme demonstrada pela curva Charpy-V (vide Figura 5.10). Observa-se que a $-10{ }^{\circ} \mathrm{C}$ o comportamento da curva P-CMOD é muito similar ao observado anteriormente para a curva obtida a $-20{ }^{\circ} \mathrm{C}$. Diante desse comportamento, novos ensaios são conduzidos a $0{ }^{\circ} \mathrm{C}$ e a temperatura ambiente $\left(\mathrm{T} \sim 25{ }^{\circ} \mathrm{C}\right)$. Com base no comportamento das curvas P-CMOD apresentadas na Figura 5.12(a), nota-se que somente a partir da temperatura ambiente é que começa a haver o surgimento de uma plasticidade precedente à fratura, conforme região nãolinear apresentada na porção final da curva P-CMOD $\left(25^{\circ} \mathrm{C}\right)$. Para essa faixa de temperatura, diante do comportamento muito frágil demonstrado pelas curvas P-CMOD, antecipa-se que as 
medidas de tenacidade à fratura no ponto de instabilidade são expressas somente em termos da componente elástica da integral- $J$, $J_{e}$ de modo que o seu correspondente valor em termos do fator de intensidade de tensão (i.e., em unidades de $\mathrm{MPa} \sqrt{ } \mathrm{m}$ ) nada mais é do que o próprio valor de $K_{I_{C}}$ calculado de acordo com a E399.

Ao contrário do que é comumente observado nos aços ferríticos-perlíticos onde a plasticidade se inicia na RITDF, a plasticidade para o aço martensítico AR 450 começa a surgir somente a partir de temperaturas características da região superior da transição dúctil-frágil (RSTDF), conforme indica a curva Charpy-V da Figura 5.10.

Embora alguns ensaios tenham sido registrados por um comportamento à fratura essencialmente elástico-linear, conforme registros das curvas P-CMOD, todos os valores de tenacidade à fratura são calculados em termos da integral-J no ponto de instabilidade $\left(J_{c}\right)$. A justificativa deve-se ao fato de o método da secante, regido pela E399 para verificar a validade do valor provisório de tenacidade $\left(K_{Q}\right)$ como $K_{I_{C}}$, penalizar excessivamente (i.e., tornar conservadores) os valores de $K_{Q}$, medidos em uma dada espessura, que se mostrarem inválidos em virtude de pequenos indícios de plasticidade (i.e., pequenos desvios na relação linear entre a carga $\mathrm{P}$ e o deslocamento CMOD). Portanto, recomenda-se utilizar parâmetros elastoplásticos como medidas de tenacidade à fratura, tal como o fator elasto-plástico de intensidade de tensão $\left(K_{J_{c}}\right)$ obtido diretamente a partir da conversão $J_{c}$ para unidades de $\mathrm{MPa} \sqrt{\mathrm{m}}$, nas estimativas dos valores medianos de tenacidade a partir da metodologia da curva mestra a fim de evitar análises demasiadamente conservadoras. 
Figura 5.12 - Curvas de carga-deslocamento (P-CMOD) a diferentes temperaturas.

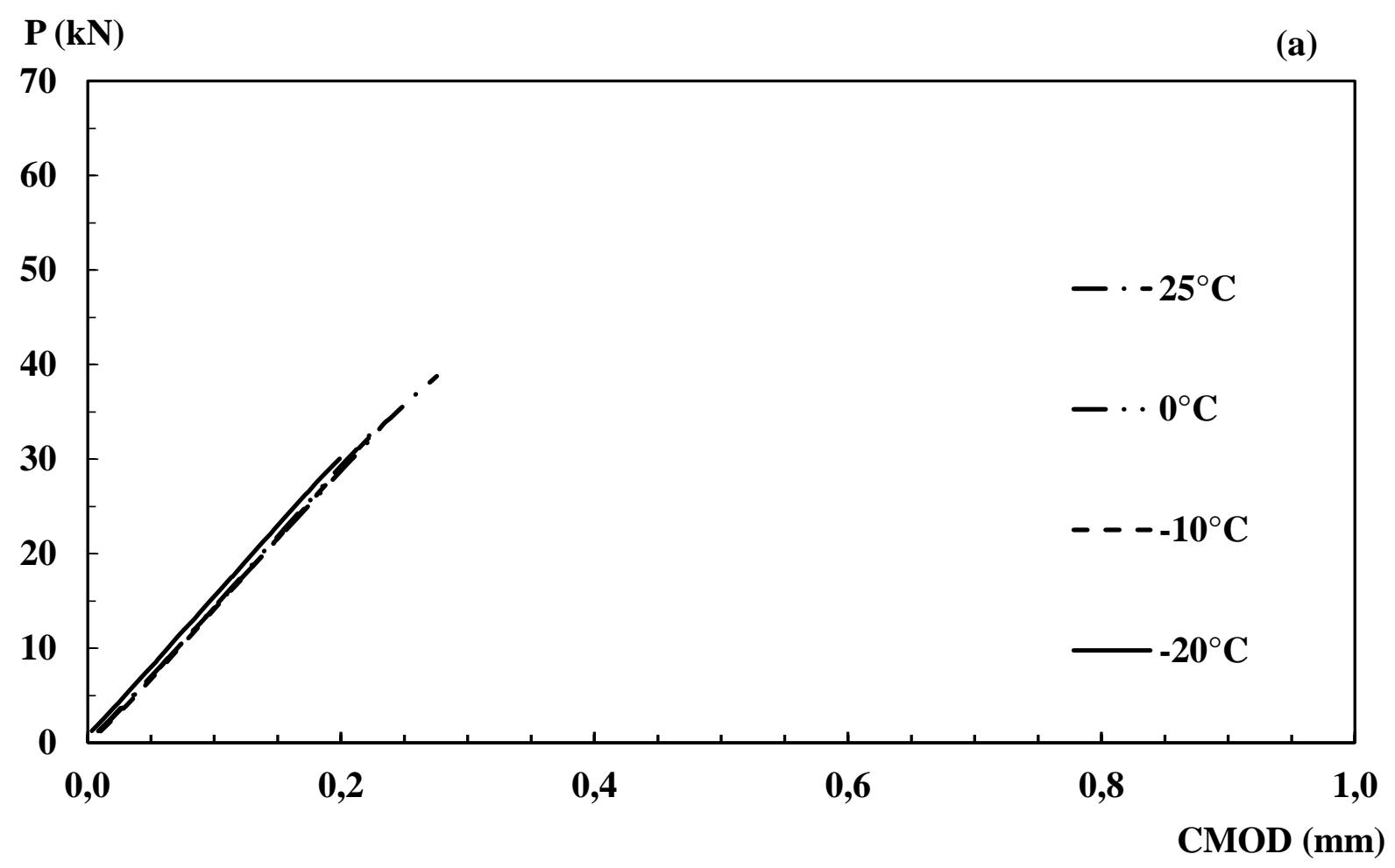

$\mathbf{P}(\mathbf{k N})$

(b)

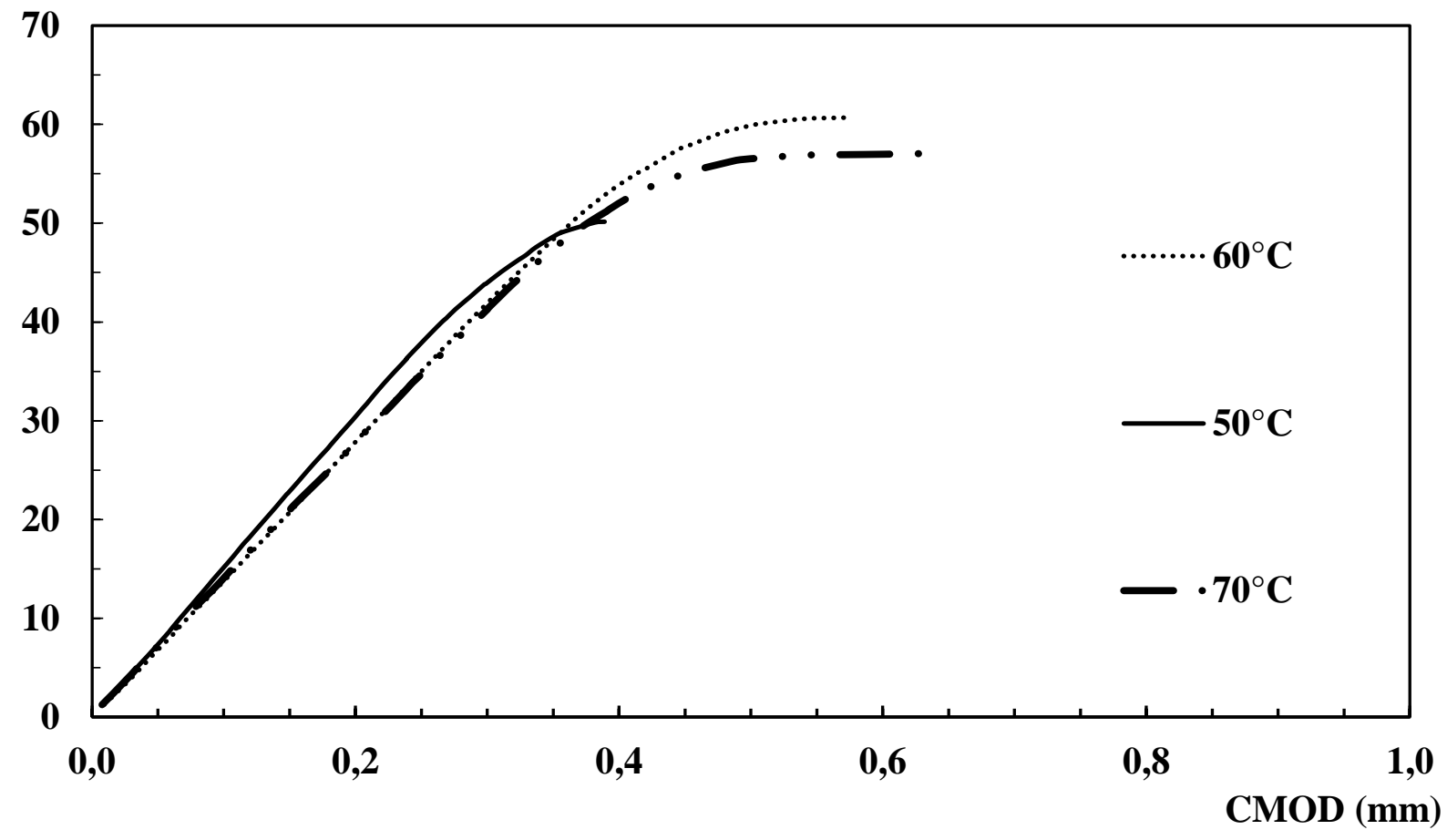




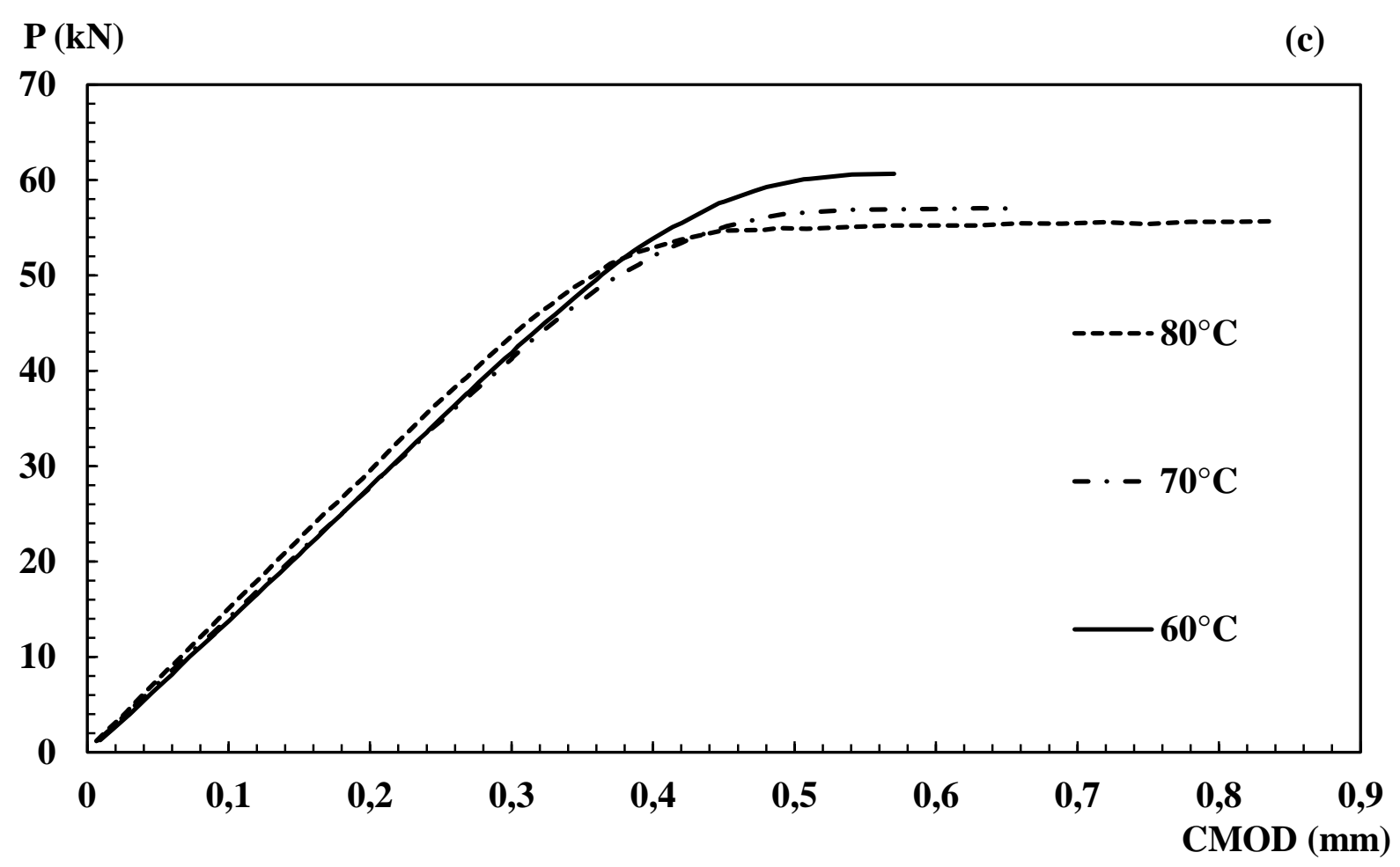

Ao se elevar as temperaturas de ensaio a níveis da RSTDF $\left(\sim 25<T \leq 70{ }^{\circ} \mathrm{C}\right)$, observase um aumento quase que gradual da plasticidade desenvolvida durante o processo de fratura, conforme indicam as regiões não-lineares das curvas P-CMOD apresentadas na Figura 5.12(b). A partir desses níveis de plasticidade, efeitos estatísticos associados às etapas de iniciação e propagação do micromecanismo de fratura começam a ficar mais evidentes, justificando assim o uso de uma abordagem probabilística mais robusta para uma melhor descrição da dispersão das medidas de tenacidade nessa região. Observa-se que os níveis da carga de instabilidade começam a atingir seu valor limite a partir dessas temperaturas, de modo que a magnitude do deslocamento de abertura da boca da trinca (CMOD) é quem passa a contribuir para maiores níveis de energia absorvida e, consequentemente, para maiores medidas de tenacidade à fratura.

Na Figura 5.12(c) é apresentada uma curva P-CMOD obtida a uma temperatura de aproximadamente $80{ }^{\circ} \mathrm{C}$ para uma análise comparativa com àquelas obtidas a $60^{\circ} \mathrm{C}$ e $70^{\circ} \mathrm{C}$. Observa-se que a magnitude da carga de instabilidade registrada a $80^{\circ} \mathrm{C}$ é próxima daquelas obtidas nas temperaturas inferiores (50, 60 e $\left.70{ }^{\circ} \mathrm{C}\right)$, porém o deslocamento CMOD é consideravelmente mais expressivo. Neste caso em particular, ao se realizar uma análise fractográfica simples por meio de uma lupa estereoscópica (vide Figura 5.27 da Seção 5.7 abordada mais adiante), observa-se um crescimento estável de trinca considerável (i.e., superior ao crescimento subcrítico de trinca dado pelo menor valor entre $1,00 \mathrm{~mm}$ e $5 \%$ do ligamento remanescente do corpo de prova, ou seja, 1,27 mm para a geometria usada neste estudo), o que 
viola as condições limites de crescimento subcrítico de trinca, tornando essa medida censurada segundo os critérios para a validade da tenacidade à fratura frágil por clivagem prescritos na E1921[5]. Em vista disso, para temperaturas dessa magnitude ou superiores, espera-se o desenvolvimento de elevados níveis de plasticidade e uma maior ocorrência de crescimentos estáveis de trinca mais expressivos, violando as condições HRR e, portanto, as condições fenomenológicas da fratura governada por tensão.

Uma característica marcante observada em grande parte dos ensaios de tenacidade conduzidos na faixa de temperatura $\sim 25<T \leq 70{ }^{\circ} \mathrm{C}$ é a elevada ocorrência de variações bruscas nas cargas registradas nas porções finais da curva P-CMOD. Essas variações são bem perceptíveis e são caracterizadas por quedas repentinas e aumentos subsequentes na carga acompanhados de deslocamentos apreciáveis, conforme evidenciado pelas Figuras 5.13 e 5.14. A significância desses eventos em relação ao comportamento das curvas carga vs. deslocamento é avaliada perante os critérios da ASTM E399 [27], [28] e ASTM E1921 [5]. Dependendo da sua magnitude, tais eventos podem ser classificados como pop-in. Nesse caso, a carga de instabilidade passa a ser definida no início da sua ocorrência, onde presume-se que a resistência à fratura do material já tenha atingido o seu limite, de forma que nada além desse ponto representa uma resistência à fratura remanescente. No entanto, é importante ressaltar que, em grande parte das curvas, essa variação ocorre mais de uma vez, de modo que o comportamento da curva P-CMOD se dá por uma espécie de “zigue-zague” após atingir pela primeira vez o pico de carga, conforme evidenciado na Figura 5.13. Esse comportamento chama a atenção, pois tais intercorrências de pop-in são mais frequentemente apresentadas com apenas uma ou duas variações, seguida da completa instabilidade do corpo de prova.

Para o aço martensítico utilizado neste estudo, observa-se que em temperaturas mais elevadas ( $\left.\mathrm{T} \sim 60{ }^{\circ} \mathrm{C}\right)$, apesar da variação brusca, o material aparenta ainda apresentar certa resistência à fratura de modo que a sua tenacidade tende a ser relativamente maior para os casos em que essa variação persiste para maiores níveis de CMOD, conforme Figura 5.14. A Figura 5.14 demonstra que o material, ao atingir a sua carga de instabilidade, ainda apresenta considerável resistência à fratura, ou seja, continua a suportar cargas relativamente altas ao longo de um apreciável deslocamento. Comportamento muito similar é relatado em alguns trabalhos envolvendo aços martensíticos de elevada resistência ao desgaste (do tipo Hardox ${ }^{\circledR}$ ), conforme demonstrado na Figura 5.15 [70], [71]. As análises fractográficas conduzidas por MEV nesses trabalhos revelam que tal comportamento ocorre devido ao micromecanismo de quase-clivagem, conforme revela a região em destaque na Figura 5.15. 
Todavia, por se tratar de um fenômeno de fratura controlado por tensão, é mais conveniente e prudente adotar como critério de instabilidade o primeiro registro de carga máxima da curva P-CMOD, de modo que todo o restante da curva P-CMOD (i.e., a porção caracterizada por um comportamento “zigue-zague") seja desprezado, fornecendo assim medidas de tenacidade à fratura mais conservadoras.

Praticamente todos os eventos de instabilidade da curva P-CMOD relatados neste estudo, independentemente das temperaturas de ensaio, são classificados como pop-in e apresentam-se mais de uma vez ao longo da porção final da curva P-CMOD. A título de curiosidade, alguns desses eventos são tão marcantes que, ao longo dos instantes finais dos registros de carga vs. deslocamento, as variações bruscas de cargas são acompanhadas simultaneamente de emissões de ruídos sonoros associados a um comportamento muito frágil.

Portanto, uma justificativa aceitável para os comportamentos das curvas P-CMOD, tal como o evidenciado pela Figura 5.13, está associada ao mecanismo de fratura por quaseclivagem que ocorre ao longo do ligamento remanescente. O fenômeno da quase-clivagem exibe simultaneamente áreas de fratura com características típicas de clivagem transgranular e regiões com evidências típicas de deformação plástica por escorregamento de planos associado a mecanismos de cisalhamento, conforme fractografia apresentada na Figura 5.15. A principal razão pela qual a fratura se dá por quase-clivagem deve-se às características cristalográficas da microestrutura martensítica cujos grãos são constituídos por pacotes de ripas com diferentes orientações cristalográficas. Naturalmente, esse arranjo microestrutural promove a formação de uma interface de elevado ângulo entre os pacotes adjacentes (similares a grãos), o que contribui efetivamente como uma barreira à propagação de microtrincas ao atuar como elemento desviador da sua direção de propagação, sendo que ao impedir (direção inicial) e consequentemente desviar a propagação da trinca, ocorra deformações plásticas caracterizadas por dimples, assim caracterizando um comportamento classificado como quase-clivagem [29]. 
Figura 5.13 - Curva P-CMOD a temperatura ambiente.

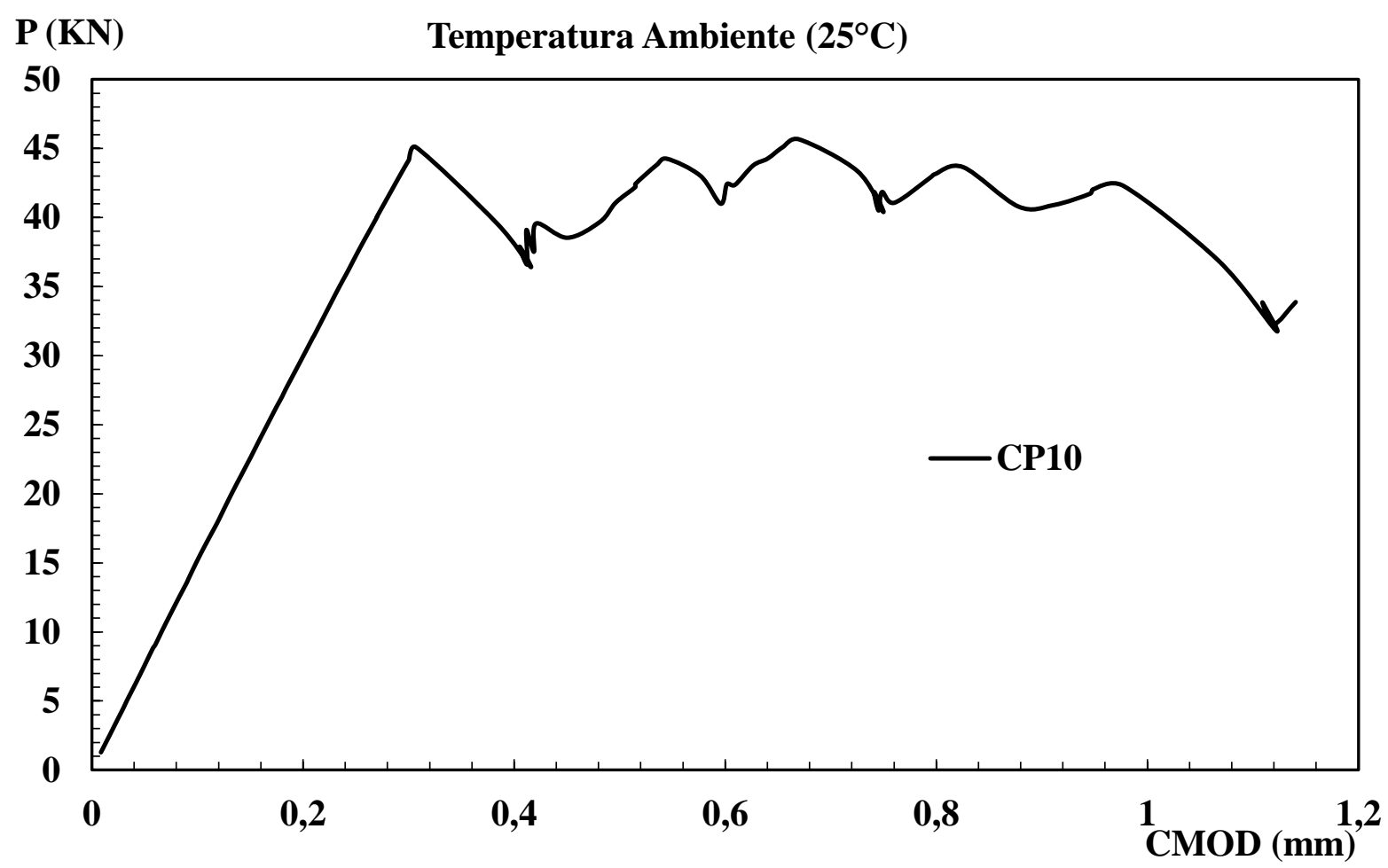

Figura 5.14 - Curva P-CMOD em condição SSY no USI AR450 ensaio a $60^{\circ} \mathrm{C}$.

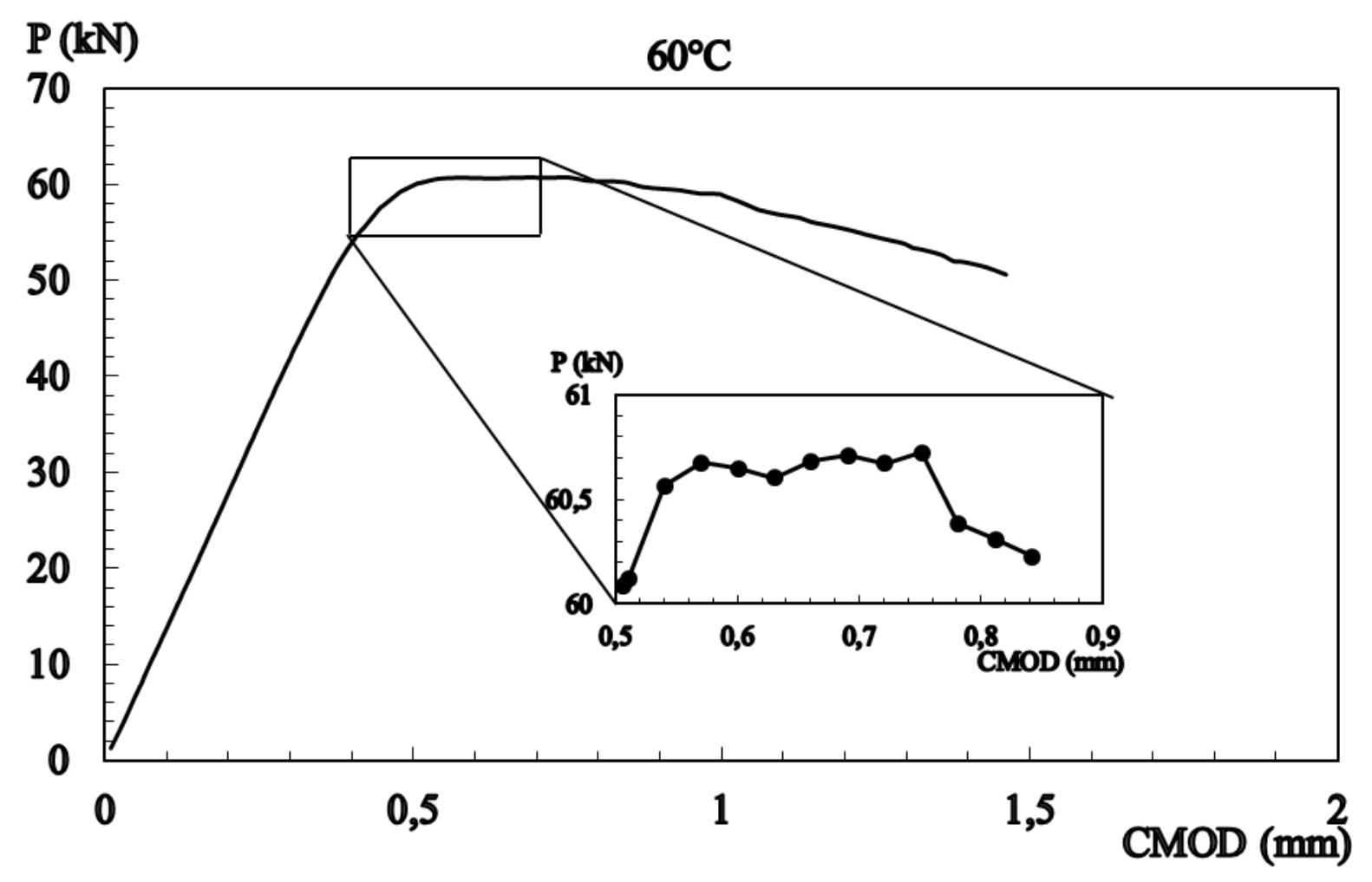


Figura 5.15 - Curva P-CMOD em condição SSY no aço Hardox [70], [71].

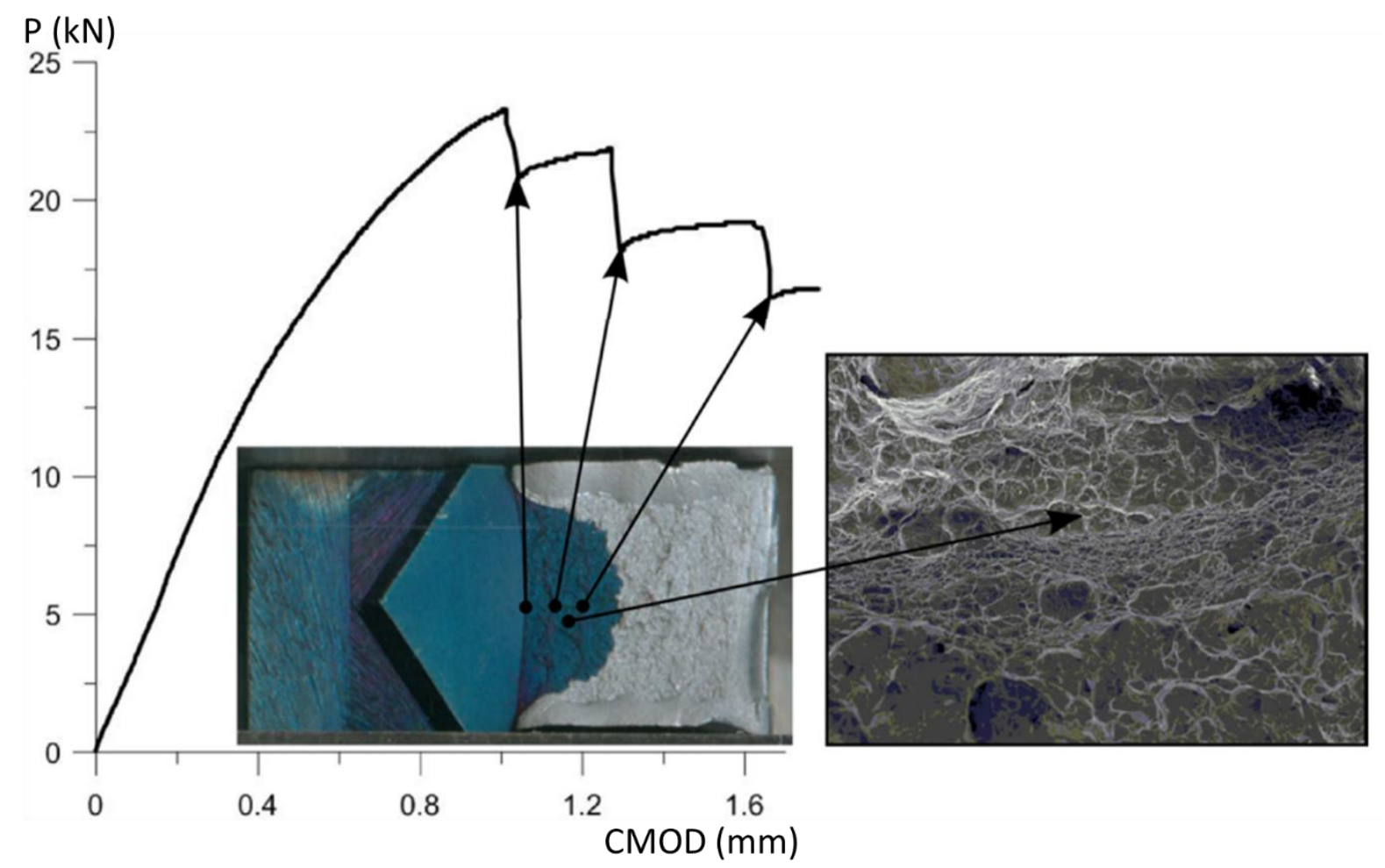

A seção a seguir faz uma análise da distribuição estatística dos dados de tenacidade à fratura do aço USI AR450 avaliado na RTDF com o intuito de verificar o comportamento da dispersão das medidas de tenacidade e potencial aplicabilidade da metodologia da curva mestra a esse material.

\subsection{Análise da distribuição estatísticas dos dados de tenacidade à fratura}

Conforme relatado na Seção 4.6.4, é de fundamental importância fazer um tratamento estatístico dos resultados de tenacidade à fratura frágil do aço USI AR450 a fim de avaliar se os dados medidos na RTDF são bem descritos pela distribuição de Weibull triparamétrica, cuja formulação compõe as bases teóricas da metodologia da curva mestra. Esse tratamento preliminar de dados envolve análises de aderência da distribuição experimental em relação à distribuição teórica-experimental de Weibull (i.e., para um valor de $\alpha=2$ para $J_{c}$ e $\alpha=4$ para $K_{J c}$ ) e análises comparativas com a distribuição experimental; isto é, definida a partir de um valor de $\alpha$ representativo do conjunto amostral dos dados de $J_{c}$ ou $K_{J c}$. A partir dos ensaios de tenacidade conduzidos e parcialmente descritos na seção anterior, a seguir são apresentadas as 
distribuições estatísticas dos dados medidos em diversas temperaturas ao longo da RTDF do aço USI AR450.

Seguindo a mesma cronologia de análise das curvas P-CMOD, inicialmente são apresentadas as distribuições dos dados obtidos na faixa de temperatura de $-20 \leq T \leq 25{ }^{\circ} \mathrm{C}$. Na Figura 5.16 são apresentadas as distribuições de Weibull triparamétrica obtidas nessa faixa de temperatura.

Figura 5.16 - Distribuições triparamétrica de Weibull dos dados de $J_{c}$ medidos a $-20 \leq T \leq$ $25^{\circ} \mathrm{C}$.

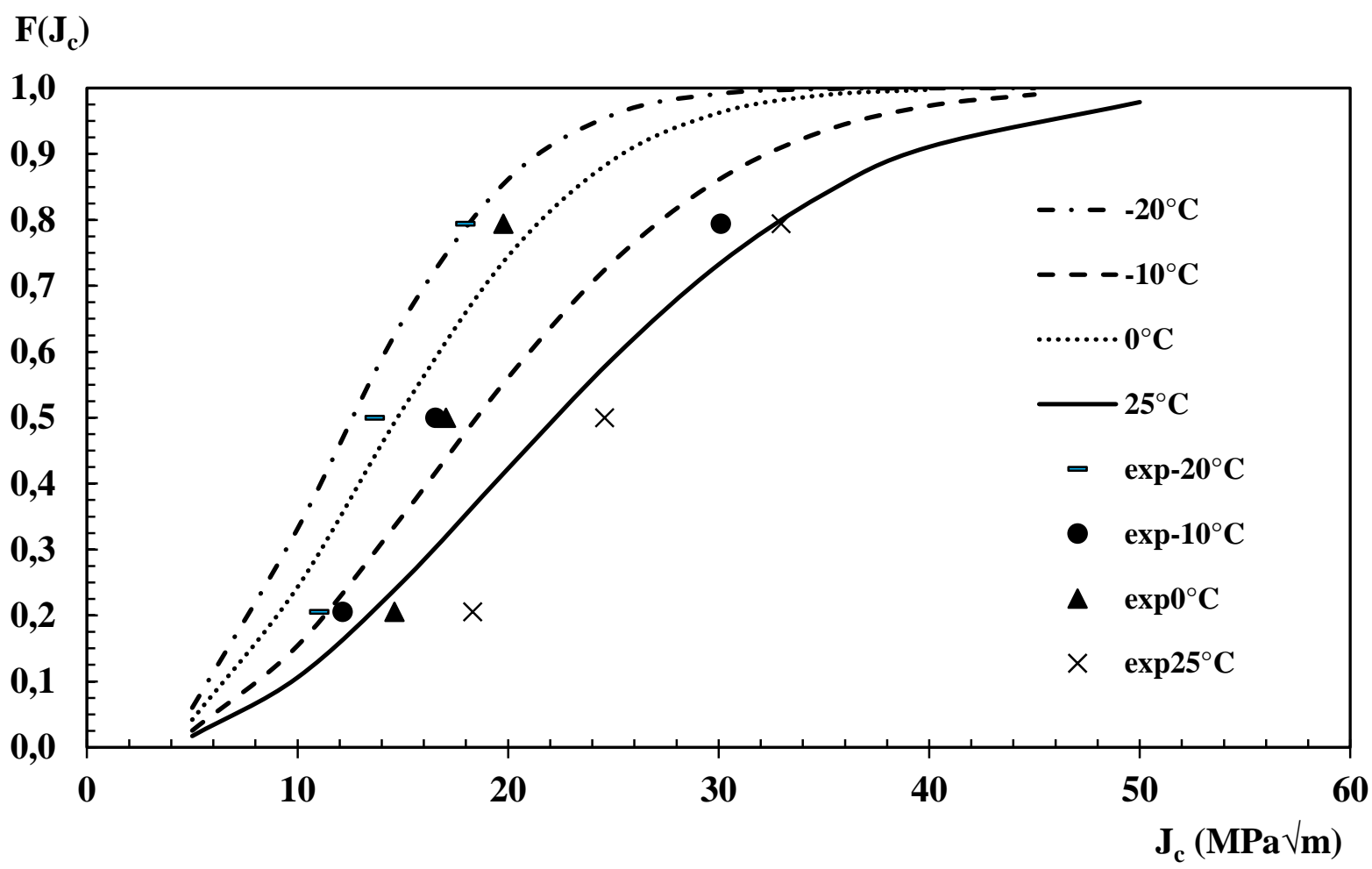

Os dados de tenacidade à fratura expressos em termos de $J_{c}$ são dispostos no gráfico de distribuição a partir do estimador de rank mediano expresso pela Eq. (4.16) apresentada na Seção 4.6.4. Observa-se que, apesar do espaço amostral dos valores de $J_{c}$ conter apenas 3 dados, a sua distribuição (distribuição experimental) é relativamente bem descrita pela função de distribuição acumulada (f.d.a.) de falha com valor de $\alpha=2$ (distribuição teórica-experimental) representada pelas linhas contínua $\left(\mathrm{T} \sim 25^{\circ} \mathrm{C}\right)$ e tracejadas $\left(\mathrm{T}<25^{\circ} \mathrm{C}\right)$. O comportamento das distribuições deixa evidente a forte influência da temperatura na tenacidade e, portanto, sobre as estimativas da temperatura de referência ( $T_{0}$, apresentadas na próxima seção) dado que a distribuição é nitidamente deslocada para a direita conforme a temperatura de ensaio aumenta. 
Na Figura 5.17 são apresentadas as distribuições de tenacidade medidas a $25<T \leq$ $70{ }^{\circ} \mathrm{C}$. De forma similar ao comportamento apresentado pelas curvas da Figura 5.16, as distribuições experimentais dos dados de $J_{c}$ medidas a $25<T \leq 70{ }^{\circ} \mathrm{C}$ também aparentam ser bem descritas pela distribuição teórica-experimental de Weibull (i.e., distribuição derivada de $J_{0}$ estimado a partir de $\alpha=2$ ). Embora o comportamento dos dados de $J_{c}$ seja descrito pela f.d.a. triparamétrica de Weibull, observa-se que a dispersão dos valores de $J_{c}$ é consideravelmente menor em relação à teoricamente prevista para um valor de $\alpha=2$, mas ainda assim o suficiente para justificar um tratamento estatístico adequado para o fornecimento de um valor médio representativo da tenacidade à fratura frágil em cada temperatura da RTDF.

Figura 5.17 - Distribuições triparamétrica de Weibull dos dados de $J_{C}$ medidos a $25<T \leq 70$.

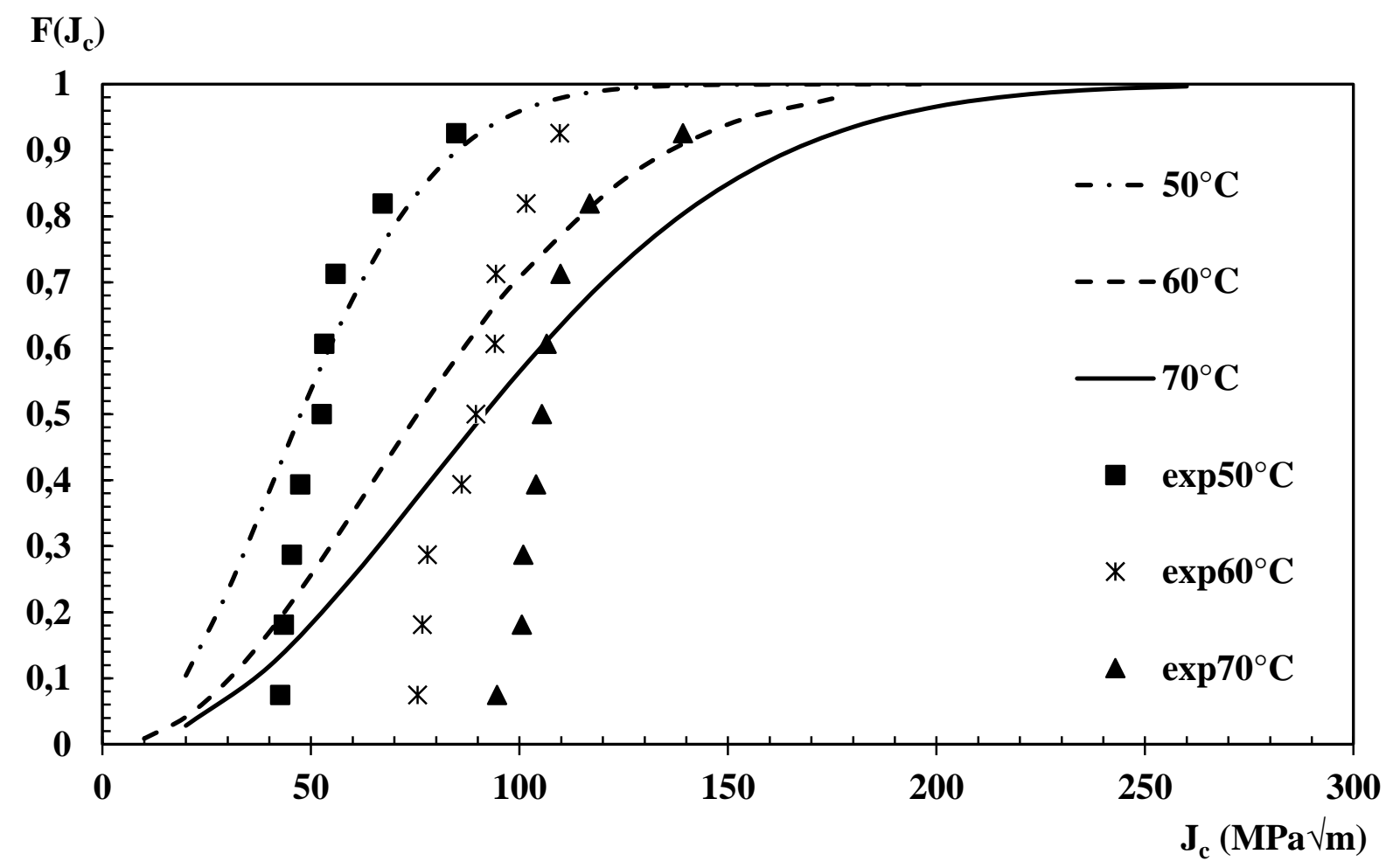

Com o intuito de evidenciar a diferença entre a dispersão prevista $(\alpha=2)$ e a dispersão real $(\hat{\alpha})$ associada aos dados de tenacidade obtidos na RTDF, na Figura 5.18 são apresentadas a forma linearizada da f.d.a. de Weibull obtida em cada temperatura de ensaio ao longo da faixa $25<T \leq 70{ }^{\circ} \mathrm{C}$. 
Figura 5.18 - Distribuições linearizadas de Weibull: (a) $50{ }^{\circ} \mathrm{C}$, (b) $60^{\circ} \mathrm{C}$ e (c) $70{ }^{\circ} \mathrm{C}$
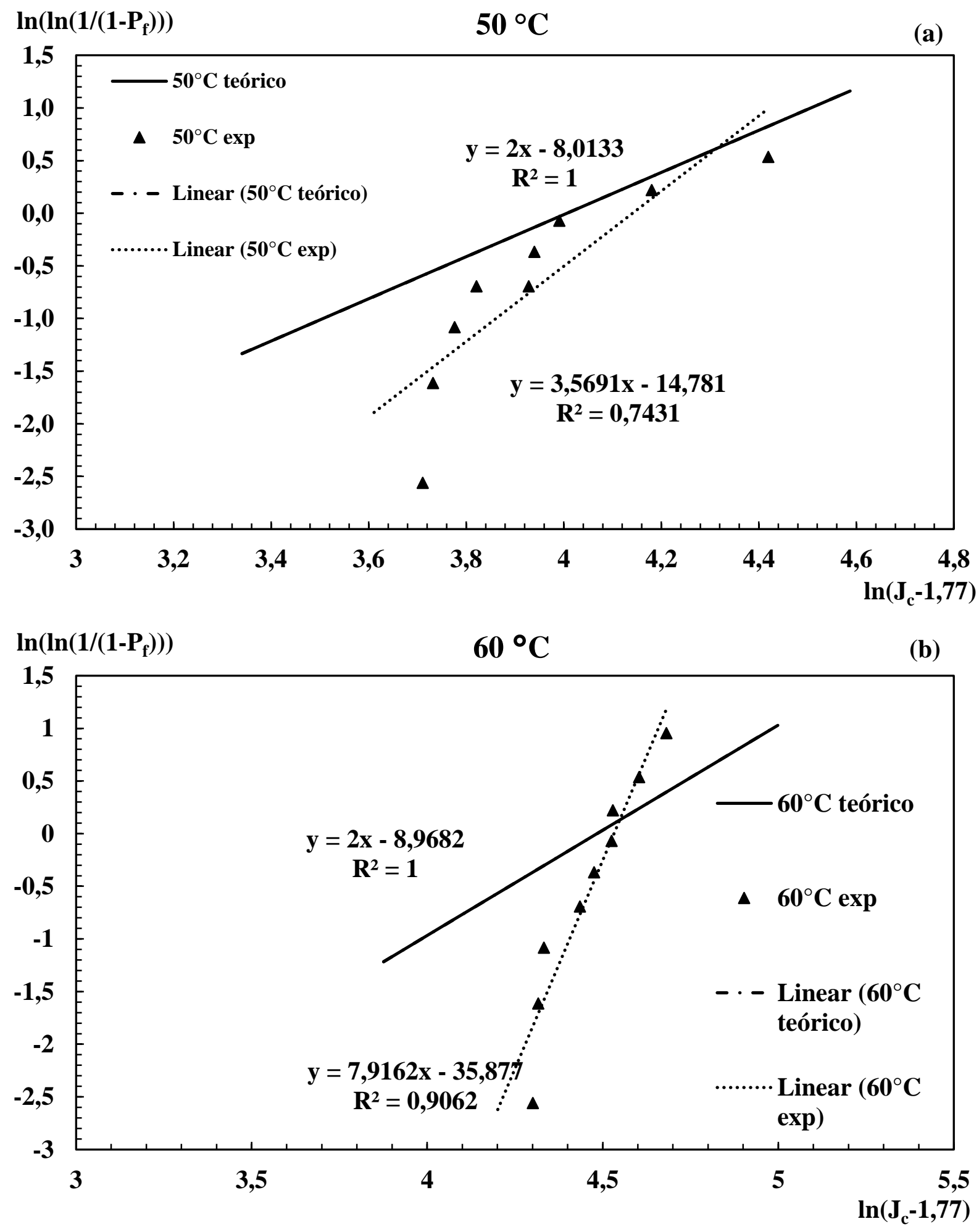


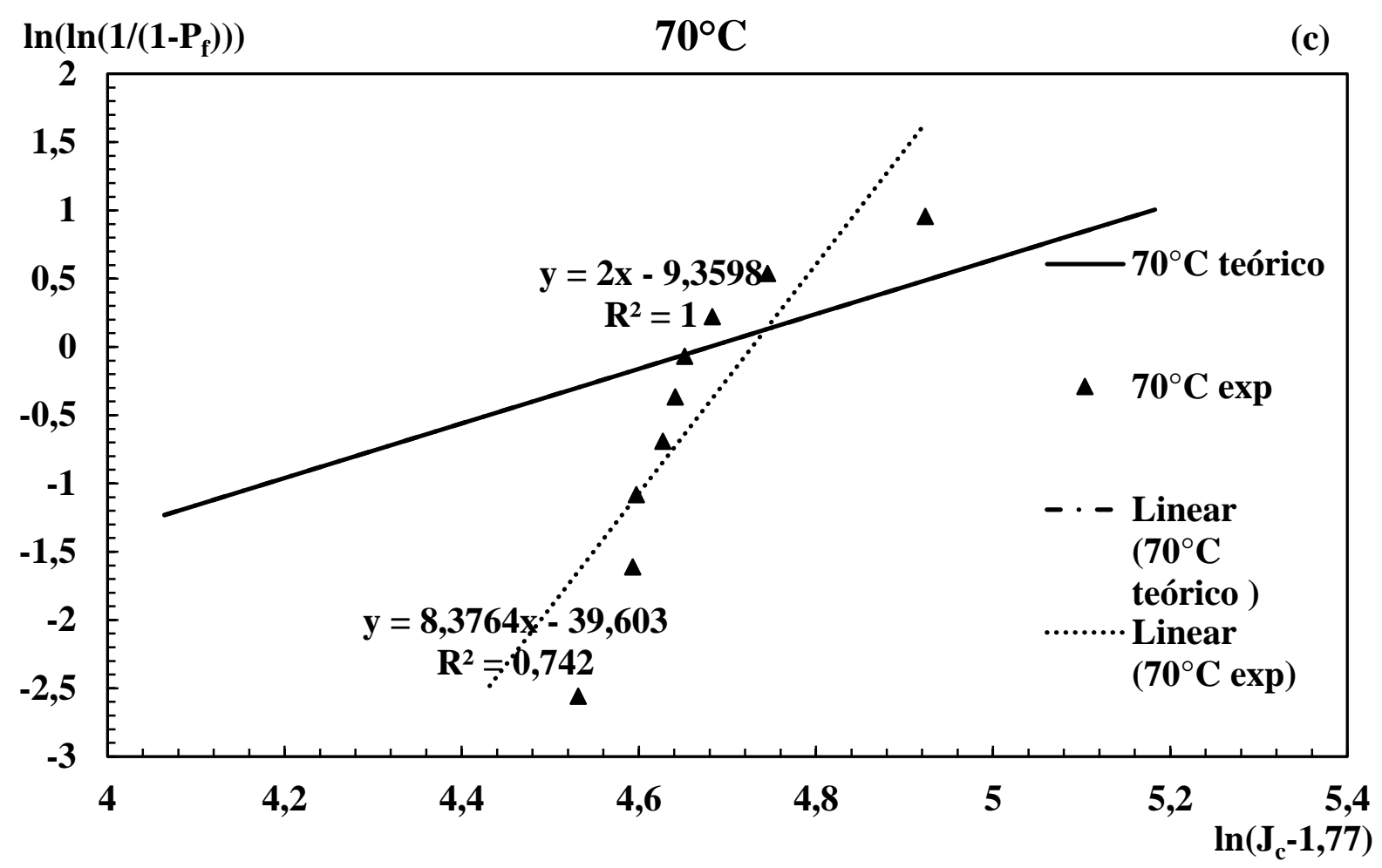

Na Tabela 5.6 são apresentados os valores reais de $\alpha(\hat{\alpha})$ bem como os valores de $J_{0}$ derivados de $\hat{\alpha}$, ambos estimados pelo método dos mínimos quadrados (MMQ).

Tabela 5.6 - Parâmetros de Weibull estimados pelo método dos mínimos quadrados em termos de $J_{c}$

\begin{tabular}{ccccc}
\hline \multicolumn{5}{c}{ MMQ } \\
\hline$T$ & $\hat{J}_{0}{ }^{\alpha}=2$ & $\hat{\alpha}_{J}$ & $\hat{J}_{0}$ & $\begin{array}{c}\text { Diferença } \\
\text { Relativa }\end{array}$ \\
$\left({ }^{\circ} \mathrm{C}\right)$ & $\left(\mathrm{kJ} / \mathrm{m}^{2}\right)$ & $(-)$ & $\left(\mathrm{kJ} / \mathrm{m}^{2}\right)$ & $(\%)$ \\
50 & 56,7 & 3,5 & 64,6 & 13,9 \\
60 & 90,3 & 7,9 & 92,9 & 2,8 \\
70 & 109,5 & 8,3 & 113,0 & 3,2 \\
\hline
\end{tabular}

Apesar da dispersão estimada dos dados de $J_{c}\left(\hat{\alpha}_{J}\right)$ ser relativamente mais baixa quando comparada com a dispersão teórica $\left(\alpha_{J}=2\right)$, principalmente nas temperaturas de 60 e $70{ }^{\circ} \mathrm{C}$, observa-se a partir da Tabela 5.6 que os valores de $\hat{J}_{0}$ não são afetados significativamente por tais medidas, conforme evidenciado pela diferença relativa entre as medidas de $\hat{J}_{0}{ }^{\alpha=2}$ e $\hat{J}_{0}$. 


\subsection{Análise fractográfica e medição da frente de trinca}

Uma vez demonstrado que o comportamento da dispersão dos dados de tenacidade à fratura pode ser bem descrito pela distribuição triparamétrica de Weibull, a metodologia da curva mestra pode ser aplicável ao aço USI AR 450 para estimar a temperatura de referência e, portanto, avaliar o comportamento da tenacidade ao longo da região de transição dúctil-frágil. No entanto, a sua aplicabilidade envolve uma análise preliminar dos dados a fim de averiguar se tais medidas condizem com os critérios de validade do campo HRR. Essa análise consiste essencialmente em avaliar a superfície de fratura, por meio de análises fractográficas, com o intuito de verificar possíveis ocorrências de crescimento de trinca precedente à instabilidade por fratura frágil. Além disso, as análises fractográficas permitem, por meio de técnicas de medição óptica, calcular os comprimentos reais das frentes de trinca os quais entram no cálculo do limite de deformação $\left(M_{o}\right)$ e, portanto, na verificação da sua validade segundo o limite estabelecido pela E1921 (i.e., $M_{o}=\left(b_{o} \sigma_{y s}^{T_{i}}\right) / J_{y s} \geq M$, onde $M=30$ e $T_{i}$ a temperatura de ensaio), conforme dados demonstrados na Tabela 5.7 apresentada na Seção 5.6.

As análises fractográficas, por microscopia eletrônica de varredura (MEV), são realizadas apenas nos corpos de prova de maior tenacidade, conforme o critério estabelecido na Seção 4.6.4. As fractografias apresentadas nas Figuras 5.20-5.22 correspondem aos corpos de prova ensaiados nas temperaturas de 50,60 e $70^{\circ} \mathrm{C}$, nessa ordem. 
Figura 5.19 - Superfície de fratura do corpo de prova CP31 ensaiado a $50{ }^{\circ} \mathrm{C}$ : (a) macrografia para medição da frente de trinca; (b) região de transição entre a pré-trinca nucleada por fadiga e início da fratura (35x); (c) microfractografia da zona de processo de fratura (200x); (d) microfractografia da zona de processo de fratura (1000x)
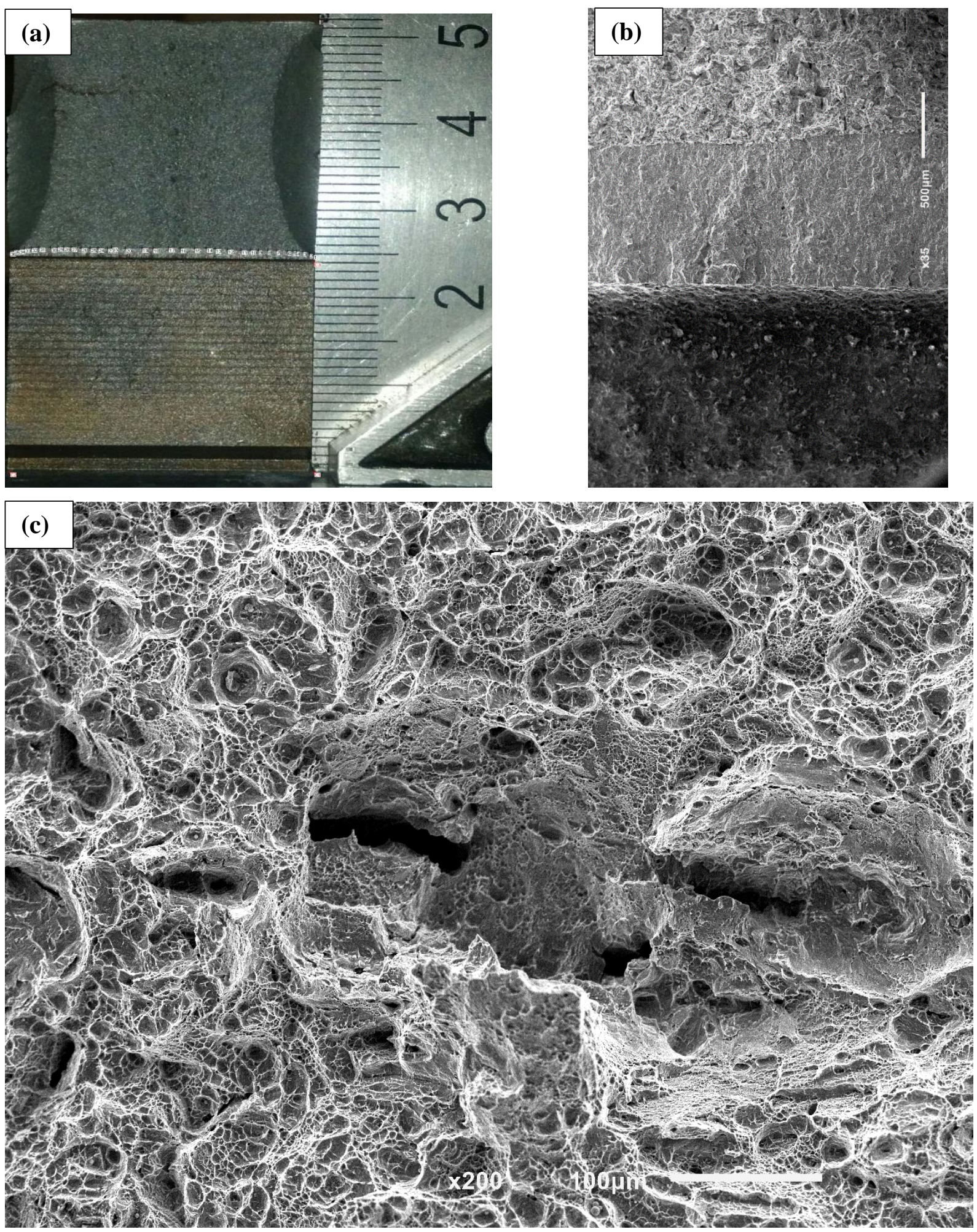


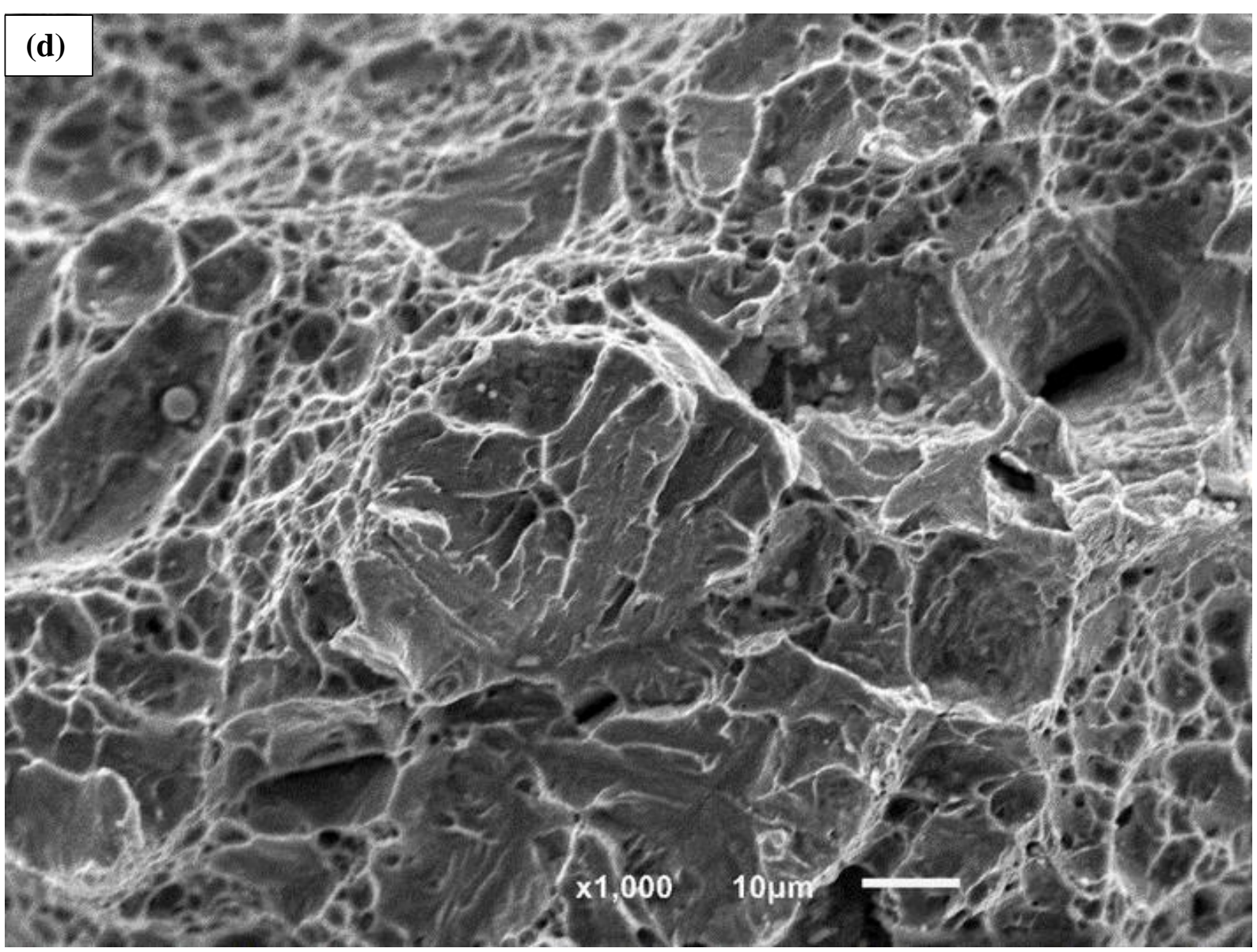


Figura 5.20 - Superfície de fratura do corpo de prova CP18 ensaiado a $60{ }^{\circ} \mathrm{C}$ : (a) macrografia para medição da frente de trinca; (b) região de transição entre a pré-trinca nucleada por fadiga e início da fratura (35x); (c) microfractografia da zona de processo de fratura (35x); (d) microfractografia da zona de processo de fratura (500x)
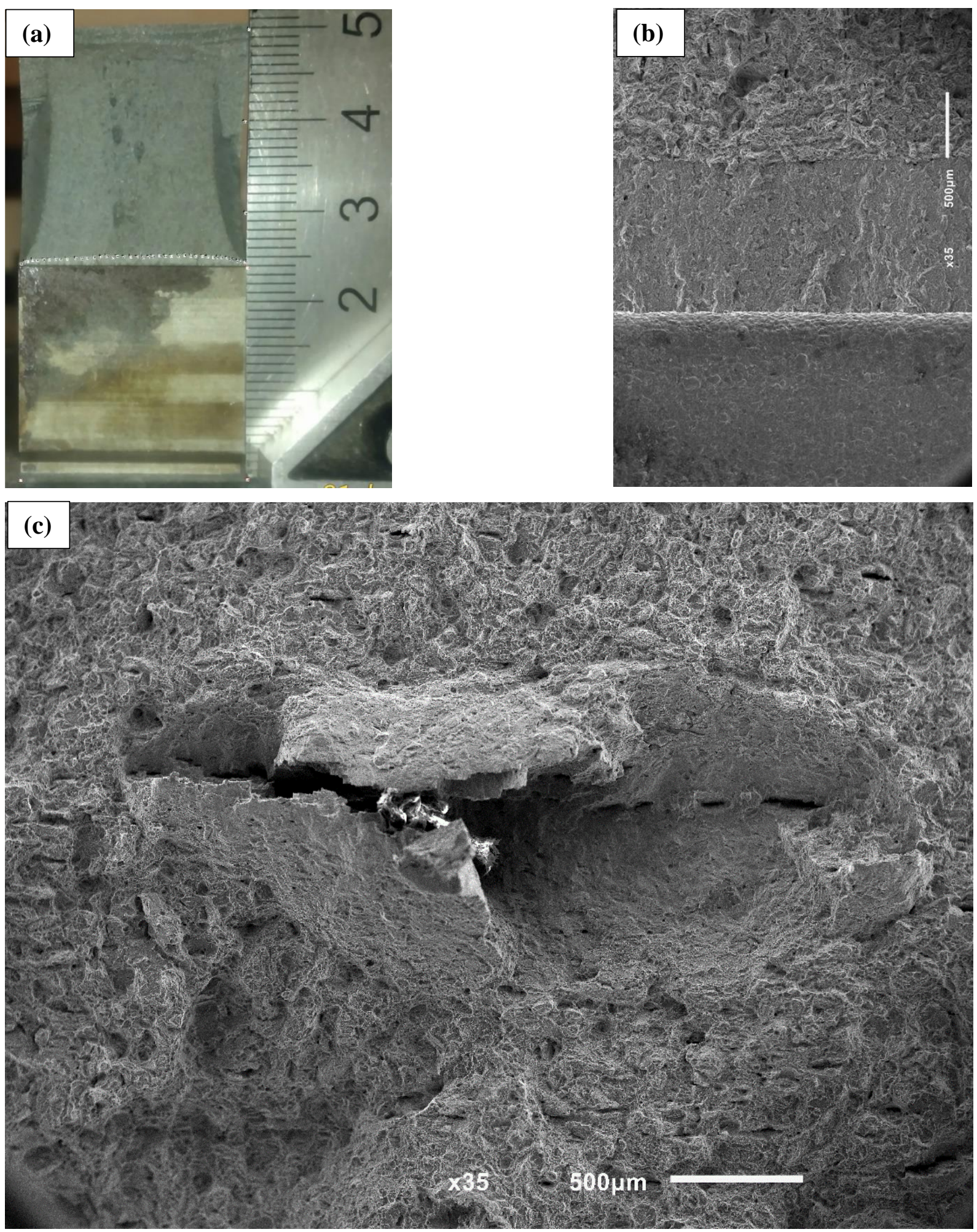


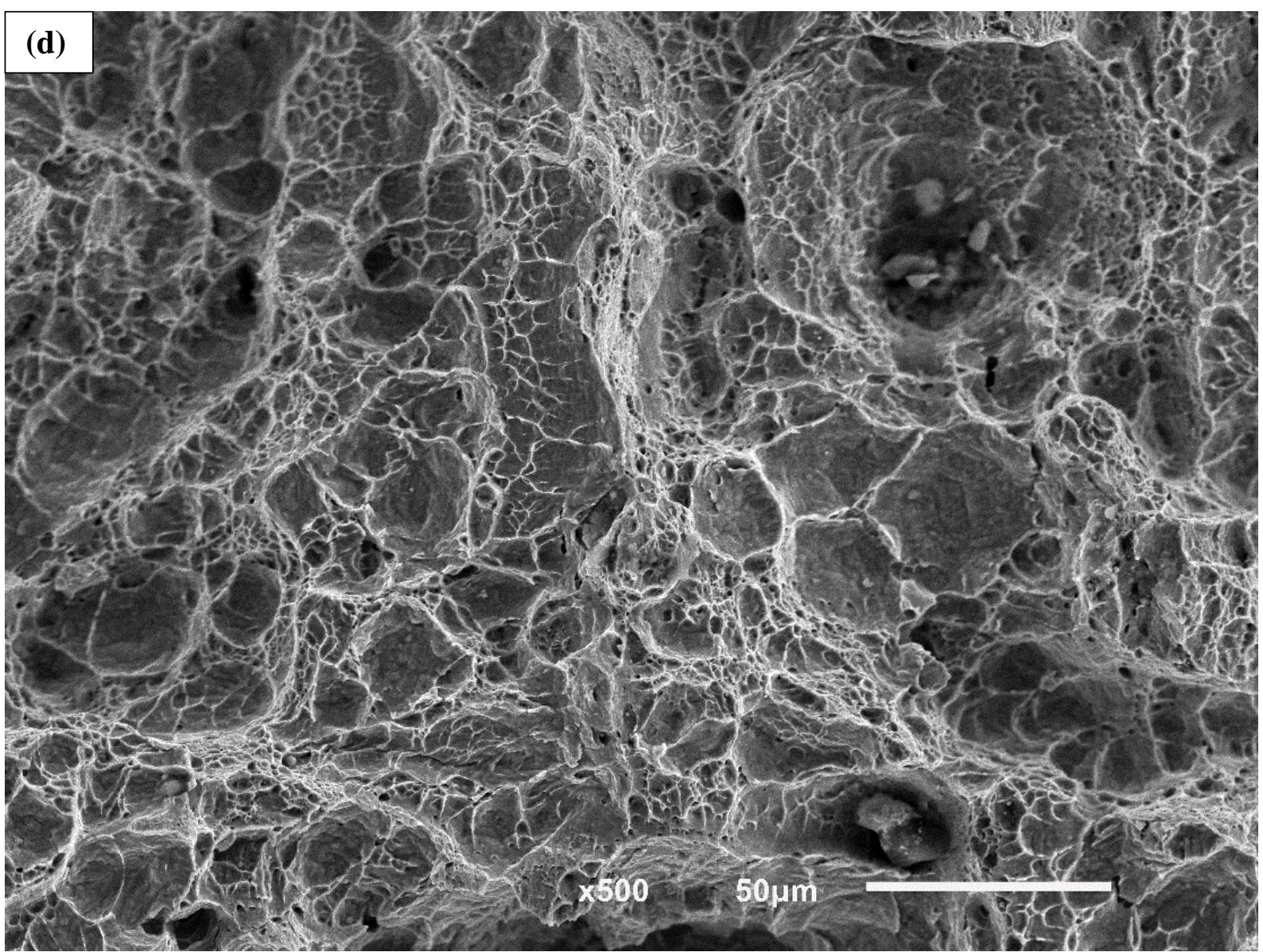

Figura 5.21 - Superfície de fratura do corpo de prova CP33 ensaiado a $70{ }^{\circ} \mathrm{C}$ : (a) macrografia para medição da frente de trinca; (b) região de transição entre a pré-trinca nucleada por fadiga e início da fratura (35x); (c) microfractografia da zona de processo de fratura (35x); (d) microfractografia da zona de processo de fratura (200x)
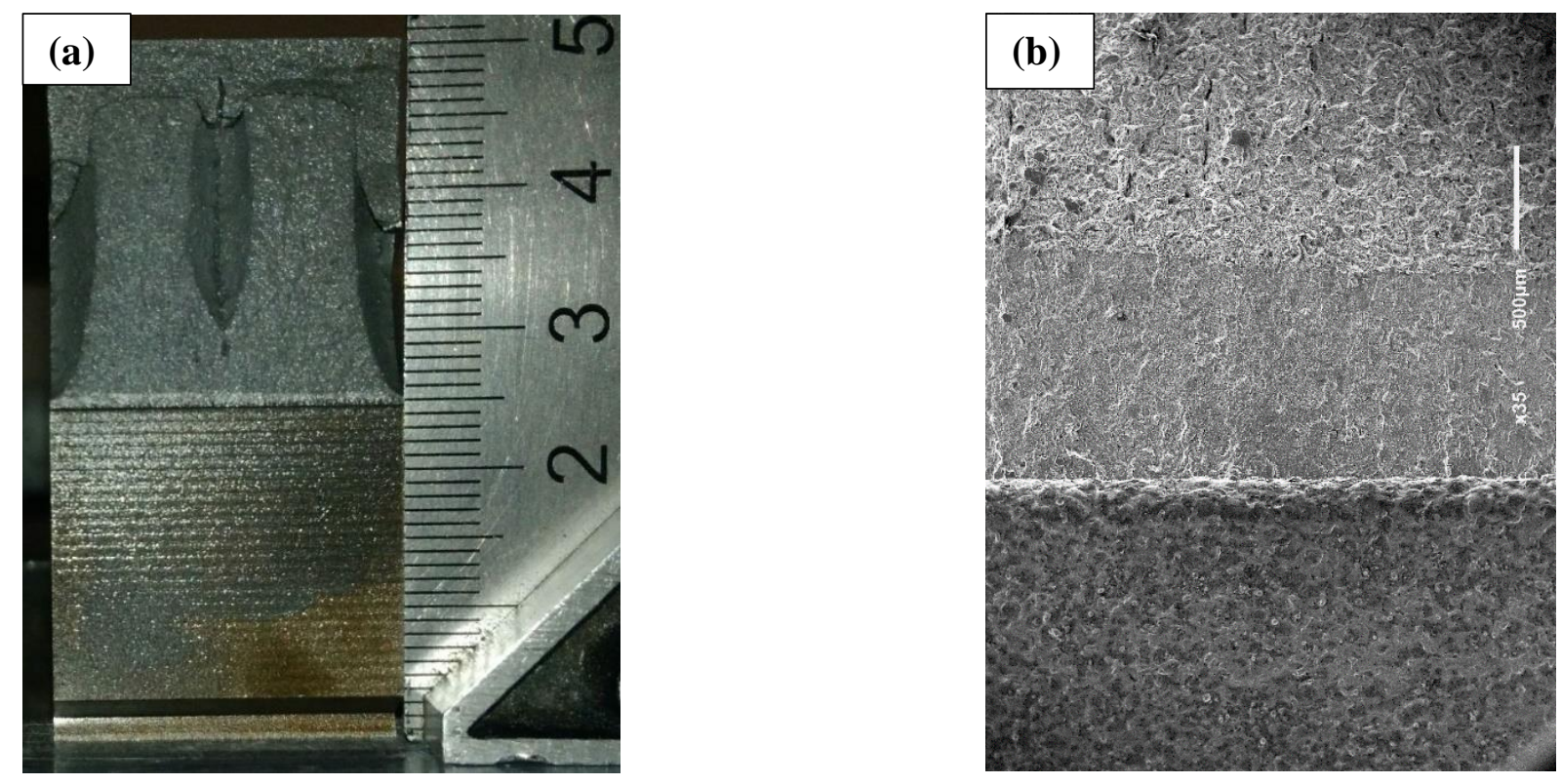


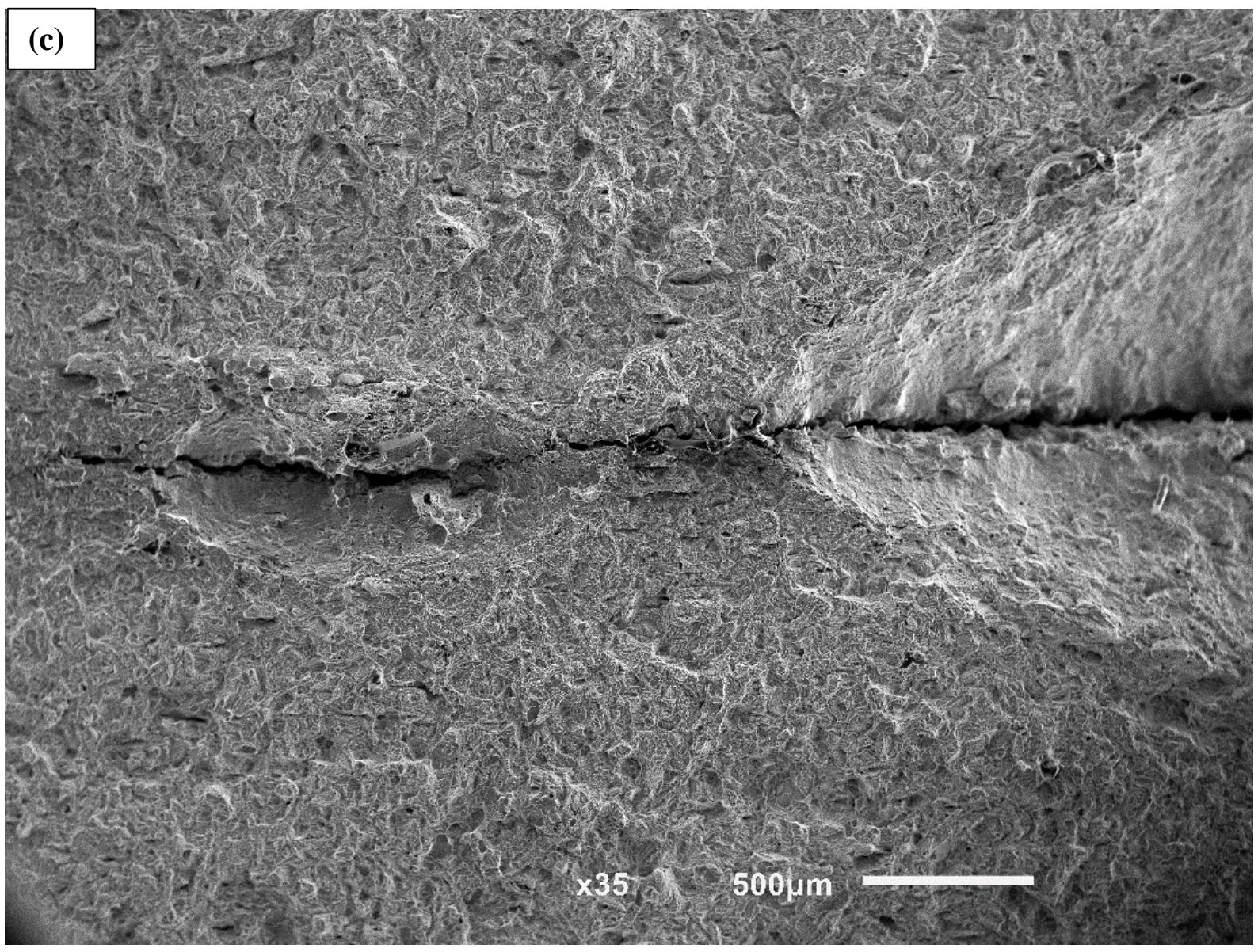

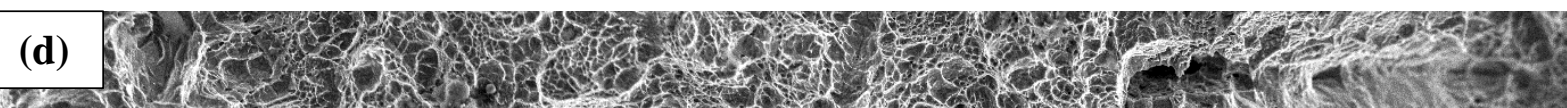

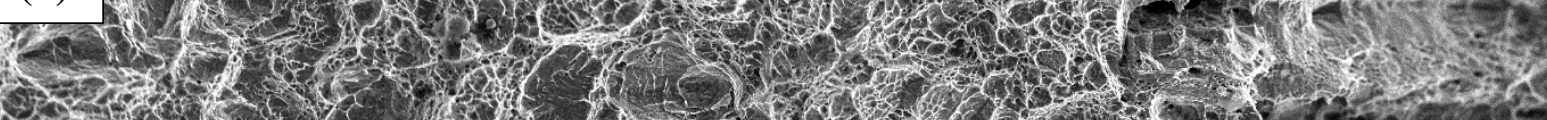

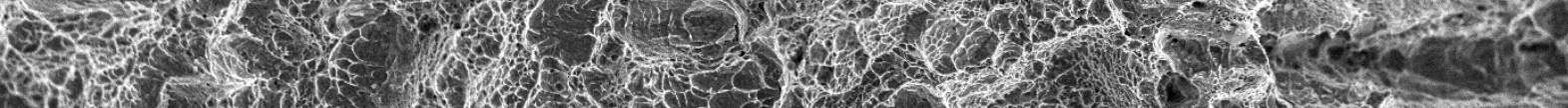

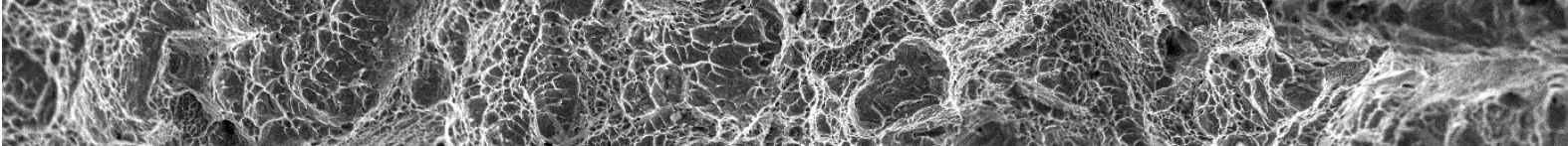

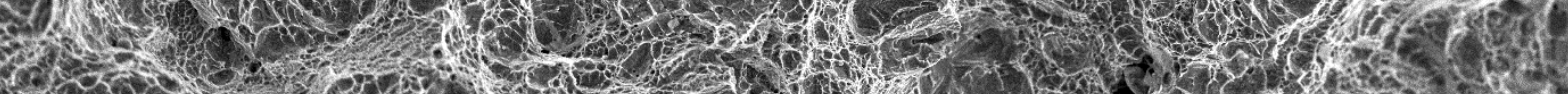

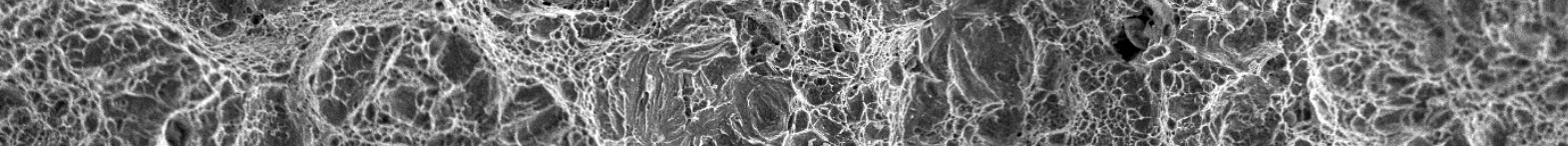

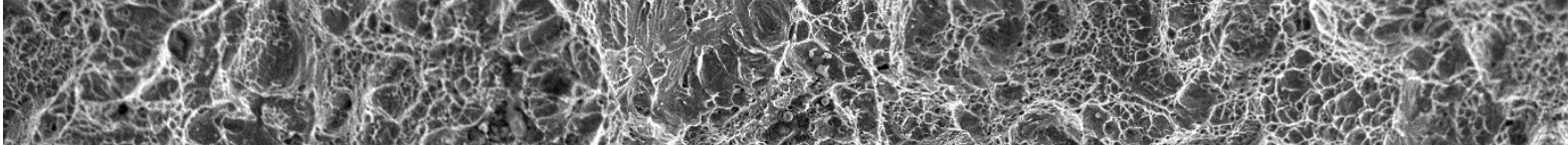

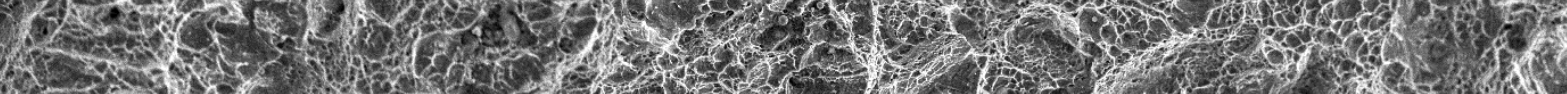

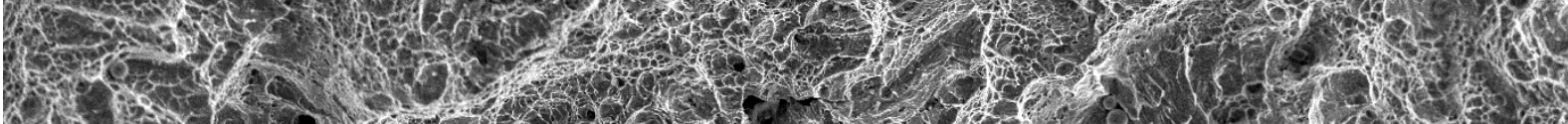

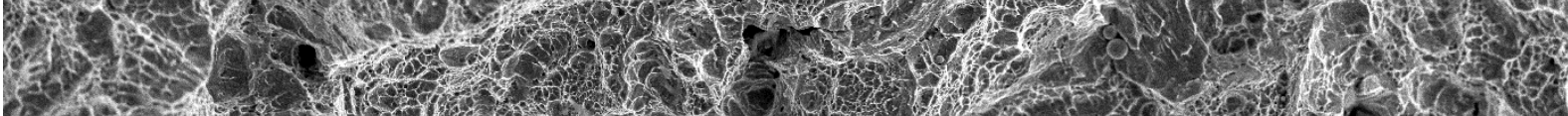

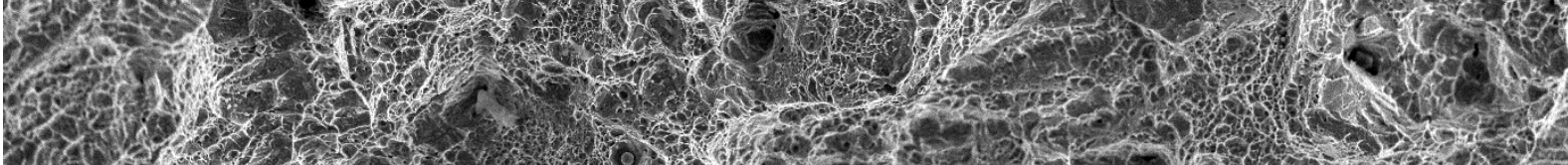

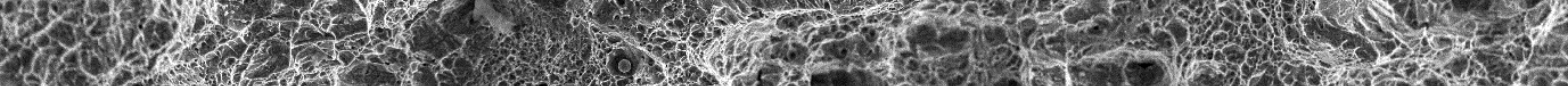

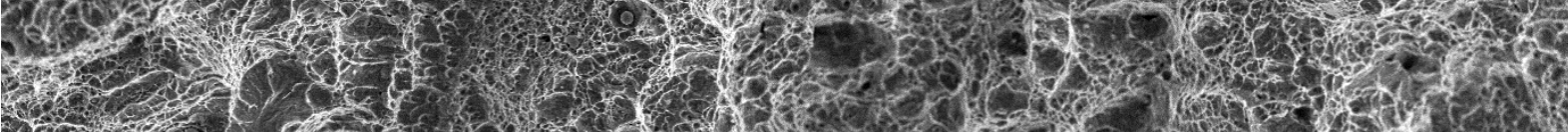

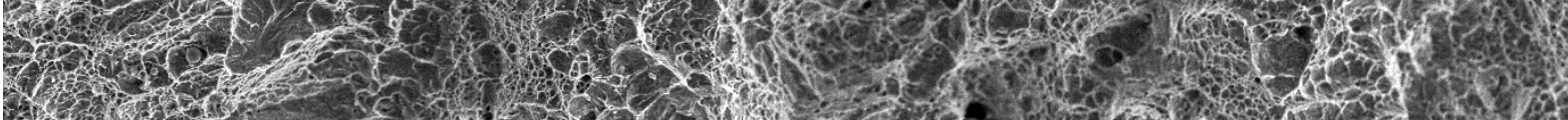

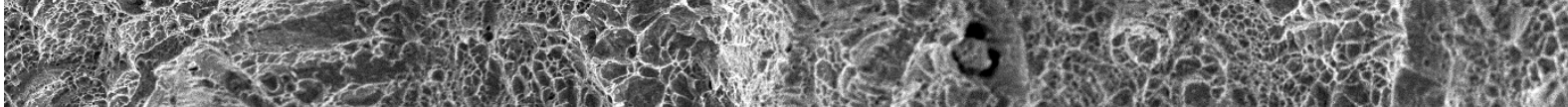

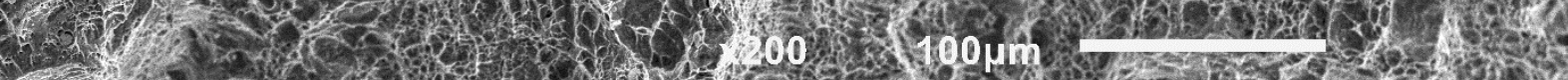

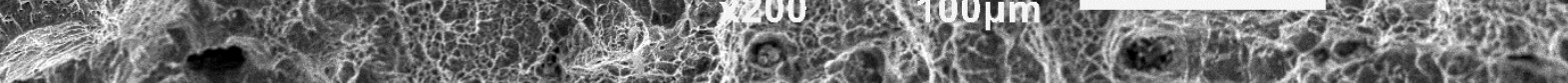


Conforme se observa nas fractografias apresentadas pelas Figuras 5.20 (a) e (b) - 5.22 (a) e (b), a instabilidade por clivagem não é precedida por crescimento subcrítico de trinca. Uma característica morfológica marcante observada em praticamente todas as superfícies é a presença de shear lips ("lábios de cisalhamento") cuja formação é governada pelos planos de deformação independentemente da espessura do corpo de prova[72]. As Figuras 5.19 (b) - 5.22 (b) mostram a transição bem definida entre a pré-trinca nucleada por fadiga e o início da superfície de fratura a qual é isenta de rasgamento dúctil.

À exceção de um único ensaio realizado a $80^{\circ} \mathrm{C}$ cuja frente de trinca é apresentada mais adiante, todos os corpos de prova apresentaram características fractográficas semelhantes; isto é, com frentes de trincas uniformes e isentas de rasgamento dúctil. Diante disso, em relação ao critério de censura estabelecido pela E1921 para as situações nas quais ocorrem crescimento subcrítico, todos os valores de tenacidade à fratura são válidos. No entanto, por mais que não haja evidências de crescimento de trinca, a validade de tais dados fica ainda condicionada ao limite de deformação imposto pela E1921 cujo valor nominal é dado como sendo $M=30$. Desse modo, torna-se necessário avaliar os reais limites de deformação $\left(M_{o}\right)$ com base no ligamento remanescente real $\left(b_{o}=W-a_{o}\right)$ o qual é dado somente a partir da medição da frente de trinca pelo método dos 9 pontos, conforme procedimento estabelecido pelas normas E1820 e E1921. Na Tabela 5.7 são apresentados os valores das medições de frente trinca $\left(a_{o}\right)$ bem como os reais limites de deformação $\left(M_{o}\right)$ os quais são definidos pela tensão de escoamento na temperatura de ensaio $\left(\sigma_{y s}^{T_{i}}\right)$. Na mesma tabela, são apresentados os valores de tenacidade à fratura expressos em termos do fator de intensidade de tensão elasto-plástico $\left(K_{J c}\right)$ cuja conversão a partir dos valores de $J_{c}$ é realizada por meio do módulo de elasticidade ajustada para a temperatura de ensaio $\left(E^{T_{i}}\right)$. É importante ressaltar que tanto o valor de $\sigma_{y s}^{T_{i}}$ quanto de $E^{T_{i}}$ é ajustado por meio das expressões da E1921 conforme já abordada na Seção 4.6.1. 
Tabela 5.7 - Resumo dos dados de tenacidade à fratura e dos limites de deformação

\begin{tabular}{|c|c|c|c|c|c|c|c|c|}
\hline $\begin{array}{l}\text { Temperatura } \\
\qquad\left({ }^{\circ} \mathrm{C}\right)\end{array}$ & $\begin{array}{l}\text { Corpos de } \\
\text { Prova } \\
\text { (Número) }\end{array}$ & $\begin{array}{c}E \\
(\mathrm{GPa})\end{array}$ & $\begin{array}{c}\sigma_{y s} \\
(\mathrm{MPa})\end{array}$ & $\begin{array}{c}J_{\min } \\
\left(\mathrm{kJ} / \mathrm{m}^{2}\right)\end{array}$ & $\begin{array}{c}J_{C} \\
\left(\mathrm{~kJ} / \mathrm{m}^{2}\right)\end{array}$ & $\begin{array}{c}K_{J_{C}} \\
(\mathrm{MPa} \sqrt{ } \mathrm{m})\end{array}$ & $\begin{array}{c}a_{0} \\
(\mathrm{~mm})\end{array}$ & $\begin{array}{l}M \\
(-)\end{array}$ \\
\hline \multirow{3}{*}{-20} & 1 & 205,250 & 1260 & 1,77 & 11 & 50 & 24,96 & 2951 \\
\hline & 2 & 205,250 & 1260 & 1,77 & 18 & 64 & 25,41 & 1588 \\
\hline & 3 & 205,250 & 1260 & 1,77 & 14 & 56 & 25,29 & 2099 \\
\hline \multirow{3}{*}{-10} & 4 & 204,625 & 1251 & 1,78 & 30 & 82 & 24,98 & 1073 \\
\hline & 5 & 204,625 & 1251 & 1,78 & 12 & 52 & 24,95 & 2665 \\
\hline & 6 & 204,625 & 1251 & 1,78 & 16 & 59 & 25,52 & 2011 \\
\hline \multirow{3}{*}{0} & 7 & 204,000 & 1244 & 1,78 & 15 & 57 & 25,16 & 2184 \\
\hline & 8 & 204,000 & 1244 & 1,78 & 20 & 67 & 25,07 & 1616 \\
\hline & 9 & 204,000 & 1244 & 1,78 & 17 & 62 & 25,71 & 1830 \\
\hline \multirow{3}{*}{25} & 10 & 202,438 & 1229 & 1,80 & 33 & 86 & 25,5 & 943 \\
\hline & 11 & 202,438 & 1229 & 1,80 & 18 & 64 & 25,11 & 1723 \\
\hline & 12 & 202,438 & 1229 & 1,80 & 25 & 74 & 25,72 & 1253 \\
\hline 80 & 13 & 199,000 & 1197 & 1,83 & 145 & 178 & 25,4 & 209 \\
\hline \multirow{9}{*}{50} & 14 & 200,875 & 1212 & 1,81 & 47 & 102 & 24,89 & 662 \\
\hline & 15 & 200,875 & 1212 & 1,81 & 67 & 122 & 25,53 & 456 \\
\hline & 16 & 200,875 & 1212 & 1,81 & 43 & 97 & 24,85 & 737 \\
\hline & 26 & 200,875 & 1212 & 1,81 & 45 & 100 & 25,23 & 682 \\
\hline & 27 & 200,875 & 1212 & 1,81 & 53 & 108 & 25,55 & 582 \\
\hline & 28 & 200,875 & 1212 & 1,81 & 53 & 108 & 25,6 & 574 \\
\hline & 29 & 200,875 & 1212 & 1,81 & 56 & 111 & 25,51 & 548 \\
\hline & 30 & 200,875 & 1212 & 1,81 & 44 & 98 & 24,48 & 733 \\
\hline & 31 & 200,875 & 1212 & 1,81 & 85 & 137 & 25,01 & 369 \\
\hline \multirow{9}{*}{60} & 17 & 200,250 & 1207 & 1,82 & 90 & 140 & 24,95 & 348 \\
\hline & 18 & 200,250 & 1207 & 1,82 & 110 & 155 & 24,92 & 285 \\
\hline & 19 & 200,250 & 1207 & 1,82 & 77 & 130 & 25,58 & 397 \\
\hline & 20 & 200,250 & 1207 & 1,82 & 102 & 150 & 25,16 & 305 \\
\hline & 21 & 200,250 & 1207 & 1,82 & 94 & 144 & 25,24 & 327 \\
\hline & 22 & 200,250 & 1207 & 1,82 & 78 & 131 & 25,28 & 395 \\
\hline & 23 & 200,250 & 1207 & 1,82 & 94 & 144 & 25,16 & 329 \\
\hline & 24 & 200,250 & 1207 & 1,82 & 76 & 129 & 25,25 & 408 \\
\hline & 25 & 200,250 & 1207 & 1,82 & 86 & 138 & 25,11 & 360 \\
\hline \multirow{9}{*}{70} & 32 & 199,625 & 1202 & 1,82 & 101 & 149 & 25,54 & 50 \\
\hline & 33 & 199,625 & 1202 & 1,82 & 139 & 175 & 25,54 & 36 \\
\hline & 34 & 199,625 & 1202 & 1,82 & 117 & 160 & 25,76 & 43 \\
\hline & 35 & 199,625 & 1202 & 1,82 & 101 & 149 & 25,48 & 50 \\
\hline & 36 & 199,625 & 1202 & 1,82 & 95 & 144 & 25,59 & 53 \\
\hline & 37 & 199,625 & 1202 & 1,82 & 107 & 153 & 25,14 & 48 \\
\hline & 38 & 199,625 & 1202 & 1,82 & 105 & 152 & 25,7 & 48 \\
\hline & 39 & 199,625 & 1202 & 1,82 & 110 & 155 & 25,58 & 46 \\
\hline & 40 & 199,625 & 1202 & 1,82 & 104 & 151 & 25,01 & 49 \\
\hline
\end{tabular}


A partir da análise da Tabela 5.7 observa-se que todos os valores de tenacidade à fratura não excedem o limite de deformação $\left(M_{o}<30\right)$, de modo que todos os dados são considerados válidos perante as condições regidas pelo campo HRR. Na realidade, os limites estão muito além do valor estabelecido pela norma. Isso deve-se principalmente à elevada tensão de escoamento do material a qual é superior $1000 \mathrm{MPa}$.

Já em relação às microfractografias apresentadas pelas Figuras 5.20 (c) e (d) - 5.22 (c) e (d), observa-se que, independentemente da temperatura de ensaio, os aspectos morfológicos demonstram se tratar de mecanismos dúcteis e frágeis, uma vez que facetas de clivagem e dimples são facilmente observados e quase que igualmente distribuídos. Essas características são típicas de um processo de fratura conhecido como quase-clivagem. Tal comportamento ocorre devido à presença de pacotes de ripas de martensita, pois ao encontrar diferentes planos de fratura na fronteira desses pacotes, a trinca sofre um desvio seguido de formação de dimples. Além disso, pode-se observar que nas regiões referentes à porção central, onde são observados possíveis indícios de delaminação (vide macrofractografias das Figuras 5.20 (a) - 5.22 (a)), a superfície de fratura mostra-se demasiadamente irregular. Tais características morfológicas podem estar associadas aos inúmeros eventos de instabilidade na carga (pop-in) durante a porção final das curvas P-CMOD, discutidas anteriormente na Seção 5.5. De modo geral, todos os corpos de prova ensaiados a $50 \leq T \leq 70^{\circ} \mathrm{C}$ apresentam características semelhantes.

Com o intuito de demonstrar o processo realizado para o cálculo do comprimento de trinca, $a_{o}$, na Figura 5.23 é apresentada uma fractografia da superfície de fratura do corpo de prova CP13 o qual é ensaiado a $80^{\circ} \mathrm{C}$. Tal ensaio trata-se apenas de uma análise exploratória para saber a partir de quais condições o material poderia começar a apresentar crescimento estável precedente à instabilidade por clivagem superior ao valor limite estabelecido por norma. Figura 5.22 - Superfície de Fratura corpo de prova 13 e ajuste de pontos da superfície.

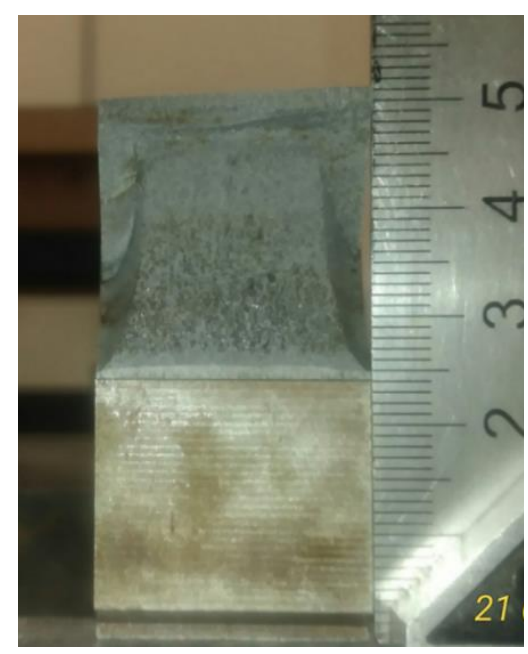

Medidas da frente de trinca

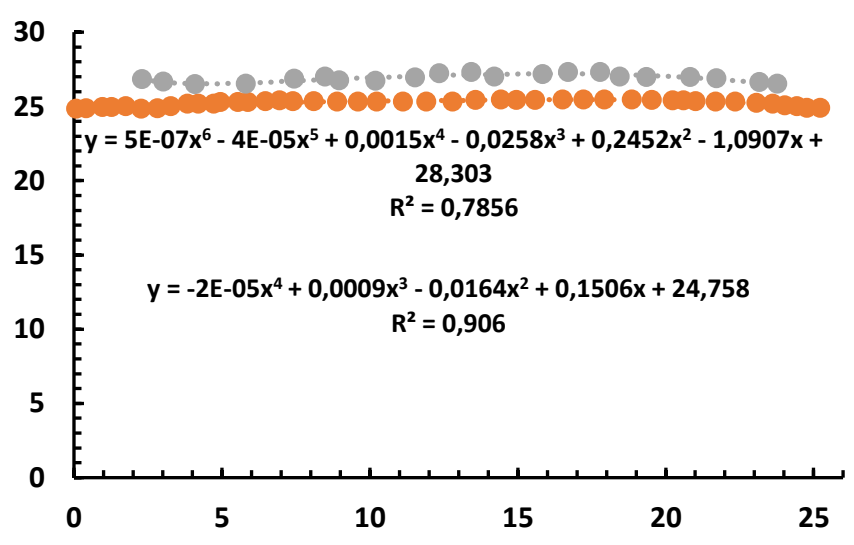


Utilizando o método dos 9-pontos é determinado a frente de trinca. O método é feito a partir do ajuste polinomial de n pontos dispersos ao longo da frente de pré-trinca e depois igualmente espaçados em 9 pontos que utilizam o melhor ajuste polinomial. Como o exemplo da Figura 5.23, deve se utilizar os critérios previstos em norma para avaliar a validade desse ensaio. Baseando-se no critério da E1921, o crescimento subcrítico de trinca, $\left(\Delta a_{p}\right)$, não pode exceder o menor valor entre $1,00 \mathrm{~mm}$ ou $5 \%$ do valor do ligamento remanescente. Assim, ao se fazer as medições na frente de trinca do corpo de prova CP13, o comprimento e o crescimento estável de trinca obtidos são, respectivamente, $a_{0}=24,88 \mathrm{~mm}$ e $a_{p}=26,90 \mathrm{~mm}$ resultado em um rasgamento de $\Delta a_{p}=2,019 \mathrm{~mm}$ o qual é superior ao valor limite de 1,00 mm. Portanto, esse ensaio é considerado inválido e o seu valor correspondente de tenacidade tratado como dado censurado. Todavia, é importante mencionar que esse dado em momento algum entra nas análises conduzidas neste estudo, sendo apresentado apenas como exemplo por justamente ter sido o único corpo a apresentar rasgamento dúctil precedente à instabilidade por clivagem. Todos as demais medições de frente de trinca seguiram rigorosamente o mesmo procedimento aqui descrito.

\subsection{Análise da temperatura de referência multitemperatura a partir da curva mestra padrão}

Após analisar o comportamento da dispersão dos dados de tenacidade à fratura por uma distribuição de Weibull triparamétrica (vide Seção 5.6) e os critérios de validade/censura das medidas experimentais de tenacidade (vide Seção 5.7), nesta seção é feita uma avaliação da aplicabilidade da metodologia da Curva Mestra (CM) para o aço temperado USI AR450 cuja principal característica é a sua alta dureza, sendo destinado principalmente a serviços de alto desgaste mecânico. Ao estabelecer uma temperatura de referência $\left(T_{0}\right)$, essa metodologia permite avaliar a dependência da tenacidade à fratura mediana com a temperatura ao longo de toda a região de transição dúctil-frágil (RTDF) bem como definir limites de tolerância associados a níveis específicos de probabilidade acumulada de falha para os valores de tenacidade à fratura expressos em termos do fator de intensidade de tensão elasto-plástico $K_{J_{C}}$.

A partir dos ensaios de tenacidade à fratura conduzidos em diversas temperaturas, são feitas estimativas da $T_{0}$ baseadas em mais de uma temperatura (multi-temperature analysis) e por meio de uma única temperatura (single-temperature analysis) segundo o procedimento 
padronizado pela ASTM E1921[5] . Como o foco do estudo é voltado para a análise multitemperatura, nesta seção são apresentadas e discutidas apenas as curvas referenciais baseadas na $T_{0}$ multitemperatura $\left(T_{0}^{M T}\right)$, enquanto as análises envolvendo o método da temperatura única são brevemente apresentadas no Apêndice B.

As curvas de tenacidade multitemperatura são determinadas inicialmente a partir de conjuntos distintos de dados de tenacidade, a saber: 1 ) dados de $K_{J_{c}}$ compreendidos na faixa de $-20 \leq T \leq 25^{\circ} \mathrm{C}$; 2) dados de $K_{J_{c}}$ compreendidos na faixa de $50 \leq T \leq 70{ }^{\circ} \mathrm{C}$ e 3 ) dados de $K_{J_{c}}$ compreendidos na faixa de $-20 \leq T \leq 70^{\circ} \mathrm{C}$ (i.e., por todos os dados de $K_{J_{c}}$ contidos na Tabela 5.7, exceto o dado de $K_{J_{c}}$ obtido a $80^{\circ} \mathrm{C}$ ). A escolha desses intervalos específicos de temperatura está associada ao comportamento das curvas P-CMOD apresentadas anteriormente nas Figuras 5.12(a) e 5.12(b) contidas na Seção 5.5, onde é possível observar que somente a partir da temperatura ambiente é que começa a haver o surgimento de uma plasticidade precedente à fratura, conforme região não-linear evidenciada na porção final da curva P-CMOD ( $25^{\circ} \mathrm{C}$ ). Já no Apêndice B, são demonstradas e discutidas as curvas baseadas na $T_{0}$ estimada por uma única temperatura $\left(T_{0}^{S T}\right)$. No que diz respeito à análise dada por uma única temperatura, embora a ASTM E1921 [5] recomende ao menos 6 ensaios válidos ${ }^{6}$ para a determinação da $T_{0}$ (vide Tabela 4.3 da Seção 4.6.5), no Apêndice B também são apresentadas as curvas obtidas a partir dos dados de $K_{J_{c}}$ determinados a $T=25,0,-10$ e $-20{ }^{\circ} \mathrm{C}$ (i.e., a partir de uma quantidade de dados de $K_{J_{c}}<6$ ) e $T=50,60,70^{\circ} \mathrm{C}$ (i.e., a partir de uma quantidade de dados de $K_{J_{c}}>6$ ), para uma análise complementar e individual das curvas mestra.

Nas Figuras 5.24-5.26 são apresentadas as curvas referenciais baseadas nas $T_{0}^{M T}$ estabelecidas nos intervalos de $-20 \leq T \leq 25^{\circ} \mathrm{C}, 50 \leq T \leq 70^{\circ} \mathrm{C}$ e $-20 \leq T \leq 70{ }^{\circ} \mathrm{C}$, respectivamente. Com exceção da CM apresentada na Figura 5.26, onde todos os conjuntos de dados de $K_{J_{c}}$ (representado por traços pretos) presentes no gráfico compõem o cálculo da $T_{0}^{M T}$, as demais curvas são determinadas apenas por um conjunto restrito conforme critério de escolha mencionado anteriormente. No entanto, com o intuito de avaliar a aderência da CM às medianas das distribuições (i.e., valor central da distribuição e que corresponde a uma $P_{f}=50 \%$ ) obtidas em temperaturas distintas daquelas usadas para se estimar a $T_{0}^{M T}$, nos gráficos das Figuras 5.24 e 5.25 também são dispostos todos os conjuntos de dados de $K_{J_{c}}$, além do ponto em destaque (representado pelo "retângulo" azul quase um traço) correspondente ao valor mediano da

${ }^{6}$ A quantidade de dados não censurados exigidos pode variar a depender do intervalo ( $\left.\mathrm{T}-\mathrm{T}_{0}\right)$ e da faixa dos valores de $\mathrm{KJ} c(\mathrm{med})$. Por exemplo, para a situação na qual T- $\mathrm{T}_{0}$ está definida entre -50 e $-36{ }^{\circ} \mathrm{C}$ e $\mathrm{KJ} c(\mathrm{med})$ entre 58 e $65 \mathrm{MPa} \sqrt{\mathrm{m}}$, a E1921 exige ao menos 8 dados de KJc não cesurados para se obter uma $\mathrm{T}_{0}$ confiável. 
tenacidade à fratura, $K_{J_{c}(m e d)}$. Essa aderência consiste em avaliar se tanto as medianas dos dados de $K_{J_{c}}$ que compõem as estimativas da $T_{0}^{M T}$ nos intervalos de $-20 \leq T \leq 25{ }^{\circ} \mathrm{C}$ (vide Figura 5.24) e $50 \leq T \leq 70^{\circ} \mathrm{C}$ (vide Figura 5.25) quanto as medianas daqueles dados obtidos posteriormente e antecedente a essas estimativas (i.e., dados de $K_{J_{c}}$ obtidos a 50, 60 e $70{ }^{\circ} \mathrm{C}$ posteriormente à primeira estimativa da $T_{0}^{M T}$ e dados de $K_{J_{c}}$ obtidos a $-20,-10$ e 0 e $25{ }^{\circ} \mathrm{C}$ anteriormente à segunda estimativa da $T_{0}^{M T}$ ) podem ser interceptadas próximas à curva mestra gerada pela referida $T_{0}^{M T}$. Além disso, nos gráficos são apresentadas as medidas em destaque correspondentes à tenacidade à fratura característica, $K_{0}$, (representadas pelo círculo preenchido em vermelho) para uma melhor visualização do comportamento da curva mestra em relação à distribuição dos dados de $K_{J_{c}}$.

Figura 5.23 - Análise da curva mestra obtida a partir da $T_{0}^{M T}$ avaliada na faixa $-20 \leq T \leq$ $25^{\circ} \mathrm{C}$ perante (a) à janela de validade e (b) à curva mediana

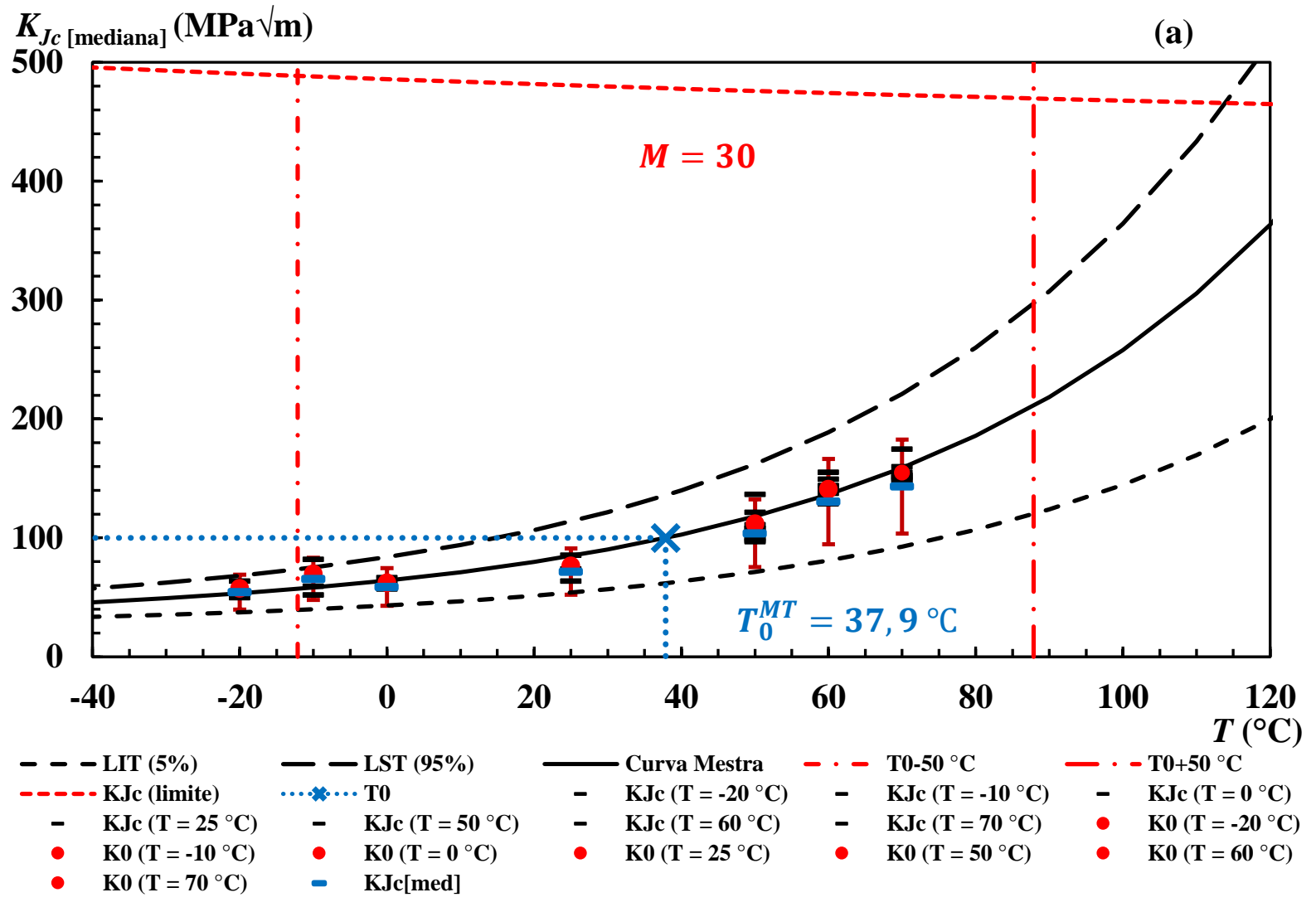




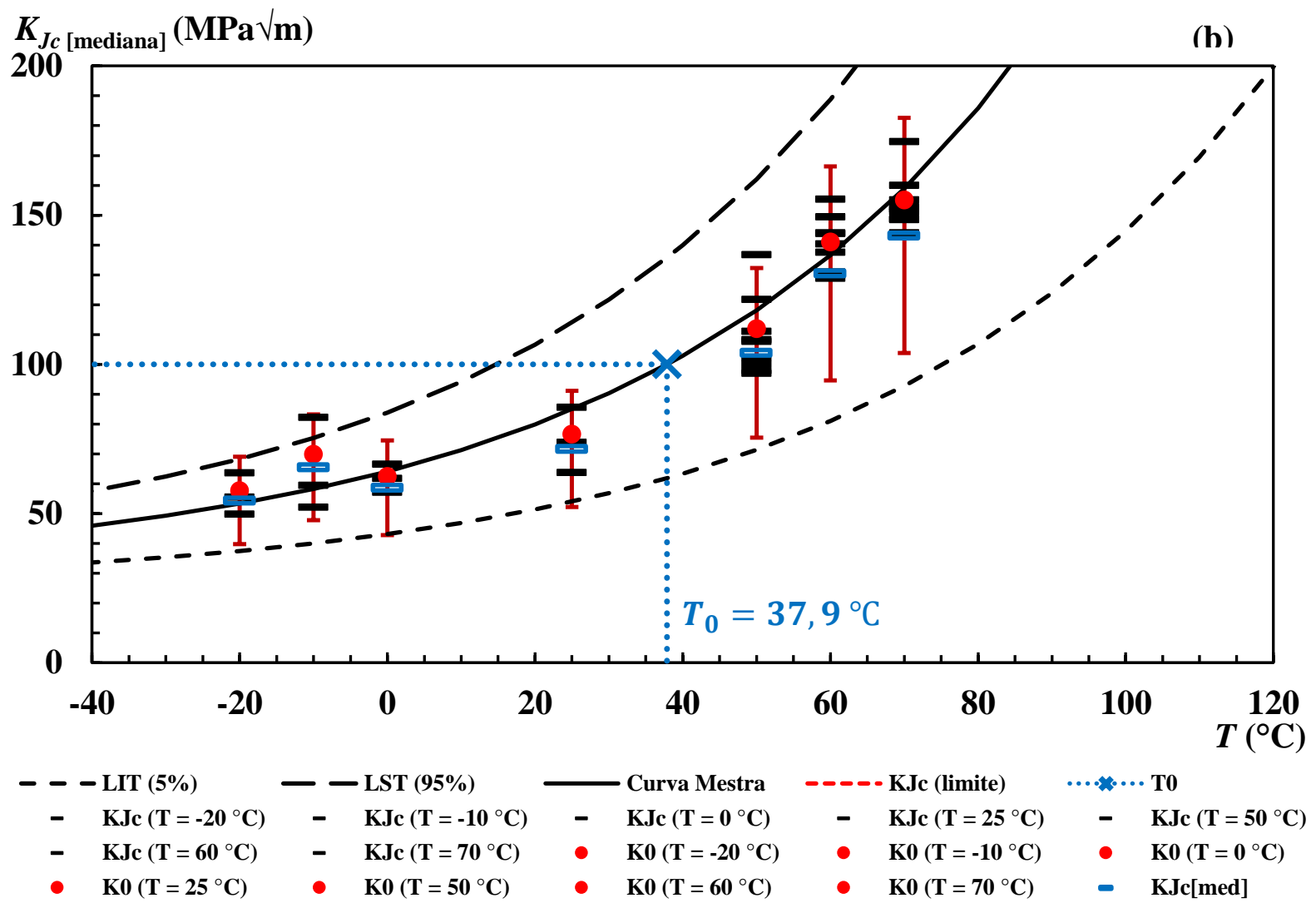

Figura 5.24 - Análise da curva mestra obtida a partir da $T_{0}^{M T}$ avaliada na faixa $50 \leq T \leq 70{ }^{\circ} \mathrm{C}$ perante (a) à janela de validade e (b) à curva mediana

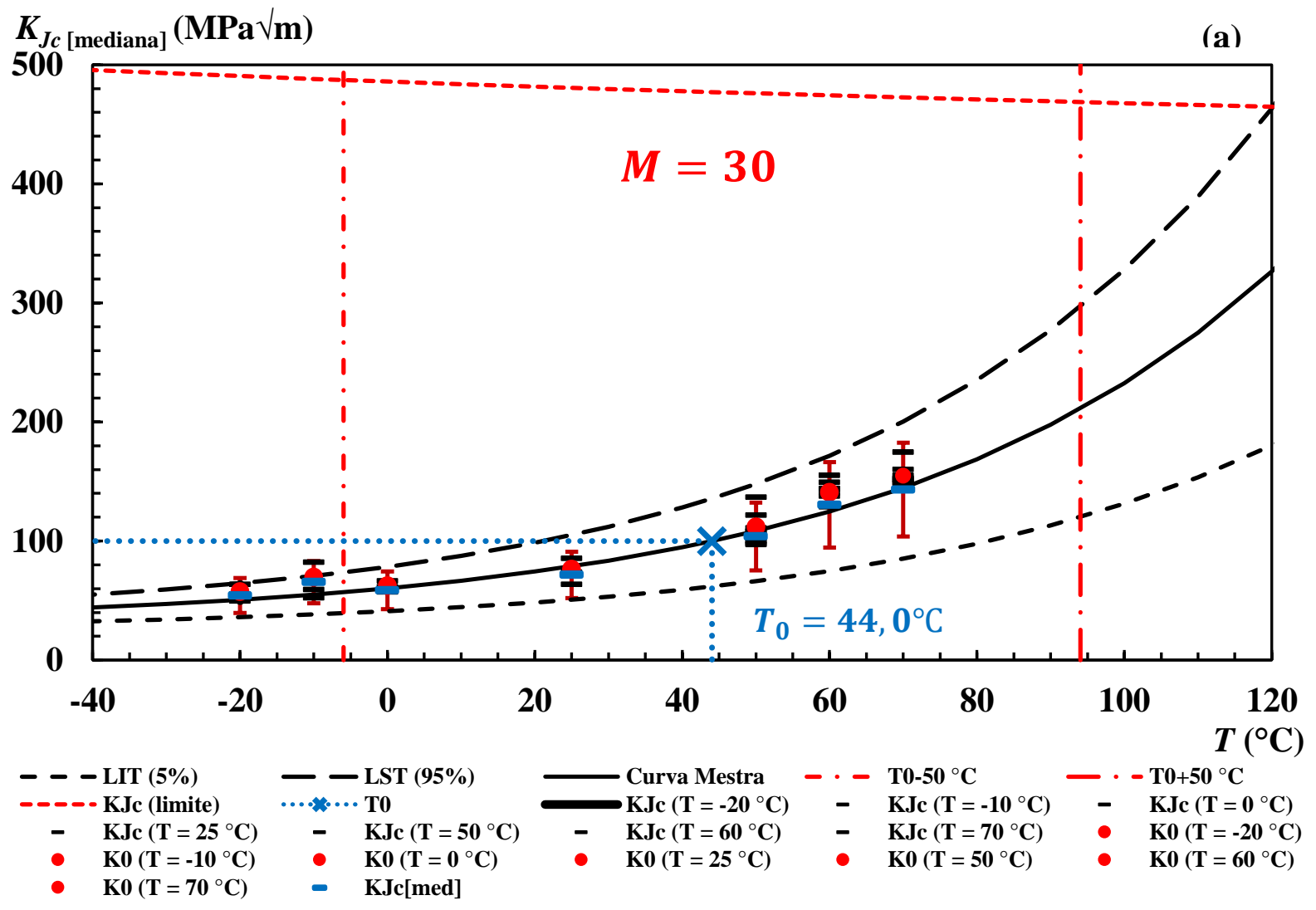




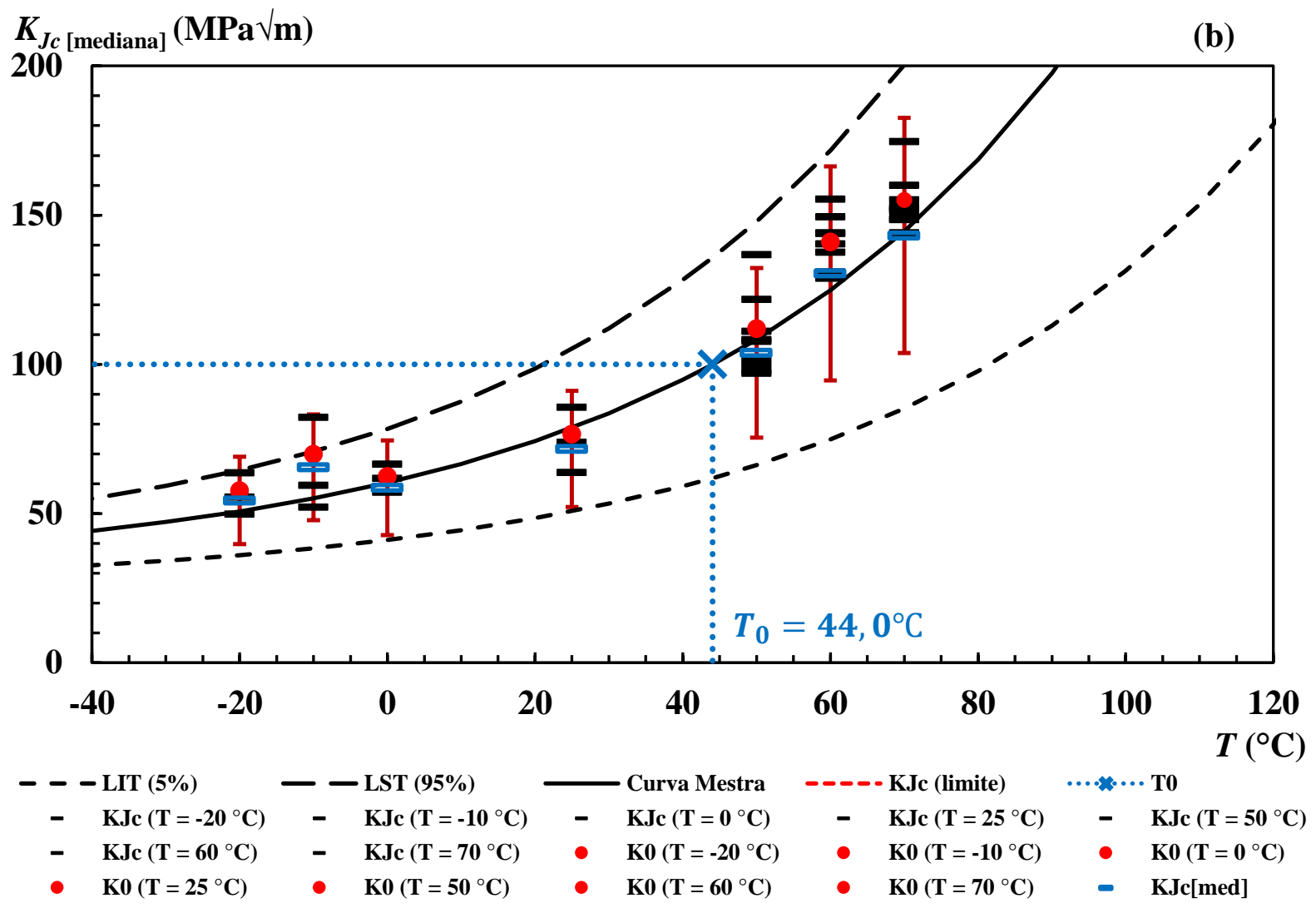

Figura 5.25 - Análise da curva mestra obtida a partir da $T_{0}^{M T}$ avaliada na faixa $-20 \leq T \leq$ $70{ }^{\circ} \mathrm{C}$ perante (a) à janela de validade e (b) à curva mediana

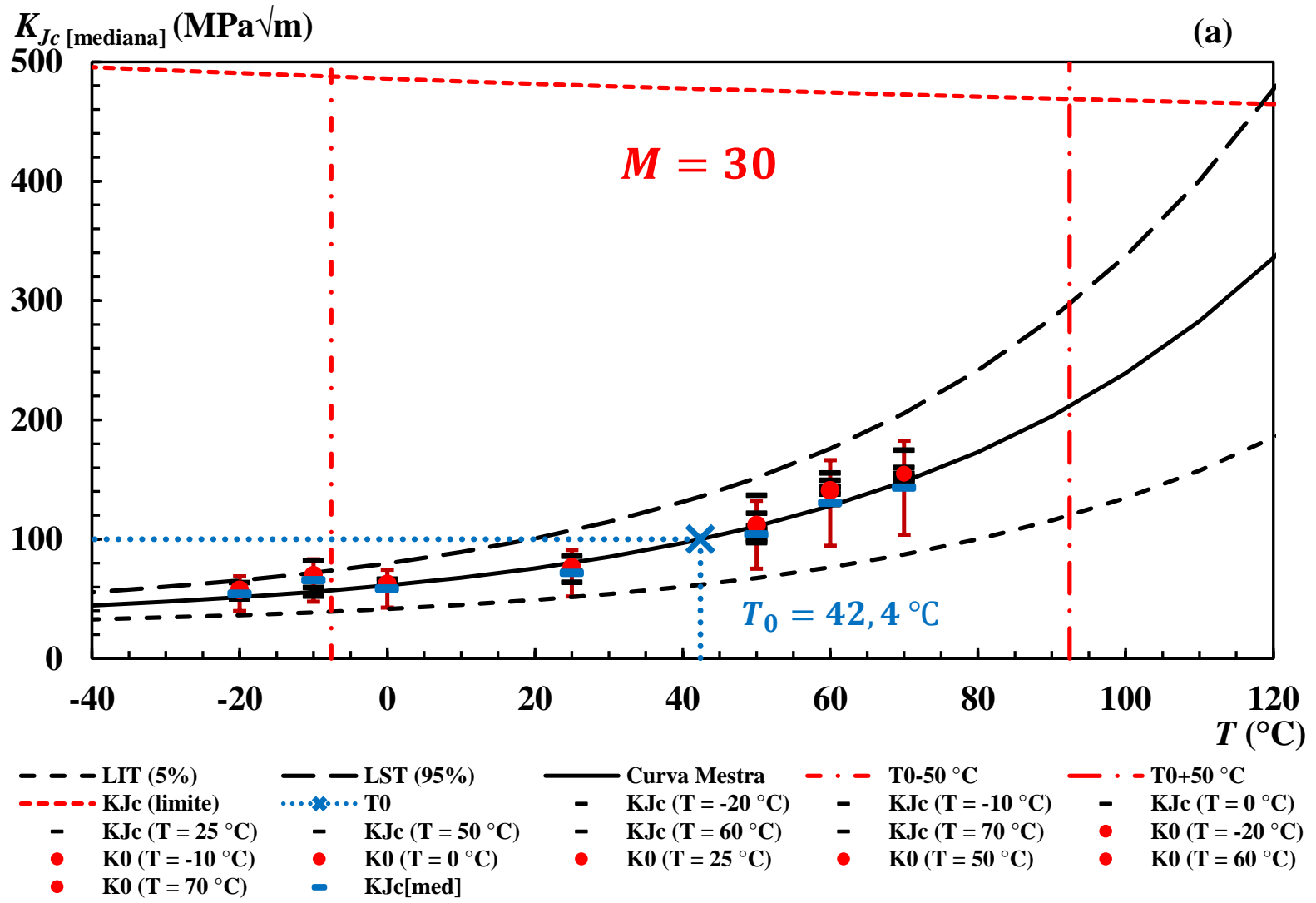




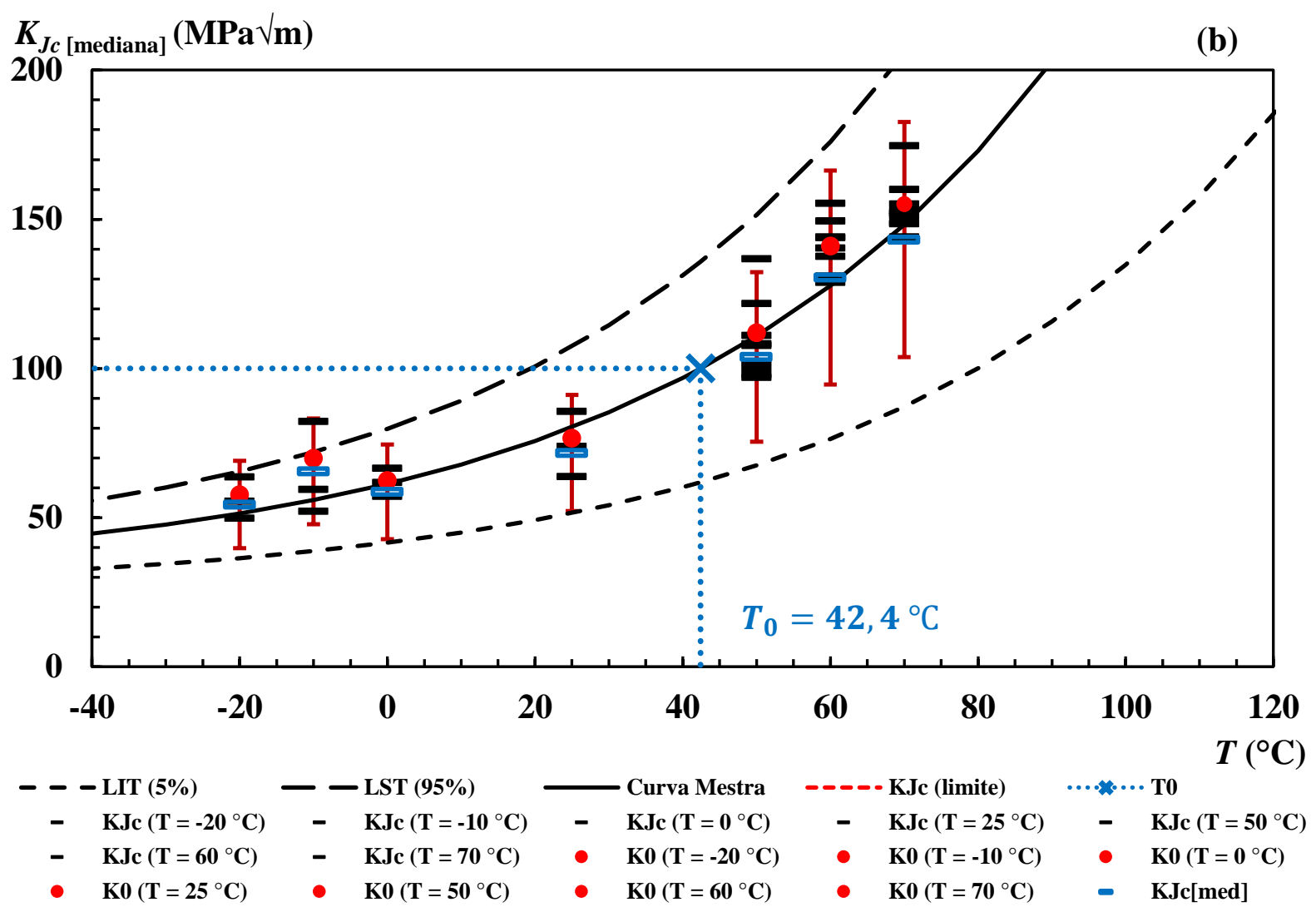

Analisando o comportamento das curvas mestra perante a janela que delimita a validade dos dados de $K_{J_{c}}$, vide Figuras 5.24(a)-5.26(a), observa-se que os dados obtidos a $-20{ }^{\circ} \mathrm{C}$ ficam excluídos da janela de validade em todas as estimativas da $T_{0}^{M T}$, o que demonstra que tais dados são obtidos a uma temperatura muito distante da $T_{0}$ do material. Essa evidência permite inferir que tais dados não são representativos da RTDF do aço USI AR450, mas sim pertencentes ao patamar inferior de tenacidade onde tais medidas são insensíveis às variações de temperatura. Embora os dados de $K_{J_{C}}$ obtidos a $-10^{\circ} \mathrm{C}$ estejam contidos dentro da janela de validade definida pela $T_{0}^{M T}$ avaliada na faixa $-20 \leq T \leq 25^{\circ} \mathrm{C}$, uma tendência similar é observada nos demais intervalos, conforme demonstrada nas Figuras 5.24(a) e 5.26(a), o que reforça a possibilidade de tais dados também não serem estimados em uma temperatura pertencente à RTDF do aço USI AR450. Em termos práticos, isso significa dizer que para $T \leq-10^{\circ} \mathrm{C}$, as medidas de $K_{J_{c}}$ são pouco sensíveis às variações de temperatura. Essa diferença relativamente alta entre a temperatura de ensaio $\left(T^{i}\right)$ e a temperatura de referência $\left(T_{0}^{M T}\right)$ impacta diretamente na acurácia e, consequentemente, na confiabilidade da $T_{0}^{M T}$ estimada a partir da inclusão desses dados, conforme discussão mais adiante. Diante disso, uma nova estimativa da $T_{0}^{M T}$ é conduzida, porém agora no intervalo de $0 \leq T \leq 70^{\circ} \mathrm{C}$. A curva mestra definida pela $T_{0}^{M T}$ no intervalo $0 \leq T \leq 70{ }^{\circ} \mathrm{C}$ é apresentada na Figura 5.27. 
Figura 5.26 - Análise da curva mestra obtida a partir da $T_{0}^{M T}$ avaliada na faixa $0 \leq T \leq 70{ }^{\circ} \mathrm{C}$ perante (a) à janela de validade e (b) à curva mediana

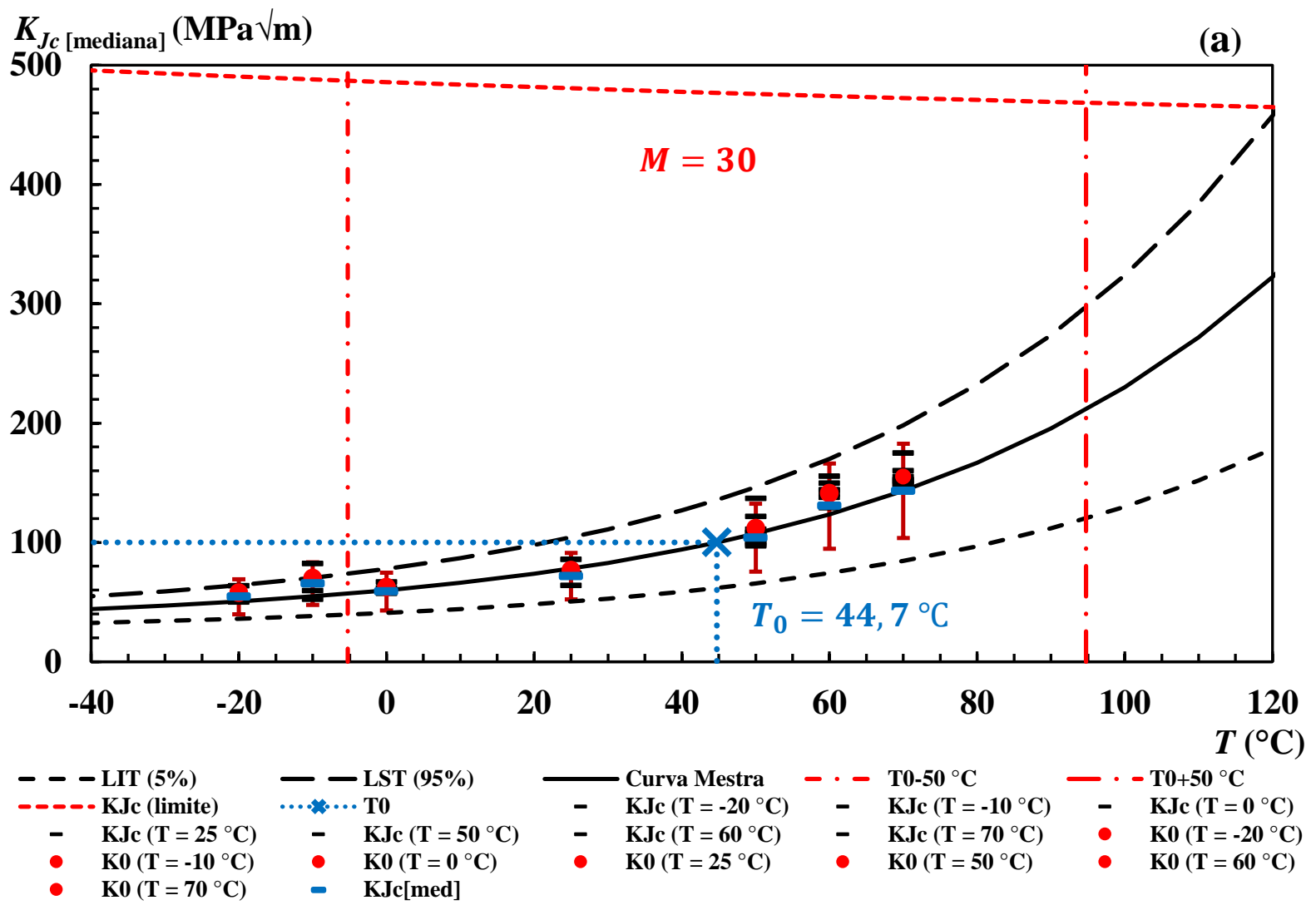

$\mathrm{K}_{\mathrm{Jc}}$ [mediana] (MPa $\left.\sqrt{ } \mathrm{m}\right)$

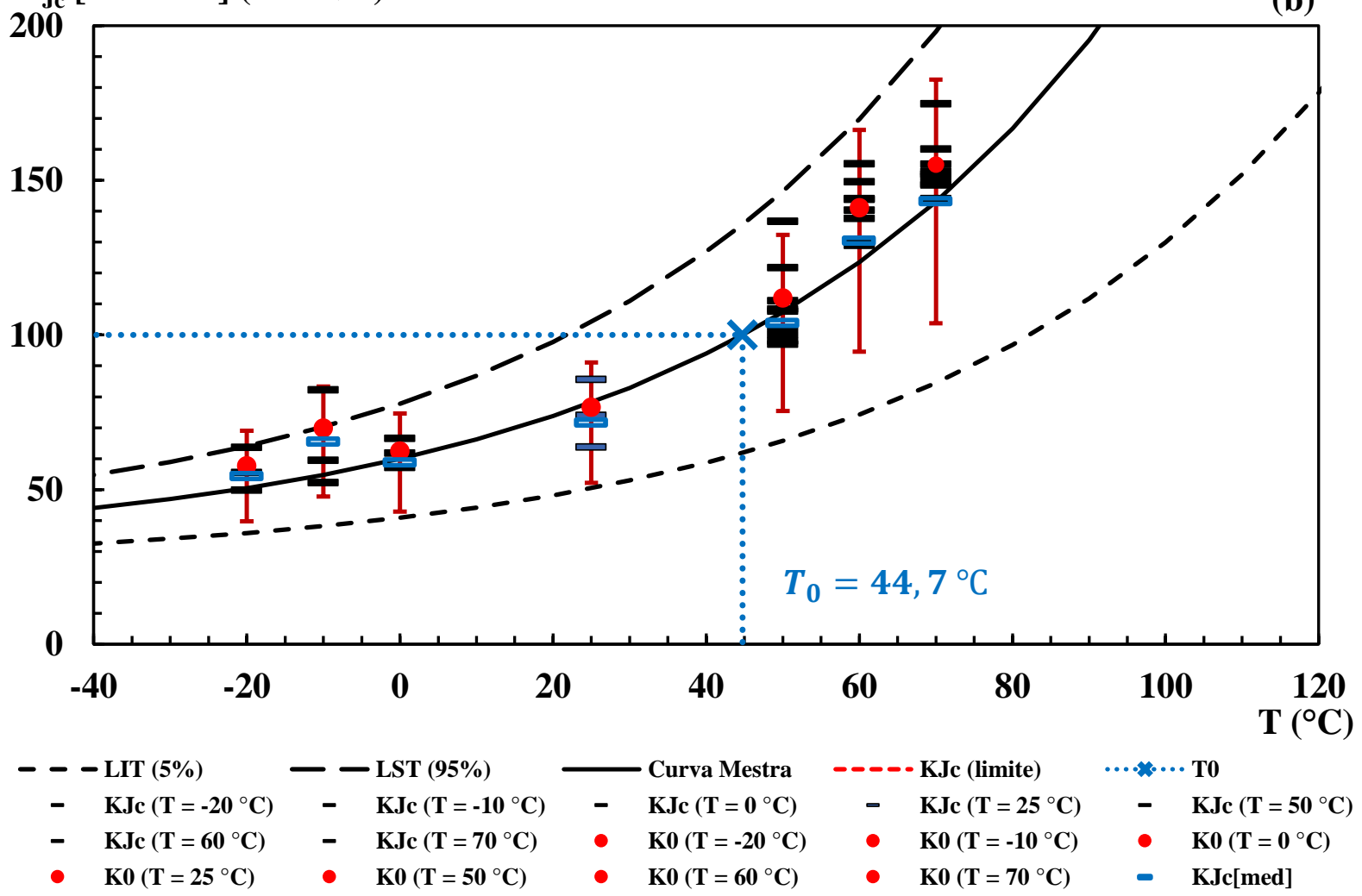


Analisando ainda a questão da validade dos dados de tenacidade, observa-se na Fig. 5.27(a) que a janela de validade contempla somente os dados de $K_{J_{c}}$ medidos na faixa $0 \leq T \leq$ $70^{\circ} \mathrm{C}$. Diante do comportamento mencionado anteriormente, é importante ressaltar alguns aspectos relacionados à determinação e acurácia da $T_{0}^{M T}$ com base nos conjuntos de dados que compõem o seu cálculo. Esses aspectos estão diretamente relacionados à janela de validade dos dados de $K_{J_{c}}$ e à quantidade de dados válidos (a qual é dada por $r_{i}=N-c$, onde $N$ é o número total de ensaios e $c$ o número de dados censurados) contidos na i-ésima faixa de temperatura $T^{i}-T_{0}$ cujo fator de ponderação depende da faixa de valores em que a medida de $K_{J_{c}(\text { med })}$ em cada temperatura está contida. Na Tabela 5.8 são apresentados resumidamente os critérios de validade em termos dos intervalos de temperatura usados nas estimativas da $T_{0}^{M T}$ e os somatórios dos fatores de ponderação com base nas recomendações feitas pela E1921 para se obter uma $T_{0}^{M T}$ mais acurada. Esses fatores podem ser consultados na Tabela 4.3 da Seção 4.6.5.

Tabela 5.8 - Análise dos requisitos referentes ao tamanho mínimo do conjunto de dados usados no cálculo da temperatura de referência via método multitemperatura

\begin{tabular}{cccc}
\hline $\begin{array}{c}\Delta \mathrm{T} \\
\left({ }^{\circ} \mathrm{C}\right)\end{array}$ & $\begin{array}{c}\text { Somatório } \\
\sum\left(\mathrm{r}_{\mathrm{i}} \mathrm{n}_{\mathrm{i}}\right)\end{array}$ & $\begin{array}{c}\text { Validade } \\
\sum\left(\mathrm{r}_{\mathrm{i}} \mathrm{n}_{\mathrm{i}}\right) \geq 1\end{array}$ & $\begin{array}{c}T_{0}^{M T} \\
\left({ }^{\circ} \mathrm{C}\right)\end{array}$ \\
\hline-20 a 25 & 1,18 & válido & 37,9 \\
50 a 70 & 4,50 & válido & 44,0 \\
-20 a 70 & 5,68 & válido & 42,4 \\
0 a 70 & 5,30 & válido & 44,7 \\
\hline
\end{tabular}

Observa-se a partir da Tabela 5.8 que todas as estimativas da $T_{0}^{M T}$ são válidas, por mais que os dados de $K_{J_{c}}$ obtidos a -20 e $-10{ }^{\circ} \mathrm{C}$ extrapolem os limites da janela de validade da curva mestra multitemperatura estimada com base em todo o banco de dados de $K_{J_{c}}$ (com exceção do valor de $K_{J_{c}}$ obtido a $80^{\circ} \mathrm{C}$ ). Embora saiba-se que, quanto maior a tenacidade à fratura menor tende a ser a temperatura de referência do material (conhecimento amplamente difundido), é importante salientar que a estimativa da $T_{0}$ não depende somente dos valores de $K_{J_{c}}$, mas também da temperatura de ensaio. Essa influência é verificada na própria formulação (vide Seção 4.6) para as estimativas da $T_{0}$, seja por meio do método multitemperatura $\left(T_{0}^{M T}\right)$, seja pelo método por uma única temperatura $\left(T_{0}^{S T}\right)$. Tal discussão deve-se à forte influência demonstrada pelas temperaturas de ensaio na faixa de $-20 \leq T \leq 25{ }^{\circ} \mathrm{C}$ sobre a estimativa da 
$T_{0}^{M T}\left(\sim 38^{\circ} \mathrm{C}\right)$ a qual mostra-se até mesmo inferior à $T_{0}^{M T}$ estimada na faixa $50 \leq T \leq 70{ }^{\circ} \mathrm{C}$ $\left(\sim 44^{\circ} \mathrm{C}\right)$ onde os valores de $K_{J_{c}}$ é da ordem de até 3 vezes superior aos valores medidos na faixa de $-20 \leq T \leq 25{ }^{\circ} \mathrm{C}$. Essa forte influência deve-se principalmente ao fato de as temperaturas de ensaio a $-20 \leq T \leq 25^{\circ} \mathrm{C}$ serem consideravelmente inferiores às estimativas da $T_{0}^{M T}$.

Já em relação ao comportamento das curvas mediana (mestra) apresentadas nas Figuras 5.24(b)-5.27(b), observa-se nitidamente que os valores de $K_{0}$, em comparação aos valores de $K_{J_{c}(m e d)}$, estão geometricamente mais centralizados entre as magnitudes extremas dos dados de $K_{J_{c}}$ (i.e., mais próximos do centro da amplitude do intervalo dos dados de $K_{J_{c}}$ ) de modo a ficarem mais próximos da curva mestra, enquanto os valores de $K_{J_{c}(\text { med) }}$ se localizam majoritariamente na banda inferior devido à grande parte dos dados $K_{J_{c}}$ se concentrar nesse patamar, conforme já demonstrado e discutido anteriormente na Figura 5.11 da Seção 5.5. Ademais, observa-se que, independentemente do valor da $T_{0}^{M T}$, as curvas de tenacidade interceptam algumas distribuições em pontos relativamente distantes da mediana.

Um dos fatores que afeta a aderência da curva mediana, $K_{J_{c}(\text { med })}\left[T_{0}^{M T}\right]-$ assim designada para indicar a sua estimativa com base no valor da $T_{0}^{M T}$ - aos valores das medianas calculadas diretamente a partir dos dados de tenacidade em uma dada temperatura $\left(T^{i}\right)$ é a acurácia da $T_{0}^{M T}$. As medianas calculadas são representadas por $K_{J_{c}(\text { med })}^{i}\left[K_{0}^{i}(M M V)\right]$ - assim designadas para demonstrar que o seu valor provém da sua relação probabilística com o valor de $K_{0}$ que, por sua vez, é estimado a partir do método da máxima verossimilhança (MMV).

Desse modo, ao se definir uma $T_{0}^{M T}$ cujo cálculo compõe apenas dados dentro da janela de validade, é possível reduzir os desvios e, portanto, o erro relativo entre as medidas calculadas, $K_{J_{c}(\text { med })}^{i}\left[K_{0}^{i}(M M V)\right]$, e as medidas estimadas de tenacidade à fratura mediana, $K_{J_{C}(\text { med })}^{i}\left[T^{i}-T_{0}^{M T}\right]$. Essa melhoria no ajuste pode ser mais facilmente visualizada na Tabela 5.9, onde é possível observar um menor erro relativo percentual para as estimativas associadas ao valor da $T_{0}^{M T}=44,7$ (i.e., medida na faixa $0 \leq T \leq 70^{\circ} \mathrm{C}$ ), o que impacta em uma melhora na aderência da curva mestra $\left(K_{J_{c}(\text { med })}\left[T_{0}^{M T}\right]\right)$ às medidas de $K_{J_{c}(\text { med })}^{i}\left[K_{0}^{i}(M M V)\right]$, conforme também indicado na Figura 5.27 (b). 
Tabela 5.9 - Análise comparativa do erro relativo percentual entre as medidas calculadas e estimadas de $K_{J_{c} \text { (med) }}$ nos intervalos de $-20 \leq T \leq 70^{\circ} \mathrm{C}$ e $0 \leq T \leq 70^{\circ} \mathrm{C}$

\begin{tabular}{cccccc}
\hline$T^{i}$ & $K_{J_{c}(\text { med })}$ & $K_{\left.J_{c} \text { (med }\right)}\left[T_{0}^{M T}\right]$ & E.R. & $K_{\left.J_{c} \text { (med }\right)}\left[T_{0}^{M T}\right]$ & E.R. \\
{$\left[K_{0}(M M V)\right]$} & $-20 \leq T \leq 70{ }^{\circ} \mathrm{C}$ & \multicolumn{2}{c}{$0 \leq T \leq 70{ }^{\circ} \mathrm{C}$} \\
$\left({ }^{\circ} \mathrm{C}\right)$ & $(\mathrm{MPa} \sqrt{\mathrm{m})}$ & $(\mathrm{MPa} \sqrt{\mathrm{m})}$ & $(\%)$ & $(\mathrm{MPa} \sqrt{\mathrm{m})}$ & $(\%)$ \\
\hline 0 & 58,7 & 61,3 & 4 & 59,9 & 2 \\
25 & 71,6 & 80,3 & 11 & 78,1 & 8 \\
50 & 103,9 & 110,9 & 6 & 107,3 & 3 \\
60 & 130,4 & 127,8 & 2 & 123,5 & 6 \\
70 & 143,2 & 148,2 & 3 & 143,1 & 0 \\
\hline
\end{tabular}

Dentre todas as estimativas de $T_{0}^{M T}$ até aqui conduzidas, a $T_{0}^{M T}$ estabelecida na faixa $0 \leq$ $T \leq 70^{\circ} \mathrm{C}$ é a mais acurada e, portanto, a que melhor descreve a relação de dependência da tenacidade à fratura mediana com a temperatura na RTDF. Embora essa estimativa $\left(T_{0}^{M T}=\right.$ $44,7^{\circ} \mathrm{C}$ ) seja praticamente igual à determinada na faixa $50 \leq T \leq 70^{\circ} \mathrm{C}$ (vide $T_{0}^{M T}=44,0^{\circ} \mathrm{C}$ ), salienta-se que a primeira é estimada a partir de um banco de dados mais representativo da RTDF por justamente englobar um faixa maior de temperatura.

Diante das análises conduzidas nesta seção verifica-se que, mesmo em se tratando de um aço temperado e de propriedades mecânicas superiores aos limites estabelecidos pela metodologia da E1921, a curva mestra descreve relativamente bem a relação de dependência da tenacidade à fratura com a temperatura na RTDF do USI AR 450. Essa constatação demonstra que a metodologia da curva mestra se aplica ao aço USI AR450, corroborando a sua robustez nas análises de um aço cujos aspectos microestruturais e mecânicos diferem daqueles que compõem as bases da metodologia e para os quais a norma da ASTM E1921 se destina.

Todavia, visando avaliar o ganho na descrição do comportamento da tenacidade com a temperatura bem como estabelecer uma estimativa de $T_{0}$ mais representativa para o material empregado neste estudo, a seção a seguir apresenta uma curva referencial modificada baseada em novos coeficientes os quais são obtidos a partir de uma metodologia de ajuste direta e relativamente simples descrita detalhadamente no Apêndice C. 


\subsection{Análise da temperatura de referência multitemperatura a partir da curva mestra modificada}

Nesta seção são apresentados os novos coeficientes ( $A, B$ e $C$ ) propostos para uma descrição mais acurada da relação de dependência da tenacidade à fratura mediana com a temperatura estabelecida pela expressão notoriamente conhecida $K_{J_{c(\text { med })}}=A+B \exp [C(T-$ $\left.T_{0}\right)$ ]. A curva de tenacidade referencial com esses novos coeficientes, doravante denominada curva mestra modificada (ou CMM), é gerada a partir de uma temperatura de referência multitemperatura $\left(T_{0}^{M T}\right)$ estabelecida em um intervalo específico de temperatura.

A análise da curva mestra modificada é conduzida inicialmente no intervalo $0 \leq T \leq$ $70{ }^{\circ} \mathrm{C}$ o qual mostra-se, perante o procedimento padrão da metodologia da curva mestra, ser o mais representativo da RTDF do aço USI AR450, conforme já discutido na Seção 5.8. Salientase ainda que, inicialmente, a $T_{0}^{M T}$ é determinada juntamente com os coeficientes propostos por meio de um procedimento de otimização que visa minimizar a soma dos quadrados dos desvios das estimativas de $K_{J_{C}(m e d)}$; isto é,

$$
\min \sum_{i=1}^{T^{i}}\left(K_{J_{c}(\text { med })}^{i}\left[K_{0}^{i}(M M V)\right]-K_{J_{c}(\text { med })}^{i}\left[T^{i}-T_{0}^{M T}\right]\right)^{2} \rightarrow 0
$$

onde $T^{i}$ representa a i-ésima temperatura de ensaio, o termo $K_{J_{c}(\text { med })}^{i}\left[K_{0}^{i}(M M V)\right]$ o valor mediano dos dados experimentais de $K_{J_{c}}^{i}$ calculado a partir da tenacidade característica $\left(K_{0}^{i}\right)$ obtida em uma dada $T^{i}$ e $K_{J_{c}(\text { med })}^{i}\left[T^{i}-T_{0}^{M T}\right]$ o valor mediano de $K_{J_{c}}^{i}$ estimado a partir da relação estabelecida entre os coeficientes de ajuste $(A, B$ e $C)$ e a temperatura de referência multitemperatura ( $T_{0}^{M T}$ ); isto é, a partir da expressão da curva mestra, seja ela padronizada ou modificada. Detalhes desse procedimento podem ser consultados no Apêndice C.

Todavia, antes de se iniciar o procedimento de ajuste, é importante mencionar algumas considerações acerca da definição padrão da $T_{0}$. De acordo com a metodologia da curva mestra padronizada pela ASTM E1921[5], a $T_{0}$ é definida como a temperatura na qual a tenacidade à fratura mediana, correspondente a uma espessura de 25,4 $\mathrm{mm}$ (1 polegada ou $1 \mathrm{~T}$ ), equivale a $100 \mathrm{MPa} \sqrt{\mathrm{m}}$.

Segundo Wallin [73], a associação da $T_{0}$ ao valor de $100 \mathrm{MPa} \sqrt{\mathrm{m}}$ deve-se ao fato de tal nível de tenacidade à fratura ser representativo de uma faixa de valores medianos onde as 
medidas de tenacidade são fortemente dependentes da temperatura e praticamente isentas dos efeitos de crescimento estável de trinca (i.e., efeitos de plasticidade). No entanto, é importante relembrar que tal valor advém de um extenso banco de dados onde as medidas de tenacidade à fratura são conduzidas em aços ferríticos e nas suas juntas soldadas aplicados particularmente na indústria nuclear. Além de serem materiais altamente tenazes, essas ligas ferríticas frequentemente apresentam uma elevada capacidade de encruamento (expoente de RambergOsgood da ordem de 3 7) e limites de resistência compreendidos na faixa de 275 a 825 MPa. Essas características mecânicas nitidamente se contrapõem às apresentadas pelo aço USI AR450, o qual além de possuir uma resistência mecânica muito superior à faixa mencionada e uma baixa capacidade de encruamento $(n \sim 20)$, apresenta uma tenacidade à fratura relativamente inferior. Esse comportamento, dentre outros fatores, está intrinsicamente relacionado à sua microestrutura martensítica que, por si só, pode ser considerada um fator relevante para justificar a adoção de um outro valor mediano de tenacidade associado à $T_{0}$. Esse valor deve representar as mesmas características associadas ao valor de $100 \mathrm{MPa} \sqrt{\mathrm{m}}$ (i.e., um valor isento de efeitos de plasticidade e que apresente forte sensibilidade às variações de temperatura), porém condizente com um comportamento menos tenaz.

A partir das considerações anteriores, o valor de tenacidade mais apropriado para a definição da $T_{0}$ para o aço USI AR450, bem como para a determinação dos novos coeficientes de ajuste da curva mestra, é dado por $88 \mathrm{MPa} \sqrt{ } \mathrm{m}$. Em outras palavras, significa dizer que a temperatura de referência específica para o aço USI AR450 é definida como a temperatura na qual a tenacidade à fratura mediana, correspondente a uma espessura de 25,4 mm (1 polegada - 1T), equivale a $88 \mathrm{MPa} \sqrt{\mathrm{m}}$. Esse valor nada mais é do que praticamente metade do valor de tenacidade à fratura medido a $80{ }^{\circ} \mathrm{C}\left(K_{J_{c}}=178 \mathrm{MPa} \sqrt{\mathrm{m}}\right)$ onde há evidências de crescimento estável de trinca precedente à instabilidade (crescimento subcrítico) significativo e, portanto, de efeitos de plasticidade sobre a medida de $K_{J_{c}}$. Ao se analisar os dados de $K_{J_{c}}$ contidos na Tabela 5.7, verifica-se que o valor de $88 \mathrm{MPa} \sqrt{ }$ insere-se nitidamente dentro das condições mencionadas anteriormente para a definição de uma temperatura de referência representativa da RTDF. Assim, a formulação geral usada para a realização do procedimento de otimização e, portanto, para a definição dos novos coeficientes é expressa por:

$$
K_{J_{c(\text { med })}}=A+(88-A) \exp \left[C\left(T-\tilde{T}_{0}\right)\right]
$$


sendo $A$, C e $\widetilde{T}_{0}$ os coeficientes explícitos de ajuste onde o coeficiente $\widetilde{T}_{0}$ nada mais do que a $T_{0}$ porém diferentemente simbolizada apenas para indicar ser proveniente de uma curva mestra modificada. Embora o coeficiente $B$ da formulação padrão da curva mestra (vide Eq. C.1 do Apêndice C) não apareça na Eq. (5.3), ele é determinado implicitamente a partir da relação $88-A=B$.

A partir do procedimento de otimização dos desvios de $K_{J_{c}(m e d)}^{i}$ com o auxílio da Eq. (5.3), é gerada a curva mestra modificada apresentada na Figura 5.28(a). Essa curva é obtida a partir dos novos coeficientes, sendo o coeficiente $\tilde{T}_{0}$ a temperatura de referência multitemperatura $\left(\widetilde{T}_{0}^{M T}\right)$ estimada no intervalo $0 \leq T \leq 70^{\circ} \mathrm{C}$. Já na Figura 5.28 (b) é apresentada uma análise comparativa ao se mostrar as curvas mestra em destaque na sua forma padrão e modificada.

Figura 5.27 - Análise da curva mestra modificada obtida a partir da $\widetilde{T}_{0}^{M T}$ avaliada na faixa $0 \leq$ $T \leq 70{ }^{\circ} \mathrm{C}$ perante (a) à janela de validade e (b) à curva mediana padrão

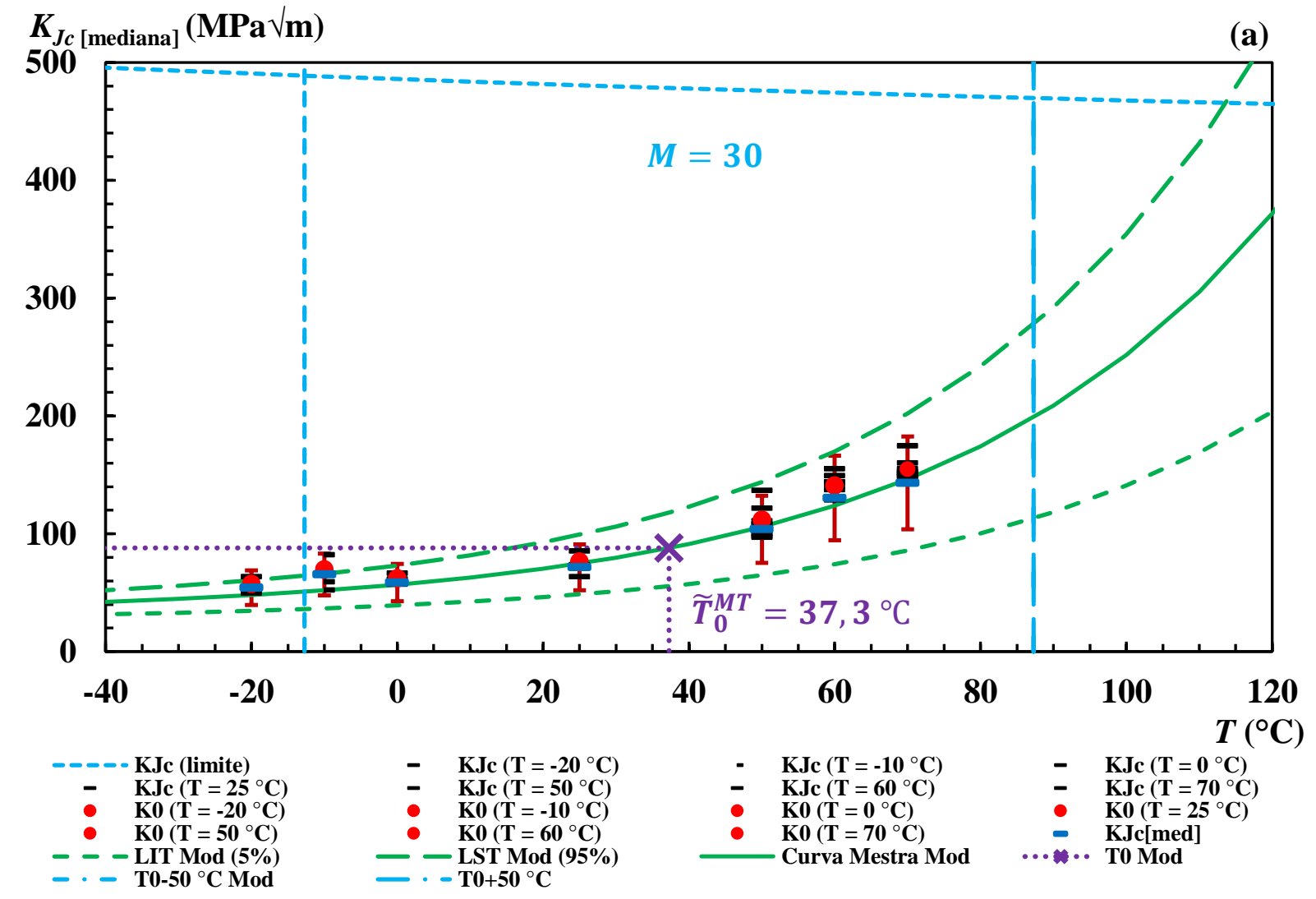




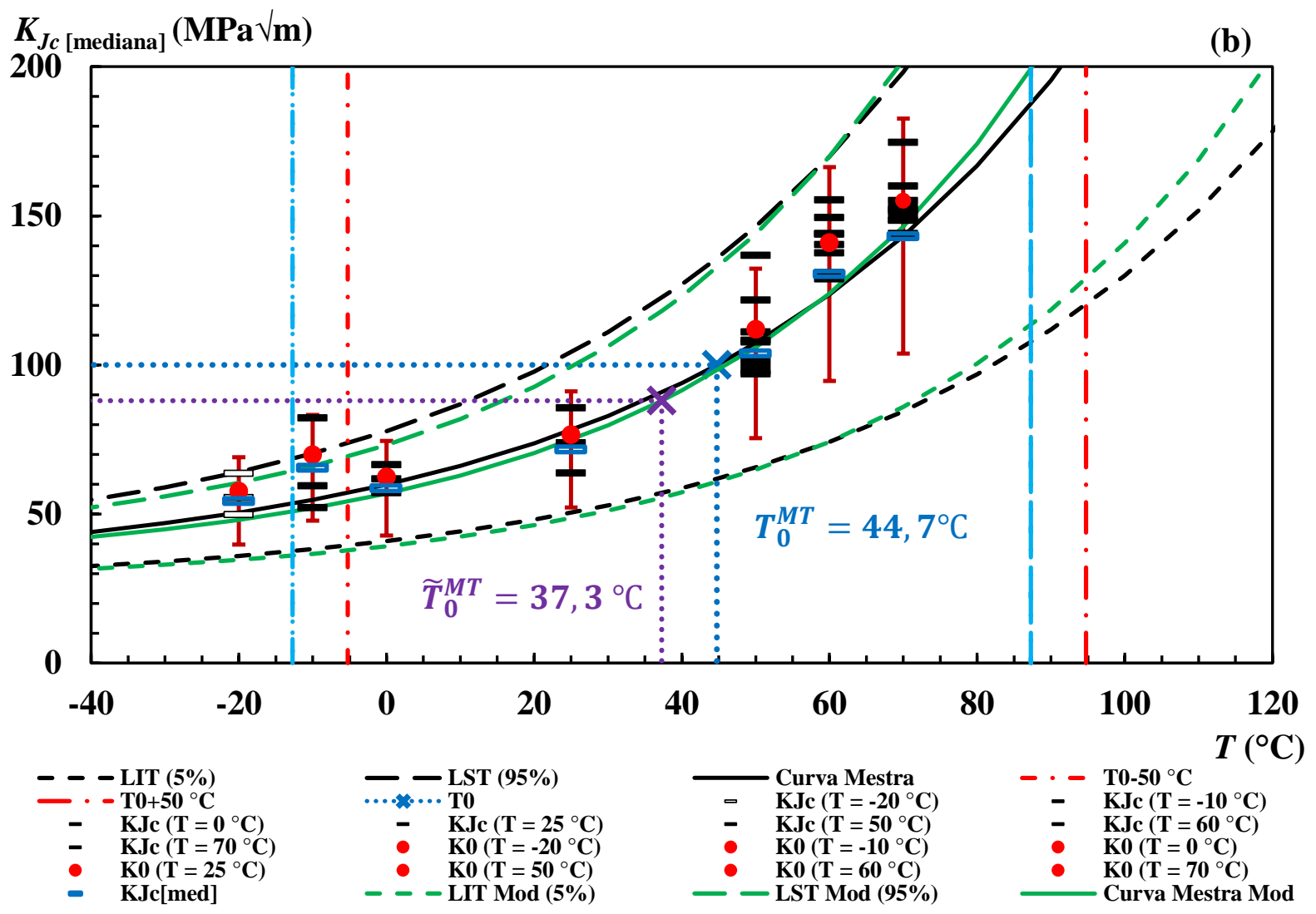

A partir da análise da Figura 5.28(a) é possível observar que a curva mestra modificada se ajusta relativamente melhor às medianas calculadas em cada temperatura (i.e., aos valores de $\left.K_{J_{c}(\text { med })}^{i}\left[K_{0}^{i}(M M V)\right]\right)$, embora o ganho de ajuste não seja muito significativo, conforme evidenciado pelos valores calculados e estimados de $K_{J_{c(\text { med })}}$ apresentados na Tabela 5.10.

Tabela 5.10 - Análise comparativa do erro relativo percentual entre as medidas calculadas e estimadas de $K_{J_{c}(\text { med })}$ no intervalo de $0 \leq T \leq 70{ }^{\circ} \mathrm{C}$ pelas curvas mestra padrão e modificada

\begin{tabular}{|c|c|c|c|c|c|}
\hline \multirow[b]{2}{*}{$\left({ }^{\circ} \mathrm{C}\right)$} & \multirow{2}{*}{$\begin{array}{c}K_{J_{c}(\text { med })} \\
{\left[K_{0}(M M V)\right]} \\
(\mathrm{MPa} \sqrt{ } \mathrm{m})\end{array}$} & $\begin{array}{r}K_{J_{C}(\text { med })}\left[T_{0}^{M T}\right] \\
\text { Curva Mes }\end{array}$ & $\begin{array}{l}\text { E.R. } \\
a d r a ̃ o\end{array}$ & Curva Mestra Modificada & $\begin{array}{l}\text { E.R. } \\
\text { ificada }\end{array}$ \\
\hline & & $(\mathrm{MPa} \sqrt{ } \mathrm{m})$ & $(\%)$ & $(\mathrm{MPa} \sqrt{ } \mathrm{m})$ & $(\%)$ \\
\hline 20 & 54,4 & 50,5 & 8 & 48,0 & 13 \\
\hline-10 & 65,5 & 54,7 & 20 & 52,0 & 26 \\
\hline 0 & 58,7 & 59,9 & 2 & 56,8 & 3 \\
\hline 25 & 71,6 & 78,1 & 8 & 74,8 & 4 \\
\hline 50 & 103,9 & 107,3 & 3 & 105,9 & 2 \\
\hline 60 & 130,4 & 123,5 & 6 & 123,9 & 5 \\
\hline 70 & 143,2 & 143,1 & 0 & 146,3 & 2 \\
\hline
\end{tabular}


A curva mestra modificada fornece uma $\widetilde{T}_{0}^{M T}=37,3{ }^{\circ} \mathrm{C}$, a qual é inferior à temperatura fornecida pela curva padrão (i.e., $T_{0}^{M T}=44,7^{\circ} \mathrm{C}$ ). Embora o valor da $\widetilde{T}_{0}^{M T}$ seja inferior ao valor da $T_{0}^{M T}$, o que pode representar em um primeiro momento uma estimativa não conservadora da $T_{0}$, é importante salientar que o valor da $\widetilde{T}_{0}^{M T}$ está associado a uma tenacidade mediana de $88 \mathrm{MPa} \sqrt{ } \mathrm{m}$, enquanto o valor de $T_{0}^{M T}$ é associado a um valor de $100 \mathrm{MPa} \sqrt{\mathrm{m}}$. Isso significa dizer que, em um primeiro momento (i.e., ajuste no intervalo de $0 \leq T \leq 70{ }^{\circ} \mathrm{C}$ ), a significância entre os valores de $K_{J_{c}(\mathrm{med})}$ e $T_{0}$ é preservada. Observa-se ainda na Figura 5.28(a) que a janela de validade gerada pela curva mestra modificada é deslocada para a esquerda de modo que os dados de $K_{J_{c}}$ obtidos a $-10{ }^{\circ} \mathrm{C}$ passam a ser incluídos na janela de validade de modo que tais dados passam a ganhar representatividade na estimativa da $T_{0}^{M T}$. Em vista disso, na Figura 5.29 é apresentada uma nova curva mestra modificada, porém agora incluindo uma faixa mais ampla de temperatura $-10 \leq T \leq 70{ }^{\circ} \mathrm{C}$.

Figura 5.28 - Análise da curva mestra modificada obtida a partir da $\widetilde{T}_{0}^{M T}$ avaliada na faixa $-10 \leq T \leq 70^{\circ} \mathrm{C}$ perante (a) à janela de validade e (b) à curva mediana padrão

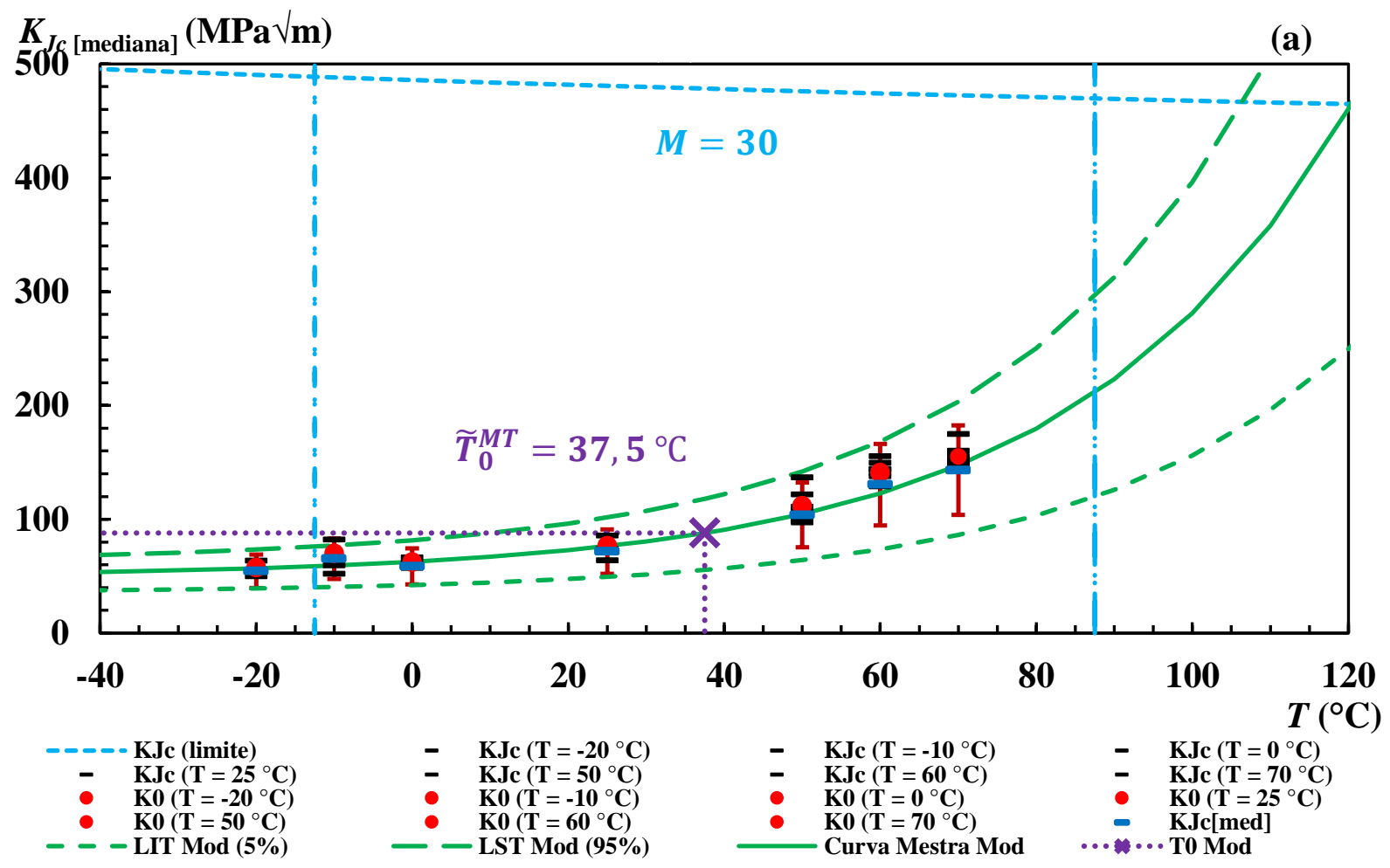




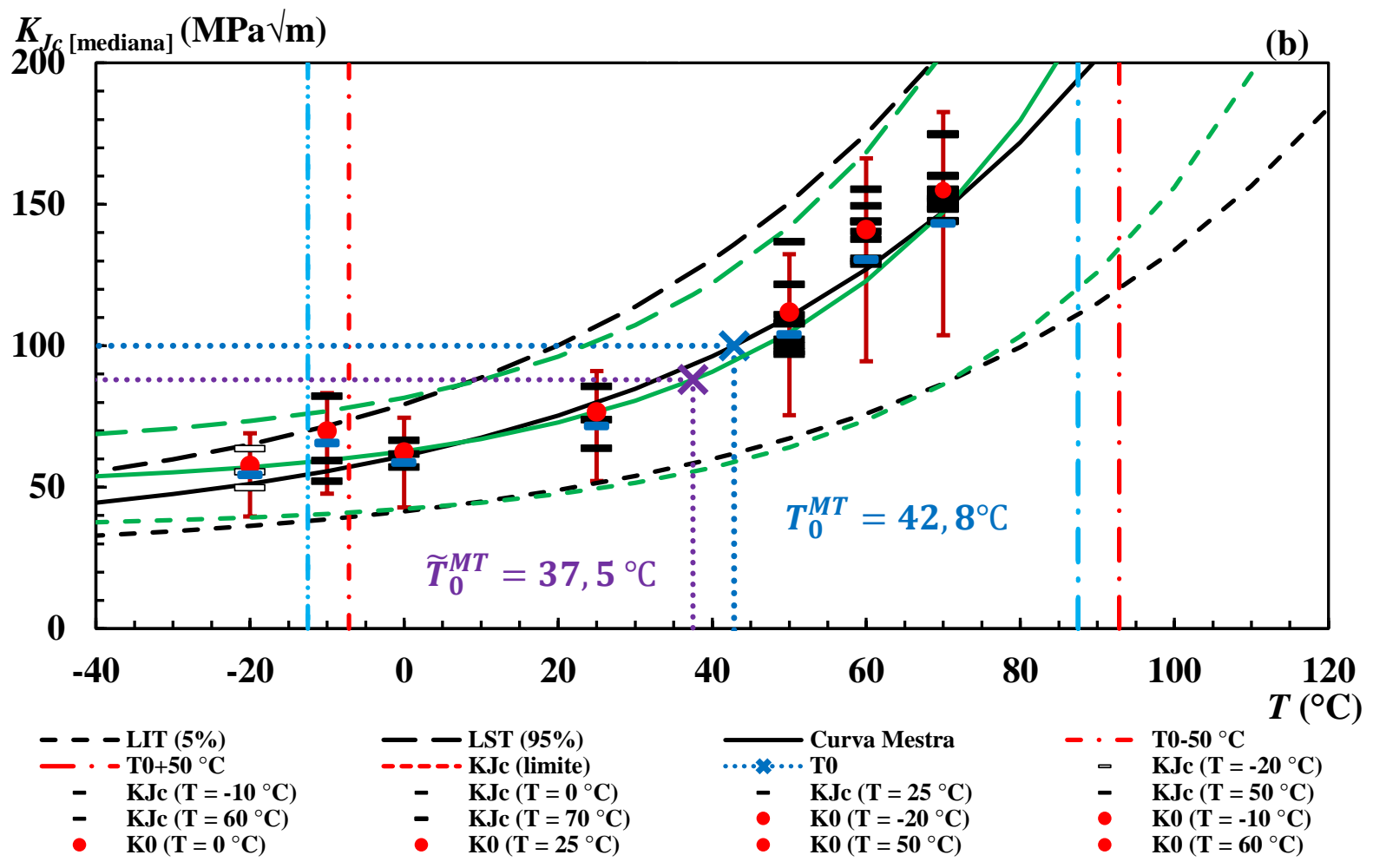

A partir da análise da Figura 5.29(a) é possível observar que a curva mestra modificada se ajusta ainda melhor às medianas calculadas em cada temperatura, quando comparado ao ajuste conduzido anteriormente no intervalo de $0 \leq T \leq 70^{\circ} \mathrm{C}$. No ajuste conduzido ao longo do intervalo de $-10 \leq T \leq 70^{\circ} \mathrm{C}$ os desvios entre os valores calculados de $K_{J_{c}(\text { med })}^{i}\left[K_{0}^{i}(M M V)\right]$ e as estimativas de $K_{J_{c}(\text { med })}\left[\widetilde{T}_{0}^{M T}\right]$ são relativamente menores, conforme apresentados na Tabela 5.11. Observa-se também que a janela de validade contempla os mesmos conjuntos de dados de tenacidade que a janela estabelecida pela $\widetilde{T}_{0}^{M T}$ estimada no intervalo de $0 \leq T \leq 70{ }^{\circ} \mathrm{C}$, corroborando a importância dos dados medidos a $-10{ }^{\circ} \mathrm{C}$ na estimativa de uma $\widetilde{T}_{0}^{M T}$ mais acurada e, portanto, mais confiável perante os novos coeficientes da curva mestra. 
Tabela 5.11 - Análise comparativa do erro relativo percentual entre as medidas calculadas e estimadas de $K_{J_{C} \text { (med) }}$ no intervalo de $-10 \leq T \leq 70^{\circ} \mathrm{C}$ pelas curvas mestra padrão e modificada

\begin{tabular}{|c|c|c|c|c|c|}
\hline \multirow{3}{*}{$\begin{array}{c}T \\
\left({ }^{\circ} \mathrm{C}\right)\end{array}$} & \multirow{3}{*}{$\begin{array}{c}K_{J_{c}(\text { med })} \\
{\left[K_{0}(M M V)\right]} \\
(\mathrm{MPa} \sqrt{ } \mathrm{m})\end{array}$} & \multirow{2}{*}{\multicolumn{2}{|c|}{$\begin{array}{rr}K_{J_{c}(\text { med })}\left[T_{0}^{M T}\right] & E . R . \\
\text { Curva Mestra Padrão }\end{array}$}} & \multirow{2}{*}{\multicolumn{2}{|c|}{ 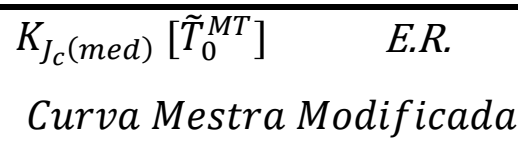 }} \\
\hline & & & & & \\
\hline & & $(\mathrm{MPa} \sqrt{ } \mathrm{m})$ & (\%) & $(\mathrm{MPa} \sqrt{ } \mathrm{m})$ & $(\%)$ \\
\hline$-2 \theta$ & 54,4 & 51,2 & 6 & 57,0 & 5 \\
\hline-10 & 65,5 & 55,7 & 18 & 59,5 & 10 \\
\hline 0 & 58,7 & 61,0 & 4 & 62,7 & 6 \\
\hline 25 & 71,6 & 79,9 & 10 & 76,4 & 6 \\
\hline 50 & 103,9 & 110,2 & 6 & 104,6 & 1 \\
\hline 60 & 130,4 & 127,0 & 3 & 122,9 & 6 \\
\hline 70 & 143,2 & 147,3 & 3 & 147,2 & 3 \\
\hline
\end{tabular}

Embora os dados de tenacidade obtidos a $-20^{\circ} \mathrm{C}$ ainda continuam excluídos da janela de validade, na Figura 5.30 é apresentada a curva mestra modificada gerada a partir da estimativa da $\widetilde{T}_{0}^{M T}$ em toda a faixa de temperatura; isto é, no intervalo de $-20 \leq T \leq 70{ }^{\circ} \mathrm{C}$. O intuito é verificar a influência desses dados na estimativa da $\widetilde{T}_{0}^{M T}$, uma vez que tais dados aparentam ser mais representativos do PIE. 
Figura 5.29 - Análise da curva mestra modificada obtida a partir da $\widetilde{T}_{0}^{M T}$ avaliada na faixa $-20 \leq T \leq 70^{\circ} \mathrm{C}$ perante (a) à janela de validade e (b) à curva mediana padrão
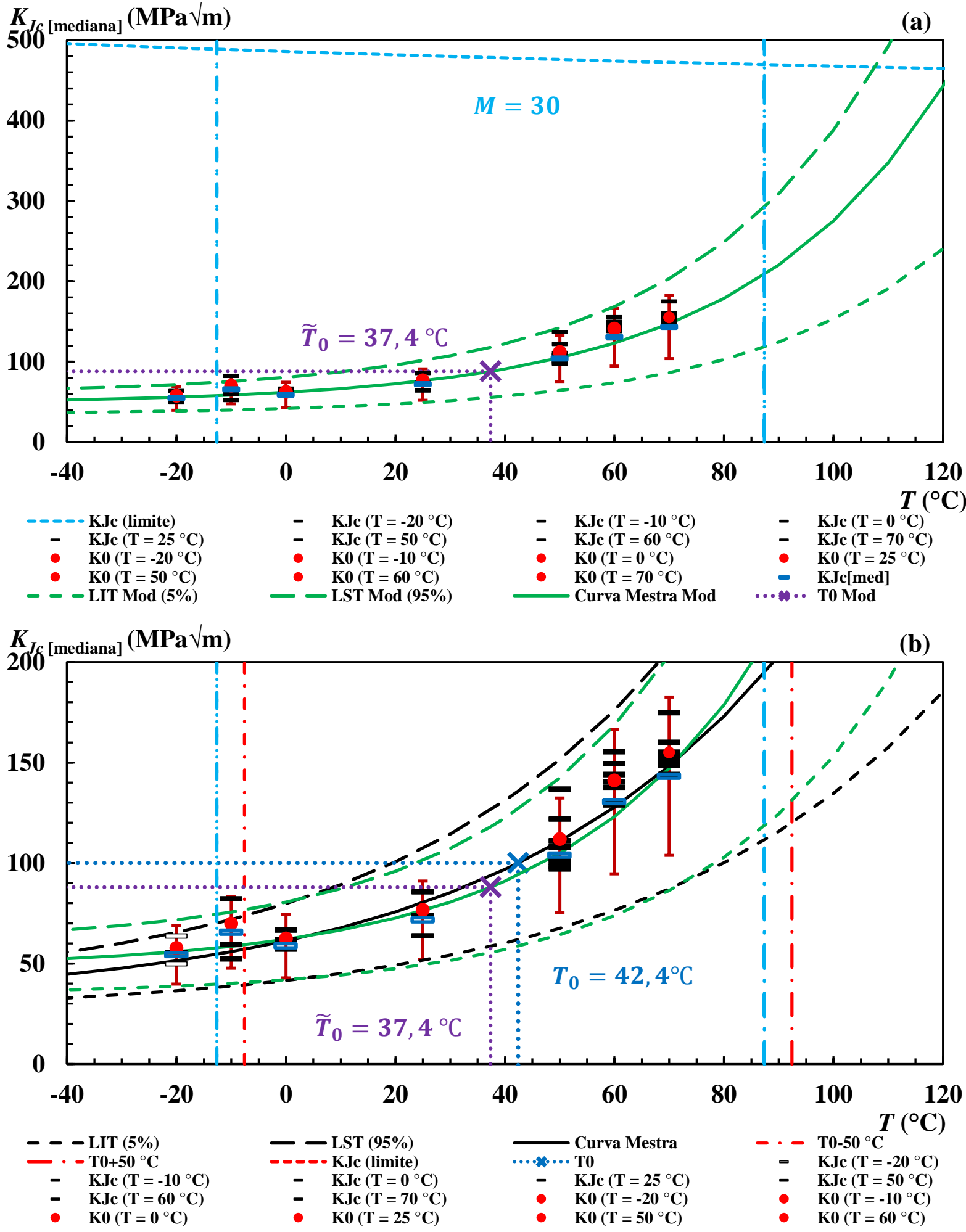

A partir da análise da Figura 5.30 observa-se que os dados de $K_{J_{C}}$ obtidos a $-20{ }^{\circ} \mathrm{C}$ ainda continuam fora da janela de validade, indicando que tais dados não devem ser incorporados no 
cálculo da $\widetilde{T}_{0}^{M T}$ posto que tais dados podem comprometer a acurácia da temperatura de referência. Todavia, o valor da $\widetilde{T}_{0}^{M T}$ calculado na faixa de $-20 \leq T \leq 70{ }^{\circ} \mathrm{C}\left(\widetilde{T}_{0}^{M T}=37,4{ }^{\circ} \mathrm{C}\right)$ é praticamente igual aos valores calculados nos intervalos de $-10 \leq T \leq 70{ }^{\circ} \mathrm{C}\left(\widetilde{T}_{0}^{M T}=\right.$ $\left.37,5^{\circ} \mathrm{C}\right)$ e $0 \leq T \leq 70{ }^{\circ} \mathrm{C}\left(\widetilde{T}_{0}^{M T}=37,3^{\circ} \mathrm{C}\right)$. Isso demonstra que o ajuste feito com base no valor de referência de tenacidade igual a $88 \mathrm{MPa} \sqrt{\mathrm{m}}$ fornece coeficientes menos sensíveis à presença de dados não representativos da RTDF evitando, assim, vieses indesejáveis, tal como o fornecimento de uma estimativa não conservadora de temperatura de referência. Apesar do cálculo da $\tilde{T}_{0}^{M T}$ incluir dados de $K_{J_{c}}$ de comportamento puramente elástico-linear, os coeficientes determinados no intervalo de $-20 \leq T \leq 70{ }^{\circ} \mathrm{C}$ também promove um bom ajuste ao fornecer erros relativos igualmente baixos aos fornecidos pelos coeficientes do ajuste a $-10 \leq T \leq 70^{\circ} \mathrm{C}$.

Tabela 5.12 - Análise comparativa do erro relativo percentual entre as medidas calculadas e estimadas de $K_{J_{c}(\text { med })}$ no intervalo de $-20 \leq T \leq 70^{\circ} \mathrm{C}$ pelas curvas mestra padrão e modificada

\begin{tabular}{|c|c|c|c|c|c|}
\hline \multirow{3}{*}{$\begin{array}{c}T \\
\left({ }^{\circ} \mathrm{C}\right)\end{array}$} & \multirow{3}{*}{$\begin{array}{c}K_{J_{c}(\text { med })} \\
{\left[K_{0}(M M V)\right]} \\
(\mathrm{MPa} \sqrt{\mathrm{m}})\end{array}$} & \multirow{2}{*}{\multicolumn{2}{|c|}{$\begin{array}{lr}K_{J_{c}(\text { med })}\left[T_{0}^{M T}\right] & \text { E.R. } \\
\text { Curva Mestra Padrão }\end{array}$}} & \multirow{2}{*}{\multicolumn{2}{|c|}{$\begin{array}{l}K_{J_{c}(\text { med })}\left[\tilde{T}_{0}^{M T}\right] \quad \text { E.R. } \\
\text { Curva Mestra Modificada }\end{array}$}} \\
\hline & & & & & \\
\hline & & $(\mathrm{MPa} \sqrt{ } \mathrm{m})$ & (\%) & $(\mathrm{MPa} \sqrt{ } \mathrm{m})$ & (\%) \\
\hline-20 & 54,4 & 51,4 & 6 & 55,9 & 3 \\
\hline-10 & 65,5 & 55,9 & 17 & 58,5 & 12 \\
\hline 0 & 58,7 & 61,3 & 4 & 62,0 & 5 \\
\hline 25 & 71,6 & 80,3 & 11 & 76,3 & 6 \\
\hline 50 & 103,9 & 110,9 & 6 & 104,9 & 1 \\
\hline 60 & 130,4 & 127,8 & 2 & 123,0 & 6 \\
\hline 70 & 143,2 & 148,2 & 3 & 147,0 & 3 \\
\hline
\end{tabular}

A Tabela 5.13 apresenta resumidamente os coeficientes e as estimativas da $T_{0}$ por eles obtidos em cada intervalo de temperatura analisado. Na mesma tabela é apresentado o somatório dos desvios contabilizados de $K_{J_{c}(\mathrm{med})}$ com base nos valores da $T_{0}$ calculados em cada intervalo de temperatura. 
Tabela 5.13 - Coeficientes de ajuste da Curva Mestra

\begin{tabular}{cccccc}
\hline$\Delta T$ & $\mathrm{~A}$ & $\mathrm{~B}$ & $\mathrm{C}$ & $T_{0}$ & $\min \sum(\text { Erros })^{2}$ \\
$\left({ }^{\circ} \mathrm{C}\right)$ & & & & & \\
\hline$-20 \leq T \leq 70^{\circ} \mathrm{C}$ & 30 & 70 & 0,019 & 44,7 & 49,8 \\
$-20 \leq T \leq 70^{\circ} \mathrm{C}$ & 48 & 40 & 0,028 & 37,4 & 35,7 \\
\hline$-10 \leq T \leq 70^{\circ} \mathrm{C}$ & 30 & 70 & 0,019 & 42,8 & 43,1 \\
$-10 \leq T \leq 70^{\circ} \mathrm{C}$ & 50 & 38 & 0,029 & 37,5 & 32,4 \\
\hline$-0 \leq T \leq 70^{\circ} \mathrm{C}$ & 30 & 70 & 0,019 & 42,4 & 19,2 \\
$-0 \leq T \leq 70^{\circ} \mathrm{C}$ & 32 & 56 & 0,022 & 37,3 & 16,9 \\
\hline
\end{tabular}

Diante de todas as análises conduzidas, baseando-se no critério de representatividade dos dados de $K_{J_{c}}$ perante a janela de validade definida pelos valores mais acurados da $T_{0}$, as expressões gerais para as curvas mestra na sua forma padrão e modificada são dadas respectivamente por:

$$
\begin{aligned}
& K_{J_{C}(0, X X)}=20+\left\{\frac{10}{[\ln (2)]^{1 / 4}}+\frac{70}{[\ln (2)]^{1 / 4}} \exp [0,019(T-42,4)]\right\}\left[\frac{B_{(1 \mathrm{~T})}}{B_{(\mathrm{nT})}}\right]^{1 / 4}\left(\ln \frac{1}{1-0, X X}\right)^{1 / 4} \\
& K_{J_{c}(0, X X)}=20+\left\{\frac{30}{[\ln (2)]^{1 / 4}}+\frac{38}{[\ln (2)]^{1 / 4}} \exp [0,029(T-37,5)]\right\}\left[\frac{B_{(1 \mathrm{~T})}}{B_{(\mathrm{nT})}}\right]^{1 / 4}\left(\ln \frac{1}{1-0, X X}\right)^{1 / 4}
\end{aligned}
$$

De modo que as expressões para a estimativa da temperatura de referência multitemperatura e temperatura única são dadas por:

$$
\begin{gathered}
\sum_{i=1}^{N} \frac{\delta_{i} \exp \left[0,019\left(T_{i}-T_{0}\right)\right]}{\frac{10}{\ln (2)^{\frac{1}{4}}}+\frac{70}{\ln (2)^{\frac{1}{4}}} \exp \left[0,019\left(T_{i}-T_{0}\right)\right]}-\sum_{i=1}^{N} \frac{\left[K_{J_{c(i)}}-20\right]^{4} \exp \left[0,019\left(T_{i}-T_{0}\right)\right]}{\left\{\frac{10}{\ln (2)^{\frac{1}{4}}}+\frac{70}{\ln (2)^{\frac{1}{4}}} \exp \left[0,019\left(T_{i}-T_{0}\right)\right]\right\}^{5}}=0 \\
\sum_{i=1}^{N} \frac{\delta_{i} \exp \left[0,029\left(T_{i}-\widehat{T}_{0}\right)\right]}{\frac{30}{\ln (2)^{\frac{1}{4}}}+\frac{38}{\ln (2)^{\frac{1}{4}}} \exp \left[0,029\left(T_{i}-\widehat{T}_{0}\right)\right]}-\sum_{i=1}^{N} \frac{\left[K_{J_{c(i)}}-20\right]^{4} \exp \left[0,029\left(T_{i}-\widehat{T}_{0}\right)\right]}{\left\{\frac{30}{\ln (2)^{\frac{1}{4}}}+\frac{38}{\ln (2)^{\frac{1}{4}}} \exp \left[0,029\left(T_{i}-\widehat{T}_{0}\right)\right]\right\}^{5}}=0 \\
K_{J_{c(\text { med })}}=30+70 \exp \left[0,019\left(T-T_{0}\right)\right] \\
K_{J_{c(\text { med })}}=50+38 \exp \left[0,029\left(T-\widehat{T}_{0}\right)\right]
\end{gathered}
$$




\section{CONCLUSÕES E CONSIDERAÇÕES FINAIS}

O presente estudo faz uma análise experimental da aplicabilidade da Metodologia da Curva Mestra (MCM) na avaliação da temperatura de referência $\left(T_{0}\right)$ de um aço martensítico a partir de dados de tenacidade à fratura frágil medidos na região de transição dúctil-frágil (RTDF) por meio corpos de prova SE(B) em configurações padronizadas de acordo com a norma ASTM E1921. Neste estudo, a temperatura de referência é avaliada a partir dos dois métodos descritos na E1921: multitemperatura e temperatura única. O trabalho também demonstra um procedimento relativamente simples e direto para a determinação de novos coeficientes de ajuste da curva mestra, a fim de obter uma melhor descrição da mediana da distribuição dos dados experimentais de tenacidade à fratura (expressos em unidades de $\mathrm{MPa} \sqrt{ } \mathrm{m})$ em função da temperatura da RTDF e, portanto, uma estimativa mais acurada da $T_{0}$.

A partir da análise estatística dos resultados experimentais de tenacidade à fratura do aço martensítico usado neste estudo, é verificado que a sua dispersão é bem descrita pela distribuição de Weibull na sua forma triparamétrica. Essas análises também demonstram que as dispersões estimadas em cada conjunto de dados amostrais obtido em diferentes temperaturas são relativamente inferiores (i.e., maiores valores de $\alpha$ ) à prevista pelo campo HRR (i.e., $\alpha=4$ para medidas de tenacidade expressas em unidades de MPa $\sqrt{ } \mathrm{m})$. Uma justificativa plausível para essa menor dispersão pode estar relacionada à microestrutura martensítica e ao micromecanismo de fratura atuante na sua matriz onde análises microfractográficas revelam um aspecto de fratura por quase-clivagem. Vale ressaltar que os mecanismos de formação de martensita também podem influenciar no comportamento à fratura, ao impedir a formação de precipitados [68], os quais atuam como sítios preferenciais para a nucleação de microtrincas de Griffith [74]. Esse micromecanismo pode também ser o responsável pela frequência relativamente alta de pontos de instabilidade da carga (pop-in's) observados nas curvas carga vs. deslocamento (P-CMOD). Em algumas situações, tais instabilidades são acompanhadas de um considerável aumento de carga, sugerindo a presença de uma resistência à fratura remanescente considerável. Tal fenômeno deve estar associado à presença dos contornos de ripa dos grãos vizinhos [30], os quais tendem a desviar a orientação de propagação da microtrinca, promovendo uma maior dissipação de energia associada à formação de microcavidades (dimples). Embora essa resistência residual esteja associada a uma maior absorção de energia, o que é corroborado pelo aparecimento de regiões alveolares (dimples) nas análises microfractográficas, a carga usada como ponto de instabilidade no cálculo da 
tenacidade à fratura precede os pontos de pop-in. Desse modo, tais medidas estão associadas a uma menor tenacidade, o que torna as análises mais conservadoras.

Ao contrário do que é comumente observado em aços ferríticos, a região superior da transição dúctil-frágil (RSTDF) da curva energia Charpy-V é a que melhor representa as condições de fratura governada pelas etapas de iniciação e propagação de microtrincas de Griffith e, portanto, uma maior dispersão nas medidas de tenacidade à fratura, que é mais evidente na temperatura de $110^{\circ} \mathrm{C}$ da curva Charpy. Além disso, observa-se que a faixa de transição dúctil-frágil fornecida pela curva de energia ao impacto Charpy-V apresenta uma faixa muito ampla de temperatura ( -100 a $\left.100^{\circ} \mathrm{C}\right)$, porém o mesmo não é observado quando se trata da resposta à fratura sob carregamento monotônica crescente quase-estático, onde temperaturas da ordem de $-20^{\circ} \mathrm{C}$ aparentam ser mais representativas do PIE de energia, uma vez que os dados de tenacidade aparentam não sofrer influência da temperatura e, assim, serem provenientes de um processo de fratura governado sob regime puramente elástico-linear.

Embora o aço martensítico utilizado neste estudo apresente propriedades mecânicas superiores $\left(\sigma_{\mathrm{ys}}>1000 \mathrm{MPa}\right)$ à faixa estabelecida pelo procedimento padrão da curva mestra (275 $\left.\leq \sigma_{\text {ys }} \leq 825 \mathrm{MPa}\right)$, aliada ainda à questão do processo de fratura se dar preferencialmente por micromecanismos de quase-clivagem, a curva mestra em sua forma padronizada mostra-se robusta ao descrever com boa acurácia a relação dependência da tenacidade à fratura com temperatura na RTDF. Portanto, essa constatação valida a aplicabilidade da curva mestra para o aço martensítico especificadamente utilizado neste estudo, ainda que as suas propriedades mecânicas estejam fora do limite recomendado pela norma da ASTM E1921.

O procedimento de otimização apresentado para a obtenção de novos coeficientes da curva mestra é relativamente simples e direto. Ao propor um ajuste pelo método dos mínimos quadrados referentes aos resíduos entre o valor experimental da tenacidade à fratura mediana (derivada da sua relação com a tenacidade característica) e o seu valor estimado com base na temperatura de referência calculada a partir de diversas temperaturas (procedimento multitemperatura pelo método da máxima verossimilhança), o procedimento se mostra confiável ao promover um melhor ajuste e, portanto, ao fornecer previsões da tenacidade à fratura mediana para o material usado neste estudo.

Observa-se que o procedimento de otimização fornece medidas de $\widetilde{T}_{0}^{M T}$ (37,3; 37,5 e 37,4 na ordem crescente dos intervalos de temperatura; isto é, 0 a $70,-10$ a 70 e -20 a $70{ }^{\circ} \mathrm{C}$ ) praticamente que iguais, independentemente do intervalo de temperatura, enquanto as medidas de $T_{0}^{M T}(44,7 ; 42,8 ; 42,4)$ apresentam maiores diferenças entre si, ou seja, maior incerteza na temperatura de transição. Portanto, o ajuste feito com base no valor de $88 \mathrm{MPa} \sqrt{\mathrm{m}}$ mostra-se 
mais robusto, pois não sofre fortes influências de dados pouco representativos da RTDF na estimativa da temperatura de referência. $\mathrm{O}$ valor de $88 \mathrm{MPa} \sqrt{\mathrm{m}}$ associado à $T_{0}$, além de ser condizente com um valor onde as medidas de tenacidade na RTDF sejam dependentes da temperatura e não sofram efeitos de plasticidade, está em consonância com a menor capacidade do material em dissipar o trabalho das forças externas na forma de deformação plástica quando comparado ao comportamento comumente apresentado pelos aços ferríticos aplicados principalmente em VPRs, onde exige-se níveis elevados de tenacidade à fratura. Além disso, os novos coeficientes propostos fornecem uma correlação mais acurada entre a tenacidade à fratura calculada e estimada para o material usado neste estudo e, portanto, uma $T_{0}$ mais confiável. Talvez mais importante do que a proposta de novos coeficientes por meio de uma rota alternativa, é a demonstração da aplicabilidade da curva mestra em um aço essencialmente martensítico requisitado em aplicações envolvendo elevada resistência à abrasão.

Por fim, o estudo aqui conduzido contribui com a literatura não só por ampliar a base de dados de tenacidade à fratura, mas também por fornecer medidas provenientes de um aço martensítico, ainda pouco estudado, de elevada resistência mecânica e com aplicações em situações que exigem uma elevada resistência ao desgaste. 


\section{SUGESTÕES E RECOMENDAÇÕES PARA ESTUDOS FUTUROS}

Como sugestão e recomendação para trabalhos futuros, é interessante:

- Conduzir ensaios adicionais nas temperaturas já ensaiadas com o intuito de mitigar possíveis efeitos relacionados ao tamanho das amostras nas estimativas de tenacidade à fratura mediana;

- Conduzir novos ensaios em mais temperaturas da RTDF, particularmente na RSTDF para averiguar com uma maior confiabilidade os níveis de tenacidade associados ao processo de crescimento estável de trinca;

- Análise metalográficas para demonstrar o caminho percorrido pela trinca na matriz martensítica ao longo da zona de processo de fratura;

- Análises fractográficas investigativas para melhor justificar a ocorrência frequentemente de instabilidade nas curvas carga vs. deslocamento;

- Ensaios complementares a partir da geometria PCVN para analisar possíveis efeitos geométricos sobre a distribuição estatística dos dados de tenacidade à fratura e o seu impacto nas estimativas da $T_{0}$;

- Fazer previsões da $T_{0}$ a partir do uso da metodologia local (local approach) com base no conceito da tensão de Weibull. 


\section{Referências bibliográficas}

[1] D. E. Mccabe, J. G. Merkle, and K. Wallin, An Introduction to the Development and Use of the Master Curve Method. West Conshokocken: ASTM International, 2005.

[2] V. S. Barbosa and C. Ruggieri, "Fracture toughness testing using non-standard bend specimens - Part I: Constraint effects and development of test procedure," Eng. Fract. Mech., vol. 195, no. March, pp. 279-296, May 2018, doi: 10.1016/j.engfracmech.2018.03.029.

[3] R. A. . O. W. ;Serve. W. L. Wullaert, W. Oldfield, and W. L. Server, Fracture toughness data for ferritic nuclear pressure vessel materials, vol. 1. Santa Barbara, California: april 1976, 1976.

[4] J. D. Landes and D. H. Shaffer, "Statistical Characterization of Fracture in the Transition Region," Fract. Mech. Twelfth Conf. ASTM, vol. STP 700, pp. 368-382, 1980.

[5] ASTM, "Standard Test Method for Determination of Reference Temperature, To, for Ferritic Steels in the Transition Range," West Conshohocken, 2018. doi: 10.1520/E192118.2 .

[6] K. H. Lee, M. C. Kim, B. S. Lee, and D. M. Wee, “Analysis of the master curve approach on the fracture toughness properties of SA508 Gr.4N Ni-Mo-Cr low alloy steels for reactor pressure vessels," Mater. Sci. Eng. A, vol. 527, no. 15, pp. 3329-3334, Jun. 2010, doi: 10.1016/j.msea.2010.02.063.

[7] Eletrobras, "Panorama da Energia Nuclear," Panor. da Energ. Nucl., p. 207, 2016.

[8] R. L. Klueh and D. R. Harries, "High-Chromium Ferritic and Martensitic Steels for Nuclear Applications," High-Chromium Ferritic Martensitic Steels Nucl. Appl., 2001, doi: 10.1520/mono3-eb.

[9] A. Neimitz, I. Dzioba, and T. Limnell, "Modified master curve of ultra high strength steel," Int. J. Press. Vessel. Pip., vol. 92, pp. 19-26, Apr. 2012, doi: 10.1016/j.ijpvp.2012.01.008.

[10] P. Mueller, P. Spätig, R. Bonadé, G. R. Odette, and D. Gragg, "Fracture toughness master-curve analysis of the tempered martensitic steel Eurofer97," J. Nucl. Mater., vol. 386-388, no. C, pp. 323-327, Apr. 2009, doi: 10.1016/j.jnucmat.2008.12.122.

[11] M. Faccoli and R. Roberti, "Probabilistic fracture toughness of a duplex stainless steel in the transition range," Eng. Fract. Mech., vol. 97, no. 1, pp. 207-215, 2013, doi: 10.1016/j.engfracmech.2012.09.027.

[12] Y. Matsumoto and K. Takai, "Method of Evaluating Delayed Fracture Susceptibility of Tempered Martensitic Steel Showing Quasi-Cleavage Fracture," Metall. Mater. Trans. A Phys. Metall. Mater. Sci., vol. 48, no. 2, pp. 666-677, Feb. 2017, doi: 10.1007/s11661016-3885-9.

[13] API, “API 5L Specification for line pipe,” Api Spec 5L, vol. Forty Four. Washington, DC, pp. 1-40, 2007, doi: 10.1520/G0154-12A.

[14] W. Ramberg and W. R. Osgood, "Description of stress-strain curves by three parameters," Natl. Advis. Comm. Aeronaut., p. Technical Note No. 902, 1943, [Online]. Available: http://hdl.handle.net/2060/19930081614.

[15] J. H. Chen and R. Cao, "Introduction," in Micromechanism of Cleavage Fracture of Metals, Elsevier, 2015, pp. 1-54.

[16] T. L. Anderson, Frature Mechanics: Fundaments and Applications, Thrird Edi. New York: CRC Press, 1995.

[17] ASM International, "Metals Handbook Volum 12 - Fractography," Mater. Inf. Co., vol. 2, p. 3470, 1987, doi: 10.1016/S0026-0576(03)90166-8.

[18] J. F. Knott, "Fundamentals of Fracture Mechanics," J. Iron Steel Inst., Inst., J. Iron Steel, p. 204, 1966.

[19] R. O. Ritchie, J. F. Knott, and J. R. Rice, "On the relationship between critical tensile 
stress and fracture toughness in mild steel," J. Mech. Phys. Solids, vol. 21, no. 6, pp. 395-410, 1973, doi: 10.1016/0022-5096(73)90008-2.

[20] D. J. Cogswell, "Statistical Modelling of the Transition Toughness Properties of Low Alloy Pressure Vessel Steels Volume 1: Main Body," EngD Thesis, vol. 1, no. July, 2010.

[21] G. T. Hahn, "Influence of Microstructure on Brittle Fracture Toughness.," Metall. Trans. A, Phys. Metall. Mater. Sci., vol. 15 A, no. 6, pp. 947-959, 1984, doi: 10.1007/bf02644685.

[22] H. W. Viehrig, J. Boehmert, and J. Dzugan, "Some issues by using the master curve concept," Nucl. Eng. Des., vol. 212, no. 1-3, pp. 115-124, Mar. 2002, doi: 10.1016/S0029-5493(01)00465-4.

[23] G. R. Irwin, "Analysis of Stresses and Strains Near the end of a Crack Traversing a Plate," J. Appl. Mech., 1957.

[24] H. M. Westergaard, "Bearing pressures and cracks," J. Appl. Mech., vol. 6., pp. 49-53., 1939.

[25] J. A. Begley and J. D. Landes, "The J Integral as a Fracture Criterion," Am. Soc. Test. Mater., vol. Part 11, A, pp. 1-23, 1972.

[26] R. H. Heyer and D. E. Mccabe, "Evaluation of a Method of Test for Plane Strain Fracture Toughness Using a Bend Specimen," Am. Soc. Test. Mater., vol. ASTM STP 4, no. Review of Develop-ments in Plane Strain Fracture Toughness Testing, pp. 22-41, 1970.

[27] ASTM, "Standard Test Method for Linear-Elastic Plane-Strain Fracture Toughness KIc of," West Conshohocken, 2017. doi: 10.1520/E0399-09E02.2.

[28] ASTM, "Standard Test Method for Plane-Strain Fracture Toughness of Metallic Materials E399," 2020, vol. 90, no. Reapproved, pp. 1-31, doi: 10.1520/E0399-09E02.2.

[29] S. Matsuda, T. Inoue, H. Mimura, and Y. Okamura, "Toughness and Effective Grain Size in Heat- Treated Low- Alloy High Strength Steels," Trnasactions ISIJ. 1972.

[30] J. P. Naylor, "The influence of the lath morphology on the yield stress and transition temperature of martensitic- bainitic steels," Metall. Trans. A, vol. 10, no. 7, pp. 861-873, Jul. 1979, doi: 10.1007/BF02658305.

[31] J. D. Eshelby, “The elastic energy-momentum tensor," J. Elast., vol. 5, no. 3-4, pp. 321335, 1975, doi: 10.1007/BF00126994.

[32] J. R. Rice, "“A Path Independent Integral and the Approximate Analysis of Strain Concentration by Notches and Cracks," J. Appl. Mech., vol. 35, no. 2, p. 379, 1968, doi: 10.1115/1.3601206.

[33] R. M. McMeeking, "Finite deformation analysis of crack-tip opening in elastic-plastic materials and implications for fracture," J. Mech. Phys. Solids, vol. 25, no. 5, pp. 357381, 1977, doi: 10.1016/0022-5096(77)90003-5.

[34] Hutchinson J.W., "Singular behaviour at the end of a tensile crack in a hardening material," J. Mech. Phys. Solids, vol. 16, no. 1, pp. 13-31, 1968, doi: 10.1016/00225096(68)90014-8.

[35] J. R. Rice and G. F. Rosengren, "Plane strain deformation near a crack tip in a powerlaw hardening material," J. Mech. Phys. Solids, vol. 16, no. 1, pp. 1-12, 1968, doi: 10.1016/0022-5096(68)90013-6.

[36] A. A. Wells, "Application of fracture mechanics at and beyond general yielding," $\mathrm{Br}$. Weld. Res. Ass. Res. Rep., vol. M13/63, 1963.

[37] J. Sumpter and C. Turner, "Method for Laboratory Determination of Jc," Cracks Fract., pp. 3-3-16, Mar. 2009, doi: 10.1520/stp28634s.

[38] "Reliability Basics: Extreme Values," The eMagazine for the reliability professional, 2011. https://www.weibull.com/hotwire/issue128/relbasics128.htm (accessed Jan. 17, 2020). 
[39] J. D. Landes and D. E. McCabe, "Effect of Sectton Size on Transition Temperature Behavior of Structural Steel," Fract. Mech. Fifteenth Symp. ASTM, vol. STP 833, pp. 378-392, 1984.

[40] K. Wallin, "The scatter in KIC-results," Eng. Fract. Mech, vol. 1085, no. 1, pp. 10851093, 1984, doi: 10.1016/0013-7944(84)90153-X.

[41] "American Society of Mechanical Engineers, Boiler and pressure vessel code," 2009.

[42] ASME, “ASME Boiler and pressure Vessel Code-Section XI," ASME Boiler \& Pressure Vessel Code, New York, p. 731, 2017.

[43] D. F. B. Sarzosa, R. Savioli, C. Ruggieri, A. Jivkov, and J. Beswick, "A local approach to assess effects of specimen geometry on cleavage fracture toughness in reactor pressure vessel steels," Am. Soc. Mech. Eng. Press. Vessel. Pip. Div. PVP, vol. 6B-2018, pp. 110, 2018.

[44] K. Wallin, "Master curve method: A new concept for brittle fracture," Int. J. Mater. Prod. Technol., vol. 14, no. 2-4, pp. 342-354, 1999.

[45] W. Merkle, J. G.; Vandersluys, W. A.; Yoon, K. K.; Server, "Technical basis for cases N-629 and N-631 as an alternative for [RT】_NDT reference temperature," in ASME Pressure Vessels and Piping Division Conference, 2007, pp. 1-10.

[46] K. Wallin, "Master curve analysis of the 'Euro' fracture toughness dataset," Eng. Fract. Mech., vol. 69, no. 4, pp. 451-481, Feb. 2002, doi: 10.1016/S0013-7944(01)00071-6.

[47] K. Wallin, "Fracture toughness transition curve shape for ferritic strutural steel," Join FCEFG/IICF Internaciona Conference on Frature of Engineering Materials and Structures, Singapure, pp. 83-88, 1991.

[48] K. Wallin, "Irradiation damage effects on the fracture toughness transition curve shape for reactor pressure vessel steel," Int. J. Press. Vessel Pip. 55, pp. 61-79, 1993.

[49] N. R. Mann, R. E. Shafer, and N. D. Singpurwalla, "Methods for statistical Analysis of Realiability and Life Data," Jonh Wiley \& Sons, New York, 1974.

[50] K. Wallin, "Statistical Aspects of Constraint with Emphasis on Testing and Analysis of Laboratory Specimens in the Transition Region," American Society for Testing and Materials-Constraint Effects in Fracture, ASTM STP 1171, Philadelphia, pp. 264-288, 1993.

[51] R. Moskovic, "Statistical analysis of censored fracture toughness data in the ductile to brittle transition temperature region," Eng. Fract. Mech., vol. 44, no. 1, pp. 21-41, 1993, doi: 10.1016/0013-7944(93)90079-8.

[52] API, “API 579 Fitness For Service,” Washington, D. C., 2007.

[53] S. T. Lie and Z. M. Yang, "BS7910: 2005 failure assessment diagram (FAD) on cracked circular hollow section (CHS) welded joints," 5th Int. Conf. Adv. Steel Struct. ICASS 2007, vol. 3, no. 4, pp. 527-532, 2007.

[54] ASTM, "ASTM E8/E8M-Standard Test Methods for Tension Testing of Metallic Materials," 2016. doi: 10.1520/E0008.

[55] ASTM, "Standard Test Methods for Notched Bar Impact Testing of Metallic Materials E23," in ASTM Internacional, 2018, vol. 16b, pp. 1-25, doi: 10.1520/E0023-12C.2.

[56] ASTM, "Preparation of Metallographic Specimens E3," 2001. doi: 10.1520/E000311R17.1.

[57] N. E. Dowling, Mechanical Behavior of Materials, Fourth edi. Boston, 2013.

[58] Mark T EricksonKirk; Atif Shaikh; MarjorieAnn EricksonKirk, M. A. M. T. EricksonKirk, A. Shaikh, and M. A. M. T. EricksonKirk, "Insights and observations arising from curve-fitting the Charpy v-notch and tensile data contained within the United States light water reactor surveillance dabase," American Society of Mechanical Engineers, Pressure Vessels and Piping Division (Publication) PVP, vol. 3, Chicago, pp. 389-396, 2008. 
[59] W. Oldfield, "Fitting Curves To Toughness Data," J. Test. Eval., vol. 7, no. 6, pp. 326333, 1979.

[60] ASTM, "Standard Test Method for Measurement of Fracture Toughness E1820-17," in ASTM Book of Standards, West Conshohocken, 2017, pp. 1-53.

[61] V. S. BARBOSA and V. B. Scarabeli, "Investigação experimental dos efeitos de geometria e de carregamento sobre a distribuição dos valores de tenacidade à fratura por clivagem medidos na região de transição dúctil-frágil de um aço estrutural ferrítico," Universidade de São Paulo, 2019.

[62] A. Benard, E. C. Bos-Levenbach, R. Schop, A. Benard, and E. C. Bos-Levenbach, "The plotting of observations on probability paper. 1)," Stat. Neerl., vol. 7, no. December, pp. 163-173, 1953.

[63] L. J. Chockie, "The 1974 edition of section XI, oyles for inservice inspection of nuclear power plant components," J. Press. Vessel Technol. Trans. ASME, vol. 97, no. 1, pp. 4950, 1975, doi: 10.1115/1.3454251.

[64] W. Server, R. Cipolla, B. Mountain, N. Carolina, and R. Cipolla, Direct use of the fracture toughness master curve in ASME code, section XI, applications, vol. $1 \mathrm{~A}$. France, 2013, pp. 2-5.

[65] N. R. Mann, Methods for Statistical Analysis of Reliability and Life Data (Wiley Series in Probability and Statistics - Applied Probability and Statistics Section). 1974.

[66] ASTM E415-17, "Standard Test Method for Analysis of Carbon and Low-Alloy Steel by Spark Atomic Emission Spectrometry," ASTM Int., pp. 1-11, 2017, doi: 10.1520/E0415-15.2.

[67] SSAB, "Hardox 450 Data Sheet," pp. 9-11, 2014.

[68] G. Krauss, Steels. Processing Structure and Performance. Ohio, 2005.

[69] W. Lei, Wei-Sheng. ; Dahl, "Short Communication- Weakest link statistics of cleavage fracture," Int. J. Press. Vessel. Pip., vol. 74, pp. 259-261, 1997.

[70] A. Neimitz, "Ductile Fracture Mechanisms in the High-strength Steel Hardox-400. Microscopic Observations and Numerical Stress-strain Analysis.," Procedia Mater. Sci., vol. 3, pp. 270-275, 2014, doi: 10.1016/j.mspro.2014.06.047.

[71] A. Neimitz, I. Dzioba, and U. Janus, "Cleavage fracture of ultra-high-strength steels. Microscopic observations. Numerical analysis. Local fracture criterion," Key Eng. Mater., vol. 598, pp. 168-177, 2014, doi: 10.4028/www.scientific.net/KEM.598.168.

[72] M. O. Lai and W. G. Ferguson, "Relationship Between the Shear Lip Size and the Fracture Toughness.," Mater. Sci. Eng., vol. 45, no. 2, pp. 183-188, 1980, doi: 10.1016/0025-5416(80)90224-4.

[73] K. Wallin, "Guidelines for deriving fracture toughness estimates from normal and miniature size Charpy-V specimen data," Raken. Mek., vol. 25, no. 3, pp. 24-40, 1992.

[74] K. Wallin, T. Saario, and K. Törrönen, "Statistical model for carbide induced brittle fracture in steel," Met. Sci., vol. 18, no. 1, pp. 13-16, Jan. 1984, doi: 10.1179/030634584790420384.

[75] D. E. Merkle, J. G.; Wallin, K.; McCabe, "Technical Basis fon an ASTM Standard on Determining the Reference Temperature , To , for Ferritic Steels in the Transition Range," pp. 1-149, 1998.

[76] M. Yu, Y. J. Chao, and Z. Luo, "An assessment of mechanical properties of A508-3 steel used in chinese nuclear reactor pressure vessels," J. Press. Vessel Technol. Trans. ASME, vol. 137, no. 3, pp. 1-7, 2015, doi: 10.1115/1.4029434.

[77] R. Kapoor, Severe Plastic Deformation of Materials. Elsevier, 2017. 


\section{APÊNDICE A Sistema de aquecimento}

Devido à necessidade de se conduzir ensaios de tenacidade à fratura em elevadas temperaturas $\left(T>25^{\circ} \mathrm{C}\right.$ ), foi necessário adaptar um sistema de aquecimento em uma cuba térmica de aço inoxidável, conforme apresentado na Figura A1. Esse sistema consiste essencialmente nos seguintes dispositivos:

- Termopar do tipo K: usado para a aferição da temperatura da solução (mistura de água + óleo solúvel biodegradável);

- Óleo mineral orgânico biodegradável: óleo solúvel utilizado para formar uma solução anticorrosiva e que auxilia no aquecimento e manutenção da temperatura;

- Ebulidor térmico com resistor de $2000 \mathrm{~W}$ : usado para o aquecimento da solução até a temperatura de ensaio;

- Equipamento de controle de temperatura: empregado para controlar a temperatura de ensaio e monitorar a temperatura na região da ponta da trinca;

- Contator tripolar de 12 A e 220V: usado para controlar o acionamento do ebulidor em associação com o equipamento de controle de temperatura;

- Bomba de recirculação de fluido: usada para homogeneizar o fluido composto de água e óleo mineral orgânico biodegradável;

- Mangueiras especiais para elevada pressão e temperatura: acopladas à bomba no circuito fechado para recirculação do fluido.

O equipamento de controle de temperatura é composto por um termostato de controle de aquecimento e um microcomputador de controle de temperatura (MH1210W), fabricado pela Meighang Technology, o qual tem a função de controlar a temperatura de acordo com a programação feita em seu menu Tabela A1. Esse equipamento permite controlar temperaturas dentro de um range de $110^{\circ} \mathrm{C}$ a $-50^{\circ} \mathrm{C}$ com um erro de $\pm 0,3^{\circ} \mathrm{C}$ e com precisão de ajuste de temperatura de $0,1^{\circ} \mathrm{C}$. O sistema ainda possui uma gama de latência de até $2{ }^{\circ} \mathrm{C}$; isto é, máxima variação de temperatura admissível que o sistema permite trabalhar sem o seu acionamento automático. Portanto, essa variação está dentro dos limites estabelecidos pela norma de ensaios ASTM E1921 a qual permite uma oscilação de até $2{ }^{\circ} \mathrm{C}$ durante a realização dos ensaios. 
Figura A1 - Sistema de controle de temperatura montado: a) cuba, microcontrolador, resistor, mangueira da bomba e termostatos (independente). b) Microcomputador, contatora e bomba.
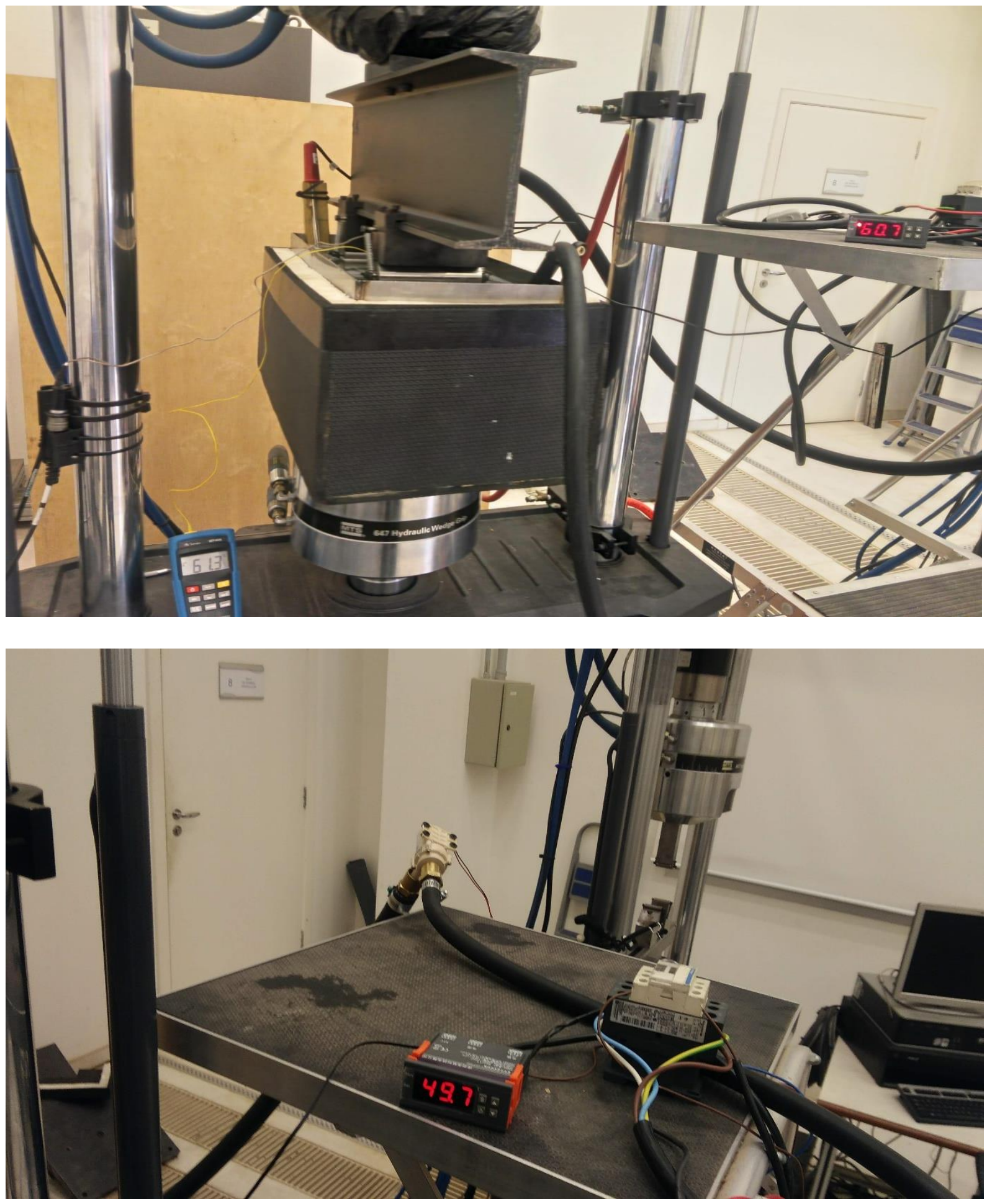

A programação do microcomputador de controle de temperatura tem duas funções, uma para aquecimento e outra para refrigeração, que é feita no menu por $\mathrm{HC}(\mathrm{H}=$ heat e $\mathrm{C}=$ refrigeration) e LS para ajustar a baixas temperaturas e HS para altas temperaturas, mais funções são expostas na Tabela A.1: 
Tabela A 1 - Funções de ajuste do microcomputador

\begin{tabular}{|c|c|c|c|}
\hline Código & Instrução do código & Função & Unidade \\
\hline $\mathrm{HC}$ & Aquecimento/resfriamento & $\begin{array}{l}\text { Ajuste para o } \\
\text { termostato }\end{array}$ & $\begin{array}{c}\mathrm{H}=\text { calor, } \\
\mathrm{C}=\text { refrigeração }\end{array}$ \\
\hline $\mathrm{d}$ & Gama de latência & $\begin{array}{c}\text { Ajuste de intervalo } \\
\text { de latência }\end{array}$ & $2^{\circ} \mathrm{C}$ \\
\hline LS & $\begin{array}{l}\text { Limite para ajuste a baixas } \\
\text { temperaturas }\end{array}$ & $\begin{array}{l}\text { Ajuste para baixas } \\
\text { temperaturas }\end{array}$ & $-50^{\circ} \mathrm{C}$ \\
\hline HS & $\begin{array}{l}\text { Limite para ajustar a altas } \\
\text { temperaturas }\end{array}$ & $\begin{array}{l}\text { Ajuste para altas } \\
\text { temperaturas }\end{array}$ & $110^{\circ} \mathrm{C}$ \\
\hline PU & $\begin{array}{l}\text { Início de atraso (delay } \\
\text { start) }\end{array}$ & $\begin{array}{l}\text { Tempo próximo a } \\
\text { abertura do } \\
\text { próximo intervalo } \\
\text { de tempo }\end{array}$ & De 0 a 90 minutos \\
\hline CA & Correção de temperatura & -10 a 10 & ${ }^{\circ} \mathrm{C}$ \\
\hline AT & Ajuste do tempo de parada & $\begin{array}{c}\text { Padrão para } \\
\text { desligar }\end{array}$ & Minutos \\
\hline
\end{tabular}

O microcomputador de controle de temperatura (MH1210W) ativa e desativa o resistor de $2000 \mathrm{~W}$ com o auxílio de uma chave contatora que aciona e protege o circuito do microcomputador, assim protegendo o circuito e mantendo um controle preciso da temperatura no recipiente de ensaio.

No recipiente de ensaio (cuba), há 4 elementos dispostos que auxiliam no controle da temperatura, Figura A1, sendo:

- 2 mangueiras: sendo uma de entrada e outra de saída da bomba recirculante que movimenta o fluido de um lado para o outro deixando a temperatura da água homogênea e assim garantindo o mínimo gradiente de temperatura.

- 2 termopares, um localizado próximo à ponta da trinca do corpo de prova, outro no fundo do recipiente proveniente para monitorar a variação e estabilização de temperatura.

- 1 resistor de $2000 \mathrm{~W}$ controlado pelo microcomputador. 


\section{APÊNDICE B Curva mestra por única temperatura}

A seguir são apresentadas e discutidas brevemente as curvas mestras geradas a partir de uma $T_{0}$ estimada pelo método da temperatura única (single-temperature method) com base na formulação padronizada $\left(T_{0}^{S T}\right)$ e modicada pelos coeficientes propostos neste estudo $\left(\tilde{T}_{0}^{S T}\right)$.

No que diz respeito à análise dada por uma única temperatura, embora a ASTM E1921 [5] recomende ao menos 6 ensaios válidos ${ }^{7}$ para a determinação da $T_{0}$ (vide Tabela 4.2 da Seção 4.6.4), neste Apêndice são apresentadas as curvas obtidas a partir de dados de $K_{J_{c}}$ determinados a $T=25,0,-10$ e $-20^{\circ} \mathrm{C}$ (i.e., a partir de uma quantidade de dados de $K_{J_{c}}<6$ ) e $T=50$, $60,70^{\circ} \mathrm{C}$ (i.e., a partir de uma quantidade de dados de $K_{J_{c}}>6$ ) para uma análise complementar e individual das curvas mestras.

Baseando-se nas considerações mencionadas anteriormente, na Figura B.1 são apresentadas as curvas mestras em sua formulação padronizada (vide curvas à direita) e modificada (vide curvas à esquerda) baseadas nas estimativas da $T_{0}^{S T}$ e $\widetilde{T}_{0}^{S T}$.

Figura B. 1 - Curvas com base em uma única temperatura para cálculo da $T_{0}$ utilizando a CM e a curva alterada(MMQ); a) $-20^{\circ} \mathrm{C}(\mathrm{MMQ})$, b) $-20^{\circ} \mathrm{C}(\mathrm{MC})$, c) $-10^{\circ} \mathrm{C}(\mathrm{MMQ})$, d) $-10^{\circ} \mathrm{C}(\mathrm{MC})$, e) $\left.0^{\circ} \mathrm{C}(\mathrm{MMQ}), \mathrm{f}\right) 0^{\circ} \mathrm{C}(\mathrm{MC})$, g) $25^{\circ} \mathrm{C}(\mathrm{MMQ})$, h) $25^{\circ} \mathrm{C}(\mathrm{MC})$, i) $\left.50^{\circ} \mathrm{C}(\mathrm{MMQ}), \mathrm{j}\right)$ $\left.\left.\left.\left.50^{\circ} \mathrm{C}(\mathrm{MC}), \mathrm{k}\right) 60^{\circ} \mathrm{C}(\mathrm{MMQ}), \mathrm{l}\right) 60^{\circ} \mathrm{C}(\mathrm{MC}), \mathrm{m}\right) 70^{\circ} \mathrm{C}(\mathrm{MMQ}), \mathrm{n}\right) 70^{\circ} \mathrm{C}(\mathrm{MC})$
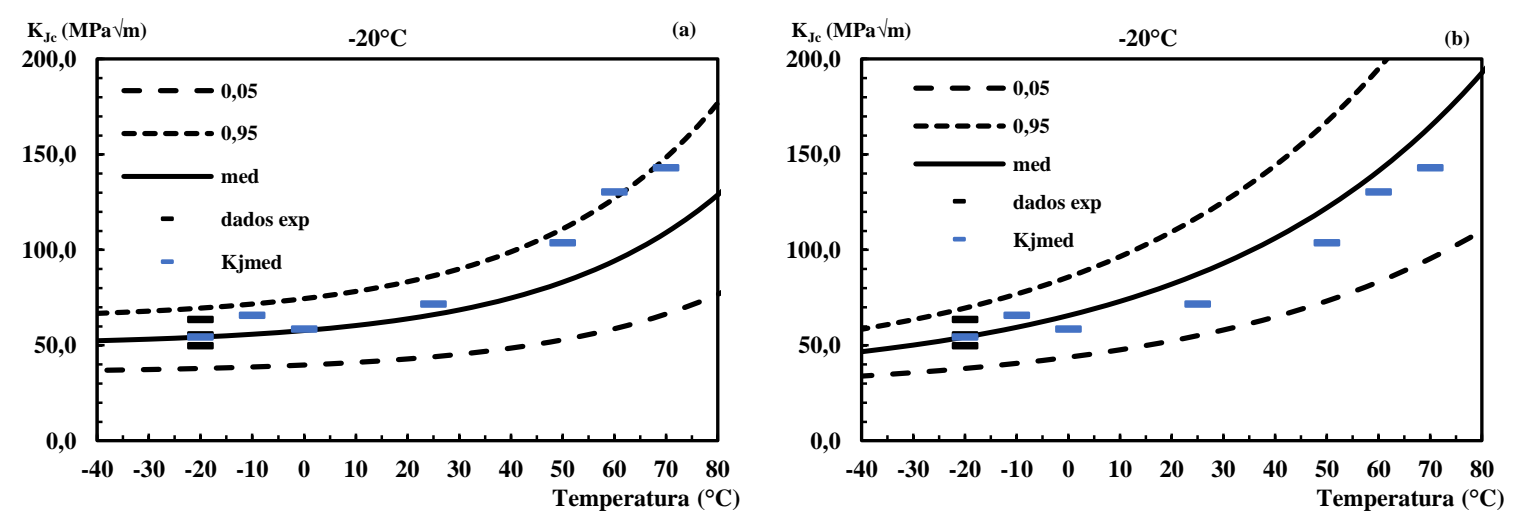

${ }^{7}$ A quantidade de dados não censurados exigidos pode variar a depender do intervalo ( $T$ - $\left.\mathrm{T}_{0}\right)$ e da faixa dos valores de $\mathrm{KJ} c(\mathrm{med})$. Por exemplo, para a situação na qual T- $\mathrm{T}_{0}$ está definida entre -50 e $-36{ }^{\circ} \mathrm{C}$ e $\mathrm{KJ} c(\mathrm{med})$ entre 58 e $65 \mathrm{MPa} \sqrt{\mathrm{m}}_{\mathrm{m}}$, a E1921 exige ao menos 8 dados de KJc não cesurados para se obter uma $\mathrm{T}_{0}$ confiável. 

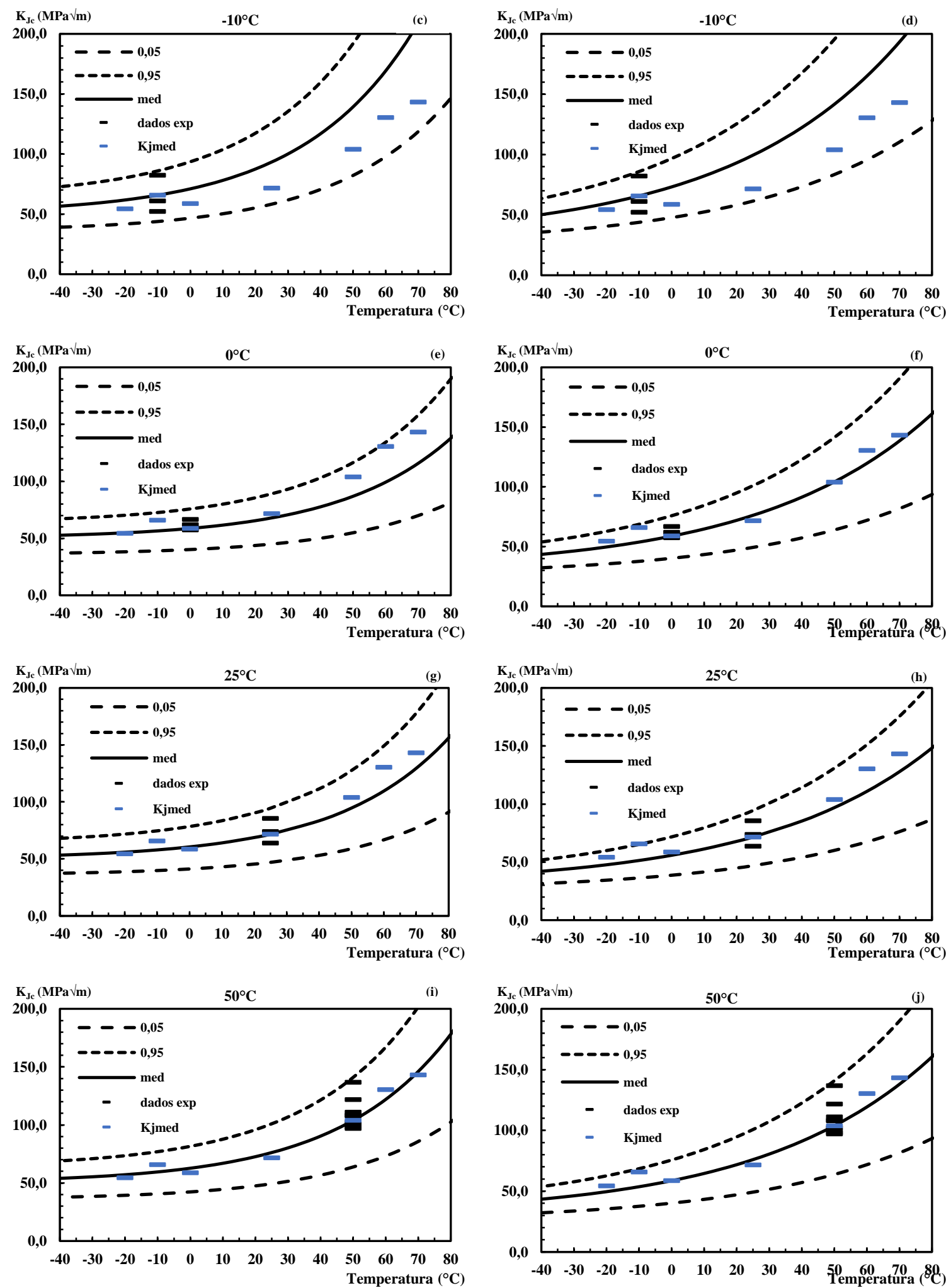

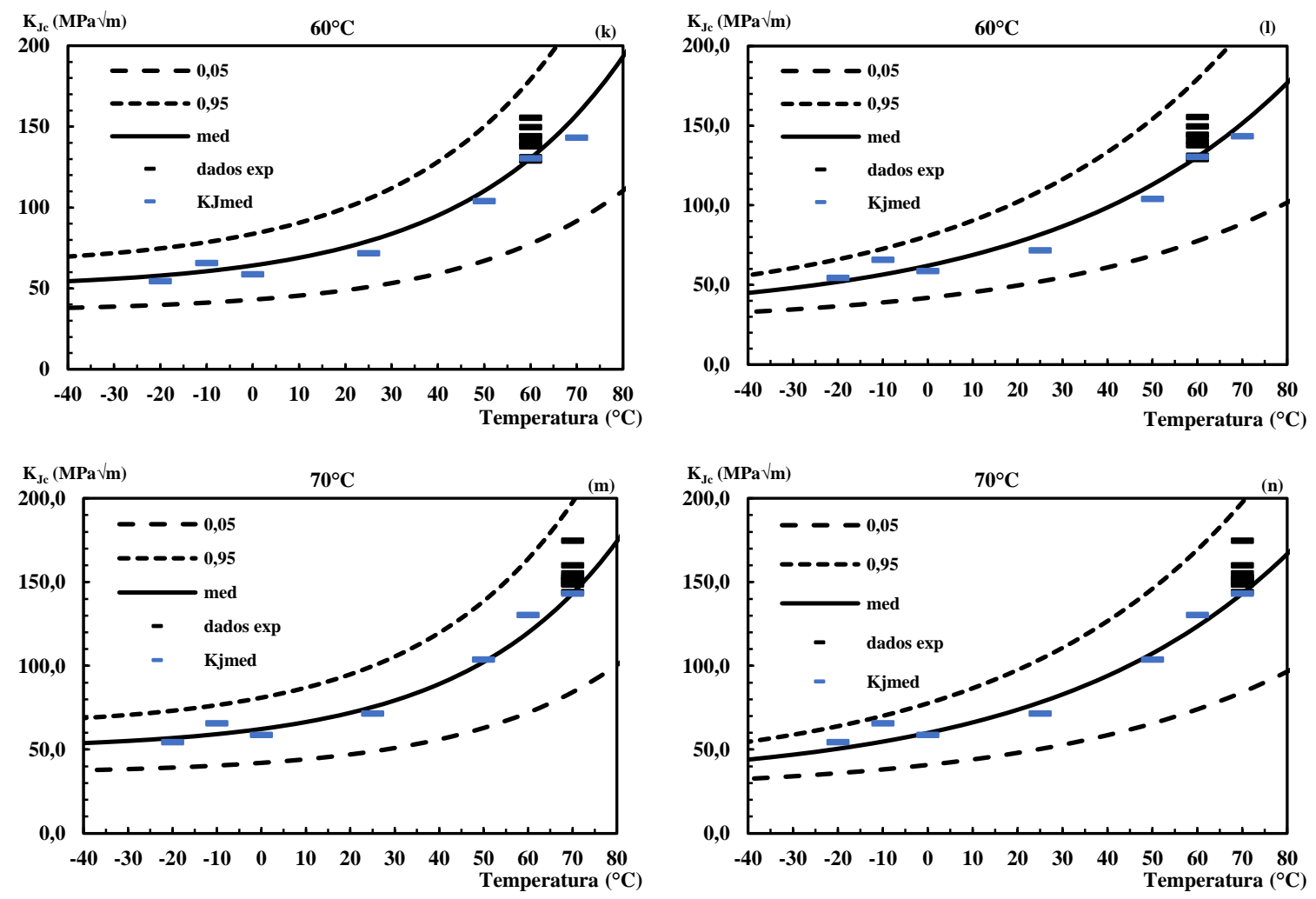

Com base na análise das curvas apresentadas na Figura B.1 é possível inferir que a alteração dos termos da curva mestra proporcionou um ajuste melhor, embora pouco imperceptível, o que corrobora a robustez da formulação padronizada da curva mestra. Na Tabela B.1 são apresentados os valores das $T_{0}$ de acordo com a temperatura de ensaio.

Tabela B.1 - Valores de $T_{0}$ para MC e curva alterada (MMQ)

\begin{tabular}{ccccc}
\hline Temperatura $\left({ }^{\circ} \mathrm{C}\right)$ & $\tilde{T}_{0}^{S T}\left({ }^{\circ} \mathrm{C}\right)$ & $\begin{array}{c}\Delta T \\
=T_{\text {test }}-T_{0}\end{array}$ & $T_{0}^{S T}\left({ }^{\circ} \mathrm{C}\right)$ & $\begin{array}{c}\Delta T \\
\end{array}$ \\
& & $-74,7$ & 35,6 & $-55,5$ \\
\hline-20 & 54,8 & $-30,4$ & 25,4 & $-35,3$ \\
-10 & 20,5 & $-51,0$ & 47,0 & $-46,9$ \\
0 & 51,0 & $-19,4$ & 52,4 & $-27,3$ \\
25 & 44,5 & 12,0 & 47,2 & 2,8 \\
50 & 37,9 & 25,9 & 41,0 & 18,9 \\
60 & 34,1 & 31,0 & 44,7 & 25,2 \\
70 & 39,0 & & &
\end{tabular}

É importante ressaltar que as estimativas da $T_{0}$ associada à temperatura de ensaio de -20 ${ }^{\circ} \mathrm{C}$ não é confiável por nenhuma das formulações, pois tal temperatura encontra-se fora da 
janela de validade da metodologia. Além disso, conforme já mencionado anteriormente, os valores das estimativas da $T_{0}$ associadas às temperaturas de ensaio na faixa de $-20 \leq \mathrm{T} \leq 25{ }^{\circ} \mathrm{C}$ também são calculados a partir de uma quantidade abaixo da recomendada, o que, a rigor, não podem ser consideradas confiáveis. No entanto, observa-se que tais valores não são tão distintos entre si para uma mesma temperatura. Na verdade, tais valores mantêm uma certa correspondência, pois as medidas da $\widetilde{T}_{0}^{S T}$ e $T_{0}^{S T}$ estão associadas a 88 e $100 \mathrm{MPa} \sqrt{\mathrm{m}}$. Esse comportamento fica mais evidente nas estimativas feitas para as temperaturas de ensaio na faixa de $50 \leq \mathrm{T} \leq 70{ }^{\circ} \mathrm{C}$ onde é possível notar que os valores da $\widetilde{T}_{0}^{S T}$ são relativamente inferiores aos valores da $T_{0}^{S T}$. Uma vez que o valor da $\widetilde{T}_{0}^{S T}$ está associado a uma tenacidade à fratura menor, o grau de correspondência se mantém. Todavia, deve-se destacar que o valor de $88 \mathrm{MPa} \sqrt{\mathrm{m}}$ é muito representativo para as estimativas medianas da tenacidade à fratura do aço uso neste estudo, o que contribui para uma melhor descrição da relação de dependência da tenacidade com a temperatura na RTDF do referido aço martensítico. 


\section{APÊNDICE C Procedimento de otimização para a determinação de novos coeficientes}

A fim de garantir uma melhor descrição da mediana das distribuições dos dados experimentais de tenacidade à fratura em termos de $K_{J_{c}}$, este apêndice propõe uma metodologia de ajuste/otimização direta e relativamente simples na determinação de novos coeficientes para curvas referencias de tenacidade.

A formulação das curvas referencias de tenacidade à fratura é baseada no uso de uma temperatura de referência característica da região de transição dúctil-frágil (RTDF) do material para indexar os valores de tenacidade. A relação de dependência expressa pela tenacidade com a temperatura na RTDF é frequentemente expressa a partir de uma função exponencial. No contexto da metodologia da curva mestra, essa dependência é avaliada a partir de corpos de prova de 25,4 mm de espessura (1T) na região de transição de aços "ferríticos" e é expressa por uma função exponencial indexada a uma temperatura de referência (simbolizada por $T_{0}$ ) cujo valor é associado a uma tenacidade à fratura mediana equivalente a $100 \mathrm{MPa} \sqrt{\mathrm{m}}$ [44], [75], conforme expressão a seguir:

$$
K_{J_{c(\text { med })}}=30+70 \exp \left[0,019\left(T-T_{0}\right)\right]
$$

onde $K_{J_{c(\text { med })}}$ representa o valor mediano (o qual é muito próximo do valor médio) e $T_{0}$ a temperatura de referência do material. A curva referencial gerada pela Eq. (C.1) recebe a denominação de curva mestra por justamente manter a sua forma para diversas classes de aços ferríticos, sendo, portanto, considerada uma curva universal. Essa característica guarda uma certa relação com a curva de transição dúctil-frágil definida nos ensaios de tenacidade ao entalhe por impacto Charpy-V em vista da manutenção da similaridade entre o patamar inferior de energia (PIE) e a região inferior da transição dúctil-frágil (RITDF) dos aços ferríticos.

A forma geral da Eq. (C.1) é representada por

$$
K_{J_{c(\text { med })}}=A+B \exp \left[C\left(R T_{D B T}\right)\right]
$$

onde os coeficientes $A$, $B$ e $C$ são constantes dependentes do material e $R T_{D B T}$ a temperatura normalizada em relação à uma temperatura de transição dúctil-frágil (RTDF ou DBT do inglês Ductile-to-Brittle Transition Region) de referência definida por algum critério específico. 
Os coeficientes da curva mestra podem ser obtidos a partir de procedimentos de otimização conduzidos por processos iterativos, tais como regressões não-lineares, visando minimizar desvios ${ }^{8}$ entre valores medidos e valores estimados de $K_{J_{c(\text { med })}}$. Geralmente, tais procedimentos exigem um banco de dados relativamente grande para se obter coeficientes robustos o suficiente para fornecer estimativas confiáveis da variável resposta/propriedade de interesse. No contexto da curva mestra, essas estimativas estão relacionadas à mediana da tenacidade à fratura explicitamente relacionada à temperatura de referência $T_{0}$ que, por sua vez, está intrinsicamente associada às medidas de $K_{J_{c(\text { med })}}$ e às temperaturas da RTDF em que tais medidas são obtidas.

Embora a mediana possa ser determinada a partir de pequenos espaços amostrais (i.e., a partir de conjuntos contendo da ordem de 6 8 dados experimentais válidos de tenacidade), nem sempre a sua estimativa é factível, principalmente quando há limitações severas na disponibilidade do material de interesse. É neste cenário e dentre outros que entra a importância da curva mestra, onde, a partir do conhecimento da $T_{0}$, é possível estimar o valor mediano da tenacidade em qualquer temperatura contida na RTDF e, portanto, diferente daquela usada para estimar a própria $T_{0}$. Além disso, é possível estimar a tenacidade em estruturas de espessuras diferentes daquelas utilizadas nos corpos de prova devido à estatística do elo mais fraco associada à formulação da curva mestra

$$
K_{J_{C}(\text { med })}=20+\left\{10+70 \exp \left[C\left(T-T_{0}\right)\right]\right\}\left[\frac{B_{(1 \mathrm{~T})}}{B_{(\mathrm{nT})}}\right]^{1 / 4}
$$

de modo que a forma geral expressa anteriormente pela Eq. (C.1) pode ser reescrita como:

$$
K_{J_{C}(\text { med })}=D+\left\{E+B \exp \left[C\left(T-T_{0}\right)\right]\right\}\left[\frac{B_{(1 \mathrm{~T})}}{B_{(\mathrm{nT})}}\right]^{1 / 4}
$$

onde $D=K_{\text {min }}, E=A-D$.

A forma geral da curva mestra evidencia a sua capacidade em gerar curvas de $\mathrm{K}$ em função de T para diferentes níveis de probabilidade acumulada de falha [e.g., mediana (50\%) e

${ }^{8}$ No campo das análises de regressão, esses desvios nada mais são do que os resíduos dados pela diferença entre a variável resposta observada e a variável resposta estimada. 
limites de tolerância inferior e superior - LIT e LST). Esses níveis de probabilidade permitem quantificar o nível de conservadorismo na estimativa da tenacidade à fratura. A título de exemplo, a BS7910 aconselha uma $P_{f}=0,05$ (5\%) quando a falha do componente representa um risco real de perdas humanas e uma $P_{f}=0,20$ (20\%) quando a falha resultar apenas na perda da sua função, sem colocar vidas humanas em risco. Desse modo, a curva mestra associada ao conceito do elo mais fraco acoplado a diferentes níveis de probabilidade acumulada de falha é expressa por:

$$
K_{J_{C}(\text { med })}=20+\left\{\frac{10}{[\ln (2)]^{1 / 4}}+\frac{70}{[\ln (2)]^{1 / 4}} \exp \left[C\left(T-T_{0}\right)\right]\right\}\left[\frac{B_{(1 \mathrm{~T})}}{B_{(\mathrm{nT})}}\right]^{1 / 4}\left(\ln \frac{1}{1-0, X X}\right)^{1 / 4}
$$

de modo que o termo $0, X X$ representa o nível de probabilidade de falha. Para o caso da curva mediana a qual é associada a uma $P_{f}=50 \%=0,50$, ao substituir o valor de $0, X X$ por 0,50 , a Eq. (C.3a) recupera a sua forma original e simplificada expressa inicialmente pela Eq. (C.1a). Portanto, a forma geral mais expandida expressa anteriormente pela Eq. (C.2b) pode ser ainda reescrita como:

$$
K_{J_{C}(0, X X)}=D+\left\{\frac{E}{[\ln (2)]^{1 / 4}}+\frac{B}{[\ln (2)]^{1 / 4}} \exp \left[C\left(T-T_{0}\right)\right]\right\}\left[\frac{B_{(1 \mathrm{~T})}}{B_{(\mathrm{nT})}}\right]^{1 / 4}\left(\ln \frac{1}{1-0, X X}\right)^{1 / 4}
$$

Nos trabalhos envolvendo propostas de curvas modificadas para classes específicas de aço [6], [9], [10], o principal interesse consiste em fornecer uma melhor descrição da tenacidade à fratura ao longo da RTDF e, portanto, uma estimativa de $T_{0}$ mais acurada e confiável. Essas propostas envolvem a determinação de novos coeficientes por meio de procedimentos de otimização.

Para manter a filosofia da curva mestra, o procedimento aqui proposto reescreve a Eq. (C.1b) da seguinte forma

$$
K_{J_{c(\text { med })}}=A+(100-A) \exp \left[C\left(T-T_{0}\right)\right]
$$

de modo que, por meio dessa representação, é possível ajustar o nível da assíntota, A, (i.e., da parte atérmica da curva mestra) bem como o formato, C, mantendo a significância de $T_{0}$ como o índice em $100 \mathrm{MPa} \sqrt{\mathrm{m}}$. 
Dentre os procedimentos mais conhecidos, tem-se o método da máxima verossimilhança, o qual foi utilizado para estimar originalmente os coeficientes da curva mestra[75] . No caso da distribuição de Weibull triparamétrica associada às medidas de tenacidade à fratura expressas em termos de $K_{J_{c}}$, a função de verossimilhança da densidade de probabilidade, $p_{f}$ ou $f\left(K_{J_{c}}\right)$ é expressa por:

$$
L=\prod_{i=1}^{N} \frac{4\left(K_{J_{c(i)}}-K_{\min }\right)^{3}}{\left(K_{0}\left(T_{i}\right)-K_{\min }\right)^{4}} \exp \left\{-\left[\frac{K_{J_{c(i)}}-K_{\min }}{\left(K_{0}\left(T_{i}\right)-K_{\min }\right)}\right]^{4}\right\}
$$

de forma que, para um dado conjunto de dados (i.e., medidas de $K_{J_{c(i)}}$ realizadas na temperatura $T_{i}$ ), os coeficientes $A, C$ e $T_{0}$ são determinados resolvendo numericamente (e.g., Newton-Raphson) e iterativamente as três equações:

$$
\begin{aligned}
& \frac{\partial \ln L}{\partial \mathrm{A}}=0 \\
& \frac{\partial \ln L}{\partial \mathrm{C}}=0 \\
& \frac{\partial \ln L}{\partial T_{0}}=0
\end{aligned}
$$

cujas soluções parciais são representadas por

$$
\begin{aligned}
& \sum_{i=1}^{N} \frac{\left\{1-\exp \left[C\left(T_{i}-T_{0}\right)\right]\right\}}{\operatorname{A-K_{\operatorname {min}}} \frac{(100-A)}{\ln (2)^{\frac{1}{4}}} \exp \left[C\left(T_{i}-T_{0}\right)\right]}-\sum_{i=1}^{N} \ln (2) \frac{\left[K_{J_{c(i)}}-K_{\min }\right]^{4}\left\{1-\exp \left[C\left(T_{i}-T_{0}\right)\right]\right\}}{\left\{\frac{A-K_{\min }}{\ln (2)^{\frac{1}{4}}}+\frac{(100-A)}{\ln (2)^{\frac{1}{4}}} \exp \left[C\left(T_{i}-T_{0}\right)\right]\right\}^{5}}=0 \\
& \sum_{i=1}^{N} \frac{\exp \left[C\left(T_{i}-T_{0}\right)\right]\left(T_{i}-T_{0}\right)}{\frac{A-K_{\min }}{\ln (2)^{\frac{1}{4}}}+\frac{(100-A)}{\ln (2)^{\frac{1}{4}}} \exp \left[C\left(T_{i}-T_{0}\right)\right]}-\sum_{i=1}^{N} \frac{\left[K_{J_{c(i)}}-K_{\min }\right]^{4} \exp \left[C\left(T_{i}-T_{0}\right)\right]\left(T_{i}-T_{0}\right)}{\left\{\frac{A-K_{\min }}{\ln (2)^{\frac{1}{4}}}+\frac{(100-A)}{\ln (2)^{\frac{1}{4}}} \exp \left[C\left(T_{i}-T_{0}\right)\right]\right\}^{5}}=0
\end{aligned}
$$




$$
\sum_{i=1}^{N} \frac{\exp \left[C\left(T_{i}-T_{0}\right)\right]}{\frac{A-K_{\min }}{\ln (2)^{\frac{1}{4}}}+\frac{(100-A)}{\ln (2)^{\frac{1}{4}}} \exp \left[C\left(T_{i}-T_{0}\right)\right]}-\sum_{i=1}^{N} \frac{\left[K_{J_{C(i)}}-K_{\min }\right]^{4} \exp \left[C\left(T_{i}-T_{0}\right)\right]}{\left\{\frac{A-K_{\min }}{\ln (2)^{\frac{1}{4}}}+\frac{(100-A)}{\ln (2)^{\frac{1}{4}}} \exp \left[C\left(T_{i}-T_{0}\right)\right]\right\}^{5}}=0
$$

O conjunto de soluções expressa pela Eq. (C.6) para a determinação dos coeficientes geralmente requer o uso algoritmos relativamente sofisticados, o que muitas pode significar um procedimento mais laborioso.

Baseando-se nas considerações anteriores, o presente estudo também faz uma análise de otimização, porém usando conceitos de regressão mais simples associados a ferramentas mais acessíveis comumente encontradas em softwares mais populares, tal como o Solver do Excel®. Esse procedimento consiste essencialmente em determinar os coeficientes que minimizem os desvios, por meio de um método iterativo não linear, entre a tenacidade à fratura mediana medida experimentalmente (i.e., $K_{J_{c}(m e d)}\left[K_{0}(M M V)\right]$ ) e a tenacidade à fratura mediana prevista a partir da temperatura de referência (i.e., $K_{J_{c}(\text { med })}^{i}\left[T^{i}-T_{0}^{M T}\right]$ ) conforme a seguinte expressão

$$
\min \sum_{i=1}^{T^{i}}\left(K_{J_{c}(\text { med })}^{i}\left[K_{0}^{i}(M M V)\right]-K_{J_{c}(\text { med })}^{i}\left[T^{i}-\tilde{T}_{0}^{M T}\right]\right)^{2} \rightarrow 0
$$

onde $T^{i}$ representa a i-ésima temperatura da $\mathrm{RTDF}, K_{0}^{i}$ a tenacidade à fratura característica obtida experimentalmente por meio do método da máxima verossimilhança (MMV) e $K_{J_{c}(m e d)}^{i}$ o valor mediano da tenacidade à fratura obtido a partir da sua relação probabilística com o valor de $K_{0}^{i}$ determinado na i-ésima temperatura. Já o termo $\widetilde{T}_{0}^{M T}$ refere-se à temperatura de referência multitemperatura associada a um valor de tenacidade específico para o material de interesse e determinada pelo método dos mínimos quadrados (MMQ).

Portanto, fica claro que o objetivo do procedimento de otimização proposto consiste em definir novos valores para os coeficientes da curve mestra (curva mestra modificada) de modo que o somatório dos quadrados das diferenças entre tais medidas ao longo da RTDF seja o menor possível a fim de produzir o melhor ajuste e estabelecer uma curva de tenacidade mais acurada para previsões futuras em quaisquer temperaturas na RTDF. 